University of Louisville

ThinkIR: The University of Louisville's Institutional Repository

Electronic Theses and Dissertations

$12-2012$

\title{
Dysregulation of microRNA expression in acquired endocrine- resistant breast cancer.
}

Tissa Thomas Manavalan

University of Louisville

Follow this and additional works at: https://ir.library.louisville.edu/etd

\section{Recommended Citation}

Manavalan, Tissa Thomas, "Dysregulation of microRNA expression in acquired endocrine-resistant breast cancer." (2012). Electronic Theses and Dissertations. Paper 897.

https://doi.org/10.18297/etd/897

This Doctoral Dissertation is brought to you for free and open access by ThinkIR: The University of Louisville's Institutional Repository. It has been accepted for inclusion in Electronic Theses and Dissertations by an authorized administrator of ThinkIR: The University of Louisville's Institutional Repository. This title appears here courtesy of the author, who has retained all other copyrights. For more information, please contact thinkir@louisville.edu. 


\title{
DYSREGULATION OF MICRORNA EXPRESSION IN ACQUIRED ENDOCRINE-RESISTANT BREAST CANCER
}

\author{
By \\ Tissa Thomas Manavalan \\ B.Sc., Bangalore University, 2005 \\ M.Sc., Bangalore University, 2007 \\ M.S., University of Louisville, 2011
}

\begin{abstract}
A Dissertation
Submitted to the faculty of the University of Louisville School of Medicine In Partial Fulfillments of the Requirements

For the Degree of
\end{abstract}

\begin{abstract}
Doctor of Philosophy
Department of Biochemistry and Molecular Biology

University of Louisville, School of Medicine

Louisville, KY
\end{abstract}

December 2012 
Copyright 2012 by Tissa Thomas Manavalan

All rights reserved 


\section{DYSREGULATION OF MICRORNA EXPRESSION IN ACQUIRED ENDOCRINE-RESISTANT BREAST CANCER}

By

Tissa T. Manavalan

B.Sc., Bangalore University, 2005

M.Sc., Bangalore University, 2007

M.S., University of Louisville, 2011

A Dissertation Approved on

September 20, 2012

by the following Thesis Committee:

Dr. Carolyn M. Klinge (Mentor)

Dr. Barbara J. Clark

Dr. Yong Li

Dr. Robert A. Mitchell

Dr. Theodore S. Kalbfleisch 


\section{DEDICATION}

This dissertation is dedicated to my parents for their constant love, encouragement and support over the course of my life and my Ph.D. program. I would also like to dedicate this to my husband, Roshan James for his motivation that helped in the completion of my graduate studies. 


\section{ACKNOWLEDGEMENTS}

I am sincerely grateful to my mentor, Dr. Carolyn Klinge for her encouragement and support for the successful completion of my Ph.D. Her guidance was invaluable for my doctoral work. I would also like to convey my sincere thanks to my committee members, Dr. Barbara Clark, Dr. Yong Li, Dr. Robert Mitchell and Dr. Ted Kalbfleisch for their valuable comments and advice towards the project. I would like to thank the members of the Klinge laboratory for their support and assistance over the years. A special thanks to Dr. Nalinie Wickramasinghe, a past member of the lab, for her guidance in the initial years of my Ph.D. 


\section{ABSTRACT \\ DYSREGULATION OF MICRORNA EXPRESSION IN ACQUIRED \\ ENDOCRINE-RESISTANT BREAST CANCER}

Tissa T. Manavalan

September 20, 2012

MicroRNAs (miRNAs) regulate gene expression at the post-transcriptional level by repressing translation or stimulating mRNA degradation. In this study, I tested the hypothesis that miRNAs are differentially expressed in antiestrogensensitive MCF-7 versus -resistant LY2 human breast cancer cells. Microarray analyses identified 97 miRNAs that are differentially expressed between two estrogen receptor alpha $(\mathrm{ER} \alpha)$-positive human breast cancer cell lines: endocrine-sensitive MCF-7 versus -resistant LY2 cells under basal conditions. Opposite expression of miRs-10a, $-21,-22,-125 b,-181,-200 a,-200 b,-200 c,-221$, and -222 was confirmed between MCF-7 and LY2 cells. The ER antagonist ICI 182,780 (fulvestrant or Faslodex) generally blocked the effect of estradiol $\mathrm{E}_{2}$ and 4-hydroxytamoxifen (4OHT) regulated miRs, i.e.., miR-10a, miR-21, miR-22, miR-200a, miR-221, and miR222, indicating that these responses in MCF-7 cells are ER-mediated. Timedependent variation in basal (ethanol, the vehicle), $\mathrm{E}_{2}$, and 4-OHT regulation of the top 8 miRNAs was detected in MCF-7 cells. Bioinformatic analyses to impute the biological significance of the identified miRNAs by identifying their computationally predicted target genes in the human genome using TargetScan, PicTar, and the Sanger 
miRBase Targets databases was performed. Thirty six putative mRNA targets were identified. Agreement in the direction of anticipated regulation was detected for 12 putative targets. These miRNAs showing opposite expression between these two breast cancer cell lines may be involved in endocrine resistance.

MiR-200 family includes two clusters i.e. miR-200 a/200b/ 429 and miR$200 \mathrm{c} / 141$ encoded on chromosome 1 and chromosome 12, respectively. Lower miR200a, miR-200 b and miR-200c expression was observed in estrogen-independent LCC1 and endocrine-resistant LCC2, LCC9, and LY2 compared to the parental, endocrine-sensitive MCF-7 human breast cancer cell line. ZEB1 protein was found to be expressed in endocrine-resistant LY2 cells but not in endocrine-sensitive MCF-7 cells. LY2 cells did not express E-cadherin, a ZEB1 target which is a marker for epithelial phenotype. This is the first demonstration that LY2 cells have undergone EMT as part of their endocrine-resistant phenotype. Concomitant with miR-200 decrease, there was an increase in ZEB1 mRNA expression in LY2 cells. Overexpression of $\mathrm{miR}-200 \mathrm{~b}$ or $\mathrm{miR}-200 \mathrm{c}$ in $\mathrm{LY} 2$ cells changed the cellular morphology from a mesenchymal to an epithelial appearance and sensitized cells to inhibition by $4-\mathrm{OHT}$ and fulvestrant. These studies indicate that reduced expression of miR-200 and a corresponding increase in ZEB1 protein is an indicator of endocrine-resistance in breast cancer cells. 


\section{TABLE OF CONTENTS}

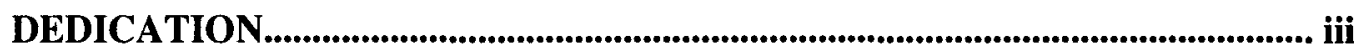

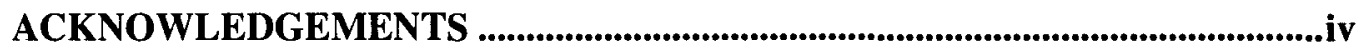

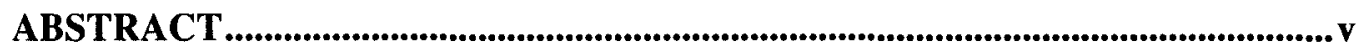

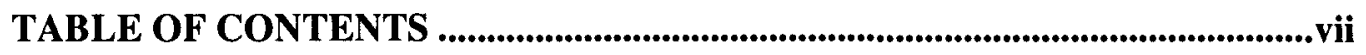

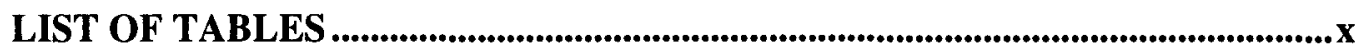

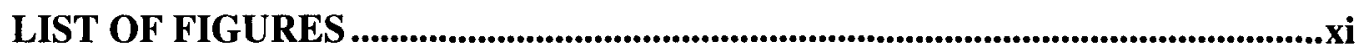

CHAPTER I: INTRODUCTION TO BREAST CANCER .....................................

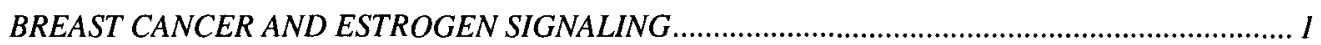

ENDOCRINE THERAPIES FOR THE TREATMENT OF BREAST CANCER …............................... 3

MECHANISMS OF ENDOCRINE/TAMOXIFEN-RESISTANCE ................................................

CHAPTER II: SIGNIFICANCE OF MICRORNA EXPRESSION IN

ENDOCRINE/TAMOXIFEN -RESISTANT BREAST CANCER .....................12

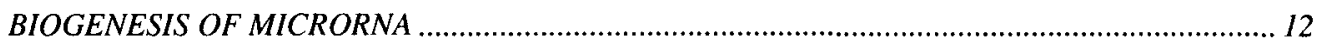

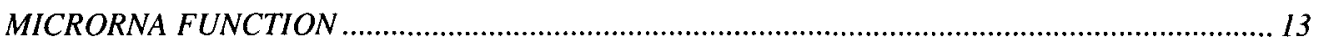

REGULATION OF MICRORNA EXPRESSION ……............................................................... 15

MICRORNA AS ONCOGENES OR TUMOR SUPPRESSORS ……………………..................... 18

MICRORNA EXPRESSION IN BREAST CANCER ............................................................. 19

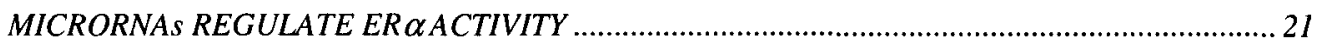

MICRORNA AND ENDOCRINE RESISTANCE …….............................................................. 23

DISSERTATION SPECIFIC AIMS AND HYPOTHESES ...............................24 


\section{CHAPTER III: DIFFERENTIAL EXPRESSION OF MICRORNAS IN TAMOXIFEN- SENSITIVE MCF-7 VERSUS TAMOXIFEN-RESISTANT LY2}

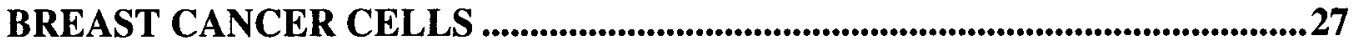

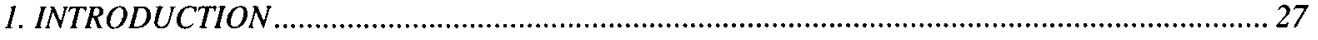

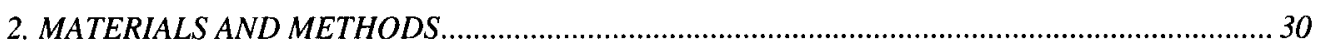

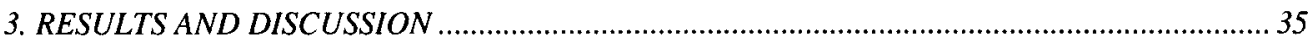

Identification of miRNAs differentially expressed in MCF-7 and LY2 cells................................. 35

Selection of endogenous control genes for Q-PCR normalization and validation of select miRNAs by

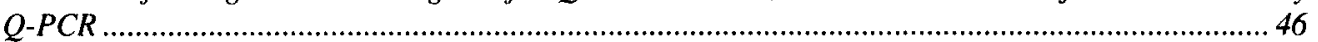

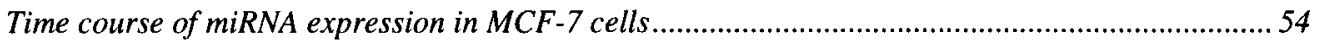

Time course of $E_{2}$ and 4-OHT regulation of $E R \alpha, E R \beta$, and Argonaute-2 (Ago2) ....................... 57

Computational identification of miRNA target mRNA genes in 4-OHT-treated MCF-7 cells...........60

PDCD4, BCL2, CYPIB1, and ERBB3 are differentially expressed in MCF-7 and LY2 cells.......... 63

ESRI and ER $\alpha$ protein expression is lower in LY2 than MCF-7 cells ......................................67

miR-200-regulated ZEB1 is reduced in LY2 cells.............................................................67

CHAPTER IV: REDUCED EXPRESSION OF MIRNA-200 FAMILY IN LY2

CELLS CONFERS RESISTANCE TO TAMOXIFEN AND FULVESTRANT.72

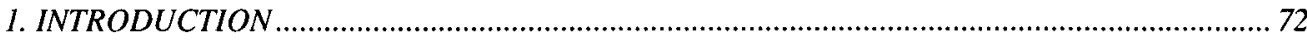

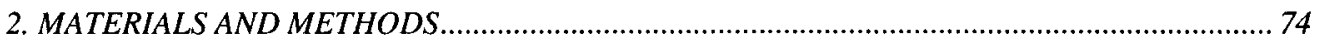

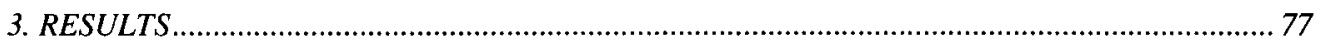

Expression of miR-200 family in MCF-7, LCC1, LCC2, LCC9 and LY2 human breast cancer cells 77 $E_{2}$ and 4-OHT regulate ZEBI in MCF-7, LCCI, LCC2, LCC9 and LY2 human breast cancer cells 78 Overexpression of miR-200b or miR-200c in LY2 cells enhanced their sensitivity to 4-OHT or

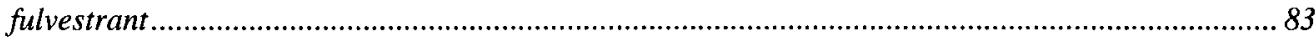

Overexpression of miR-200b or miR-200c changes morphology of LY2 cells to a 'cobblestone'

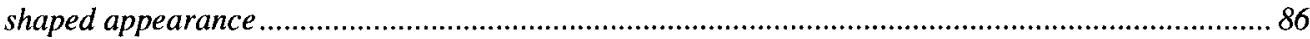

Inhibitors of deacetylation and methylation increase miR-200 family expression in LY2 cells ........ 91

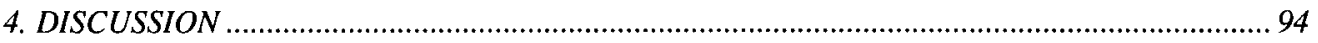

CHAPTER V: RESEARCH IMPLICATIONS ....................................................100

REFERENCES.................................................................................................................. 105 


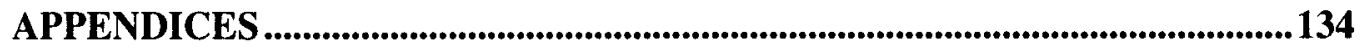

CURRICULUM VITAE.......................................................................................... 153 


\section{LIST OF TABLES}

Table 1: MicroRNAs Differentially Expressed in MCF-7/EtOH vs. LY2/EtOH in human breast cancer cells. ...........................................................38

Table 2: MicroRNAs Differentially Expressed in MCF-7/4-OHT vs. LY2/4OHT in human breast cancer cells .............................................................4 41

Table 3: MicroRNAs Differentially Expressed in MCF-7/E 2 vs. MCF-7/4-

OHT in human breast cancer cells............................................................43 


\section{LIST OF FIGURES}

Figure 1: Heat map (hierarchical clusters) of significant differences in miRNA expression between MCF-7 and LY2 cells...................................................37

Figure 2: Venn diagrams summarizing differentially expressed (DE)

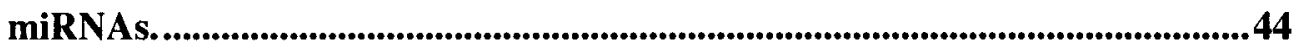

Figure 3: Select miRNAs that are differentially expressed in MCF-7 (TAM-S) and LY2 (TAM-R) breast cancer cells.....................................................................45

Figure 4: Selection of endogenous control genes for analysis of miRNA expression by Q-PCR........................................................................................................47

Figure 5: Q-PCR analysis of the miRNA expression in MCF-7 and LY2 cells.

Figure 6: Time course analysis of miRNA expression...............................................56

Figure 7: Time-dependent changes in ER $\alpha, E R \beta$, and Ago2 expression in E2-

or 4-OHT- treated MCF-7 cells. .............................................................................................58

Figure 8: Computational identification of mRNA gene targets of 12 miRNAs oppositely expressed in MCF-7 and LY2 cells. ......................................................662

Figure 9: miR-21 target genes expression in MCF-7 and LY2 cells.................66

Figure 10: CYP1B1, ERBB3, and ESR1 gene expression in MCF-7 and LY2 cells.

Figure 11: ZEB1 and E-cadherin expression. .70

Figure 12: Q-PCR analysis of the expression of miR-200 family in MCF-7, LCC1, LCC2, LCC9 and LY2 cells. .79 
Figure 13: Q-PCR analysis of the expression of miR-200 family in MCF-7,

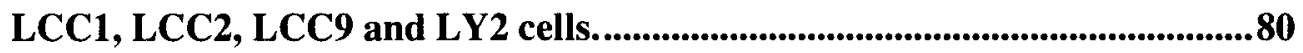

Figure 14: Q-PCR analysis of the expression of ZEB1 mRNA in MCF-7,

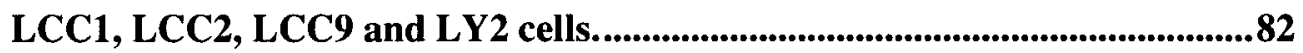

Figure 15: Overexpression of miR-200b or miR-200c in LY2 cells transfected with pre-miR-200b or pre-miR-200c or negative control. .84

Figure 16: Overexpression of $\mathrm{miR}-200 \mathrm{~b}$ or $\mathrm{miR}-200 \mathrm{c}$ restores sensitivity of LY2 cells to 4-OHT and fulvestrant. .85

Figure 17: Knockdown of miR-200b or miR-200c does not promote resistance of MCF-7 to 4-OHT or fulvestrant. . .87

Figure 18: Overexpression of miR-200 family changes morphology of LY2 cells.

Figure 19: 5-aza-dC and TSA co-administration results in an increase in miR-200b and miR-200c expression, and a concomitant decrease in ZEB1 mRNA in $L Y 2$ cells. .92 Figure 20: Proposed model of miR-200 function in endocrine-resistant breast cancer. .99 


\section{CHAPTER I: INTRODUCTION TO BREAST CANCER}

\section{BREAST CANCER AND ESTROGEN SIGNALING}

Breast cancer is the leading non-cutaneous form of cancer that is diagnosed in women of the United States [1]. According to the American Cancer Society, it is estimated that in 2011 about 230,000 women will be diagnosed with invasive breast cancer and approximately 39,520 women are expected to die from breast cancer [2] (http://www.cancer.org/Research/CancerFactsFigures/BreastCancerFactsFigures/brea st-cancer-facts-and-figures-2011-2012). Although the highest incidence of breast cancer is seen on non-hispanic white women, death due to this cancer is highest in African-American women because they have triple-negative breast cancer (TNBC). In TNBC, which is the most aggressive form of breast cancer, cells do not express estrogen receptor $(\mathrm{ER})$, progesterone receptor $(\mathrm{PR})$ or the epidermal growth factor receptor (HER2/neu/erbB2). In the last two decades, the incidence rates for breast cancer in women over 50 has declined by $2 \%$ due to early detection and better therapy, including the use of the antiestrogen tamoxifen.

http://www.breastcancer.org/symptoms/understand_bc/statistics.jsp .

The breast tissue is composed of milk producing lobules and ducts that connect lobules to the nipple. The luminal epithelial cells that line the ducts of the breast are regulated by steroid hormones, such as estrogens and progesterone and peptide hormones i.e. Prolactin, Oxytocin. Estrogens are steroid hormones produced by the ovary. The three forms of estrogen produced in the ovary are Estrone $\left(E_{1}\right)$, 
Estradiol $\left(E_{2}\right)$ and Estriol $\left(E_{3}\right) . E_{1}$ is the major form of estrogen in postmenopausal women, $E_{2}$ is the predominant form of estrogen in pre-menopausal women and $E_{3}$ is primarily synthesized in pregnancy. Estrogens promote cell replication by binding to their receptors, estrogen receptors alpha $(E R \alpha)$ and beta $(E R \beta)$ that mediate the subsequent recruitment of coregulators, chromatin remodeling complexes, and RNA polymerase leading to transcription of estrogen responsive genes [3]. The two modes of signaling through the ER include genomic and non genomic.

Genomic ER signaling - Binding of $\mathrm{E}_{2}$ to $\mathrm{ER}$ induces a conformation change to the ER leading to its activation and binding to DNA sequences called estrogen response elements (EREs). This is the classic or genomic mode of estrogen signaling. Alternatively, the $\mathrm{E}_{2}-\mathrm{ER}$ complex may interact with DNA indirectly by a 'tethering' mechanism involving direct interaction of ER with transcription factors including AP1, Spl or NF- $\mathrm{NB}[4]$. Depending on the type of transcriptional coregulators associated with ER, the $\mathrm{E}_{2}$-ER complex can have different effects $[5,6]$. For example, $\mathrm{E}_{2}$-ER binds to the ERE of the NRF-1 gene in MCF-7 cells and recruits AP1 coactivator and RNA polymerase to increase the expression of TFAM mitochondrial gene [7]. Ligand independent ER signaling involves protein kinases that phosphorylate and activate ER.

Non-genomic ER signaling - In addition to genomic ER signaling a small percent of total cellular ER $\alpha$ that are localized in the plasma membrane (PM) can initiate rapid activation of intracellular phosphorylation cascades mediated by extracellular signal regulated kinases 1/2 (ERK1/2) and phosphoinositide 3-kinase (PI3K or AKT) [8,9]. This rapid $E_{2}$-initiated cascade is referred to as "membrane-initiated" or "nongenomic" ER signaling and is independent of gene transcription, although "non- 
genomic' estrogen activation of signaling pathways can stimulate gene transcription in breast cancer cells [10].

GPR30/GPER: In addition to ER $\alpha$, there is a plasma membrane-bound estrogen receptor that is a G-coupled protein receptor (GPR30/GPER) [11,12]. Filardo et al. have shown that $E_{2}$ can activate the MAPK signaling cascade via binding to GPR30 leading to transcription of cell proliferative genes [13] . ER antagonists ICI 182, 780 and 4-OHT were found to activate GPR30 and mediate MAPK signaling [14].

In addition, ligand activated membrane ER $\alpha$ can phosphorylate and activate key signaling molecules including Epidermal Growth Factor Receptor (EGFR), c- src, Shc and p85 $\alpha$ regulatory subunit of MAPK [15-17]. Although this mechanism is independent of $\mathrm{E}_{2}$-mediated transcription, the activation of signaling pathways may affect downstream molecules, subsequently leading to nuclear ER activity and also induce transcription of $\mathrm{E}_{2}$-responsive genes [18]. Thus there is cross-talk between growth factor receptor pathways and genomic ER signaling [17].

\section{ENDOCRINE THERAPIES FOR THE TREATMENT OF BREAST CANCER}

Estrogens are natural ligands of ER. Blocking estrogen-mediated tumor growth has been the mode of breast cancer treatment for many years. Endocrine therapies either target ER $\alpha$ action or block estrogen synthesis. Antiestrogens (e.g., Tamoxifen (TAM) and Raloxifene (RAL)) function by binding to the ER and blocking its transcriptional activity. ICI 46, 474 (now known as TAM) was originally developed by Imperial Chemical Industries (ICI) Ltd. Pharmaceuticals Division [19]. It was developed by a group of scientists that included Arthur Walpole, Dora Richardson and Michael J.K Harper. Although initial studies focused on its role as a contraceptive drug, it was Walpole who later on suggested its use as an antiestrogen. 
He identified that TAM acts as an estrogen in the mouse vagina while it is an antiestrogen in rat vaginal epithelium and uterus [20,21]. Walpole also suggested that TAM may inhibit tumor formation in the breast. After his death in 1977, significant studies on TAM's role as a SERM (Selective Estrogen Receptor Modulator) as well as an antitumor agent was investigated by Craig V. Jordan [22-25] .

It was in 1977 that TAM was approved by the FDA to be used clinically as an antiestrogen in the United States. Since then, TAM, a non-steroidal antiestrogen, has been widely used for the prevention and treatment of ER $\alpha$-positive breast cancer $[26,27]$. TAM has cell-type-specific mixed agonist/antagonist activity, and is thereby classified as a SERM [28]. SERMs are classified according to its structure, which are more or less similar to $\mathrm{E}_{2}$. TAM is a triphenylethylene which is metabolized in the liver to its active form 4-OHT by the cytochrome P450 enzyme CYP2D6. In the breast, 4-OHT acts as an ER antagonist and competes with $\mathrm{E}_{2}$ for binding to the ER. For over 30 years, TAM has been the 'gold standard' for the treatment of breast cancer in pre-menopausal women [29]. One of the disadvantages of TAM is that women on TAM therapy have an increased risk of uterine cancer due to its agonist activity in the uterus [30].

RAL and arzoxifene are benzothiophenes. RAL avoids some of the side effects associated with TAM due to its antagonist activity in both breast and uterus. RAL was first approved in 1997 by the FDA to be used in the treatment of osteoporosis in post-menopausal women [31]. It was subsequently demonstrated to prevent recurrent disease and primary breast cancer by a number of clinical trials [32]. The RUTH (Raloxifene Use For The Heart) is a significant trial that demonstrated the use of RAL in the treatment of osteoporosis in post-menopausal women who had cardiovascular disease [33]. The trial showed that RAL is effective not only in the 
treatment of osteoporosis but also for ER-positive breast cancer. Results of the STAR (Study of Tamoxifen and Raloxifene) trial that was published in 2006 further confirmed the role of RAL in the treatment of osteoporosis as well as invasive breast cancer in women [34].

Another class of antiestrogens used in the treatment of breast cancer is called Selective Estrogen Receptor Downregulators (SERD) with the prototype fulvestrant. It is a SERD because it binds the ligand binding domain (LBD) noncovalently, and targets $\mathrm{ER} \alpha$ to the $26 \mathrm{~S}$ proteasome for degradation [35].

Aromatase inhibitors (AIs) are a class of antiestrogens that block estrogen synthesis [36]. In post-menopausal women, estrogens are no longer synthesized by the ovaries. However estrogens are synthesized from either locally produced or adrenal androgenic precursors (e.g. DHEA or Dehydroepiandrosterone, DHEAsulphate) in peripheral tissues including adipose tissue, brain, skin, bone, endometrium, and breast [37]. In these tissues, the enzyme aromatase (CYP19AI) catalyzes the conversion of androgens, (i.e., testosterone and androstenedione) to estrogens (i.e., $\mathrm{E}_{1}$ and $\mathrm{E}_{2}$, respectively). The three most commonly used AIs are letrozole, anastrozole and exemestane. AIs have been shown to be more effective than TAM in promoting disease-free survival in post-menopausal women [38]. Exemestane is a steroidal AI that bind to the substrate-binding site of aromatase enzyme and irreversibly inhibits its action [39]. Letrozole and Anastrozole are nonsteroidal Als that bind reversibly to the substrate binding site of the aromatase enzyme [4]. Unlike TAM, AIs do not increase the risk of endometriosis and thromboembolism [40]. However AIs increase osteoporosis and fractures along with side effects such as hot flashes and headaches. The use of AIs is limited by musculoskeletal pain which some breast cancer survivors find intolerable [41]. 


\section{MECHANISMS OF ENDOCRINE/TAMOXIFEN-RESISTANCE}

Although hundreds of thousands of women are alive today because TAM prevents breast cancer recurrence [42], the majority of tumors that initially respond to TAM develop resistance. It is estimated that $40 \%$ of the women who receive adjuvant hormonal therapy acquire endocrine resistance $[43,44]$. The mechanisms of acquired endocrine/TAM- resistance remain to be fully elucidated despite intense study by many labs over the past 25 years [45]

Loss of ER $\alpha$ and aberrant expression of coregulators contribute to endocrineresistance- Acquired endocrine resistance, which occurs after a woman was initially successfully treated on TAM, was originally thought to be due to loss of ER $\alpha$ expression. Mechanisms involved in the loss of ER $\alpha$ expression include activation of EGFR and MAPK signaling [46,47], methylation of ER $\alpha$ promoter [48] and hypoxia [49]. However, ER $\alpha$ was found to be lost in only 15-20\% of TAM-resistant cancers, suggesting other mechanisms for the development of endocrine/TAM-resistance [50]. Recent studies show that a variant of ER $\alpha$ called ER $\alpha 36$ is expressed in tumors that are not responsive to TAM [51]. Another variant of ER $\alpha$ called ER $\alpha 46$ was found to be decreased in TAM-resistant breast cancer [52].

Other factors that play a role in the development of endocrine/TAM-resistance include altered expression of coregulators [53-56]. For example, AIB1 (also known as SRC-3 or NCoA-3), a nuclear coactivator is overexpressed in breast tumors and is associated with increased $\mathrm{ER} \alpha$ mediated transcription [56] and reduced TAMresponsiveness in patients [57]. On the other hand, reduced expression of Nuclear receptor co-repressor ( $\mathrm{NCoR}$ ) was observed in a mouse model of human breast cancer and correlated with TAM-resistance [58]. Low NCoR is associated with a shorter disease-free survival and is used as predictor of TAM-resistance in ER $\alpha$-positive 
breast cancer [59]. Increased expression of AP-1, Sp1 and NF- $\mathrm{KB}$ transcription factors have been associated with endocrine resistance [60-62]. TAM-liganded ER $\alpha$ acts as an antagonist and increase $\mathrm{AP}-1$ and NF-kB transcriptional activities in MCF7 breast cancer cells [63]. TAM-liganded ER $\beta$ was found to act as an agonist and induce AP-1 regulated gene transcription in MCF-7 and MDA-MB-453 breast cancer and Ishikawa endometrial cancer cells transfected with an ER $\beta$ expression plasmid [63]. This leads to enhanced cell proliferation and growth, resulting in TAMresistance. Increased NF- $\mathrm{KB}$ transcriptional response was reported in TAM- resistant and ERBB2-positive cell lines, MCF-7/HER2 and BT474 [62]. The study showed that the increase in NFkB transcriptional response was reversed by the NF-kB inhibitor Parthenolide leading to better response to TAM. The study also showed that the increased TAM-responsiveness in these cells was due to enhanced recruitment of the corepressor NCoR to the TAM-ER complex upon treatment with the inhibitors.

Post-translational modifications of ER $\alpha$ contributes to endocrine resistance Posttranslational modifications such as phosphorylation, sumoylation and acetylation can alter the conformation of $E R \alpha$ such that it affects its ligand binding properties and interaction with proteins such as coregulators [64-66]. Phosphorylation of ER $\alpha$ takes place mainly by activation of kinase pathways such as protein kinase A (PKA), MAPK and Src pathways [67-69]. Some of the phosphorylation sites within ER $\alpha$ that can alter the response of cells to TAM include Ser102/4/6, Ser 118 and Ser 305 [66]. The Ser 118 residue on ER $\alpha$ can be phoshorylated by pathways such as MAPK, PI3K, CDK7 and IKK $\alpha$ [70-72]. $\mathrm{E}_{2}$ or EGF can induce the MAPK pathway and thus phosphorylate Ser118 leading to enhanced ER $\alpha$ activation [73]. Phosphorylation of $\mathrm{ER} \alpha$ on Ser 118 by MAPK was found to reduce its affinity for TAM [72]. ER $\alpha$ that is 
phosphorylated at Ser-118 was also found to have decreased DNA binding capacity when bound to TAM. Another consequence of phosphorylation of ER $\alpha$ at Ser 118 is its altered interaction with coactivator AIB1 [72]. Phosphorylation of ER $\alpha$ at Ser305 by PKA has been shown to result in TAM resistance by altering the interaction of $\mathrm{ER} \alpha$ with coactivator NCoA-1(also known as SRC-1), and promote transcription by TAM [74-76]. P21-activated protein kinase-1(Pak1) phosphorylates ER $\alpha$ at Ser305. This leads to transactivation of ER $\alpha$ independent of ligand binding and increases ER $\alpha$-mediated transcriptional activity. As a result there is reduced responsiveness of tumors to TAM [77,78]. Hence expression of Pak1 is considered as a poor prognostic marker for TAM resistance.

Altered glycosylation is an early step in carcinogenic transformation [79] and yet is an understudied field of knowledge regarding modification of ER $\alpha$ and other proteins that can move between the plasma membrane and nuclear compartment. Glycosylation of ER $\alpha$ at the hydroxyl group of its Ser or Thr residues has been reported $[80,81]$. O-linked $\mathrm{N}$-acetyl glucosamine (O-GlcNAC) residues were identified on $\mathrm{ER} \alpha$ that was isolated from bovine calf uteri and insect cells expressing mouse ER $\alpha$ [80]. The Thr575 residue on the C-terminal fragment of ER $\alpha$ was identified as a major site of glycosylation site in these ER $\alpha$. Additional glycosylation sites were later identified on Ser10 and Thr50 of mouse $\operatorname{ER} \alpha$ [81]. However these modifications were not found to alter the DNA-binding properties of ER $\alpha$.

Acetylation of transcription factors by histone acetyl transferases (HATs) such as p300, CBP and P/CAF makes the DNA accessible to nuclear coregulators [82]. Acetylation of ER $\alpha$ by p300 at Lys residues 266 and 268 in its hinge/ ligand binding domain was reported by Mi et al. [83]. Their study demonstrated that acetylation of 
$\mathrm{ER} \alpha$ did not modify its localization or ability to bind $\mathrm{E}_{2}$ or coregulators. However, acetylation increased ER $\alpha$ 's DNA binding properties and transactivation. Contrary to this observation, mutation of Lys302 and 303 residues of ER $\alpha$ to Arg enhanced its activation by $E_{2}$ [84]. They found that acetylation is specific to Lys302 and 303 residues in the hinge region of $E R \alpha$. This indicates an inhibitory effect of acetylation on the sensitivity of ER $\alpha$ to ligands. Mutation of Lys residues could thus contribute to development of breast cancer. Interestingly, an ER $\alpha$ K303R mutation has been reported in breast cancer patients with atypical hyperplasia [85]

Sumoylation is a post- translational modification involving addition of SUMO (small ubiquitin-like modifier) moieties to proteins. SUMOylation is increased in carcinogenesis [86]. ER $\alpha$ is sumoylated by (SUMO)-1, at the Lys residues in the hinge region [87]. Sumoylation enhanced ER $\alpha$ transcriptional activity. Proteins PIAS1 and PIAS3 were found to stimulate sumoylation of ER $\alpha$ in the presence of ligands, e.g., $\mathrm{E}_{2}$ and TAM [87]. This would be expected to increase $\mathrm{ER} \alpha$ turnover. Using mutation studies involving substitution of Lys residues in the hinge region with Arg, the authors observed that there was an inhibition of sumoylation and reduced $E R \alpha$ transcriptional activity. Thus posttranslational modifications of ER $\alpha$ alter its transcriptional activity as well as interaction with coregulators.

Aberrant growth factor receptors and cytoplasmic signaling contribute to endocrine resistance

Role of Receptor Tyrosine Kinases (RTK) - Enhanced RTK signaling mediated by growth factor overexpression or intrinsic activation has a role in endocrine resistance. Further, overexpression of EGFR, insulin like growth factor receptor (IGFR) and the mutant human epidermal growth factor receptor (HER-2/neu or ERBB2) contribute to 
endocrine/TAM-resistance because they activate cell survival/proliferation responses independent of estrogen-ER activity [88-91].

Endocrine resistance also involves activation of the intracellular protein kinase pathways, (e.g. the MAPK and the PI3K) that are downstream of plasma membraneinitiated EGFR, IGFR and ERBB2 signaling [89,92]. Deregulation of these pathways could be due to genetic modifications such as mutation of PTEN, a tumor suppressor that inhibits PI3K, or due to amplification of ERBB2 [64,93,94]. The mechanism of ERBB2 overexpression in endocrine resistance is not fully understood. However it is proposed that the intrinsic activation of $\mathrm{ERBB} 2$ and subsequent activation of the MAPK pathway that leads to phosphorylation of ER $\alpha$ at Ser118 results in its ligandindependent activation [94-96]. This would lead to non-responsiveness of cells to TAM-mediated repression of ER $\alpha$-mediated transcription. Another mechanism of antiestrogen-resistance in ERBB2 overexpressing cells is the impaired recruitment of transcriptional corepressors such as NCoR and SMRT by TAM-occupied ER $\alpha$ [94]. As a result there is reduced responsiveness of ERBB2-overexpressing cells to TAM. This was seen in ERBB2-expressing tumor samples.

Role of cell cycle modulators - Aberrant expression of cell cycle regulators that are targets of antiestrogens can lead to endocrine resistance [97]. Overexpression of MYC, cyclin E1 or cyclin D1, inactivation of the retinoblastoma ( $\mathrm{Rb}$ ) tumor suppressor, or the decreased expression of cyclin-dependent kinase (CDK) inhibitors p21 and p27 lead to loss of antiestrogen-responsiveness [98-102]. c-Myc, a nuclear transcription factor has mitogenic effects similar to $E_{2}$ and is, in fact, an immediate early gene product stimulated by $\mathrm{E}_{2}-\mathrm{ER} \alpha$ [103]. MYC promotes cell cycle progression by regulating cell cycle modulators (e.g. p21 and p27) [104]. MYC overexpression has been shown to promote TAM-resistance by suppressing the 
expression of CDKNIA that encodes $\mathrm{p} 21$ which is a repressor of cell cycle regulators cyclin-cdk2 [105]. This relief of repression of cyclin E1 CDK2 complexes by p21 results in enhanced growth rate in response to TAM. Along with CDK2, Cyclin E1 promotes entry of cells into the S-phase of the cell cycle [97]. Cyclin D1 overexpression also leads to increased tumor growth in response to TAM [106]. This is due to enhanced cyclin D1 binding to ER $\alpha$ through STAT3, thus activating ER $\alpha$. TAM was found to enhance binding of ER $\alpha$ to STAT3 in the presence of cyclin D1, thus promoting tumor growth. Overexpression of MYC and Cyclin D1 and Cyclin $\mathrm{E} 1$ has also been reported in patients with breast cancer [107].

Loss of $\mathrm{Rb}$ function has also been linked to endocrine resistance [102]. $\mathrm{Rb}$ is $\mathrm{a}$ critical regulator of cell growth [108]. Inactivation of $\mathrm{Rb}$ function due to phosphorylation has been reported in breast cancer [109]. This loss of function is associated with aberrant cyclin/CDK activity. Other factors that can result in loss of $\mathrm{Rb}$ function in breast cancer includes mutation and epigenetic silencing [110]. Aberrant $\mathrm{Rb}$ pathway function has also been reported in ER-negative breast cancer and is used as a predictor of poor response to TAM therapy [111]. 


\section{CHAPTER II: SIGNIFICANCE OF MICRORNA EXPRESSION IN ENDOCRINE/TAMOXIFEN -RESISTANT BREAST CANCER}

\section{BIOGENESIS OF MICRORNA}

Regulation of gene expression is critical for the normal development of an organism. MicroRNA (miRNA) are a class of short non-coding RNA that regulate gene expression at the post-transcriptional and/or translational level [112]. These RNAs, which are 21-22 nucleotides in length, regulate a number of cellular processes including growth, development, differentiation, apoptosis and cell cycle [113]. miRNAs were first described by Lee et. al. in Caenorhabiditis elegans [114]. Today there are over 9200 publications listed in PubMed on miRNAs in humans, reflecting the interest in how these RNAs post-transcriptionally regulate protein expression and cell function.

miRNAs are given a three lettered prefix depending on the species that they originate in i.e., hsa for homo sapiens, mmu for mouse, and so on [115]. If miRNAs originate from different genomic loci, they are assigned a numerical suffix, i.e. hsamiR-29b-1 and hsa-miR-29b-2. miRNAs that differ by a few bases are given a lettered suffix of the form miR-125a and miR-125b. Those miRNAs that originate from opposite arms of the hairpin precursor are assigned suffixes of the type miR142-5p and $\mathrm{miR}-142-3 p$. $\mathrm{miR}-21$ and $\mathrm{miR}-21 *$ refers to miRNAs that arise from the same hairpin precursor. An asterix in the miRNA name indicates that it is a less predominant form of the miRNA[116]. miRNA cluster arises due to gene duplication, e.g., the miR-200 cluster of miRNAs is located in two chromosomes, i.e., miR-200a, 
miR-200b and miR-429 are located on chromosome 1 and miR-200c and miR-141 are located on chromosome 12. Each cluster is transcribed into a common precursor RNA. A miRNA family refers to miRNAs that arise from a common ancestor and whose sequences are similar e.g. miR-221 and miR-222 family.

MiRNA are located mostly in the introns of protein coding genes [117]. In eukaryotes, most miRNAs are transcribed by RNA polymerase II into long transcripts called primary miRNA (pri-miRNA) [118]. A few miRNAs are transcribed by RNA pol III, e.g., miR-515-1, miR-517a, miR-517c [119]. Primary miRNA is processed into $\sim 70$ nucleotide precursor miRNAs (pre-miRNA) by a ribonuclease III (RNase III) enzyme Drosha in association with an RNA binding protein DGCR8 (together called the Microprocessor complex). Recent studies show that some intronic miRNAs (mirtrons) are processed by splicing machinery instead of Drosha and DGCR8 [120]. Pre-miRNA is then exported from the nucleus to the cytoplasm by Exportin and RanGTP. In the cytoplasm, the pre-miRNA is further cleaved by RNase III Dicer along with RNA-binding proteins TRBP and PACT (in humans) to a mature double stranded miRNA. Mature miRNAs is incorporated into the RNA-induced silencing complex (RISC) consisting of Argonaute 2 (Ago2) and TRBP protein. The miRNA duplex unwinds and the RISC degrades one of the strands of the miRNA (passenger strand, e.g., $\operatorname{miR}-21^{*}$ ) while the functional strand (guide strand, e.g., miR-21) targets messenger RNA (mRNA) for degradation or translational repression. According to miRBase (version 18, November 2011), the human genome encodes more than 1500 human miRNAs.

\section{MICRORNA FUNCTION}

MiRNAs affect mRNA stability or repress translation. The 5'UTR of miRNA harbours a 2-8 nucleotide seed region that binds to the 3'UTR of mRNA in a 
complementary fashion. Perfect base pairing between the miRNA and mRNA leads to mRNA degradation [121]. This type of perfect complementarity between miRNA and the target mRNA is seen in mostly in plants and rarely in vertebrates and viral miRNAs.

In most metazoans, there is mostly imperfect base pairing leading to translational repression. Many theories have been proposed for the repression of translation by miRNAs. One theory states that the AGO2 protein of the miRNAribonucleoprotein (miRNP) complex (consisting of mature miRNA, Ago2 and TRBP protein) competes with the eIF4E elongation factor from binding to the 5' cap of mRNA, thus repressing translation [122]. Another study shows that the elongation factor eIF6 is a major target of miRNPs. The authors of this study propose that AGO2 interacts with eIF6 and inhibits joining of the $60 \mathrm{~S}$ ribosomal subunit to the $40 \mathrm{~S}$ initiation complex [123]. It has also been proposed that repression of translation occurs at post-initiation stages of translation due to slow elongation of mRNA $[124,125]$. Repression of mRNAs by binding of miRNPs induce deadenylation mediated by a glycine-tryptophan protein called GW182 and poly (A) binding protein (PABP) which in turn recruits deadenylase $\mathrm{CCR} 4$ and $\mathrm{CAF} 1$, and subsequently results in decay of mRNAs [126,127]. An alternate mechanism of repression by miRNA is by sequestration of mRNA in P-bodies [128]. mRNAs that undergo translational repression by the RISC were found to accumulate in these P-bodies [129]. In eukaryotes, there are two modes of mRNA decay induced by miRNAs. The mRNA is degraded either by $3^{\prime} \rightarrow 5^{\prime}$ exosome activity or by removal of the $5^{\prime}$ cap followed by 5 ' $\rightarrow$ ' degradation catalyzed by XRN1 [130].

Currently there are over 10,000 miRNAs that have been reported in different organisms [131]. It is estimated that miRNAs regulate $-50 \%$ of protein-coding 
genes in the human genome [132]. MiRNA target prediction software programs have shown that each miRNA can have more than one mRNA target. MiRNAs have been shown to fine-tune the expression of genes to allow optimal expression during different stages of development. In humans, miRNAs exhibit tissue specific expression and regulate cellular processes by targeting key proteins and signaling networks [133].

\section{REGULATION OF MICRORNA EXPRESSION}

Role of miRNA processing proteins - MiRNA expression is regulated at different levels. The ratio of the ribonuclease Drosha and its binding partner DGCR8 is tightly regulated to ensure proper pri-miRNA processing [134] . DGCR8 stabilizes Drosha. Drosha in turn regulates DGCR8 levels by cleaving and thus inactivating it. Thus a tight feedback loop maintains the cellular Drosha/DGCR8 ratio [135].

A number of co-activators and co-repressors can alter Drosha activity. Transforming growth factor beta (TGF $\beta$ ) signaling and bone morphogenetic protein (BMP) and SMAD proteins stimulate, while the nuclear factor NF90-NF45 heterodimer suppresses Drosha activity [136,137]. ER $\alpha$ along with helicases p68 and p72, and Drosha have been shown to affect Drosha complex formation, thus repressing primiRNA processing[138].

Defects in Exportin 5 results in accumulation of pre-miRNAs in the nucleus

[139]. Another ribonuclease that is a key point of regulation in the miRNA biogenesis pathway is Dicer. Altered Dicer expression can affect processing of premiRNA to mature miRNA. Dicer mutation has been reported in non-small cell lung cancer and prostate cancer $[140,141]$. It has been shown that Dicer cofactors, TRBP and PACT are critical in maintaining the stability of Dicer in cells $[142,143]$. 
Increased phosphorylation of TRBP by MAPK signaling was found to enhance Dicer activity and promote miRNA processing [144].

Role of Ago2 proteins - After cleavage of the pre-miRNA by the ribonuclease Dicer, one of the strands of the mature miRNA is incorporated into the RISC by Ago2 protein. Although the human genome encodes about 8 Ago proteins, Ago2 is the major protein involved in RNA cleavage and silencing. The level of Ago2 determines the amount of mature miRNA synthesized. Ago2 is subject to regulation at the transcriptional and post-transcriptional level. For example in MCF-7 breast cancer cells Ago2 expression is inhibited by $\mathrm{E}_{2}$ and EGF-MAPK signaling [145].

Regulation of miRNA transcription - A number of transcription factors have been shown to regulate miRNA expression. For example, p53 has been shown to increase the expression of miR-34 and miR-107 families [146,147]. MYC stimulates the expression of miR-17-92 cluster of miRNAs in lymphoma cells [147]. In neuronal cells, the RE1 Silencing Transcription Factor (REST1) inhibits transcription of miR124 by recruiting histone deacetylases (HDACs) and methyl $\mathrm{CpG}$ binding protein MeCP2 to the miR-124 gene promoter [148]. The transcription of primary miRNA transcripts have been shown to be regulated by platelet-derived epidermal growth factor (PDGF) and transforming- growth factor-beta (TGF- $\beta$ ) $[149,150]$

Steroid hormone regulation of miRNA expression- Steroid hormones and their receptors have been reported to regulate miRNA expression in a variety of cancer cell lines [151-153]. Because the focus of my dissertation is the role of miRNA expression in endocrine resistant breast cancer, I will focus on estrogen regulation of miRNA expression $[154,155] . E_{2}$ regulation of miRNA expression was studied by Cohen et. al. in adult zebrafish [156]. miR-196b and Let $7 \mathrm{~h}$ were up-regulated, and miR-130c and miR-101a were downregulated by $E_{2}$ treatment in this study. Further, 
Hoxb8a, a target of miR-196b was downregulated regulated by $E_{2}$ in zebrafish. In a model of mammary carcinogenesis in rats, $E_{2}$ was found to regulate the expression of miRs after 6, 12 and 18 weeks of treatment in female August Copenhagen Irish (ACI) rats [157]. Some of the miRNAs that were altered after $E_{2}$ treatment include miR22*, miR-99a, miR-127, miR-499, miR-17-5p, miR-20a, and miR-92. Castellano et. al. have shown that $\mathrm{E}_{2}$ upregulates the expression of miRNAs encoded by the miR17-92 and miR-106a-363 paralogous cluster in MCF-7 breast cancer cells [158]. Microarrays identified 23 miRNAs to be downregulated by $E_{2}$ in MCF-7 cells [159]. Of these, the expression of 8 were confirmed by quantitative real time PCR (Q-PCR) in MCF-7, BT474, T47D and ZR-75-1 breast cancer cells. The expression of primiR-21 and pri-miR-181a were also found to be regulated by $E_{2}$ in MCF-7 cells. Another study by Cicatiello et al. identified miR-424 and miR-760 to be increased by $E_{2}$ while miR-107, miR-570 and miR-618 were found to be decreased by $E_{2}[160]$. This study identified miRNA binding sites in the mRNA of $E_{2}$-regulated target genes by global mapping.

Work done in our laboratory has also shown that $\mathrm{E}_{2}$ regulates miRNA expression in MCF-7 breast cancer cells $[161,162] . E_{2}$ was found to decrease miR-21 expression which in turn increased the expression of its target genes, PDCD4 and BCL2. Contrary to our results, Nakshatri $e$. al. reported an increase in miR-21 expression in MCF-7 cells after treatment with $10 \mathrm{nM} \mathrm{E}_{2}$ for $4 \mathrm{~h}$ [163]. However, others have likewise reported that $E_{2}$ reduces miR-21 expression $[159,164-166] \quad A$ summary of miRNAs that are regulated by $E_{2}$ was recently reviewed [167]

Epigenetic control of miRNA expression -DNA methylation and histone modifications regulate miRNA expression. These mechanisms have been attributed to the aberrant expression of miRNAs seen in diseases such as cancer. For example, 
hypermethylation of miR-134, $\mathrm{miR}-34 \mathrm{~b} / \mathrm{c}$, miR-137, miR-342 has been reported in different types of cancer $[168,169]$. Hypomethylation of let $7 \mathrm{a}-3$ has been reported in lung adenocarcinoma [170]. The promoter of miRNA genes e.g. miR-1 and miR-27a are altered by histone modification [171]. Acetylation of miR-1 gene promoter results in its decreased expression in lung cancer. HDAC inhibitors reversed this effect.

\section{MICRORNA AS ONCOGENES OR TUMOR SUPPRESSORS}

Aberrant miRNA expression has been reported in a number of diseases including cancer [172]. MiRNAs act as oncogenes or tumor suppressors by regulating the expression of genes associated with key pathways. As such, their expression and the regulation of their expression is of keen interest in cancer research, both for use as clinical biomarkers and as targets for prevention or treatment.

MicroRNAs as tumor suppressors- miR-15a and miR-16 act as tumor suppressors by negatively regulating the anti-apoptotic gene BCL2. Downregulation of miR-15a and miR-16 has been observed in chronic lymphocytic leukemia (CML), resulting in increased expression of BCL2 and anti-apoptotic activity [173]. miR-34a is downregulated in colon, ovarian, lung and pancreatic cancers [174-176]. It targets the oncogene MYCN [177]. miR-34 indirectly controls p53 activation through SIRT1 [178]. The Let-7 family of miRNAs were found to be deleted in a number of cancers including lung, colon and lymphomas $[179,180]$. They act as tumor suppressors by negatively regulating cell cycle regulators, CDK6 and CCND [181]; and oncogenes such as RAS, MYC and HMGA2 by translational repression [182,183].

MicroRNAs as oncogenes- One of the most important miRNAs that acts as an oncogene is miR-21. It has been shown to repress the expression of tumor suppressors such as the programmed cell death protein (PDCD4), tropomyosin 
(TPM1), phosphatase and tensin homologue (PTEN) and maspin[184-188]. miR-21 is overexpressed in lung, breast, pancreatic and prostate cancer [189-191].

In addition to miR-21, the miR-17-92 cluster is overexpressed in aggressive lung cancer and its putative targets include PTEN and $R B 2[132,192]$. The expression of miR-155 is increased in most lymphomas, e.g., miR-155 was found to be significantly decreased in Burkitt's lymphoma and Diffuse Large cell B-lymphoma (DLBCL)[193]. It has been suggested that this overexpression of miR-155 downregulates the expression of the transcription factor PU.1 that is important in Bcell differentiation [194].

\section{MICRORNA EXPRESSION IN BREAST CANCER}

MiRNAs are aberrantly expressed in breast cancer $[195,196]$. MiRNA expression is either upregulated or downregulated in breast cancer cells or tumors when compared to normal breast tissue. miRNAs have been shown to have a role in tumor progression by altering the expression of oncogenes and tumor suppressors [197]. miRNAs promote metastasis and invasive properties of breast cancer cells. Expression profiling of miRNAs in solid tumors and breast tissues have identified miRNAs that are associated with breast cancer subtypes [198]. A few examples of the miRNAs that are deregulated in breast cancer include tumor suppressors such as Let-7, miR-125, miR-200, and the oncogenic miRs such as miR-21 and miR-155 [199]. Downregulation of the tumor suppressor Let-7a alters the expression of its targets Ras and HMGA2 [200]. miR-125a and miR-125b have been shown to target tumor suppressors ERBB2 and ERBB3 [201]. Downregulation of Let-7a, miR-200 and miR-205 promotes epithelial-to-mesenchymal transition (EMT) in breast cancer [202-204]. The targets of miR-200 include nuclear transcription factors ZEB1, ZEB2;

phospholipase C, gamma 1(PLCG1) and TGF- $\beta 2$ [205-207]. Other metastatic 
promoting miRNAs that promote migration and invasion of cancer cells include miR10b, miR-520c and miR-373 [208,209]. miR-10b targets HOXD10 expression [210]. HOXD10 has been shown to target genes involved in angiogenesis and cell migration [211]. Loss of HOXD10 thus promotes an invasive phenotype in breast cancer.

The miRNAs that are oncogenic, and overexpressed in breast cancer, are miR21 and miR-29, miR-34, miR-155, and miR-210 [199]. MiR-21 has been shown to promote tumor formation by targeting PDCD4, PTEN, TPM1, and BCL2 [187,212]. The miR-17/92 cluster has been shown to have a dual role as a tumor suppressor and an oncogenic miRNA. Hossain et al. reported its role as a tumor suppressor by reducing the expression of the ER coactivator AIB1 [213]. AIB1 was originally identified as an oncogene by Myles Brown [214] and further studies have confirmed AIB1's role in breast cancer [215-217]. Li et al. described miR-17-5p of the 17/92 cluster to be a metastasis promoting miRNA in breast cancer by suppressing HMG box-containing protein 1HBP1 expression [218]. HBP1 is a suppressor of Wnt/3catenin signaling. Downregulation of HBP1 by miR-17-5p activates Wnt/ $\beta$-catenin signaling and thus promotes migration and invasion of MCF-7 breast cancer cells.

Analysis of miRNA expression in breast tumors using tissue microarray identified a number of miRNAs that are differentially expressed in breast cancer tissue when compared to normal tissue, e.g., miR-10b, miR-21, miR-145 were upregulated in breast cancer tissue [219]. There was also a correlation between miRNA expression, ER and PR status, lymph node status in these samples. In another study, miR-342 and miR-520g were found to be overexpressed in ER-positive and HER2 positive tumors when compared to normal tissue [220]. miRNA signatures associated with specific breast cancer cell type such as luminal and basal-like has been reported [198]. Let-7a, miR-21, miR-141 and miR-214 were expressed in 
luminal cell type while miR-145 and miR-205 were associated with the myoepithelial cell type [221].

Circulating miRNAs have been detected in the blood, plasma and serum of breast cancer patients $[222,223]$. The level of plasma miRNAs was higher in breast cancer patients when compared to control groups [224,225]. For example miR-425*, Let $7 \mathrm{c}$ were found to be higher in the plasma of women with early stage breast cancer when compared to healthy controls. Higher expression of miR-10b and miR-34 was found in the serum of breast cancer patients correlated with metastasis [222]. Systemic miR-195 and Let-7a were higher in breast cancer patients when compared to normal subjects[226]. The expression of these miRNAs also correlated with ER status [227]. These reports indicate that miRNAs could be valuable diagnostic markers in the prognosis and treatment of breast cancer.

\section{MICRORNAs REGULATE ER $\alpha$ ACTIVITY}

MiRNAs regulate ER $\alpha$ expression and activity. MiR-206 downregulates ER $\alpha$ mRNA and protein level in MCF-7 human breast cancer cells [228]. This study showed that miR-206 expression is increased in ER $\alpha / E R B B 2$-negative tumors when compared to ER $\alpha$-positive tumor specimens. Adams et al. reported a double negative feedback loop between miR-206 and ER $\alpha$ in MCF-7 cells [229]. Another study by the same group reported increased miR-206 expression in MCF-7 and T47D breast cancer cells [230]. This increased miR-206 expression was found to suppress estrogenic effects in cells by decreasing the expression of ER $\alpha$ and coactivators such as $\mathrm{NCoA}-1, \mathrm{AIB} 1$ and GATA3 that are involved in $\mathrm{ER} \alpha$ signaling. The authors propose that enhanced EGF signaling contributes to the loss of ER $\alpha$ by increasing miR-206 expression. This loss of ER $\alpha$ is one of the factors responsible for the 
transformation of cells from luminal to a basal-type. Among the other miRNAs that target ER $\alpha$ are miR-22, miR-221 and miR-222. miR-22 degraded ER $\alpha$ mRNA [231]. The expression of this miRNA was lower in ER $\alpha$-positive breast cancer cell lines such as MCF-7, T-47D and BT474 when compared to ER $\alpha$-negative cell lines including MDA-MB-231 and SK-Br3 [232]. In contrast to miR-22, miR-221/222 suppressed ER $\alpha$ protein and not mRNA [233]. This study identified two binding sites for miR-221 and miR-222 in the 3'UTR of ER $\alpha$. Further, a negative feedback loop between miR-221/222 cluster and ER $\alpha$ has been reported in breast cancer cells [234]. miR-221/222 represses ER $\alpha$, which in turn represses the expression of miR-221/222. Thus miR-221/222 acts as a tumor suppressor in ER $\alpha$-positive cells. However Rao et al. have shown that prolonged treatment of cells with $\mathrm{E}_{2}$ or fulvestrant releases miR$221 / 222$ from the negative feedback loop. This results in increased miR-221/222 expression leading to enhanced cell proliferation and endocrine-resistance [235].

Let-7 family of miRNAs target ER- $\alpha 66$. There is an inverse correlation between the expression of Let -7 family and its target $E R \alpha-66$ in breast cancer samples [236]. Let-7 family also targets an isoform of $\mathrm{ER} \alpha, \mathrm{ER} \alpha-36$ that is located in the plasma membrane [237]. Loss of Let-7 family was found to confer TAM-resistance due to increased ER- $\alpha 36$ and enhanced non-genomic signaling. Among the other miRNAs that target $\mathrm{ER} \alpha$ include miR-18a, miR-18b, miR-193b and miR-302c [238]. This study utilized a protein lysate microarray approach where a library of pre-miRs were transfected into MCF-7 and T47D cell lines, and the expression of $\mathrm{ER} \alpha$ was analyzed in the protein lysates. 


\section{MICRORNA AND ENDOCRINE RESISTANCE}

Computational analysis of microRNAs have identified miRNAs and their targets that have a role in fulvestrant resistance [239]. miR-221/222 has been reported to promote TAM-resistance by targeting $\mathrm{ER} \alpha$ and the cell cycle regulator p27 (also known as Kipl) [233,240,241]. Miller et al. showed that miR-221/222 is overexpressed in ER $\alpha$-negative cells lines and tumors, as well as HER2-positive tumors. Overexpression of miR-221/222 was associated with fulvestrant-resistance [235]. Prolonged fulvestrant treatment induced miR-221/222 expression in MCF-7 cells. Some of the signaling pathways that are involved in promoting the miR221/222-mediated fulvestrant resistance and oncogenic activity include the $\beta$-catenin, TGF- $\beta$ and p53 pathways [235]. miR-221/222 is also increased in $\mathrm{CD}_{4} 4^{+} \mathrm{CD} 24^{- \text {low }}$ lineage ${ }^{-}$human breast cancer stem cells, indicating a role for these stem cells in drug resistance [242]. A study by Lu et al. shows that anti-miR-221 suppressed the growth of TAM-resistant xenografts in mice [243]. miR-15a/16 was found to downregulate the anti-apoptotic gene BCL2 and promote TAM resistance in MCF-7 cells expressing the HER2delta 16 mutant [244]. miR-451, a tumor suppressor miRNA was reported to be suppressed in MCF-7 derived cell lines that are TAM-

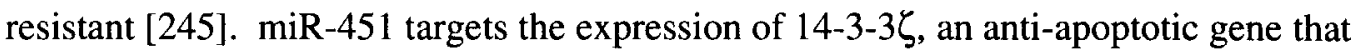
is overexpressed in TAM-resistant tumors and is also associated with poor clinical outcome in breast cancer. Thus the loss of miR-451 in ER-positive breast cancer upregulates $14-3-3 \zeta$ and contributes to TAM-resistance.

A PubMed search for 'MicroRNA and endocrine resistance in breast cancer' generates 12 publications as of September 2012. Most recently, global miRNA expression profiling using Exiqon microarrays in $152 \mathrm{ER} \alpha+$ tumors in 52 patients who received adjuvant tamoxifen as mono-therapy identified 10 miRNAs that 
discriminated between patient samples according to patient outcome[246] . Patients with recurrence in general had lower levels of miRs- 190b, 339-5p, 520c-3p, 520g, $520 \mathrm{~h}, 139-3 \mathrm{p}, 204,502-5 \mathrm{p}, 365$, and 363 . However, none of the data were statistically significant except that miR-7 increased with tumor grade. The authors concluded that "the miRNA profile does not seem to provide information with regard to the probability of recurrence following adjuvant tamoxifen-treatment in postmenopausal ER+ breast cancer patients." [246]. However, they also noted that tumor heterogeneity might be a factor in miRNA expression.

\section{DISSERTATION SPECIFIC AIMS AND HYPOTHESES}

As reviewed in Chapter I, breast cancer is one of the leading causes of death among women in the United States [1]. Although TAM prevents recurrence of breast cancer in women, about $40 \%$ of women who receive adjuvant hormonal therapy acquire resistance $[53,248]$. The mechanisms of acquired endocrine resistance remain to be fully elucidated [249]. This study was focused towards identifying miRNAs that are dysregulated in acquired endocrine/TAM- resistant breast cancer. By identifying miRNAs that are differentially expressed in antiestrogen-sensitive MCF-7 cells versus antiestrogen-resistant LY2 breast cancer cells, it would be possible to use them as prognostic markers of antiestrogen resistance in breast cancer.

Our laboratory identified miRNAs that are differentially regulated by TAM in endocrine-sensitive MCF-7 and endocrine-resistant LY2 human breast cancer cells $[161,247]$. Microarray expression profiling identified miRNAs that are regulated by $E_{2}$ and TAM. They were found to be regulated in the opposite direction in MCF-7 and LY2 cells. Q-PCR was preformed to confirm the expression 12 miRNAs that 
showed significant opposite expression between the two cell lines. Bioinformatic prediction identified 36 putative mRNA targets of the 12 miRNAs whose expression was validated by Q-PCR. Some of the mRNA targets include PDCD4, BCL2, CYP1B1, ERBB3. ZEB1, a target of miR-200 family of miRNAs and a promoter of EMT, was found to be overexpressed in LY2 cells when compared to MCF-7 cells. This was a significant finding as it indicated that LY2 cells represent cells that have undergone EMT. This study identified miR-200 family of miRNAs to have a role in suppressing endocrine-resistance in breast cancer.

Identification of specific miRNAs and their gene targets will advance our understanding of mechanisms of antiestrogen/endocrine-resistant breast cancer. The overall hypothesis of this proposal is that miRNAs are dysregulated in acquired endocrine-resistant breast cancer.

The specific aims to test the hypothesis were:

\section{SPECIFIC AIM 1: Identify miRNAs oppositely regulated by 4-OHT in antiestrogen-sensitive MCF-7 and antiestrogen-resistant LY2 human breast cancer cells.}

I hypothesized that there is inverse regulation of miRNAs in tamoxifen-sensitive versus-resistant breast cancer cell lines, and that the regulation of these miRNAs that are altered in tamoxifen resistance is mediated through the ER. Microarray was used to identify miRNAs that are differentially expressed between MCF-7 and LY2 cells. Results of the microarray analyses were validated by quantitative real time polymerase chain reaction (Q-PCR). 
SPECIFIC AIM 2: Identify the genes targeted by select miRNAs and correlate these miRNAs with changes in mRNA in MCF-7 and LY2 cells.

I hypothesized that changes in miRNA expression correlate with changes in target gene expression in MCF-7 and LY2 cells. miRNAs thus mediate dysregulated expression of target oncogenes or tumor suppressors and hence alter critical gene pathways in tamoxifen/endocrine-resistance. Bioinformatics was used to identify putative targets of select miRNAs that were identified and some were experimentally verified in Aim 1.

\section{SPECIFIC AIM 3: Determine if knockdown of miRNAs upregulated and} overexpression of miRNAs downregulated in endocrine-resistant breast cancer cells restore endocrine-sensitivity.

I hypothesized that changes in miRNA and mRNA expression correspond to changes in functional outcomes in cells. These changes can be reversed by knockdown or overexpression of those miRNAs that are up or downregulated respectively. Transfection using anti-miRNA or precursor miRNA oligonucleotides followed by functional assays were used to determine whether knockdown or overexpression of miR-200 restored endocrine-sensitivity/resistance and alter biological functions in cells. 


\section{CHAPTER III: DIFFERENTIAL EXPRESSION OF MICRORNAS IN TAMOXIFEN- SENSITIVE MCF-7 VERSUS TAMOXIFEN-RESISTANT LY2 BREAST CANCER CELLS}

The text of this chapter was published in Cancer Lett. 2011 Dec 26;313(1):26-43

\section{INTRODUCTION}

The ability of selective estrogen receptor modulators (SERMs, e.g., tamoxifen and raloxifene) and aromatase inhibitors (AI) to prevent disease recurrence in patients whose initial breast tumors expressed estrogen receptor alpha (ER $\alpha)$ provides compelling data supporting the role of ER $\alpha$ in the pathogenesis of breast cancer [250]. Unfortunately, approximately $40 \%$ of patients relapse after tamoxifen (TAM) or other endocrine therapies [251]. The mechanisms for the acquired resistance to endocrine therapies is complex and, even in the presence of continued ER $\alpha$ expression, includes amplification of growth factor signaling pathways, e.g., epidermal growth factor receptor (EGFR), MAPK, PI3K/AKT, JNK, and p38 MAPK [251-253], but the role of microRNAs in endocrine-resistance remains to be fully elucidated.

MicroRNAs are short, non-coding RNAs that regulate gene expression at the post-transcriptional level by direct binding to the 3'UTR of mRNA targets within the ribonucleoprotein RNA-induced silencing (RISC) complex, causing translational repression usually accompanied by mRNA decay [254,255]. miRNAs regulate diverse cellular processes including differentiation, replication, migration, and apoptosis [256]. Microarray technology has been used to generate miRNA profiles 
and demonstrate aberrant miRNA expression in a variety of cancers including breast tumors and cell lines [257-262]. These miRNA expression profiles correlate with classification of tumor grade and patient prognosis [257,258,263]. Altered miRNA expression in cancer may result from chromosomal rearrangements, deletions or epigenetic modifications in DNA or chromatin structure [263]. Bioinformatic analyses are used to identify putative mRNA targets of miRNAs, thus linking miRNAs to the regulation of complex protein networks involved in a variety of cellular functions [264]. miRNAs in breast cancer cells function as tumor suppressors, e.g., Let-7 family members, miR-125a and miR-125b, and miR-200; or as oncogenes, i.e., 'oncomirs', e.g., miR-21, miR-10b, miR-155, and the miR-17-92 cluster $[262,265]$.

miRNAs are processed from longer transcripts called precursor (pre)-miRNAs by Dicer within the cytoplasm. Pre-miRNAs are, in turn, the products of the processing, within the nucleus by DROSHA, of the initial miRNA gene transcripts called primary (pri)-miRNAs [266]. Recent studies have identified miRNAs regulated by estradiol $\left(E_{2}\right)$ in breast cancer cells and other cells and tissues (reviewed in [267]). For example, we and others reported that miR-21 and the Let- 7 family of miRNAs are downregulated by $E_{2}$ in breast cancer cells $[260,261,267,268]$. Interestingly, $\mathrm{E}_{2}$ upregulates transcription of miR-17-92 and its paralog miR-106a-363 clusters in MCF-7 human breast cancer cells, but appears to delay processing of the miR-17-92 gene product into its final miRNAs, including miR-18a and miR-20a [269], although the mechanism remains to be identified.

There are only a few studies of miRNA in TAM/endocrine-resistant breast cancer cells. Cell-based studies found that miRNA-221/222 are overexpressed in TAM-, fulvestrant-, and tumor necrosis factor (TNF)- resistant derivative of MCF-7 
cells [270-272]. However, no one has examined the effect of TAM on the expression of miRNAs in TAM-sensitive versus resistant breast cancer cells.

To investigate whether antiestrogen-resistance correlates with changes in miRNA expression, we profiled miRNA expression in TAM- sensitive MCF-7 and TAM/endocrine-resistant LY2 human breast cancer cells. LY2 cells were derived from MCF-7 by serial passage in the antiestrogen LY 117018, a precursor to Raloxifene (RAL) [273], and express wild-type ER $\alpha$ mRNA levels similar to MCF-7 cells [274], but are resistant to TAM, RAL, and fulvestrant (ICI 182,780) [275]. I hypothesized that differences in miRNA expression with TAM treatment between the TAM-sensitive MCF-7 versus TAM-resistant LY2 cells would identify miRNAs and their mRNA gene targets contributing to antiestrogen-sensitivity and resistance, respectively. miRNA microarrays were used to identify TAM-regulated miRNAs in these two cell lines. This study identified 97 miRNAs that were differentially expressed between the two cell lines and focused on 12 miRNAs that showed the greatest difference in expression between the two cell lines. Quantitative real time polymerase chain reaction (Q-PCR) was used to confirm the results obtained by microarray. In addition to miRNAs differentially regulated in the two cell lines, eight endogenous controls, including 6 miRNAs, 5S rRNA, and SNORD38B, were identified from the microarray data and their expression confirmed by Q-PCR.

A search of the Sloan-Kettering Targets and Expression (http://www.microrna.org/microrna/getDownloads.do) dataset was used to identify 36 putative gene targets of these miRNAs from amongst those that were reported to be regulated by 4-OHT in MCF-7 cells [276]. Q-PCR was used to examine the expression of 8 miRNAs. Q-PCR and Western analyses were used to examine the expression of gene/protein targets of the miRs- 21, 125b, 200a, 200b, 200c, 221 and 
222: PDCD4/Pdcd4, BCL2/Bcl-2, CYPIB1, ERBB3/ErbB3, ESR1/ER $\alpha$, and ZEB-1.

Results from this chapter show opposite regulation of select miRNAs and target proteins between the two cell lines, thus indicating a putative role of these miRNAs in TAM/endocrine resistance.

\section{MATERIALS AND METHODS}

\subsection{Cells and treatments}

MCF-7 human breast cancer cells were purchased from ATCC (Manassas, VA, USA) and maintained in IMEM supplemented with $10 \%$ fetal bovine serum (FBS) and $1 \%$ penicillin/streptomycin (Invitrogen, Carlsbad, CA, USA). LY2 tamoxifen/fulvestrant-resistant human breast cancer cells were provided by Dr. Robert Clarke, Georgetown University, and were used at $\mathrm{P}<16$ from this source. LY2 cells were originally derived from MCF-7 cells by selection in increasing concentrations of LY 117018 [273]. LY2, selected for resistance to LY 117018, are cross-resistant to TAM, raloxifene, fulvestrant (ICI 182,780), and are ER $\alpha$ positive, although ER $\alpha$ protein expression is lower than MCF-7 cells [273,277]. LCC1, LCC2, LCC9 are also derivatives of MCF-7 cell lines that are $\mathrm{E}_{2}$, tamoxifen, and multiple SERMindependent, respectively [278], and were provided by Dr. Robert Clarke, Georgetown University, and were, like LY2, used at $\mathrm{P}<16$ from this source. MDAMB-231 'triple negative' breast cancer cells were purchased from ATCC. $\mathrm{E}_{2}$ and 4OHT were purchased from Sigma (St. Louis, MO, USA). ICI 182,780 was from Tocris (Ellisville, MO, USA). Prior to treatment, the medium was replaced with phenol red-free IMEM supplemented with 5\% dextran charcoal-stripped FBS (DCCFBS) and $1 \%$ penicillin/streptomycin (stripped medium) for $48 \mathrm{~h}$ (referred to as 'serum-starving' or 'serum starved' cells). Cells were treated with ethanol (EtOH, the 
vehicle control, $0.01 \%$ final volume), $10 \mathrm{nM} \mathrm{E}_{2}$ or $100 \mathrm{nM} \mathrm{4-OHT}$ for $6 \mathrm{~h}$. For the microarray profiling, 4 separate experiments (biological replicates) were performed at different times over a 6 month period for each cell line. Note: Referrals in the text to ER and not specifically to ER $\alpha$ or ER $\beta$ indicated that either $E R \alpha$ or $E R \beta$ or both may be involved in the response tested.

\subsection{MicroRNA microarray analyses}

RNA was isolated from MCF-7 and LY2 cells, treated as above, using the mirVana miRNA Isolation Kit from Ambion (Austin, TX, USA) and sent to Exiqon (http://exiqon.com//) where the RNA samples were labeled with either Hy3 or Hy5 fluorescent labels and hybridized into the miRCURY LNA ${ }^{\mathrm{TM}}$ microarray (miRbase 11.0 human array). This microarray featured 1275 bone fide and putative human miRNAs plus additional controls. Four separate experiments (biological replicates) were performed. Data analysis was performed by Exiqon as follows: clustering of miRNAs was performed using $\log 2$ (Hy3/Hy5) ratios which passed the filtering criteria on variation across sample groups using a two tailed T-test p-value $<0.001$. The Hy3 signals were normalized using the single color approach 'Quantile' followed by a background correction. The data were deposited in GEO as GSE28267 http://www.ncbi.nlm.nih.gov/geo/query/acc.cgi?acc=GSE28267. The subset of miRNAs showing the highest variation among the 1275 miRNAs were used for clustering which provided a subset of 50 miRNAs that showed maximum variation between the two cell lines. The heat map (Figure 1) shows the result of clustering of miRNAs. The miRNA clustering tree is shown on the left and top. Each column represents a treatment and each row a miRNA.

\subsection{RNA isolation and quantitative Real-Time-PCR (Q-PCR) for miRNA expression}


miRNA-enriched total RNA was extracted from MCF-7 and LY2 cells treated as above using the miRNA isolation kit (Exiqon). The quality and quantity of the isolated RNA was analyzed using a NanoDrop spectrophotometer and Agilent Bioanalyzer. cDNA was synthesized using the miRCURY LNA ${ }^{\mathrm{TM}}$ first strand cDNA synthesis kit (Exiqon) and Q-PCR was performed using the miRCURY LNA ${ }^{\mathrm{TM}}$ SYBR Green master mix (Exiqon) using the miRNA primer sets for miR-10a, -21, 22, -125b, -181a, -200a, -221 and -222 (Exiqon). SNORD38B and 5SRNA were used for normalization of miRNA expression. Analysis and fold change was determined using the comparative threshold cycle $(\mathrm{Ct})$ method. The change in miRNA expression was calculated as fold-change, i.e., relative to EtOH-treated (control).

\subsection{RNA Isolation, RT-PCR and Q-PCR for mRNA expression}

RNA was extracted from cells using Trizol (Invitrogen) or RNeasy (Qiagen). The High Capacity cDNA Reverse Transcription kit (PE Applied Biosystems) was used to reverse transcribe total RNA using random hexamers. Q-PCR for $B C L 2$, $C Y P 1 B 1, E R B B 3, E S R 1, P D C D 4$, and $18 \mathrm{~S}$ using Taqman primers and probes as Assays-on-Demand was performed in the ABI PRISM 7900 SDS 2.1 (PE Applied Biosystems) using relative quantification. Analysis and fold differences were determined using the comparative CT method. Fold change was calculated from the $\Delta \triangle \mathrm{CT}$ values with the formula $2^{-\Delta \Delta \mathrm{CT}}$ and data are relative to EtOH-treated cells.

2.5 Whole cell and nuclear lysate preparation for western blotting

Whole cell lysates were prepared and western blots were performed as described [277]. Nuclear extracts (NE) were prepared using the NE-PER kit from Thermo Scientific (Rockford, IL, USA). Antibodies were purchased as follows: ER $\alpha$ (Santa Cruz Biotechnology, Santa Cruz, CA, USA), ER $\beta$ (H150, Santa Cruz, CA, USA), Argonaute 2 (Anti-Ago2, clone 9E8.2, \#04-642, Millipore, Billerica, MA, 
USA), Pdcd4 (GeneTex,Irvine, CA ), Bcl-2 (Assay Designs, Plymouth Meeting, PA), E-cadherin (Cell Signaling, Danvers, MA, USA), $\alpha$-tubulin (Thermo Scientific, Rockford, IL, USA), $\beta$-actin (Sigma, St. Louis, MO, USA). The ZEB-1 antibody was generously provided by Dr. Douglas Darling, University of Louisville. Chemiluminescent bands on the PVDF membranes were visualized on a Kodak Carestream Imager using Carestream Molecular Imaging software (New Haven, CT, USA).

\subsection{Statistical analysis}

Data preprocessing was performed on two sets of samples sent to Exiqon at different times (sample set 1 and 2 contained 6 and 14 cell treatments, respectively; different miRNA chips were utilized for the 2 sets of samples) separately before combining them for further analysis. Two-step filtering (1) excluding empty and blank spots and (2) keeping only those spots for which foreground intensities were greater than $1.1 \mathrm{x}$ background intensities for 2 or more samples in the 6-sample group and 10 or more samples in the 14-sample group was done before normalization. For the remaining spots, background intensities were subtracted from the foreground intensities. Since even after the filtering step, some spots had backgrounds larger than foregrounds; we treated those as missing and imputed them using the $k$-nearest neighbor algorithm. Normalization within-arrays was performed using the loess method [279], while for between-arrays the quantile method was applied. The two sets of samples were then matched by their miRNA names and combined for further analysis.

In order to identify miRNAs which are expressed by MCF-7 and LY2 cells treated with EtOH and 4-OHT and by MCF-7 cells treated with $\mathrm{E}_{2}$, the four technical replicates on each chip and the four arrays (biological replicates) corresponding to 
each of the five treatment groups $(n=20)$ were averaged. All expression values were represented as $\log 2$ ratios of Hy3 (experimental) versus Hy5 (universal reference). Differential expression of miRNAs between different TAM-sensitive and TAMresistant cell lines treated with either 4-OHT or EtOH were determined by fitting a hierarchical linear model using the limma package [280] and testing the corresponding contrasts of interest, e.g., MCF-7 vs. LY2 treated with 4-OHT, MCF-7 vs. LY2 treated with EtOH, and $\mathrm{E}_{2}$ vs. 4-OHT treated MCF-7 cells, for each miRNA. Fold change, adjusted t-statistic, unadjusted and false discovery rate (FDR) adjusted p-values were calculated for each miRNA for each comparison. Of the 225 miRNAs that passed the filter for analysis, only those miRNAs with adjusted p-values below 0.10 , i.e., FDR of $10 \%$, were considered as differentially expressed.

2.7 Gene pathway analysis

Functional and network analyses of differentially expressed miRNAs gene expression changes were performed using Ingenuity Pathways Analysis (IPA) 8.8 (Ingenuity ${ }^{\circledR}$ Systems, http://www.ingenuity.com). Networks were generated using 12 differentially expressed miRNAs (Figure 3) that were uploaded into IPA. Analysis considered all genes from the dataset that met the 2 -fold (p-value $<0.05$ ) change cutoff and that were associated with biological functions in the Ingenuity Pathways Knowledge Base. For all IPA analyses, Fisher's exact test was used to determine the probability that each biological function assigned to the genes within the data set was due to chance alone. 


\section{RESULTS AND DISCUSSION}

\section{Identification of miRNAs differentially expressed in MCF-7 and LY2 cells.}

To identify miRNAs that might be involved in TAM- resistance, we compared the miRNA transcription profiles between MCF-7 TAM-sensitive and LY2 TAMresistant cells in response to 4-OHT using ethanol as the vehicle control. The cells were treated for $6 \mathrm{~h}$, a time point selected as that at which maximal primary ER $\alpha$-gene target transcription occurs [281]. Since serum levels of 4-OHT in breast cancer patients on oral TAM-citrate are $8-18 \mathrm{nM}$ and breast tumors concentrate 4-OHT to 74 $\mathrm{nM}-1.5 \mu \mathrm{M}$ [282], the $100 \mathrm{nM} 4-\mathrm{OHT}$ concentration used in our experiments is at the lower range of that found in women on TAM therapy. In addition, MCF-7 cells were treated with $10 \mathrm{nM} \mathrm{E}_{2}$, as per previous investigations of miRNA transcriptional responses [260,261,268,269,283]. Four separate experiments were performed for each treatment group and cell line.

A total of 97 miRNAs exhibited differential expression between TAMsensitive MCF-7 and TAM-resistant LY2 cells with either EtOH or 4-OHT treatment (Figure 1, Tables 1 and 2). Forty-seven miRNAs were exclusively differentially expressed between the two cell lines in the presence of EtOH and 21 miRNAs were exclusively differentially expressed between the two cell lines in the presence of 4OHT. Twenty-nine miRNAs were commonly differentially expressed between the two cell lines both with treatment by EtOH or 4-OHT. A Venn diagram is provided to schematically represent these results (Figure 2, left hand side). We represent the same data by separating up-regulated and down-regulated miRNAs on the right hand side of Figure 2. For example, 53 miRNAs demonstrated enhanced and 23 miRNAs demonstrated reduced expression in MCF-7 cells when compared to LY2 cells treated with the vehicle control EtOH (Table 1). Twenty-nine miRNAs demonstrated 
increased and 21 miRNAs demonstrated decreased expression in MCF-7 cells when compared to LY2 cells treated with 4-OHT (Table 2). Differentially expressed miRNAs for EtOH-treated MCF-7 versus LY2 are shown in Table 1, 4-OHT-treated MCF-7 versus LY2 are shown in Table 2, and $\mathrm{E}_{2}$ versus 4-OHT-treated MCF-7 are shown in Table 3. Of the total 225 miRNAs analyzed, 128 miRNAs were not differentially expressed between MCF-7 and LY2 in cells treated with EtOH or 4OHT (data not shown). One miRNA, miR-423-5p demonstrated higher and miR181a, demonstrated lower expression in MCF-7 cells treated with $E_{2}$ compared to MCF-7 cells treated with 4-OHT (Table 3).

From that list of 76 miRNAs showing opposite direction of expression in MCF-7 versus LY2 cells (Figure 2, Tables 1 and 2), 12 miRNAs were selected for further study (Figure 3A and B). The microarray expression data show that miR-10a, miR-22, miR-29a, miR-125b, miR-181a, and miR-222 were lower in EtOH-treated MCF-7 than in LY2 cells. In contrast, miR-21, miR-93, and miR-200a, b, and c were lower in EtOH-treated LY2 than MCF-7. Of these miRNAs, only miR-21 and miR$181 \mathrm{a}$ were $\mathrm{E}_{2}$ regulated, i.e., inhibited by $\mathrm{E}_{2}$, in MCF-7 cells. Of these miRNAs exhibiting opposite expression in MCF-7 and LY2 cells, miR-10a, miR-21, miR-22, miR-125b, miR-181a, miR-200a and miR-222 were selected for Q-PCR validation. In addition, we included miR-221 for analysis because of its reported role in TAM/endocrine resistance [270], although its expression was not significantly different between MCF-7 and LY2 cells in the microarray. A literature review of the relationship between these miRNAs and breast cancer is summarized in Appendix 1. 


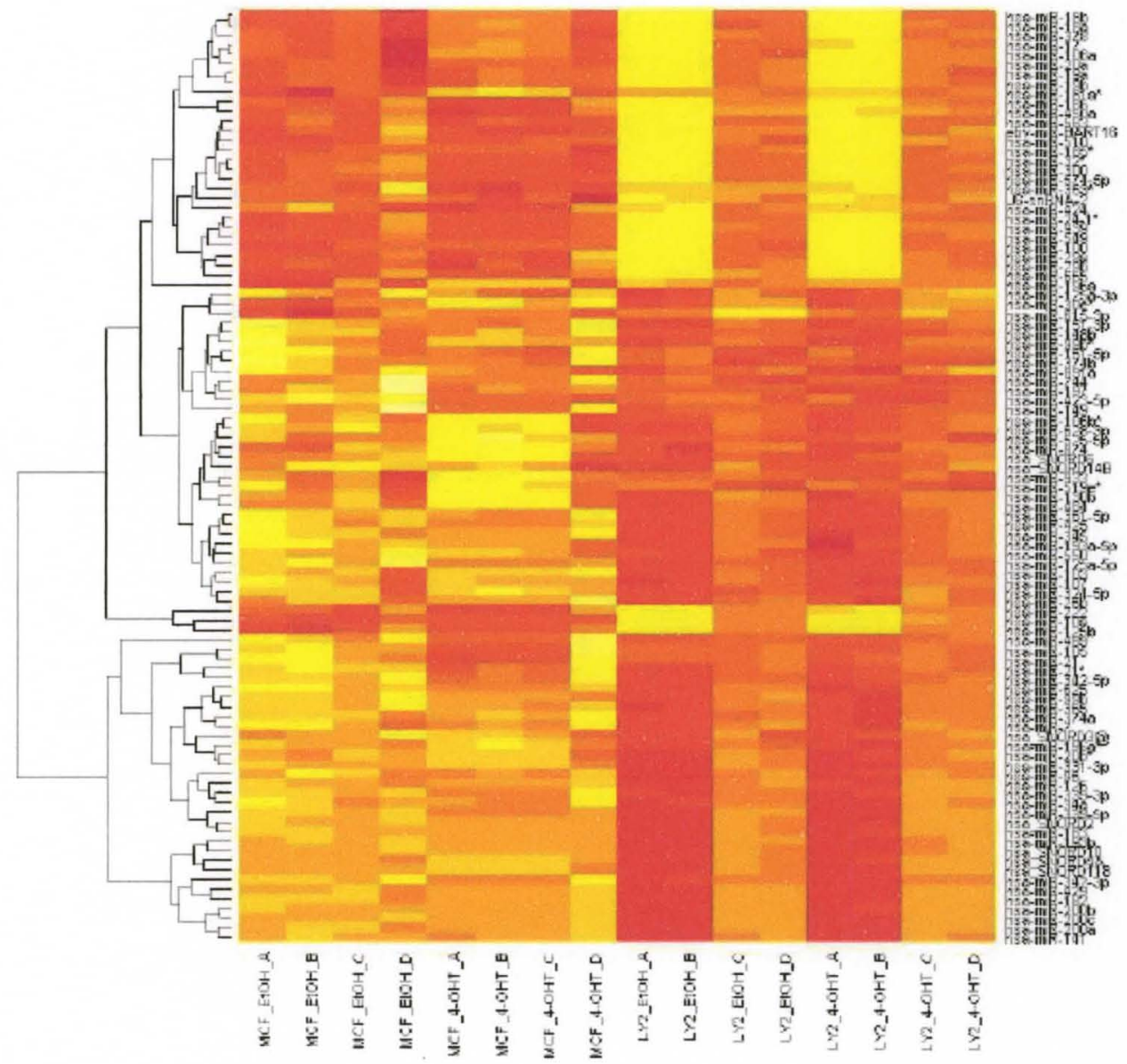

Figure 1: Heat map (hierarchical clusters) of significant differences in miRNA expression between MCF-7 and LY2 cells.

MCF-7 and LY2 cells were treated with EtOH, or $100 \mathrm{nM} 4-\mathrm{OHT}$ for $6 \mathrm{~h}$ and miRNA expression determined by microarray analyses of 4 separate experiments. The heatmap shows 97 miRNAs significantly differentially expressed (adjusted p-value < 0.10 ) for at least one of the two comparisons between cell lines (MCF-7/EtOH versus LY2/EtOH and MCF-7/4-OHT vs. LY2/4-OHT, see Tables 1 and 2, respectively). Each row of the heat map represents a gene, and each column represents a cell line/treatment group (as labeled at the bottom. Yellow indicates an increase in miRNA gene expression (relative to the other expression measurements in the same row) and orange/red indicates a decrease in expression. 
Table 1: MicroRNAs Differentially Expressed in MCF-7/EtOH vs. LY2/EtOH in human breast cancer cells.

Gene expression from TAM-sensitive (MCF-7) and TAM-resistant (LY2) human breast cancer cells treated with $\mathrm{EtOH}$ were filtered and the average fold change for each gene was calculated for MCF-7 vs. LY2. Only those genes that demonstrated a statistically significant (adjusted $\mathrm{p}<0.10$ ) increase or decrease in expression for the $\mathrm{MCF}-7 / \mathrm{EtOH}$ vs. LY2/EtOH expression comparison are included in this table. Note that MCF-7/EtOH vs. LY2/EtOH means that expression for LY2 cells was utilized as reference group. Therefore, ratios above 1.0 indicate higher expression in MCF-7 than LY2 whereas ratios below 1.0 indicate lower expression in MCF-7 vs. LY2 cells 1 empirical Bayes' t-statistic from the hierarchical linear model fitted by limma, see Materials and Methods for description

${ }^{2} \mathrm{p}$-Value corrected for the false-discovery rate (FDR) 


\begin{tabular}{|c|c|c|c|c|c|}
\hline \multicolumn{2}{|c|}{ MEF-YGEOH > WhETOH } & \multirow[t]{2}{*}{ Fold change } & \multirow[t]{2}{*}{ t.stat } & \multirow[t]{2}{*}{ DNalio } & \multirow[t]{2}{*}{ Adjutad p-valus } \\
\hline caneldx & mikNh gene family & & & & \\
\hline $10 \sin 8$ & $h s a-m i R-12 s a-5 p$ & 241 & 525 & $0 \times 0$ & $000 \%$ \\
\hline 42576 & hea-mik-342-sp & 7.15 & 4.16 & 0000 & 0,26 \\
\hline 14001 & hos-mik-361-sp & 236 & 4.30 & 0,00 & 6126 \\
\hline 4214 & hxa-mik-s:at & 20 & 405 & 0,001 & axt2s \\
\hline 1760 & $h x d-m i R-425$ & 219 & 403 & $0,0 \mathbf{1}$ & 0028 \\
\hline $1 / 978$ & $h s a-m a R-193 a-3 p$ & 216 & 391 & 0.01 & 0030 \\
\hline 1เช้ & hes-mik-365 & 232 & 280 & $\Delta \omega \mathbf{w 1}$ & 0,032 \\
\hline 2356.5 & hed-mik-423-sp & 1.5 & 178 & $0.0 \times 1$ & 0002 \\
\hline 17973 & $1 \times 1-m i R+2 s$ & $2 \mathrm{As}$ & 168 & $a x x_{2}$ & 003 \\
\hline 4294 & hed-miR-3As & 153 & 162 & 0,00 & 00038 \\
\hline 42924 & hea-miR $21^{\circ}$ & 3.6 & 2.58 & 0.002 & 0,08 \\
\hline THES & hed-mik-1 s1-3p & $13 x$ & 148 & ans & 0040 \\
\hline 1184 & has-mR $A M P$ & $25 x$ & .132 & $0, x 44$ & 0047 \\
\hline 32884 & $h \omega 3-m R-3 \alpha-3 p$ & 1125 & 231 & $0, x$ & $004 ?$ \\
\hline 42912 & hod-miR-399-3p & W01 & 325 & 0005 & 0048 \\
\hline 42594 & has-mik-489 & 130 & 324 & 0.005 & 0048 \\
\hline 27378 & $m a-m i R-3>4$ & 233 & 3.24 & 0005 & 0048 \\
\hline 42339 & has-min-13a-sp & 7.15 & 200 & 0.007 & $\cos 7$ \\
\hline $1000 \%$ & ha sanolo Ja & 284 & $2 \sin$ & $040 \%$ & 0,057 \\
\hline 42538 & hos-mik-1 & 244 & 393 & 0,007 & 0061 \\
\hline 2727 & hes mik-3ata & 3.5 & 290 & ano & aks \\
\hline $14 \times 8 \%$ & $h \mathrm{~s}-\mathrm{mik}-\mathrm{l}) \mathrm{stb}$ & 83 & 289 & 0.010 & 0.060 \\
\hline 14302 & $n a-\sqrt{n} x-3>b$ & 168 & 288 & 0.010 & 0.000 \\
\hline 4283 & $h \mathbf{m}-\operatorname{miR}-\{9\}$ & 1.57 & 287 & 0.010 & 0068 \\
\hline 19008 & tro SNokO2 & 445 & 286 & a.011 & 0 axt \\
\hline 10097 & $h a-m i R-16 z$ & $\$ .13$ & 2.81 & 6012 & $0.5 \%$ \\
\hline tont & hud SNOKD 10 & 11.15 & 280 & 0,012 & awo \\
\hline 11250 & hw-mik-ls $1-5 p$ & 1.53 & 273 & 0.014 & 0000 \\
\hline $1314 ?$ & hes-mik-6s & 419 & $2 \pi 3$ & 6,014 & 00070 \\
\hline $42 x+7$ & $h \times s-m i R-j\} 1-3 p$ & 2.25 & 273 & 0.014 & $00 \%$ \\
\hline 1338.5 & $h s a-m i R-148 b$ & 14 & 27 & 0.015 & oort \\
\hline 1107 & hos-miR-2ook & $13 a_{2}$ & 253 & 0.115 & 0071 \\
\hline 10013 & hea , SNOND +48 & 1.49 & $25 \%$ & 0.016 & $0 \cot 1$ \\
\hline Natio & hsd-mik-1 26 & 319 & 236 & 0016 & 0071 \\
\hline 10yrs & $h e d-m i k-1 / 2$ & $s i z$ & 26.3 & 0.017 & 0.974 \\
\hline 109:3 & nsa-miR-103 & $1+2$ & 2.62 & 0.018 & 0,04 \\
\hline 10004 & hos SNDRD4A & 787 & 262 & 0.018 & $00 m$ \\
\hline 12810 & 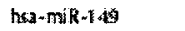 & 223 & 260 & 0,018 & 0644 \\
\hline 10023 & $h x^{2}-m i k-10 y$ & 100 & 260 & onis & 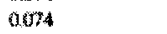 \\
\hline 1980 & hes-mik-y & 2,8 & 259 & 0.019 & 0.41 \\
\hline $42 \$ 7$ & hat-mik-124-5p & 1.48 & 237 & 0.020 & 0036 \\
\hline 5740 & $h \times 3-m i k-21$ & 302 & $25 s$ & 0.021 & טm \\
\hline 18909 & $h a-m i k-2 x k h$ & 1083 & 2.52 & $\$, 02$ & 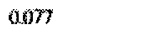 \\
\hline 11000 & has-mik-atos & $10 \% 2$ & 2.5 & 0,02 & $06 m$ \\
\hline 28559 & has-mik-y th & $1 A 5$ & 252 & 0022 & ann \\
\hline $2 \times 61$ & 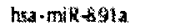 & 1.37 & 24 & 60024 & 0084 \\
\hline $118 \% 2$ & $h \in d-\pi i R-2 a b^{\circ}$ & 2,62 & 245 & 0,025 & 0005 \\
\hline 1992 & $h x_{3}-m i k-12 x a-4 p$ & 1.42 & 238 & 000 & $0.2+1$ \\
\hline 10246 & $h(m-2)-141$ & 11.11 & 238 & $0,0 \times$ & 001 \\
\hline 3250 & hxa-miletas & 250 & 237 & 0,000 & 0991 \\
\hline 1317 & ha.min-420 & 325 & 234 & $0,0 \times 1$ & 00006 \\
\hline 4298 & $h w_{d}-m R+28-3 p$ & $1,4 i$ & 233 & 0.082 & 000 \\
\hline 1789 & has-miksso & 14 & 2.31 & o. ous & 0006 \\
\hline \multicolumn{6}{|c|}{ MCF-7/ERH $\times 1$ LYENOH } \\
\hline 13455 & has-mik-lios & 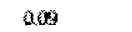 & 5.53 & 0.00 & $0 x 07$ \\
\hline Why & hed-miR-1 2sb & $a k$ & (4) & $0,0)$ & 00028 \\
\hline $4 \geq 649$ & hะa - mile - 2 a & 0.43 & 353 & 0502 & 0100 \\
\hline 42762 & hatmikgse & 030 & 146 & 0,003 & $0 \times 40$ \\
\hline 864 & res-mik-4sos & 043 & 14 & 0 ws & 0040 \\
\hline 10\% & $h \Leftrightarrow-m U R-1 \& b$ & asts & $\mathrm{k}, 10$ & 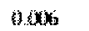 & 0.57 \\
\hline 12829 & 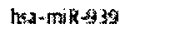 & 0.34 & 310 & $0 \mathrm{n}$ & otosy \\
\hline 42644 & hsa-mik-1bb & ass & 293 & 000 & 006 \\
\hline
\end{tabular}




\begin{tabular}{|c|c|c|c|c|c|}
\hline \multicolumn{2}{|c|}{ MCF-T/EROH : LY 3 LEtuH } & \multirow[t]{2}{*}{ Fold chingen } & \multirow[t]{2}{*}{$t-\dot{x} a t$} & \multirow[t]{2}{*}{ 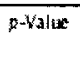 } & \multirow[t]{2}{*}{ Wjustad p-value } \\
\hline feneldos & miknd gene family & & & & \\
\hline 12650 & ha-mik-ti & 45 & 38 & anto & d/6 \\
\hline 11108 & hรa-mik-378 & 0.16 & 25 & boi & 9069 \\
\hline towe $x$ & has-mik-1 & a*o & $28 \%$ & 0.013 & 0006 \\
\hline 19681 & hat-mifin-160 & 1.0 & $27 \%$ & ants & 0009 \\
\hline 10618 & ha-mik-10ka & 0.45 & $2 \%$ & 0.013 & 000 \\
\hline w2.88 & hat-mik-1 \&a & 0 & $\ldots 273$ & a) & 0070 \\
\hline Wot & hasa-mik-185+ & 063 & $2 \times 3$ & 0014 & a. 80 \\
\hline 2612 & haz-mikfots-tp & $a s:$ & 290 & 0.015 & aon \\
\hline Whas & $h=2-\min -540$ & 016 & 2666 & 0016 & 0001 \\
\hline nowo & 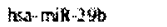 & a.t5 & 2.53 & onot & want \\
\hline 42575 & Ms-mik-24-1 & $a * 3$ & 2.51 & $0.0 \% 2$ & aors \\
\hline $6 \% 0$ & $h<\mathrm{a}-\mathrm{rr} i \mathrm{R}-1<\mathrm{s}$ & 02 & 243 & 0026 & (3) \\
\hline nors & (na-niR-IBIa" & 008 & 239 & ows & 0001 \\
\hline 17258 & ebr-mik-BARTs & ass & 237 & at? & 0,01 \\
\hline 11142 & had-mines 10 & 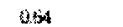 & 231 & 0033 & dures \\
\hline
\end{tabular}


Table 2: MicroRNAs Differentially Expressed in MCF-7/4-OHT vs. LY2/4-OHT in human breast cancer cells

Gene expression values from TAM-sensitive (MCF-7) and TAM-resistant (LY2) human breast cancer cells treated with $100 \mathrm{nM} 4-\mathrm{OHT}$ for $6 \mathrm{~h}$ were filtered and the average fold change for each gene was calculated for MCF-7 vs. LY2. Only those genes that demonstrated a statistically significant (adjusted $p<0.10$ ) increase or decrease in expression for the MCF-7/4-OHT vs. LY2/4-OHT expression comparison, were included in this table. Note that MCF-7/4-OHT vs. LY2/4-OHT means that expression for LY2 cells was utilized as reference group. Therefore, ratios above 1.0 indicate higher expression in MCF-7 relative to LY2 and conversely, ratios below 1.0 indicate lower expression in MCF-7 compared to LY2 cells.

1 empirical Bayes t-statistic from the hierarchical linear model fitted by limma, see Materials and Methods for description

${ }^{2} \mathrm{p}$-Value corrected for the false-discovery rate (FDR) 


\begin{tabular}{|c|c|c|c|c|c|}
\hline \multicolumn{2}{|c|}{$M \mathrm{MF}-334 \mathrm{OHT}=1.234-0 \mathrm{HT}$} & \multirow[t]{2}{*}{ Fold change" } & \multirow[t]{2}{*}{ t-3tat } & \multirow[t]{2}{*}{$p$ - valut } & \multirow[t]{2}{*}{ Adjaxted p-value } \\
\hline andids & miRNe gene family & & & & \\
\hline 1$)+19$ & hsa-miR-193 & 209 & 397 & 0,001 & 005 \\
\hline $273 x$ & hea-mik-374 & 243 & 150 & 00 & $40 \% 4$ \\
\hline 4258 & $\operatorname{ma}-m i k-16 \mathrm{sa}^{+}$ & 2.70 & 338 & 6003 & aud \\
\hline 42339 & $\mathrm{had-mik-ma}$ & 1.67 & 37 & a.tas & 0074 \\
\hline 42098 & hra-mintas & 29 & 335 & 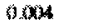 & $60 \%$ \\
\hline $1280 \%$ & hsa-miksha & 182 & 3.31 & 0.004 & aos \\
\hline 42887 & mad-mik-3.31-3p & 3.31 & 321 & a.tas & axp? \\
\hline 4964 & has-mik-2hb & 1.98 & 317 & 0,005 & $00 \%$ \\
\hline lasul & hes-mik-361-5p & 1 s 6 & 3.11 & 0,46 & aurr \\
\hline torist & has - mik-1 $k$ kb & 238 & 605 & $9 \%$ & 000 \\
\hline 11125 & hea-mik-szs.sp & 1.45 & $30 t$ & 00006 & ausa \\
\hline $1500 \%$ & ha SWOROG & 163 & 295 & 9.60 & 0006 \\
\hline 4294 & trat-mik-34s & $1+2$ & 288 & (10) & 1069 \\
\hline 12A7? & hsa-mik-324-sp & 1.55 & 2.86 & 0 att & 0,459 \\
\hline $1 \infty 04$ & has SNOROM & 8.83 & 276 & 0.913 & 01089 \\
\hline 11184 & had-miksyb & $2 a 4$ & 276 & 9.912 & 0.349 \\
\hline$w 023$ & hsa-milk-167 & 196 & 274 & 0.014 & anss \\
\hline $110 \%$ & hat-min-3s5 & 1.83 & 272 & 0.914 & 0.080 \\
\hline 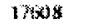 & hsa-miR-425 & 1.69 & $2 \% 0$ & 0.915 & acosis \\
\hline 14585 & $h s a-m i x+14 x b$ & 1.44 & 270 & w015 & adsiga \\
\hline 17802 & has $-m i f-2 \omega^{*}$ & 2.36 & 267 & $\$ 016$ & 0,080 \\
\hline 13132 & ha-miR-S19e' & $s t$ & 264 & 9.917 & atogs \\
\hline+610 & had miR-1 26 & 3.15 & 263 & 6.917 & 1099 \\
\hline 2914 & hsa-mik-s 50 & 1.6 & 2.61 & 9018 & $a \times 2$ \\
\hline 1122 & hรsa-miR-30" & 162 & 256 & 0000 & $\alpha w 9 t$ \\
\hline $1000 s$ & ras sorums & 7.50 & 253 & $0 m 21$ & 0,000 \\
\hline 17854 & hea-miR-106b & $1 s ?$ & 254 & 0001 & avoss \\
\hline kxon & has SNORD to & 8.85 & 253 & 0001 & 0,008 \\
\hline $\cos 2 \mathrm{~B}$ & $\operatorname{msa}-\operatorname{mik}-125 \mathrm{~s}-\mathrm{sp}$ & 1.32 & 252 & $0, y 2$ & $400 \times$ \\
\hline \multicolumn{6}{|c|}{ MA. } \\
\hline $1348:$ & hat-mik-1 ba & 9.10 & .53 & owos & anot \\
\hline ISBAY & hat -miR-4sia & 0.33 & 442 & Daw & 4039 \\
\hline 1758 & Ebv-mik-BARThs & 0,49 & 399 & 0001 & ouss \\
\hline 1127 & L6. $\operatorname{snkNA}-2$ & 0.38 & 3.69 & 1) & $0.0 \% 4$ \\
\hline 42762 & ham mak 668 & 0.29 & 360 & 9002 & 00074 \\
\hline 1003 & hst mif- 12 & 0.14 & 142 & \.w & 0.994 \\
\hline $2 \times 344$ & hea-mik-361 & 0.53 & 324 & 0.005 & $06 \%$ \\
\hline $30 \% 87$ & has-mik-125b & 0.15 & 3.12 & 0.206 & abry \\
\hline 42383 & has - miR - 935 & 0.41 & 3.11 & 0.006 & 0. \\
\hline 2958 & $r a-\min -32^{*}$ & 9.49 & 309 & 0.606 & 0.07 \\
\hline 17004 & $\operatorname{los}-\mathrm{min}-185^{\circ}$ & 0.9 & -235 & 0.600 & 3006 \\
\hline 11040 & hal-mik-2sb & 0.31 & 284 & 0.011 & absy \\
\hline 1079 & les-mifin-1 & 0.44 & 281 & (1. 912 & 0,080 \\
\hline 17205 & les mikn-si & 6.58 & 278 & a.ta 3 & 0089 \\
\hline 16030 & $\operatorname{lnsa-mik-2503}$ & 0.4 & 275 & 0.013 & 0 orse \\
\hline 11142 & ked-mifi-s: 10 & 0.58 & 273 & 0.6914 & Dotes \\
\hline $42 / 38$ & tra-mik-549 & 3.3 & $27 z$ & 0.014 & 090 \\
\hline $2 Y 340$ & had-mik-s/4-sp & 0.6 & -270 & ajes & $0 \alpha \omega$ \\
\hline 42513 & $h=-5 i k-300$ & $0.5 t$ & 2.38 & 0.016 & aros \\
\hline 42375 & has-mik $\geq 4^{\circ}$ & 63 & 3.64 & 0.17 & 1060 \\
\hline $4 \operatorname{los}_{5} \mathrm{~s}$ & hes-mint 424 & 04 & 260 & 0.018 & oos \\
\hline
\end{tabular}


Table 3: MicroRNAs Differentially Expressed in MCF-7/E2 vs. MCF-7/4-OHT in human breast cancer cells.

Gene expression from TAM-sensitive (MCF-7) and TAM-resistant (LY2) human breast cancer cells were filtered and the average fold change for each gene was calculated for MCF-7 treated with $\mathrm{E}_{2}$ vs. MCF-7 treated with 4-OHT. Only those genes that demonstrated a statistically significant (adjusted $\mathrm{p}<0.10$ ) increase or decrease in expression for the $\mathrm{MCF}-7 / \mathrm{E}_{2}$ vs. MCF-7/4-OHT expression comparison were included in this table. Note that MCF-7/E 2 vs. MCF-7/4-OHT means that expression for MCF-7 cells treated with 4-OHT was utilized as reference group. Therefore, ratios above 1.0 indicate an increase $\mathrm{E}_{2}$ relative to 4-OHT-treated MCF-7 cells and ratios below 1.0 indicate a decrease in expression in 4-OHT-treated cells relative to $\mathrm{E}_{2}$-treated $\mathrm{MCF}-7$ cells.

${ }^{1}$ empirical Bayes $\mathrm{t}$-statistic from the hierarchical linear model fitted by limma, see Materials and Methods for description

${ }^{2} \mathrm{p}$-Value corrected for the false-discovery rate (FDR)

\begin{tabular}{|c|c|c|c|c|c|}
\hline \multicolumn{2}{|c|}{$\mathrm{MCF}-7 \mathrm{E}_{2}$ versus $\mathrm{MCF}-4 / 4 \mathrm{OHT}$} & \multirow[t]{2}{*}{ fold tang } & \multirow[t]{2}{*}{ Stat } & \multirow[t]{2}{*}{ pralue } & \multirow[t]{2}{*}{ Njusted pwalue } \\
\hline ConnelDs & mirNk gene family & & & & \\
\hline $278 \times 5$ & 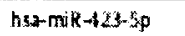 & 183 & 429 & 0000 & 0052 \\
\hline 10013 & hsa-miR-1sta* & 9.12 & 173 & $a(x)$ & 0043 \\
\hline 42665 & $h+a-m i k-18 k$ & 023 & $\ldots .3 .94$ & $0 \leq 01$ & $9 \pi 4$ \\
\hline
\end{tabular}




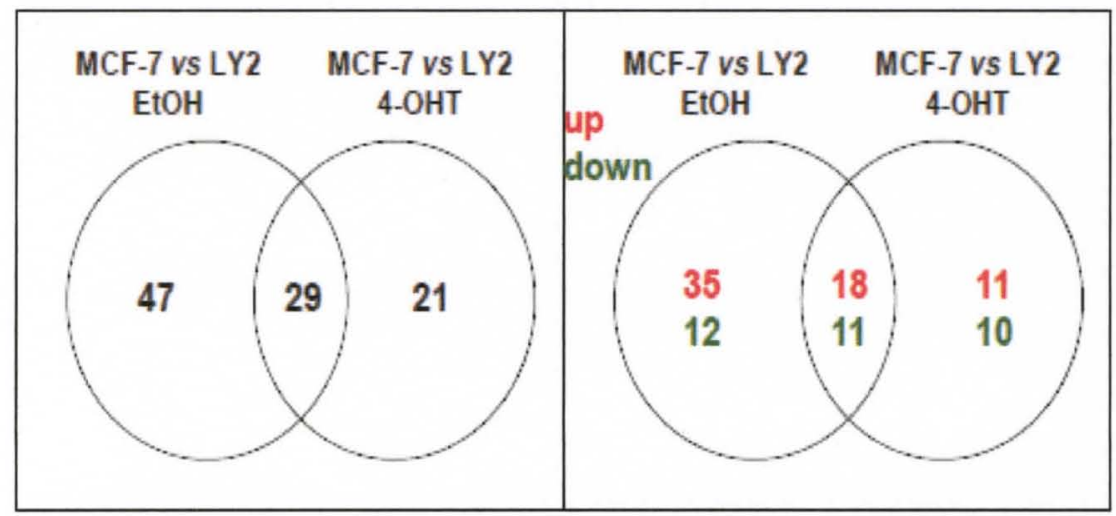

Figure 2: Venn diagrams summarizing differentially expressed (DE) miRNAs.

A) Venn diagram of miRNAs differentially expressed between TAM-sensitive (MCF7) and TAM-resistant (LY2) human breast cancer cells by the indicated treatments (EtOH and 4-OHT). Cells were treated as described in Figure 1. B) Venn diagram showing miRNAs either UP- (increased expression) or DOWN- (reduced expression) regulated between TAM-sensitive (MCF-7) and TAM-resistant (LY2) human breast cancer cells by treatment. 
Figure 3: Select miRNAs that are differentially expressed in MCF-7 (TAM-S) and LY2 (TAM-R) breast cancer cells.

These 12 miRNAs were identified as differentially expressed in microarray analysis of miRNAs in $\mathrm{EtOH}, \mathrm{E}_{2}$ or 4-OHT treated cells. Values are $\log 2(\mathrm{Hy} 3 / \mathrm{Hy} 5)$ ratios in the sample versus the common reference pool. Each value is the avg. \pm SEM of 4 separate experiments.

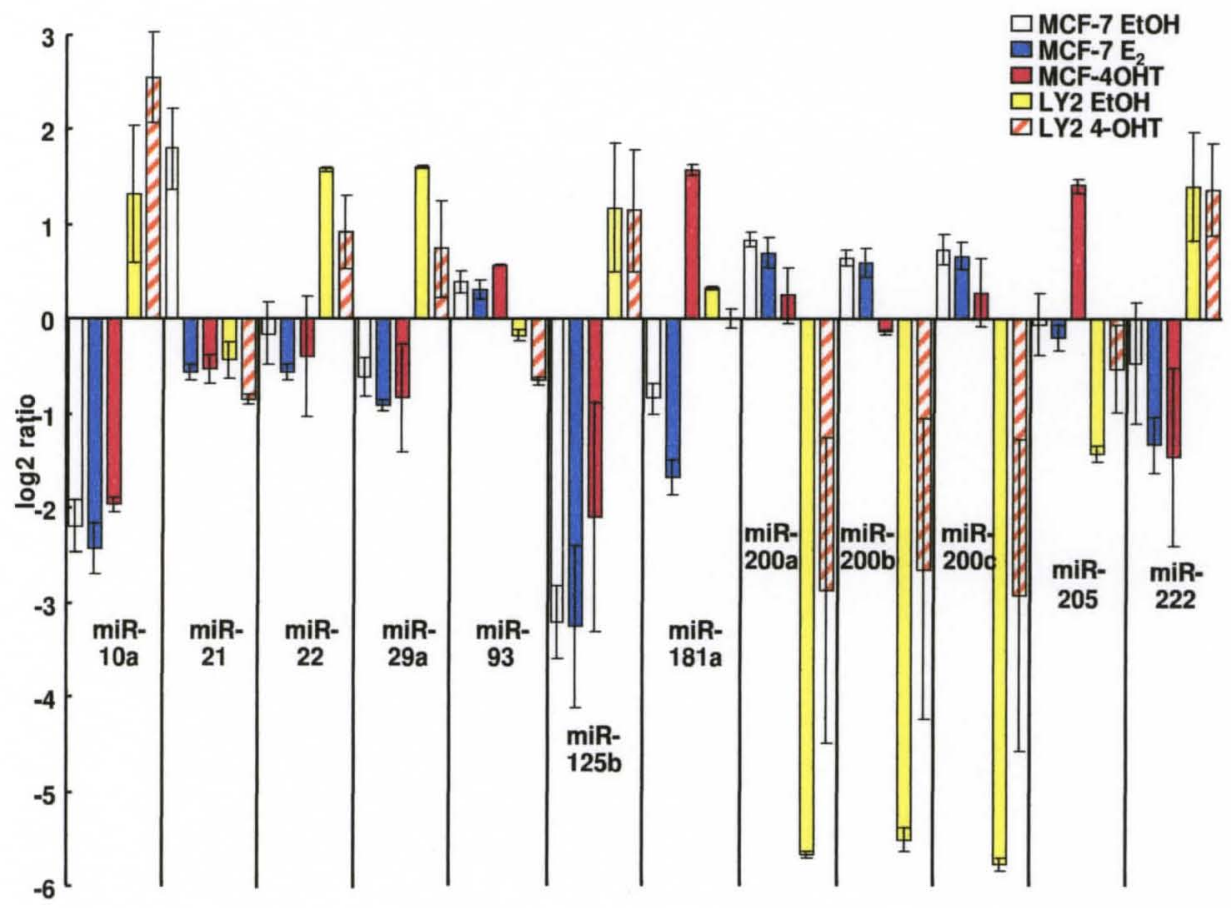




\section{Selection of endogenous control genes for Q-PCR normalization and validation of select miRNAs by Q-PCR}

Prior to performing Q-PCR to confirm the miRNA microarray data it was necessary to identify endogenous control genes (ECG) for normalization of miRNA transcript expression. First, we compared the expression of U6 (RNU6-1) and U48 (RNU48) RNA genes, traditionally used as controls for miRNA expression [284-286], in MCF-7 and LY2 cells after $6 \mathrm{~h}$ of 4-OHT or EtOH treatment (Figure 4A and 4B). U6 expression was increased by 4-OHT in MCF-7 and reduced by 4-OHT in LY2

cells. U48 expression was comparable between the two cell lines and unaffected by 4-OHT.

Eight additional candidate ECG were identified as showing low variation in expression in the miRNA microarray: high signal: miR-16, Let-7f, and 5SrRNA; medium signal: SNORD38D (U38B), Let-7d, and miR-340; low signal: miR-765, miR-744, miR-887, miR-92b. Eight of these ECG were screened for their expression in MCF-7 and LY2 cells after $6 \mathrm{~h}$ or vehicle (EtOH) or $100 \mathrm{nM} 4-\mathrm{OHT}$ treatment (Figure 4A and 4B). Two general conclusions can be made from these data: 1) ECG expression differs between the two cell lines; 2) 4-OHT affects ECG expression more in MCF-7 than LY2 cells. Expression of Let-7f was reduced by 4-OHT in both cell lines. miR-744 was reduced by 4-OHT whereas Let-7d and miR-340 were increased by 4-OHT in MCF-7 cells. Overall, the best ECG in MCF-7 and LY2 cells are U48, 5S rRNA, U38B, and miR-765 for high, medium, and low expression miRNAs, respectively. Because of the low expression of miR-765, we selected 5S rRNA, U48, and $\mathrm{U} 38 \mathrm{~B}$ to normalize miRNA expression in the rest of the studies in this chapter. 


\section{Figure 4: Selection of endogenous control genes for analysis of miRNA expression by Q-PCR}

The expression of RNU6-1 (U6) and RNU48 (U48) RNA genes, traditionally used as controls for miRNA expression and eight candidate endogenous control genes (ECG) identified by miRNA microarray: high signal: miR-16, Let-7f, and 5SrRNA; medium signal: SNORD38D (U38B), Let-7d, and miR-340; low signal: miR-765 and miR-744 were examined in MCF-7 (A) and LY2 (B) cells treated for $6 \mathrm{~h}$ with EtOH (vehicle control) or $100 \mathrm{nM}$ 4-OHT. (C) The expression of the Let-7 family members was determined by Exiqon Microarray analysis of miRNAs in EtOH, $\mathrm{E}_{2}$ or 4-OHT treated cells, as indicated. Values are $\log 2(\mathrm{Hy} 3 / \mathrm{Hy} 5)$ ratios in the sample versus the common reference pool. Each value is the avg. \pm SEM of 4 separate experiments. D) The relative expression of MYC in MCF-7 and LY2 cells treated with EtOH, $10 \mathrm{nM}$ $\mathrm{E}_{2}$, or $100 \mathrm{nM} 4-\mathrm{OHT}$ for $6 \mathrm{~h}$ was determined by Q-PCR and CT values are the mean of 3 separate determinations \pm SEM. E) Relative MYC expression in MCF-7 was normalized to $18 \mathrm{~S}$. * $\mathrm{p}<0.05$ versus EtOH control. F) The relative expression of ESR $1(\mathrm{ER} \alpha)$ in MCF-7 cells treated as in panel D. CT values are shown as avg. \pm SEM of 3 replicates in one experiment. The inset shows a western blot of ER $\alpha$ protein. The blot was stripped and reprobed for $\beta$-actin. The ratio of $E R \alpha / \beta$-actin in MCF-7 was set to 1 and the relative expression of ER $\alpha$ in MCF-7 was $0.4=60 \%$ lower $\mathrm{ER} \alpha$ in LY2 compared to MCF-7 cells. 

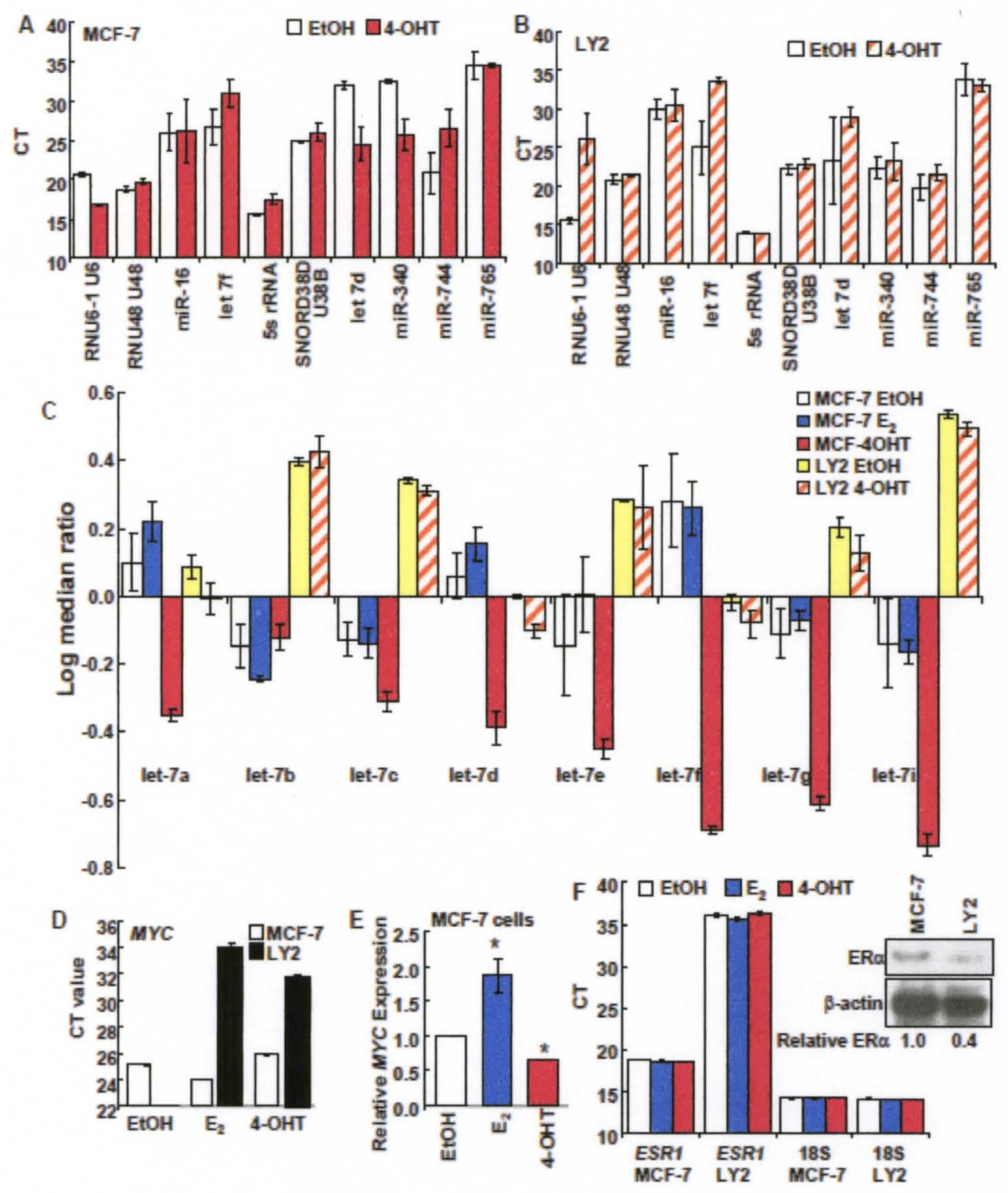
Although Let-7a was reported to be an ECG for miRNA [285], Let-7a expression was increased by $\mathrm{E}_{2}$ and reduced by $4-\mathrm{OHT}$ in MCF-7 cells (Figure $4 \mathrm{C}$ ). Let-7 family members are highly conserved in sequence and function across species [287]. Misregulation of Let-7 leads to a less differentiated cellular state and the development of cancer; hence, Let-7 family members are considered as tumor-suppressor miRNAs $[288,289]$. We observed that $4-\mathrm{OHT}$ repressed the expression of all eight Let-7 family members in MCF-7 cells and none of the Let-7 family members in LY2, commensurate with a less differentiated cellular state. Let-7b, Let-7c, Let-7g, and Let-7i showed opposite expression between MCF-7 and LY2 cells. Since Let-7a [290] and Let-7g [291] downregulate Myc and high Myc expression results in a negative feedback loop inhibiting Let-7a expression [287], we examined Myc mRNA in MCF-7 and LY2 cells (Figure 4D). Based on the higher Let-7 expression in LY2, we expected lower Myc in LY2 and our data confirmed significantly lower Myc expression in LY2 compared with MCF-7 cells (Figure 4D). In agreement with an earlier report [292], $E_{2}$ increased and 4-OHT inhibited Myc transcription in MCF-7 cells (Figure 4E). Since transient overexpression of Let-7a, Let-7b, and Let-7i was reported to inhibit ER $\alpha$ expression in MCF-7 cells [293], we examined ESRI mRNA and protein levels in MCF-7 and LY2 cells. As expected, ESRI mRNA and ER $\alpha$ protein were lower in endocrine-resistant LY2 compared to endocrine-sensitive MCF7 cells (Figure 4F). The reduced expression of ER $\alpha$ in LY2 also reflects higher expression of miR-221 and miR-222 that have been reported to suppress ER $\alpha$ expression [234,294,295]. 
Figure 5: Q-PCR analysis of the miRNA expression in MCF-7 and LY2 cells.

A) Cells were treated with EtOH, $10 \mathrm{nM} \mathrm{E}_{2}$, or $100 \mathrm{nM} \mathrm{4-OHT} \mathrm{for} 6 \mathrm{~h}$. Where indicated MCF-7 (B) and LY2 (C) cells were pretreated with $100 \mathrm{nM}$ ICI 182,780 for $6 \mathrm{~h}$. Values are the average of 3-8 separate experiments were normalized by U38 or $5 \mathrm{~S}$ rRNA and are expressed as fold relative to EtOH-treated MCF-7 expression for each miRNA. In A: * Significantly different from EtOH in MCF-7. In B and C: * Significantly different from $\mathrm{E}_{2}$ or 4-OHT in the absence of ICI. 

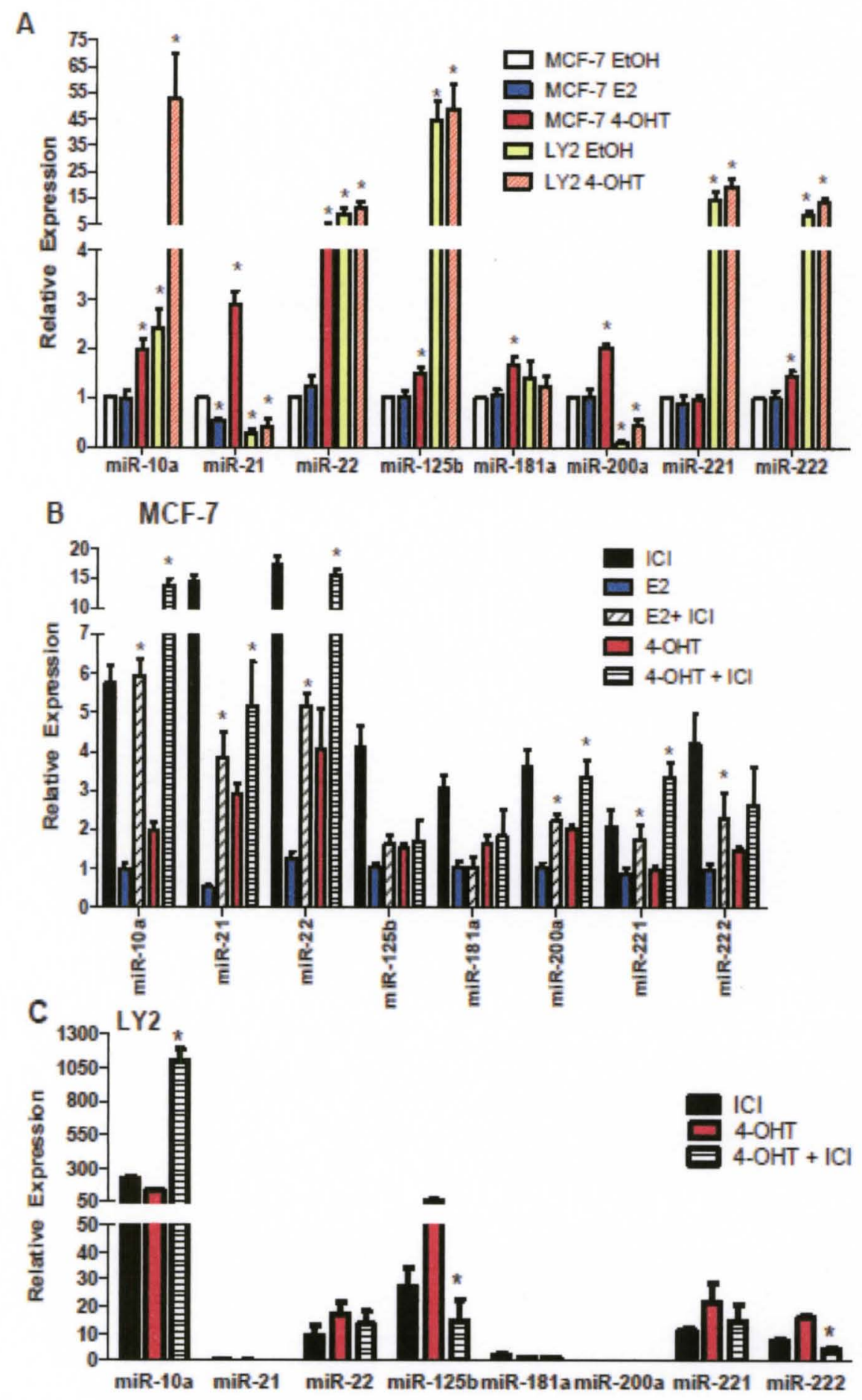
To validate the changes in miRNA expression detected in the miRNA microarrays, Q-PCR was performed on 7 of the 12 miRNAs in Figure 3: miR-10a, miR-21, miR-22, miR-125b. miR-181a, miR-200a and miR-222 in MCF-7 and LY2 cells treated with EtOH or $100 \mathrm{nM} 4-\mathrm{OHT}$ for $6 \mathrm{~h}$, and MCF-7 cells treated with 10 $\mathrm{nM} \mathrm{E}_{2}$ for $6 \mathrm{~h}$ (Figure 5A). In addition, miR-221 was analyzed because it, along with miR-222, has been reported to be overexpressed and involved in endocrine-resistance in breast cancer cells [270,283,296].

For comparison between the two cells lines, miRNA expression was normalized to the value in EtOH treated MCF-7 cells. There was general agreement in the direction (up- or down- regulation) of miRNA expression in MCF-7 and LY2 cells between the Q-PCR and microarray data. The exception is that 4-OHT increased miR-200a in MCF-7 cells in Q-PCR. In agreement with other recent results examining $E_{2}$-regulation of miRNA expression in MCF-7 cells $[260,261,268,269]$, the miRNA expression changes in response to $E_{2}$ or 4-OHT were less than five-fold. $E_{2}$ decreased miR-21 expression in MCF-7 cells, as observed in our earlier experiments [268] and as reported by others [261]. 4-OHT increased miR-21 expression in MCF-7 cells. LY2 cells had lower expression of miR-21 and miR-200a, in agreement with the data in the microarray (Figure 3). A recent analysis of miRNA expression in breast tumors by deep sequencing showed upregulation of miR-21 in ER+ breast tumors relative to normal breast tissue and triple negative breast tumors [297].

To determine if the effects of $\mathrm{E}_{2}$ and 4-OHT on miRNA expression were ERmediated, MCF-7 cells were pretreated with 100 nM ICI 182,780 (ICI, Fulvestrant) for $6 \mathrm{~h}$, a time that reduces ER $\alpha$ protein and activity [298]. For each of the eight miRNAs, ICI increased expression relative to $\mathrm{EtOH}$ in MCF-7 cells (Figure 5B). These data suggest that unliganded ER may suppress transcription of these miRNAs 
or that some component regulating miRNA expression or processing is inhibited by unliganded ER. Alternatively, since ICI is an agonist for GPER/GPR30 [13,299], it is possible that ICI activates intracellular signaling pathways, e.g., MAPK, that increase miRNA expression. For example, MAPK increases miRNA expression by phosphorylating TRBP, a component of the Dicer complex that processes pre-miRNA into mature miRNA [300]. Testing GPER/GPR30 is beyond the scope of the current study. ICI ablated the inhibition of miR-21 by $\mathrm{E}_{2}$ in MCF-7 cells. These data indicate that $E_{2}$-occupied ER suppresses the transcription of miR-21. The combination of ICI and 4-OHT did not further increase miRNA expression in MCF-7 cells with the exception of miR-10a, a result seen in both MCF-7 and LY2. While the mechanism involved for the increase in miR-10a appears to be, at least in part, ER-mediated, future studies are needed to address this mechanism in greater detail. There is only one report about miR-10a regulation [301]. That report found that $\mathrm{miR}-10 \mathrm{a}$ expression increased as mouse embryonic stem cells differentiated into smooth muscle cells [301]. Others reported that miR-10a associates with the 5' UTR of mRNAs encoding ribosomal proteins, enhances their translation, increases global protein synthesis, and thus contribute to oncogenesis [302]. For miR-21, miR-125b, and miR-181a, 4-OHT inhibited the stimulation over basal expression detected with ICI treatment in MCF-7 cells.

For LY2 cells, ICI had no significant effect on basal miRNA expression (Figure 5C). These data indicate that, unlike MCF-7 cells, the regulation of miRNA expression in LY2 cells is independent of ER. These data are in agreement with the estrogen-independent, endocrine-resistant phenotype of LY2 cells $[273,303]$. As discussed above, ICI and 4-OHT synergistically increased miR-10a transcription. ICI reduced 4-OHT-stimulated miR-125b and miR-222 expression (Figure 5C), a result 
implicating ER involvement in 4-OHT-regulating the expression of these miRNAs, a result commensurate with higher miR-125b in ER $\alpha / \mathrm{PR}$-positive than ER $\alpha / \mathrm{PR}$ negative breast tumors [304]. The apparent synergy of ICI and 4-OHT in upregulating miR-10a transcription may be mediated by GPR30/GPER, for which both ICI and 4OHT are agonists [12]. However, others have reported that an ER $\alpha$ variant called ER $\alpha 36$, and not GPR30, mediates non-genomic ER signaling, including ICI agonist activity [305]. ER $\alpha 36$ arises from a promoter in the first exon of $E R \alpha$, but lacks both the $\mathrm{N}$ - and $\mathrm{C}$ terminal transcription activation domains, AF-1 and $\mathrm{AF}-2$, respectively, of full-length wild type ER $\alpha 66$ [306,307]. Further studies would be required to examine ER $\alpha 36$ expression in LY2 cells. However, ER $\alpha 36$ was not detected using an antibody that recognizes epitopes conserved in ER $\alpha 66$ and ER $\alpha 36$ [307,308] (Appendix 4).

\section{Time course of miRNA expression in MCF-7 cells}

Time-dependent changes in the expression of 8 miRNAs were detected after 1 , 4, 6, and $8 \mathrm{~h}$ treatment with EtOH, $\mathrm{E}_{2}$, or 4-OHT (Figure 6). $\mathrm{E}_{2}$ repressed the expression of miR-22, miR-125b, miR-181a, miR-200a (except at the $6 \mathrm{~h}$ time point), and miR-221 (except at the $6 \mathrm{~h}$ time point) relative to EtOH. 4-OHT increased expression of miR-21a, miR-22, miR-181a, and miR-200a relative to EtOH at the $6 \mathrm{~h}$ time point. 4-OHT inhibited miR-221 expression, although the difference was not statistically significant at the $6 \mathrm{~h}$ time point. To our knowledge, there are only two reports examining the effect of $E_{2}$ on miRNA at various times $(0,1,3,4,6$, and $12 \mathrm{~h})$ of treatment in MCF-7 cells [260,269]. The time-course of miR-21 expression does not agree with a previous report showing $E_{2}$ increased miR-21 over time [260]. This difference is likely the result of differences in the MCF-7 cells used since Bhat- 
Nakshatri et al. used MCF-7 cells stably transformed with a bicistronic vector control [260] whereas we used MCF-7 cells at passages less than 9 from ATCC. 
Figure 6: Time course analysis of miRNA expression. MCF-7 cells serum starved for $72 \mathrm{~h}$ and were treated for $1,4,6$ and $8 \mathrm{~h}$ with EtOH, $10 \mathrm{nM} \mathrm{E}_{2}$, or $100 \mathrm{nM}$ 4-OHT. Values are the avg. \pm SEM of 3-6 separate experiments in which each point was run in triplicate. Values were normalized by $5 \mathrm{~S}$ rRNA and are expressed as fold relative to basal (time 0).
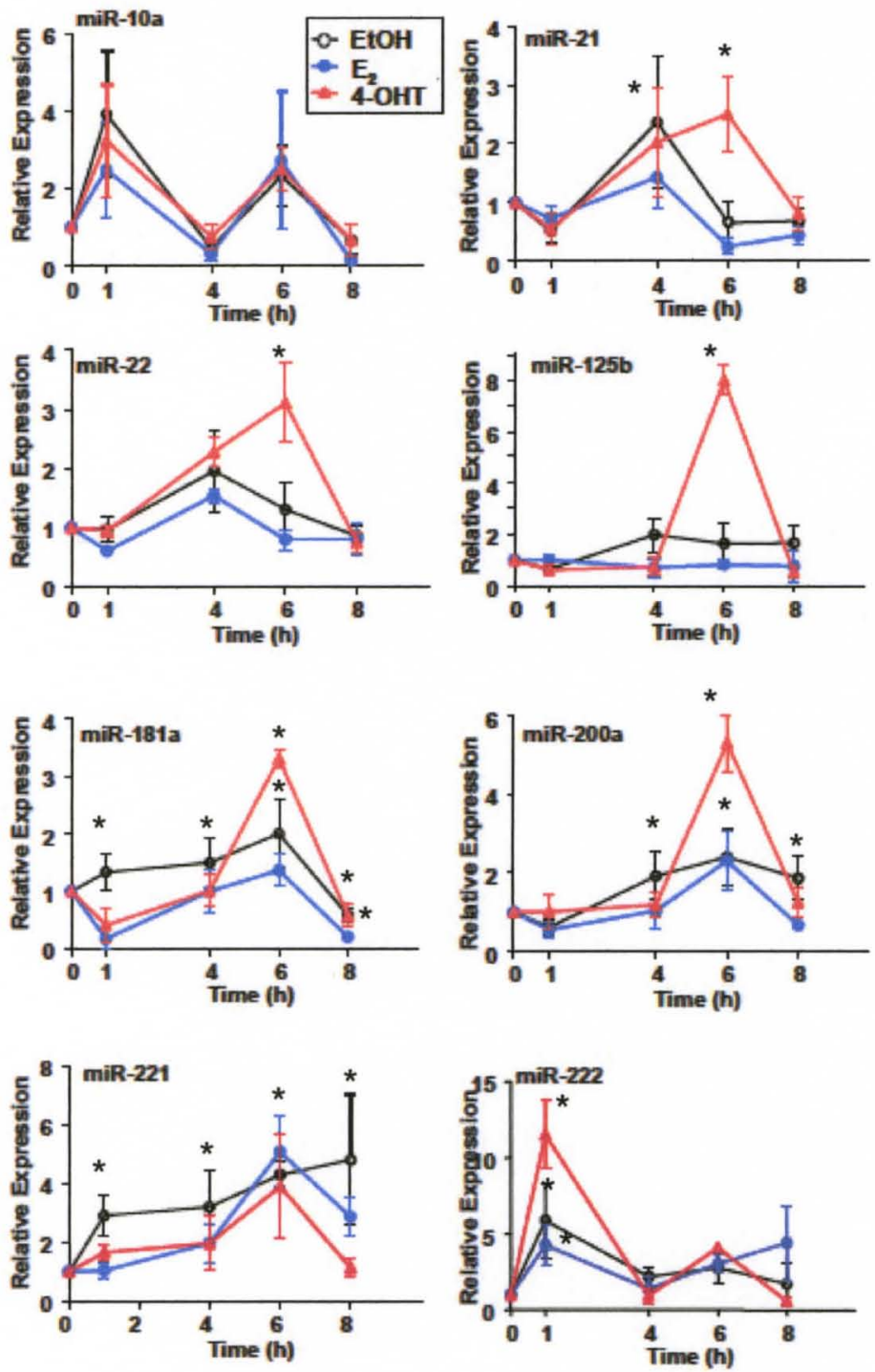
Time course of $E_{2}$ and 4-OHT regulation of $E R \alpha, E R \beta$, and Argonaute-2 (Ago2)

To determine if changes in miRNA expression with time reflect changes in $\mathrm{ER} \alpha, \mathrm{ER} \beta$, or Ago 2 expression, MCF-7 cells were treated with EtOH, $\mathrm{E}_{2}$, or 4-OHT for $1,4,6$, or $8 \mathrm{~h}$ prior to western blot for ER $\alpha$, ER $\beta$, and Ago2 protein expression (Figure 7A). These data show that ER $\alpha$ was increased after $4 \mathrm{~h}$ of treatment with EtOH and remained increased through the $8 \mathrm{~h}$ time course in MCF-7 cells. Consistent with previous investigations [309], $\mathrm{E}_{2}$ reduced $\mathrm{ER} \alpha$ and 4-OHT stablized ER $\alpha$ in MCF-7 cells. ER $\beta$ was increased with $\mathrm{EtOH}, \mathrm{E}_{2}$, and 4-OHT treatment for $1 \mathrm{~h}$, but at $4 \mathrm{~h}, \mathrm{E}_{2}$ and 4-OHT reudced ER $\beta$. At $6 \mathrm{~h}$, only 4-OHT reduced ER $\beta$. At $8 \mathrm{~h}, \mathrm{ER} \beta$ was increased and this increase was inhibited by $\mathrm{E}_{2}$ and 4-OHT. Ago2 was unaffected by EtOH until $8 \mathrm{~h}$ when there was an increase in Ago2. Ago2 was decreased by $\mathrm{E}_{2}$ and 4-OHT with time and the increase in Ago 2 with $\mathrm{EtOH}$ at $8 \mathrm{~h}$ was further increased by 4-OHT. This is the first examination of the effect of $E_{2}$ or 4-OHT on Ago2 expression. The changes in miR-21 expression with time and treatment correspond to the expression of ER $\alpha$ protein and at some time points/treatments appear to inversely correspond to $E R \beta$ protein expression (Figure 7B). These data suggest that $E_{2}-E R \alpha$ regulates miR-21 expression. 
Figure 7: Time-dependent changes in ER $\alpha, E R \beta$, and Ago2 expression in E2- or 4-OHT- treated MCF-7 cells. MCF-7 cells were serum-starved for $48 \mathrm{~h}$ and either untreated (No Tx) or treated for 1, 4, or $6 \mathrm{~h}$ with EtOH, $10 \mathrm{nM} \mathrm{E}$, or $100 \mathrm{nM}$ 4-OHT. A) WCE (30 $\mu \mathrm{g}$ protein) were separated on SDS-PAGE gels and western blotted with two different ER $\alpha$ antibodies (D-12 and AER320), ER $\beta$ antibody H150, or an antibody for Ago2. The blot was stripped and re-probed for $\alpha$-tubulin as a loading control. The values below each blot are the ratio of the indicated protein $/ \alpha$-tubulin normalized to the No Tx control. The last lane shows MCF-7 cells that were not serum-starved or treated. B) The relative expression of miR-21 in MCF-7 cells treated as indicated are plotted with ER $\alpha(\mathrm{AER} 320)$ and $\mathrm{ER} \beta$ protein expression. The miR-21 data are the same as in Figure 6. 


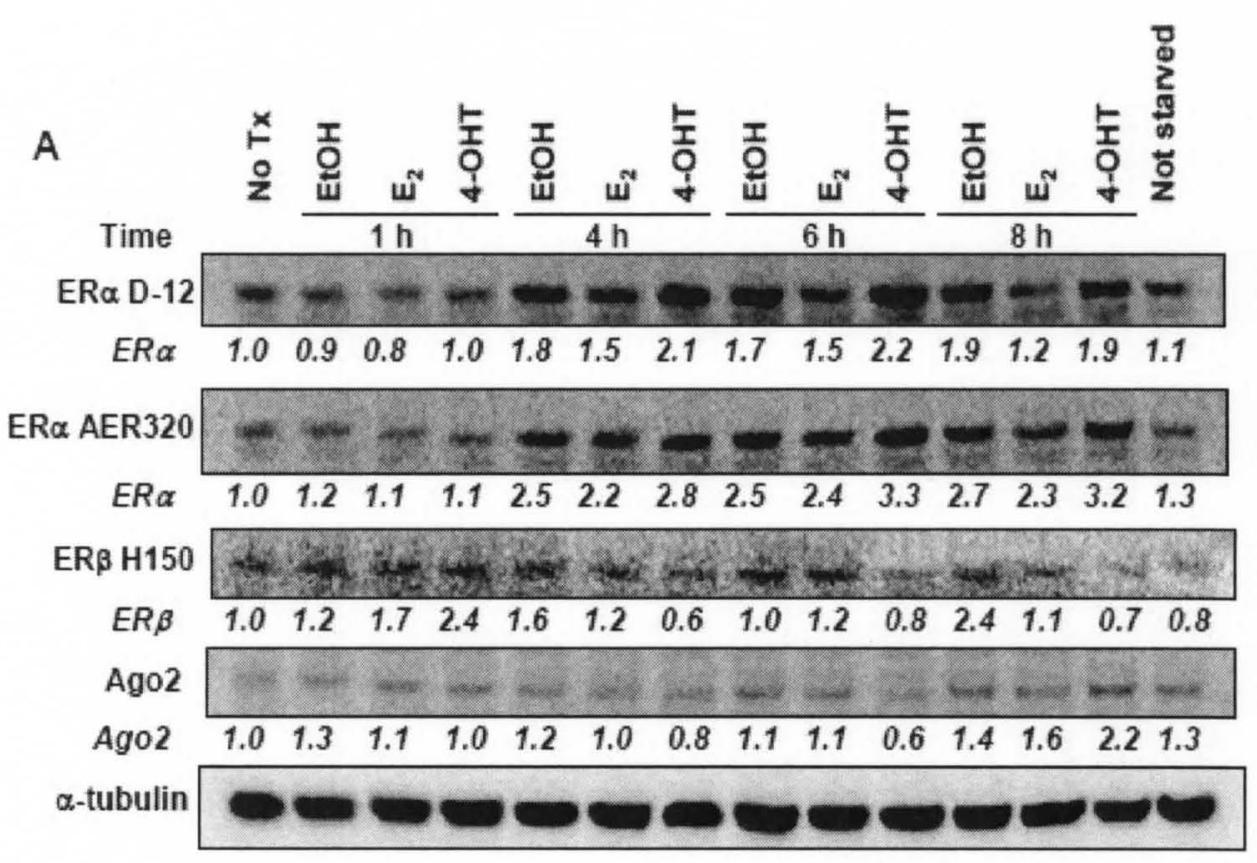

B

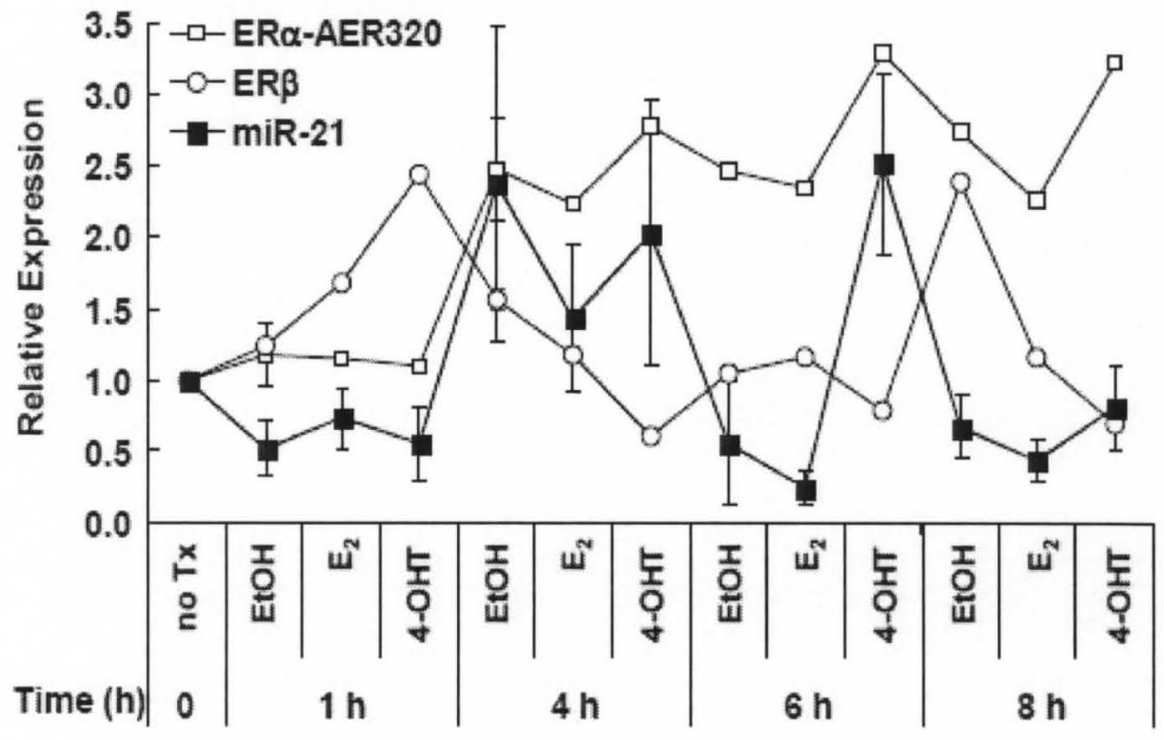




\section{Computational identification of miRNA target mRNA genes in 4-OHT-treated}

\section{MCF-7 cells}

mRNA targets of the 12 miRNAs that were differentially expressed between MCF-7 and LY2 cells (Figure 2) were identified in silico using target identification software:, Target Scan 5.1 (http://www.targetscan.org/), PicTar (http://pictar.mdcberlin.de/), miRanda (http://www.microrna.org/microrna/getGeneForm.do), and miR Base Release 15 (http://www.mirbase.org/). This data was integrated with mRNA targets regulated by 4-OHT after 4, 8, 24 and $48 \mathrm{~h}$ treatment of MCF-7 cells [276]. The gene symbols were transcribed from [276] and were searched against the miRanda predicted Human Target Site Predictions data contained in the file named human_predictions_aug2008.txt, $\quad$ downloaded http://www.microrna.org/microrna/home.do. It was necessary to update several of the HUGO gene symbols presented in [276] in order to be consistent with the current HUGO identifiers for these transcripts in the human predictions dataset. Examples include updating C1orf24 to FAM129A, and RENT1 to UPF1. All genes listed in [276] were found the predicted target of at least one miRNA in the human_predictions_aug2008.txt dataset with the exception of SNCG, SLC16A5, RAP140, LOC441453, ELF3, LSS, CLIC3, EHD4,SERPINA1, EGFL5, SRD5A1, and KRT13. This analysis identified 36 genes that were regulated by 4-OHT in MCF7 cells and which are putative targets of the 12 miRNAs identified in miRNA microarray analyses (Figure 8, Appendix 2). Appendix 2 also lists the putative miRNA target mRNA genes, their mRNA expression in 4-OHT treated cells at 8 and $48 \mathrm{~h}$ from [310], and whether these data agree with the data on miRNA expression in response to 4-OHT (Figure 5). In general, the predicated gene targets agree with the direction of miRNA expression in 4-OHT treated MCF-7 cells. 
In order to identify gene networks involving 12 miRNAs that were differentially expressed in LY2 and MCF-7 cells (Figure 3), Ingenuity Pathway Analysis (IPA) was performed. Networks created by IPA are groups of proteins that interact directly or indirectly with genes or proteins in a dataset. As expected, IPA identified cancer as the top category followed by reproductive system disease and cellular development as significantly associated with the miRNAs in the data set (Appendix 6). Core analysis using IPA generated 2 networks containing the 12 differentially expressed miRNAs and key proteins involved in breast cancer (Appendix 7). Network 1 and 2 shows 35 and 9 molecules respectively (Appendix 7). The identity and cellular location of these molecules are provided in Appendix 3. Functional analysis with IPA tools identified 14 molecules in network 1 and 5 in network 2 as having roles in breast cancer (indicated by red lines in Appendix 7). Network 1 identified Myc as a central node, although none of the miRNAs directly connect to Myc. miR-10a mapped to a number of gene targets in Network 1 while miR-200b mapped to only one target, VIM. However, recent studies show that downregulation of the miR-200bc/429 cluster is associated with breast tumor progression through upregulation of phospholipase $\mathrm{C}$ gamma 1 (PLCG1) which, in turn, regulates cell mobility, proliferation, and viability [311]. APC, MYC, CYRB, CASP3, CSF1, UNCX, NPTX1, miR-10a, miR-22, miR29a, miR-93, miR-200a, miR-205 and miR-222 are the genes associated with breast cancer in this network. Network 2 centers on estrogen receptor in breast cancer and supports our observation that the expression of miR-21 in MCF-7 cells is regulated by ER (Figure 4B). 
Figure 8: Computational identification of mRNA gene targets of 12 miRNAs oppositely expressed in MCF-7 and LY2 cells. Target prediction software was used to identify mRNA targets of the miRNAs. Predicted genes were overlapped with microarray data of 4-OHT regulated genes by [310]. This identified 36 gene targets as indicated.

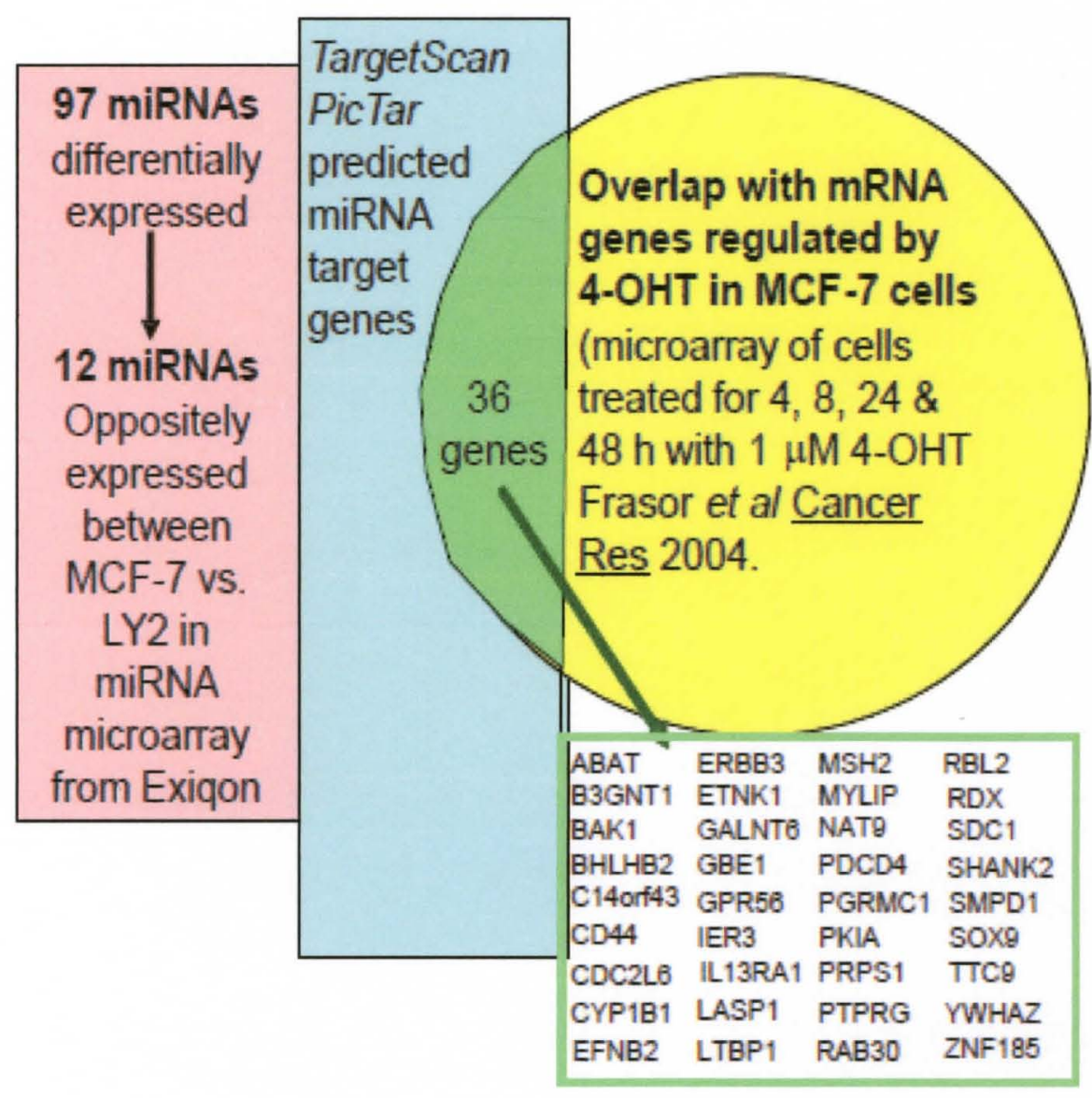


PDCD4, BCL2, CYP1B1, and ERBB3 are differentially expressed in MCF-7 and LY2 cells

Among the 36 putative gene targets in Appendix 2, we focused first on the PDCD4 tumor suppressor because we had previously identified $P D C D 4$ tumor suppressor as a bone fide mRNA target downregulated by miR-21 in MCF-7 cells [268]. Since miR-21 expression was significantly lower in LY2 than MCF-7 cells, we anticipated that $P D C D 4$ mRNA and protein expression would be higher in LY2 than in MCF-7 cells. However, PDCD4 mRNA was undetectable in EtOH-treated LY2 cells. With 4-OHT treatment, PDCD4 mRNA was detected at low levels in LY2 cells (Figure 9A). Neither $\mathrm{E}_{2}$ nor 4-OHT affected GADPH expression and GADPH CT values were similar in MCF-7 and LY2 cells, indicating that the quality of the RNA was not an issue in the lack of PDCD4 expression in control (EtOH)-treated LY2 cells (Appendix 5). 4-OHT reduced PDCD4 mRNA in MCF-7 cells (Figure 8A and 8B), consistent with the increase in miR-21 induced by 4-OHT. As reported previously, $\mathrm{E}_{2}$ increased PDCD4 mRNA (Figure 9A and 9B). We did not detect Pdcd4 protein expression in LY2, although Pdcd4 was expressed in MCF-7 (Figure 8C).

The anti-apoptotic, pro-survival $B C L 2$ is also a target of miR-21 [268]. Again, since miR-21 expression was lower in LY2, we expected higher BCL2 expression in LY2 than MCF-7 cells. However, BCL2 mRNA could not be detected in LY2 cells, whether EtOH or 4-OHT treated (data not shown). As expected based on our previous data and the work of others [268,312], $\mathrm{E}_{2}$ increased $B C L 2 \mathrm{mRNA}$ in MCF-7 cells. 4-OHT had no significant effect on BCL2 mRNA expression in MCF-7 cells. We did not detect Bcl-2 protein expression in LY2, although Bcl-2 was expressed in MCF-7 cells (Figure 9C). Others reported that $1 \mu \mathrm{M}$ 4-OHT suppressed Bcl-2 expression in MCF-7 cells after $7 \mathrm{~d}$ of treatment [313]. 
CYPIBI is a cytochrome P450 enzyme implicated in the metabolism of exogenous and endogenous substrates, including $\mathrm{E}_{2}$, and $C Y P 1 B 1$ polymorphisms are associated with breast cancer risk [314]. CYPIB1 was stimulated by $8 \mathrm{~h}$ treatment with $1 \mu \mathrm{M} 4-\mathrm{OHT}$ in MCF-7 cells [310] and is a putative target of regulation by miR200 family members that are reduced in LY2 compared to MCF-7 cells. Because 4OHT increased miR-200a expression, we examined CYPIB1 expression after $6 \mathrm{~h}$ treatment with 4-OHT or EtOH in MCF-7 and LY2 cells. CYP1B1 mRNA expression was very low $(C T-39)$ in LY2 cells and 4-OHT did not affect CYPIB1 expression (Figure 10A). These results are in contrast to a previous report showing 2-6-fold higher CYPIBI in TAM- and fulvestrant- resistant cell lines derived from of MCF-7 cells [315]. The reason for this difference in CYPIBI expression may be cell line- or cell culture- condition mediated. As another possible difference, we noticed that the endocrine resistant cell lines used in the previous report were supplemented with insulin [315], whereas we do not supplement our cell culture media with insulin. Although studies in diabetic rats indicate that insulin represses hepatic CYPIB1 [316], the regulation of $C Y P I B I$ by insulin in breast cancer cells has not, to our knowledge, been examined. CYPIBI mRNA expression was higher in MCF-7 than LY2 cells, but was not significantly regulated by $\mathrm{E}_{2}$ or 4-OHT with $6 \mathrm{~h}$ treatment in MCF-7 cells. These data reflect previous findings regarding detection of CYPIBI expression in MCF-7 cells [317]. We did not detect an increase in CYPIBI with $6 \mathrm{~h}$ of treatment, as reported for $12 \mathrm{~h}$ of $\mathrm{E}_{2}$ treatment in MCF- 7 cells [318]. The reduction of miR200b and miR-200c detected with 4-OHT treatment in MCF-7 cells in microarray (Figure 3) would be expected to increase targets of these miRNAs, including CYPIB1. Indeed, CYPIBI mRNA was increased in the microarray study with $8 \mathrm{~h}$ of 
$1 \mu \mathrm{M}$ 4-OHT treatment (Appendix 2) [310]; but after $6 \mathrm{~h}$ of treatment, no reduction in CYP1B1 was detected.

$E R B B 3$ is an oncogene that is a member of the epidermal growth factor receptor (EGFR) family of transmembrane tyrosine kinases that is bound by heregulin and is involved in the pathogenesis and progression of breast cancer [319]. ERBB3 is frequently over-expressed in breast cancer and increased in TAM resistance [319,320]. ERBB3 is a putative target of miR-22, miR-125b, miR-221, miR-222, miR-93 according to our bioinformatic analyses and is a bone fide target of miR-125b [201]. Increased expression of these miRNAs in LY2 cells would be expected to reduce the expression of $E R B B 3$ in LY2 cells. In agreement with this idea, we did not detect ERBB3 mRNA in LY2 cells, even when treated with 4-OHT (Figure 10B and data not shown). We did not detect regulation of ERBB3 mRNA by $\mathrm{E}_{2}$ or 4-OHT with $6 \mathrm{~h}$ treatment in MCF-7 cells. Others reported that ERBB3 mRNA was inhibited by $48 \mathrm{~h}$ treatment of MCF-7 cells with $1 \mathrm{nM} \mathrm{E}_{2}$ and this inhibition blocked by $1 \mu \mathrm{M}$ TAM in MCF-7 cells [321]. The difference in time of treatment is likely responsible for differences in $E R B B 3$ regulation. 
Figure 9: miR-21 target genes expression in MCF-7 and LY2 cells. MCF-7 and LY2 cells were serum-starved for $48 \mathrm{~h}$ and then treated with EtOH, $10 \mathrm{nM} \mathrm{E}$, or 100 $\mathrm{nM} 4-\mathrm{OHT}$ for $6 \mathrm{~h}$ prior to RNA isolation (A) or $24 \mathrm{~h}$ prior to WCE preparation (B) as described in Materials and Methods. (A) Q-PCR was performed for the indicated genes and fold-expression determined compared to EtOH as described in Materials and Methods. Values are the average of 3 separate determinations \pm SEM. (B) Western blot for the indicated proteins. The membrane was stripped and reprobed for $\alpha$-tubulin for normalization as described in Materials and Methods. The blot shown is representative of three separate biological replicates.
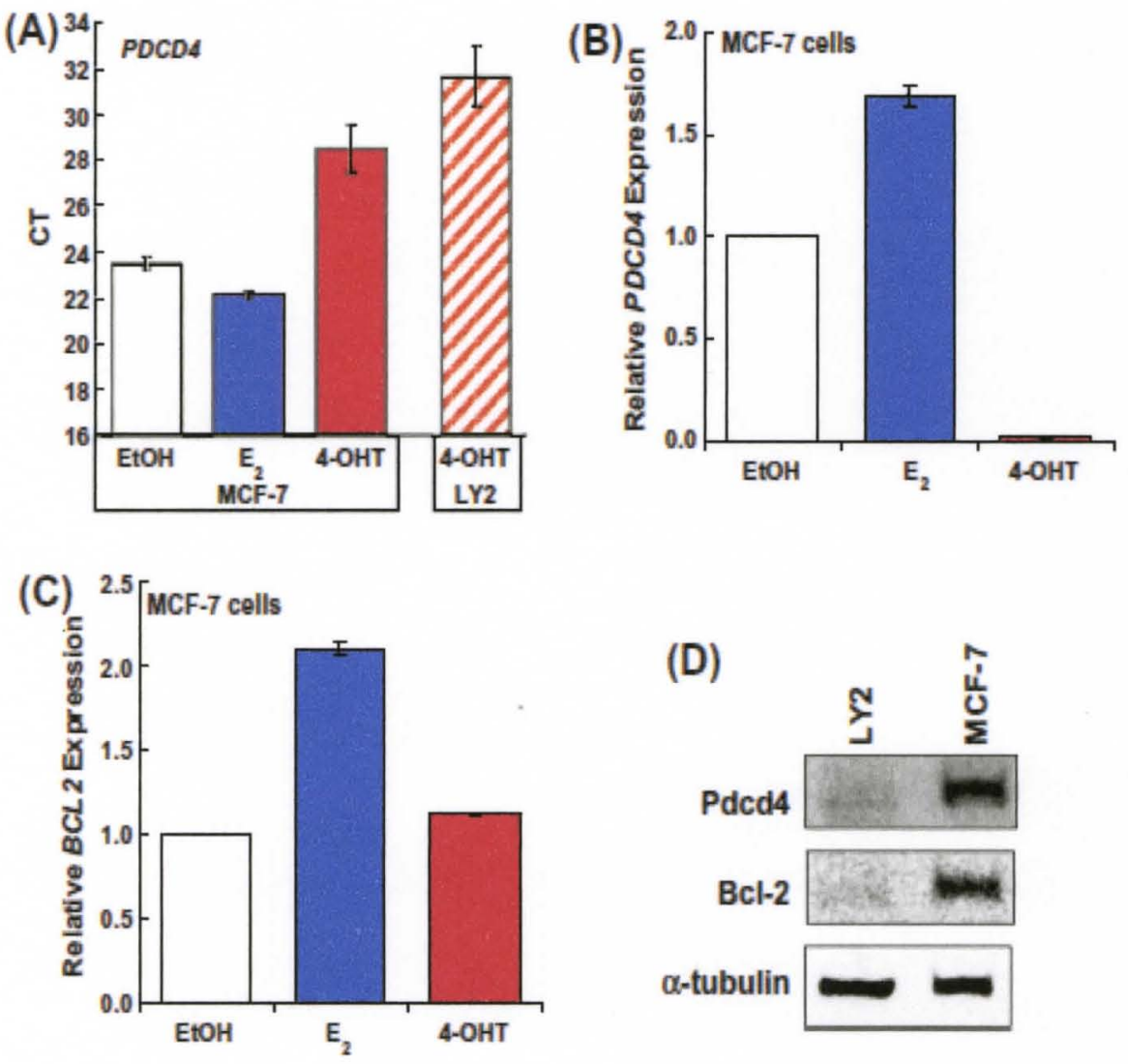


\section{ESR1 and ER $\alpha$ protein expression is lower in LY2 than MCF-7 cells}

MiR-221 and miR-222 expression was higher in LY2 compared to MCF-7 cells. miR-221 and miR-222 are overexpressed in ER $\alpha$-negative and TAM-resistant breast cancer cell lines $[270,295]$. Knockdown of miR-221 and miR-222 in MDAMB-468 breast cancer cells partially restored ER $\alpha$ expression and TAM-sensitivity [295]. ESR1 mRNA expression is lower in LY2 than MCF-7 cells (Figure 10C). Western confirmed lower ER $\alpha$ protein expression in LY2 cells when compared to MCF-7 cells (Figure 4F). These data agree with reports that miR-221/222 is overexpressed in TAM-resistant breast cancer cell lines and suppresses ER $\alpha$ expression.

miR-200-regulated ZEB1 is reduced in LY2 cells

miR-200 family members suppress expression of the transcription factor ZEB1 that initiates epithelial to mesenchymal transition (EMT) by repressing transcription of E-cadherin and other genes regulating cell polarity [203,205,322326]. Because all three miR-200 family members were expressed at significantly lower levels in LY2 than MCF-7 cells, we examined ZEB1 as a miR-200 target in MCF-7, LCC1, LCC2, LCC9, LY2, and MDA-MB-231 breast cancer cells by western blot (Figure 11A). LCC1 are estrogen-independent derivatives of MCF-7 cells and LCC2 and LCC9 are also endocrine-resistant derivatives of MCF-7 cells [278]. MDA-MB-231 serve as a positive control since ZEB 1 expression is higher in MDAMB-231, but not in MCF-7 [327]. As expected, ZEB 1 was not expressed in MCF-7, but was expressed in MDA-MB-231 (Figure 11A). LY2 cells express ZEB1, indicating that this cell line has undergone EMT. However, LCC1, LCC2, and LCC9 cells do not express ZEB1, indicating that these estrogen-independent (LCC1) and tamoxifen/endocrine-resistant (LCC2 and LCC9) cell lines have not undergone EMT. 
Because E-cadherin is inversely correlated with ZEB1 expression and inversely correlated with miR-200c [324], we examined E-cadherin in MCF-7, LY2, and MDA-MB-231 cells (Figure 11B). E-cadherin was not expressed in LY2 or MDAMB-231 cells, indicating that LY2 cells have undergone EMT. This is, to our knowledge, the first demonstration of EMT in the LY2 endocrine-resistant breast cancer cell line. 
Figure 10: CYP1B1, ERBB3, and ESR1 gene expression in MCF-7 and LY2 cells. MCF-7 and LY2 cells were serum-starved for $48 \mathrm{~h}$ and then treated with EtOH, $10 \mathrm{nM} \mathrm{E}_{2}$, or $100 \mathrm{nM} 4-\mathrm{OHT}$ for $6 \mathrm{~h}$ prior to RNA isolation (A) or $24 \mathrm{~h}$ prior to WCE preparation (B) as described in Materials and Methods. Q-PCR was performed for the indicated genes and fold-expression determined compared to EtOH as described in Materials and Methods. Values are the average of 3 separate determinations \pm SEM.

A
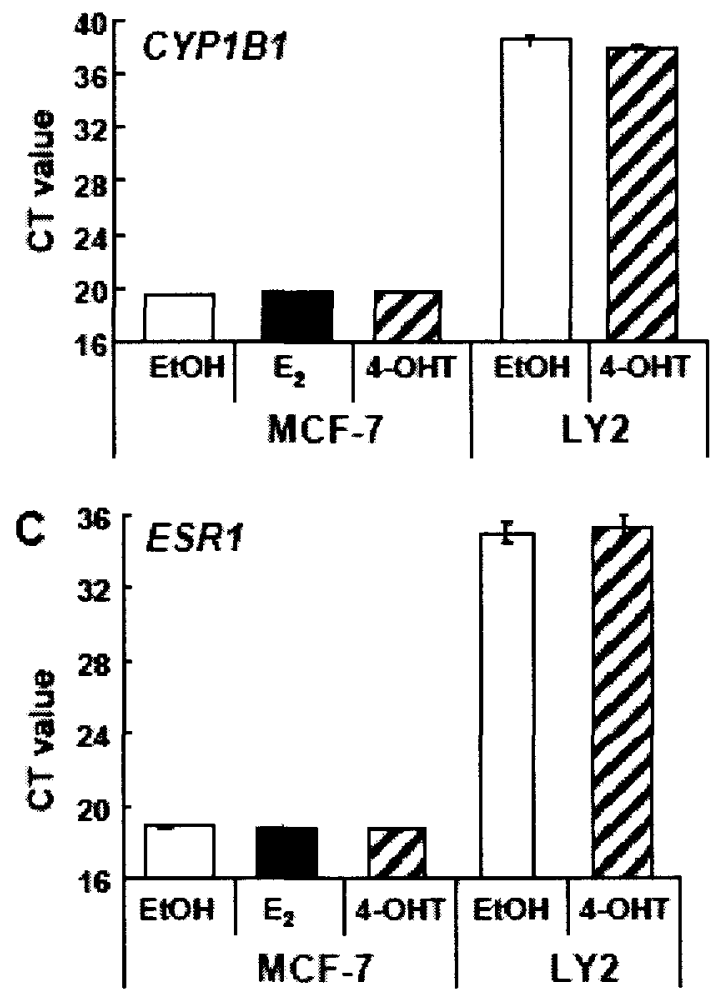

B

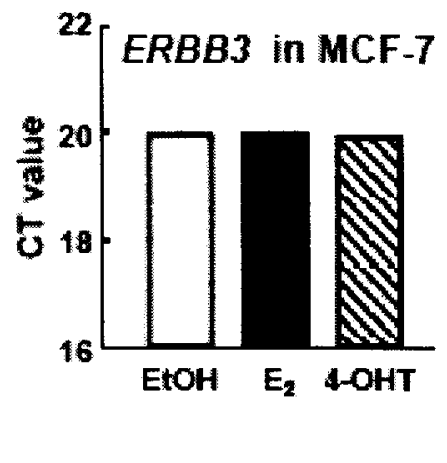


Figure 11: ZEB1 and E-cadherin expression. Whole cell lysates or nuclear extracts were prepared from the indicated breast cancer cell lines. Identical amounts $(30 \mu \mathrm{g})$ of protein were immunoblotted for ZEB 1 and E-cadherin as described in Materials and Methods. The membranes were stripped and reprobed for $\beta$-actin. These blots are representative of three separate experiments. 


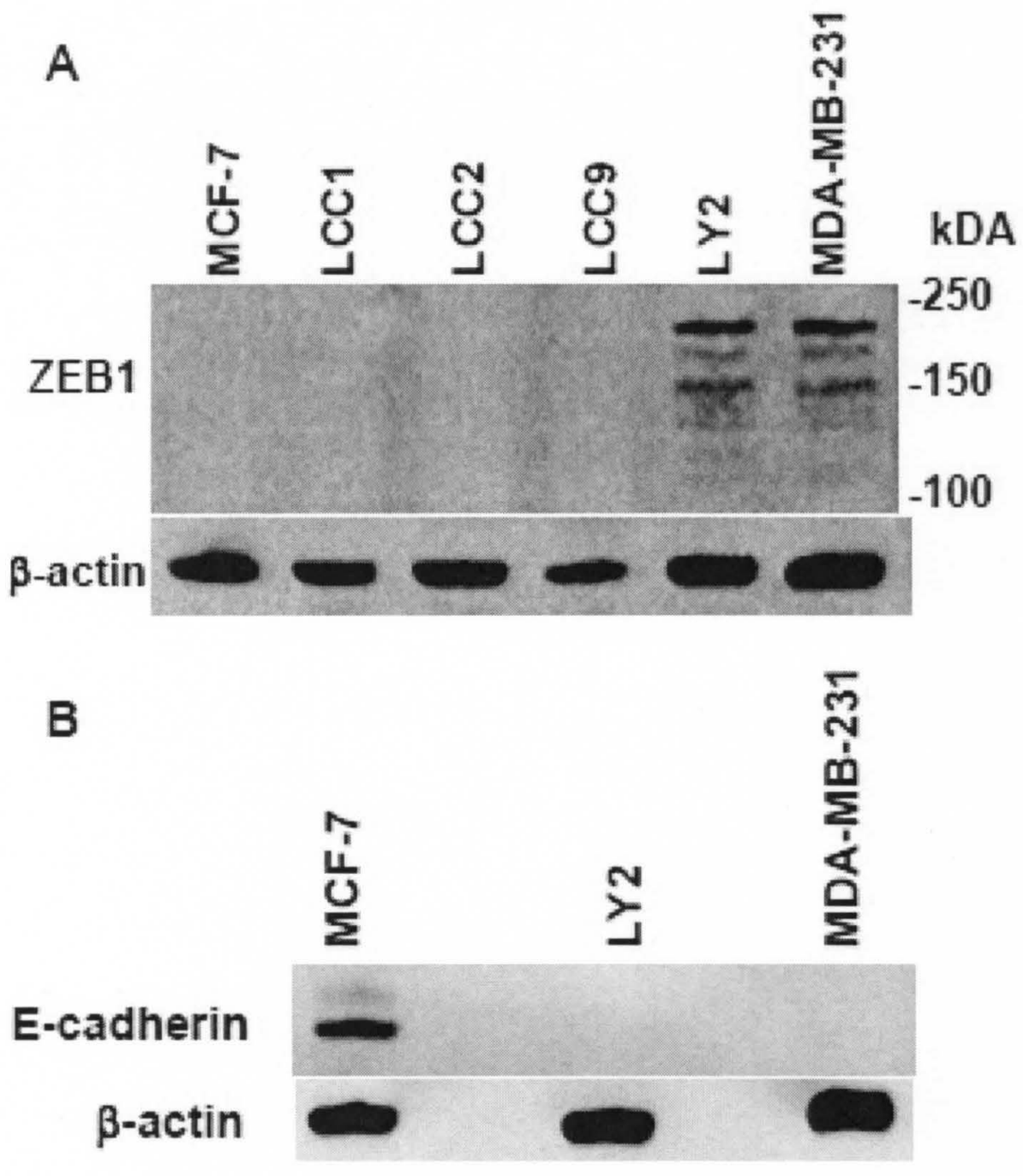




\section{CHAPTER IV: REDUCED EXPRESSION OF MIRNA-200 FAMILY IN LY2 CELLS CONFERS RESISTANCE TO TAMOXIFEN AND FULVESTRANT}

\section{INTRODUCTION}

As previously discussed in earlier chapters, miRNAs regulate gene expression at the post-transcriptional level [328]. miRNAs are aberrantly expressed in different types of cancer including breast cancer [197].

EMT (epithelial-to-mesenchymal transition) is a hallmark of metastatic cancer [329]. EMT is induced by several signaling pathways such as TGF- $\beta$, Wnt and Notch [330,331]. It is characterized by loss of the epithelial marker E-cadherin due to gene methylation or repression by upregulation of transcription factors Zinc finger E-box binding homeobox domain proteins such as ZEB1 (also known as TCF1 or $\delta E F 1$ ) or ZEB2 (also known as SIP1), Snail1/2 and TWIST that repress E-cadherin in epithelial cells [332-335]. As a result, cells acquire a mesenchymal phenotype characterized by the expression of markers such as vimentin and N-cadherin [336]. Reduced expression of miRNA-200 and miR-205; and increased expression miR-221/222 are implicated in EMT and metastasis [337]. Aberrant expression of these miRNAs has been reported to increase metastatic breast cancer [338,339]. The link between the development of endocrine resistance and EMT in breast cancer is still not clearly understood. Studies have shown that endocrine resistance confers metastatic properties to cells. For example, some endocrine-resistant cells and tumors show activation of the $\beta$-catenin pathway and induction of Snail and TWIST that contribute 
to EMT by repressing E-cadherin transcription [340-342]. A few studies have shown that miRNAs have a role in conferring endocrine-resistance which subsequently led to induction of EMT and metastasis. For example, re-expression of miR-375 restored TAM sensitivity and reverted EMT in breast cancer cells [343]. Prolonged growth of MCF-7 breast cancer cells as mammospheres induced EMT and resistance to TAM [344]. Notably, these MCF-7 mammospheres exhibited higher expression of miR$221 / 222$ and reduced expression of $\mathrm{miR}-200 \mathrm{c}, \mathrm{miR}-203$ and miR-205 compared to MCF-7 cells [344].

The miR-200 family of miRNAs are derived from two chromosomal locations: miR-200b, miR-200a, and miR-429 are located on chromosome 1p36; miR-200c and miR-141 are located on $12 \mathrm{p} 13$ [203]. The miR-200bc/429 cluster differs from the miR-200a/141 cluster by the fourth nucleotide ( $U$ to $C$ ) in the seed region and this means that they regulate different genes in breast cancer [206]. Reduced expression of miR-200 family of miRNAs has been observed in breast, ovarian, endometrial, lung and gastric cancers compared to normal tissue [322]. Many studies have identified an inverse relationship between the expression of miR-200 family and its targets ZEB1 in cells [205,345-347]. We recently reported increased expression of ZEB1 protein and loss of its target E-cadherin in an endocrine-resistant cell line LY2 compared to parental MCF-7 human breast cancer cells[247]. We observed that the LY2 cell line had undetectable levels of miR-200 family members compared to the parental MCF-7 cell line, suggesting a role for miR-200 in tamoxifen/endocrineresistance and loss of ZEB1 repression.

Here I examined the expression of miR-200a, miR-200b, and miR-200c and their regulation by $E_{2}$ and 4-OHT, an active TAM metabolite in a panel of ER $\alpha$ positive breast cancer cell lines representing progression towards 
endocrine/tamoxifen-resistance. Further, I tested how overexpression of miR-200b and miR-200c affected LY2 cell morphology, expression of $Z E B I$ and vimentin, and cell proliferation. I also examined how knockdown of miR-200b and miR-200c affected the sensitivity of MCF-7 cells to TAM and fulvestrant. Lastly, I examined if epigenetic modification of miR-200b and miR-200c could be responsible for the lower expression of these miRNAs in LY2 cells compared to the parental MCF-7 cells.

\section{MATERIALS AND METHODS}

\section{Cell culture}

MCF-7 human breast cancer cells were purchased from ATCC (Manassas, VA, USA) and maintained in IMEM supplemented with $10 \%$ fetal bovine and $1 \%$ penicillin/streptomycin (Invitrogen, Carlsbad, CA, USA) serum [203]. LCC1, LCC2, LCC9, and LY2 are derivatives of MCF-7 cells that are $E_{2}$, tamoxifen, and multiple SERM-independent, respectively, and were graciously provided by Dr. Robert Clarke, Georgetown University. Prior to treatment, the medium was replaced with phenol red-free IMEM supplemented with 5\% dextran charcoal-stripped FBS and 1\% penicillin/streptomycin (stripped medium) or $48 \mathrm{~h}$ (referred to as 'serum-starving').

\section{Chemicals}

$\mathrm{E}_{2}$ and 4-OHT were purchased from Sigma-Aldrich (St. Louis, MO). ICI 182,780 was from Tocris (Ellisville, MO). Cells were treated with ethanol (EtOH, the vehicle control, $0.01 \%$ final volume) $10 \mathrm{nM} \mathrm{E}_{2}$ or $100 \mathrm{nM} 4-\mathrm{OHT}$ for $6 \mathrm{~h}$ as indicated. Where indicated LY2 cells were treated with $2.5 \mu \mathrm{M}$ 5-aza-2'-deoxycytidine (5-aza-dC, Sigma-Aldrich, St. Louis, MO) alone or in combination with $100 \mathrm{ng} / \mu \mathrm{l}$ Trichostatin A (TSA, Sigma-Aldrich) for $72 \mathrm{~h}$, with TSA added $16 \mathrm{~h}$ prior to RNA extraction. 
RNA isolation and quantitative Real-Time-PCR (Q-PCR) for miRNA and mRNA expression

miRNA-enriched total RNA was extracted from MCF-7 and LY2 cells treated as above using the miRNA isolation kit (Exiqon, Woburn, MA). The quality and quantity of the isolated RNA was analyzed using a NanoDrop spectrophotometer. cDNA was synthesized using the miRCURY LNA ${ }^{\mathrm{TM}}$ first strand CDNA synthesis kit (Exiqon) and Q-PCR was performed using the miRCURY LNA ${ }^{\mathrm{TM}}$ SYBR Green master mix (Exiqon) using the miRNA primer sets for miR-200a, miR-200b or -miR200c (Exiqon). SNORD38D, SNORD48 and 5SRNA were used for normalization of miRNA expression. Analysis and fold change was determined using the comparative threshold cycle $(\mathrm{Ct})$ method. The change in miRNA expression was calculated as fold-change, i.e., relative to EtOH-treated (control).

For mRNA expression, the High Capacity cDNA Reverse Transcription kit (PE Applied Biosystems) was used to reverse transcribe total RNA using random hexamers. Q-PCR for ZEBI was performed using SYBR green in the ABI PRISM 7900 SDS 2.1 (PE Applied Biosystems,Carlsbad, CA) using relative quantification. The sequence of ZEB1 primers is described in [205]. Analysis and fold differences were determined using the comparative CT method. Fold change was calculated from the $\Delta \Delta \mathrm{CT}$ values with the formula $2^{-\Delta \Delta \mathrm{CT}}$ and data are relative to EtOH-treated cells.

\section{Transient transfection}

MCF-7 or LY2 cells were transfected with either anti-miRNAs (antimiRs, Ambion, Life Technologies, Carslbad, CA) or precursor microRNA (pre-miRs, Ambion) respectively for miR-200b or miR-200c using Lipofectamine RNAimax (Invitrogen) 
reagent. After 1 or $5 \mathrm{~d}$, RNA was isolated (as described above) to confirm knockdown or overexpression of $\mathrm{miR}-200 \mathrm{~b}$ or $\mathrm{miR}-200 \mathrm{c}$.

\section{MTT assay}

MCF-7 or LY2 cells were grown in 96 well plates. Following transfection with antimiRs or pre-miRs respectively for $24 \mathrm{~h}$ or 5 days, cells were treated with vehicle control EtOH, $10 \mathrm{nM} \mathrm{E}, 100 \mathrm{nM}$ or $1 \mu \mathrm{M} 4-\mathrm{OHT}, 100 \mathrm{nM}$ or $1 \mu \mathrm{M}$ fulvestrant for 4 or 6 days. $20 \mu$ l of Cell Titer reagent (Promega, Madison, WI) was added to the wells and absorbance was read at $490 \mathrm{~nm}$ using a spectrophotometer (SpectraMax M2, Molecular Devices, Sunnyvale, CA).

\section{Whole cell preparation for western blotting}

Whole cell lysates were prepared and western blots were performed as described in [161]. Protein concentrations were determined by BioRad DCC protein assay (Hercules, CA).

\section{Antibodies and reagents}

Antibodies were purchased as follows: E-cadherin (Cell Signaling, Danvers, MA), vimentin (Santa Cruz Biotechnology, Santa Cruz, CA), $\beta$-actin (Sigma-Aldrich). Chemiluminescent bands on the PVDF membranes were visualized on a Kodak Carestream Imager using Carestream Molecular Imaging software (New Haven, CT).

\section{Microscopy images}


LY2 cells were untransfected or transfected with pre-miR-200b or pre-miR-200c or negative control for $48 \mathrm{~h}$ (described above). Images were captured using a digital microscope (EVOS, AMG, Bothell, WA) at a magnification of 20x and $100 \mu \mathrm{m}$ scale.

\section{Statistical analysis}

Statistical evaluations were performed using GraphPad PRISM. Student's t-test was used to compare control and treatment values. P-values indicate statistical significance.

\section{RESULTS}

Expression of miR-200 family in MCF-7, LCC1, LCC2, LCC9 and LY2 human breast cancer cells

Microarray analysis of miRNA expression revealed low miR-200a, miR-200b and miR-200c expression in LY2 endocrine-resistant breast cancer cells compared to MCF-7 endocrine-sensitive breast cancer cells [161]. To follow up on this initial observation, the expression of miR-200a, miR-200b and miR-200c was measured by Q-PCR in a panel of human breast cancer cell lines, i.e., MCF-7 cells and LCC1, LCC2 and LCC9 cells that were derived from the parental MCF-7 cell line by propagation in mice (LCC1), and then in long-term culture with tamoxifen (LCC2) or fulvestrant (LCC9) [348]. LY2 tamoxifen/fulvestrant-resistant human breast cancer

cells were independently derived from MCF- 7 cells by culture in a precursor to raloxifene: LY 117018 [349]. LY2 are cross-resistant to TAM, raloxifene, fulvestrant (Faslodex or ICI 182,780), and are ER $\alpha$ positive, although ER $\alpha$ protein expression is lower than MCF-7 cells [247]. These cells represent a model of the progression of breast cancer cells towards TAM/endocrine-resistance. 
The effect of $\mathrm{E}_{2}$ and 4-OHT on miR-200 expression was examined by Q-PCR in the cell lines described above (Figure 12). $10 \mathrm{nM} \mathrm{E} \mathrm{E}_{2}$ and $100 \mathrm{nM}$ 4-OHT significantly decreased miR-200a and miR-200b expression in MCF-7 cells. Similarly, $\mathrm{E}_{2}$ significantly decreased the expression of miR-200a, miR-200b and miR$200 \mathrm{c}$ in estrogen-independent, but tamoxifen-sensitive LCCl cells. However, there was no effect of $E_{2}$ and 4-OHT on the expression of miR-200 family in LCC2 and LY2 (Figure 13A-C). In LCC9, $\mathrm{E}_{2}$ and 4-OHT decrease miR-200a and miR-200b expression and 4-OHT decreases miR-200c expression. LCC1 cells showed highest basal miR-200a expression. LY2 cells had undetectable levels of miR-200 family expression (Figure 12A-C). This is the first report of 4-OHT regulation of miR-200 family expression in LCC1, LCC2, LCC9 and LY2 cells. We and others previously reported that $E_{2}$ reduces miR-200 family expression in MCF-7 cells $[159,161]$

\section{$\mathrm{E}_{2}$ and 4-OHT regulate ZEB1 in MCF-7, LCC1, LCC2, LCC9 and LY2 human breast cancer cells}

miR-200 family members repress ZEB1 [203,322,345]. Next we evaluated ZEB 1 mRNA expression in each cell line. Basal expression of ZEB1 was lower in LCC1, LCC2, and LCC9 compared to MCF-7 (Figure 14A). As previously reported, ZEB1 expression was higher in LY2 compared to MCF-7 [247]. $E_{2}$ and 4-OHT decreased the expression of ZEB1 in MCF-7 cells (Figure 14A). There was no significant effect of either $\mathrm{E}_{2}$ or 4-OHT on ZEB1 expression in LCC1, LCC2, or LCC9 cells (Figure 14B). In contrast, in LY2 cells, $E_{2}$ increased the expression of ZEB I mRNA. Notably, there is an inverse relationship between the expression of miR-200 family and ZEB1 in LY2 cells (compare Figures. 12 and 14A). 
Figure 12: Q-PCR analysis of the expression of miR-200 family in MCF-7, LCC1, LCC2, LCC9 and LY2 cells. Cells were treated with vehicle control EtOH, or $10 \mathrm{nM} \mathrm{E} \mathrm{E}_{2}$ or $100 \mathrm{nM} 4-\mathrm{OHT}$ for $6 \mathrm{~h}$. Values are the average of 3-4 experiments normalized to 5SrRNA or SNORD38D or SNORD48 and are expressed as fold relative to $\mathrm{EtOH}$-treated MCF-7 expression. * $\mathrm{p}<0.05$ versus $\mathrm{MCF}-7 \mathrm{EtOH}$ treated.
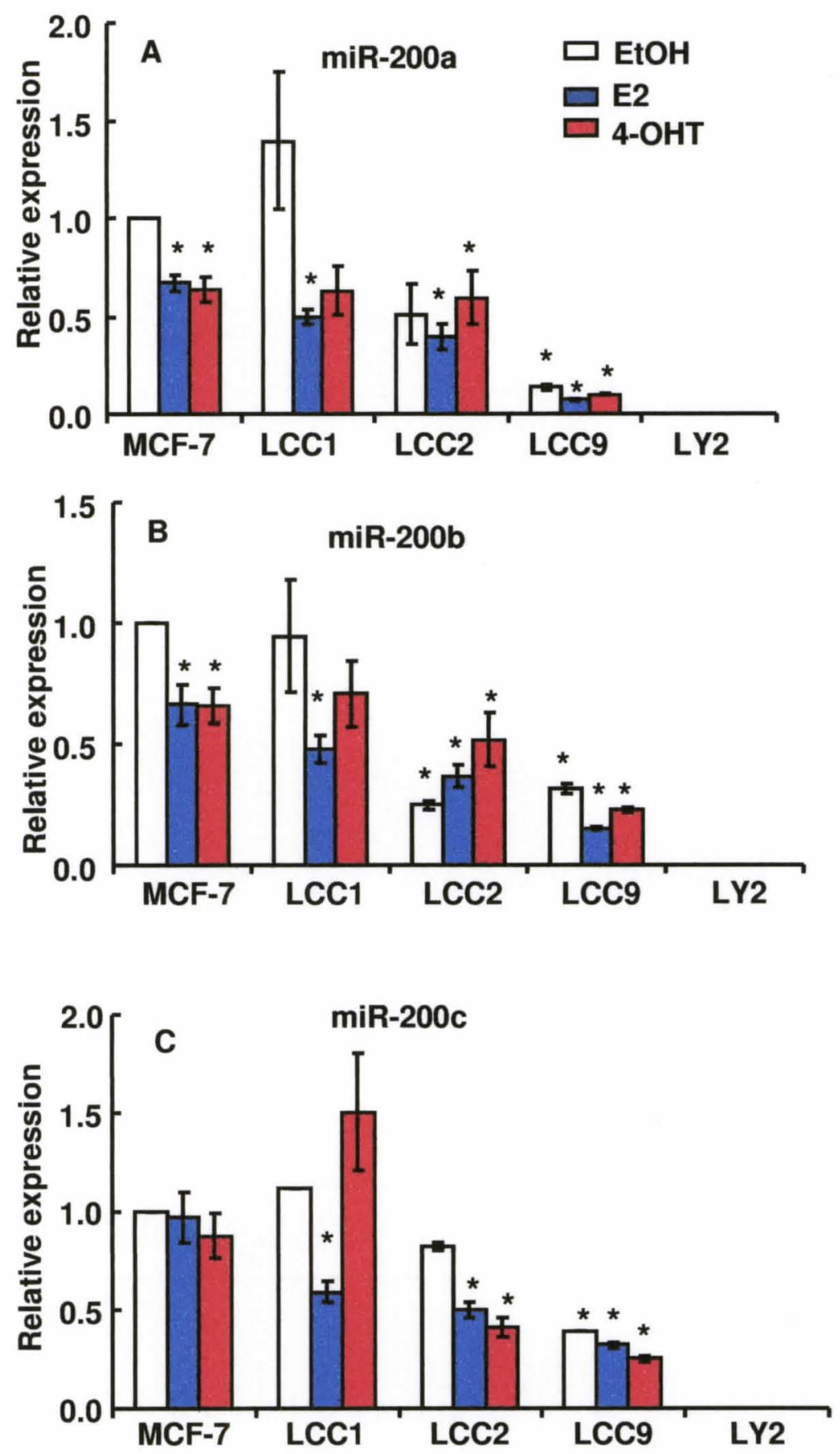
Figure 13: Q-PCR analysis of the expression of miR-200 family in MCF-7, LCC1, LCC2, LCC9 and LY2 cells. Cells were treated with vehicle control EtOH, or $10 \mathrm{nM} \mathrm{E} \mathrm{E}_{2}$ or $100 \mathrm{nM} 4-\mathrm{OHT}$ for $6 \mathrm{~h}$. Values are the average of 3-4 experiments normalized to 5SrRNA or SNORD38D or SNORD48 and are expressed as fold relative to EtOH-treated expression for each cell line. ${ }^{*} \mathrm{p}<0.05$ versus $\mathrm{EtOH}$ treated for each cell line. 

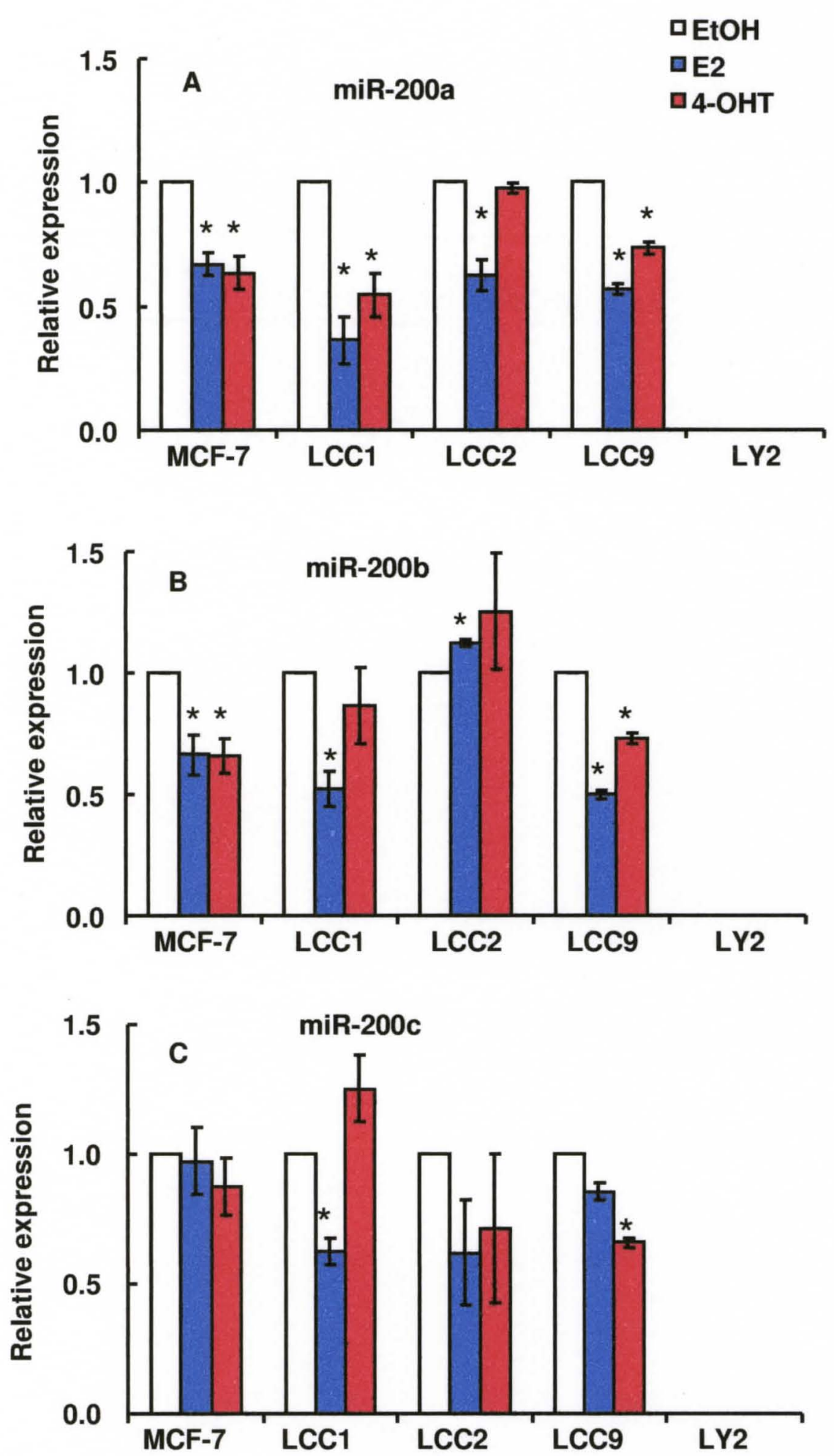
Figure 14: Q-PCR analysis of the expression of ZEB1 mRNA in MCF-7, LCC1, LCC2, LCC9 and LY2 cells. Cells were treated with vehicle control EtOH, or $10 \mathrm{nM}$ $\mathrm{E}_{2}$ or $100 \mathrm{nM} 4-\mathrm{OHT}$ for $6 \mathrm{~h}$. A. Values are the average of 3-4 experiments normalized to GAPDH and are expressed as fold relative to EtOH-treated MCF-7 expression for each cell line. ${ }^{*} \mathrm{p}<0.05$ significantly different from MCF-7 EtOH treated. B. Values are the average of 3-4 experiments normalized to GAPDH and are expressed as fold relative to EtOH-treated for each cell line. ${ }^{*} \mathrm{p}<0.05$ significantly different from EtOH treated for each cell line.
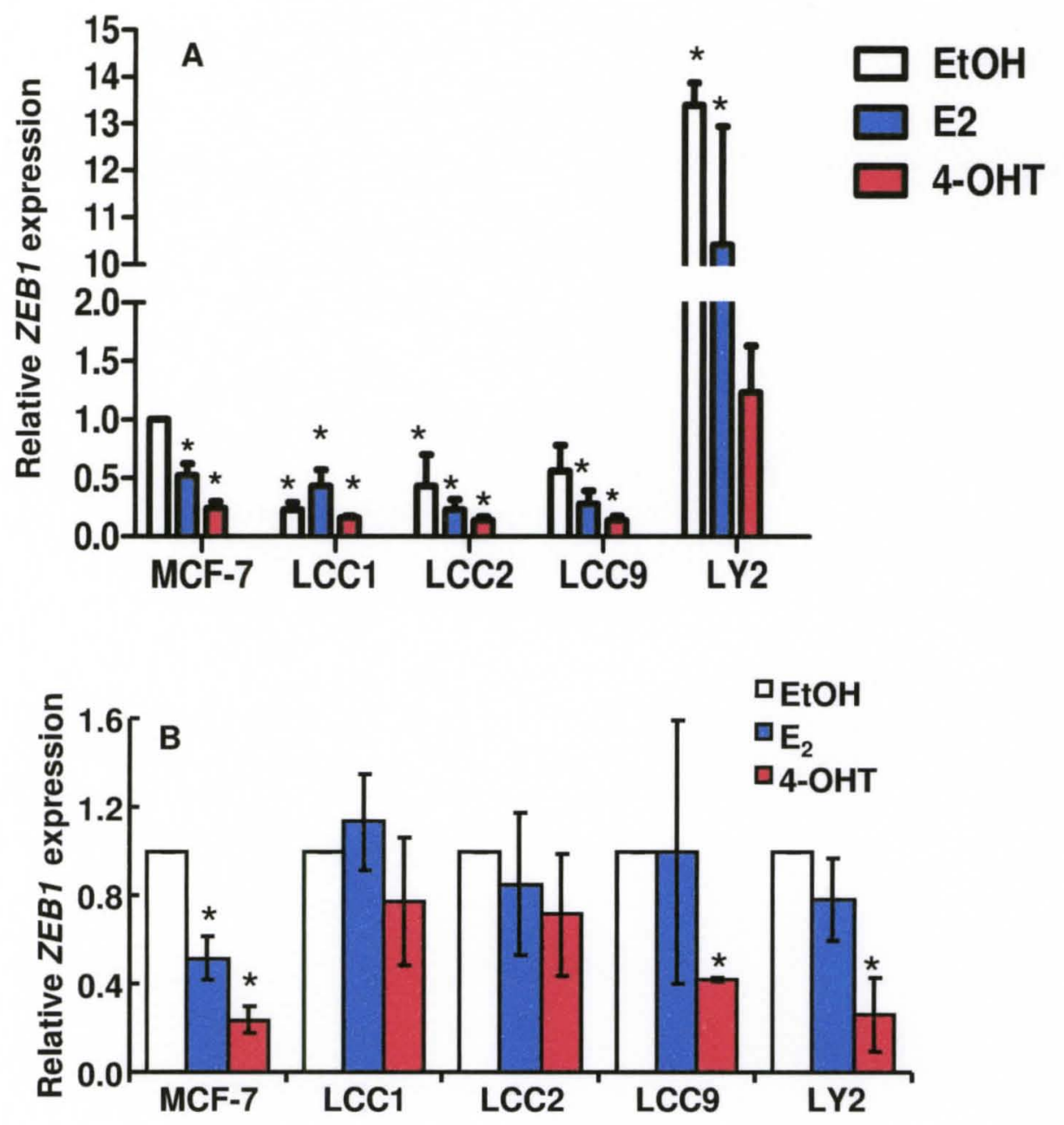


\section{Overexpression of miR-200b or miR-200c in LY2 cells enhanced their sensitivity to 4-OHT or fulvestrant}

To examine if expression of miR-200 family members affects sensitivity of endocrine-resistant LY2 cells to antiestrogens, cells were transiently transfected with precursors for miR-200a, miR-200b and miR-200c and MTT cell viability assays were performed in cells treated with vehicle control, 4-OHT, or fulvestrant for 6 days. Increased miR-200a, miR-200b and miR-200c expression was confirmed by Q-PCR even 7 days after transfection (Figure 15A). Treatment of nontransfected or control miRNA-transfected LY2 cells with 4-OHT or fulvestrant had no effect on cell viability (Figure 16A). LY2 cell viability was unaffected by overexpression of miR200a regardless of treatment (Figure 16A). Overexpression of miR-200b increased LY2 cell sensitivity to inhibition by 4-OHT and fulvestrant. Overexpression of miR200c reduced basal LY2 viability and fulvestrant, but not 4-OHT, further inhibited LY2 viability.

To determine if a shorter time of pre-miR-200b and pre-miR-200c transfection increases sensitivity of LY2 cells to inhibition by 4-OHT and fulvestrant, cells were transfected with pre-miR-200b or pre-miR-200c for $24 \mathrm{~h}$ and then treated with higher concentrations of 4-OHT and fulvestrant for 4 days. Q-PCR confirmed miR-200b and

miR-200c overexpression in the transfected cells $5 \mathrm{~d}$ after transfection (Figure 15B). Notably the level of miR-200b was higher after $7 \mathrm{~d}$ than $5 \mathrm{~d}$. Cell viability assays demonstrated lower basal level of proliferation in cells overexpressing miR-200b or miR-200c regardless of treatment (Figure 16B). 
Figure 15: Overexpression of miR-200b or miR-200c in LY2 cells transfected with pre-miR-200b or pre-miR-200c or negative control. LY2 cells were transfected either with negative control or pre-miR-200a, pre-miR-200b or pre-miR200c. RNA was harvested at 5 or 7 days and Q-PCR performed to confirm overexpression of miR-200a, miR-200b or miR-200c. Values are the mean \pm SEM of triplicate determinations.
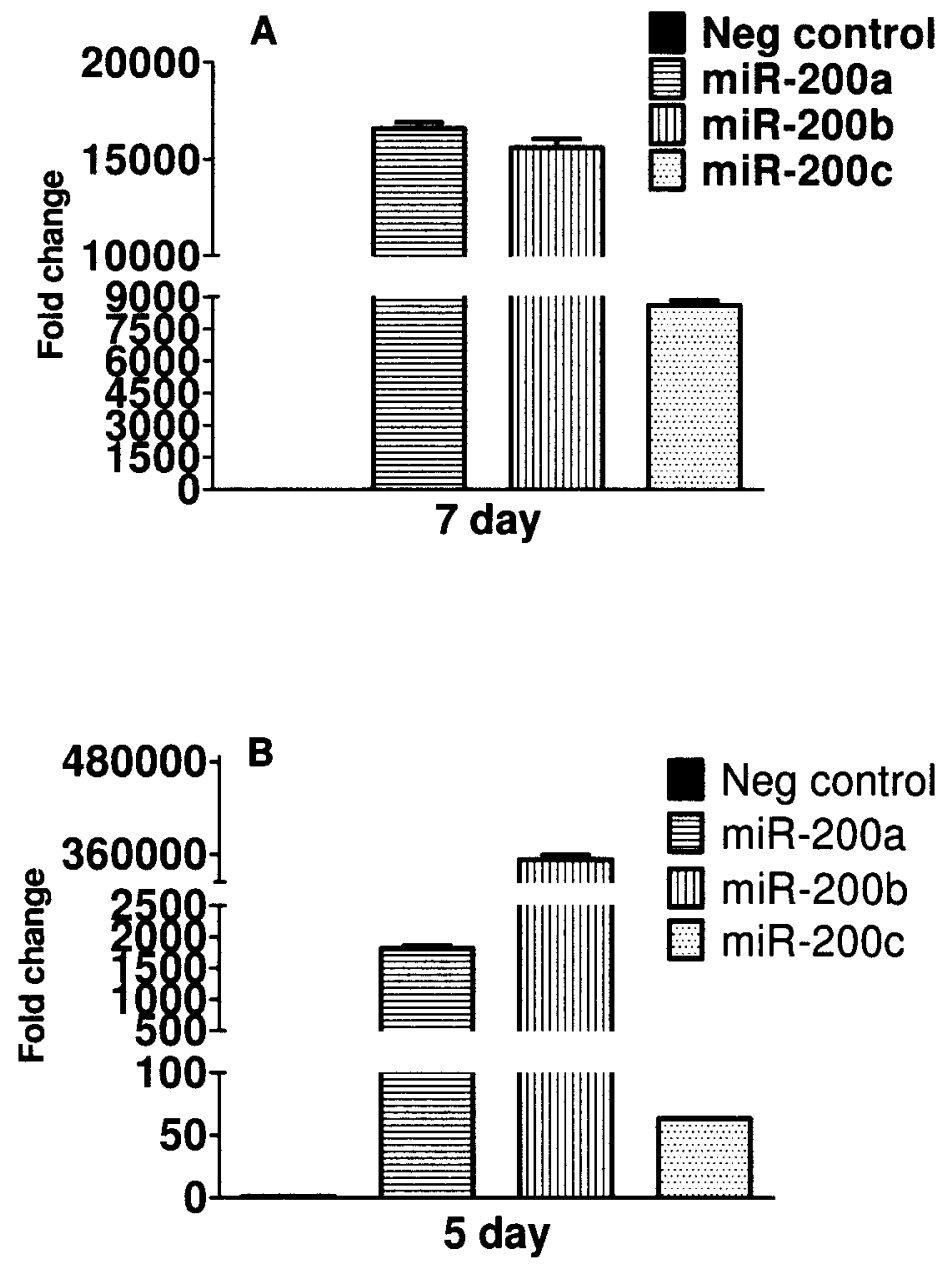
Figure 16: Overexpression of miR-200b or miR-200c restores sensitivity of LY2 cells to 4-OHT and fulvestrant. A. LY2 cells were either untransfected (No TF) transfected with negative control (Neg control) or pre-miR-200a, miR-200b or miR200c. 5 days post-transfection, cells were starved for $24 \mathrm{~h}$ and treated with $100 \mathrm{nM} 4$ OHT or $100 \mathrm{nM}$ fulvestrant for 6 days $* \mathrm{p}<0.05$ versus LY2 EtOH treated negative control. \# $\mathrm{p}<0.05$ versus $\mathrm{LY} 2 \mathrm{EtOH}$ treated for each miRNA. B. LY2 cells were either untransfected (No TF) or transfected with pre-miR-200b or miR-200c. 1 day post-transfection, cells were treated with $1 \mu \mathrm{M} 4-\mathrm{OHT}$ or $1 \mu \mathrm{M}$ fulvestrant for 4 days and MTT assays were performed. Values are the mean \pm SEM of 3 experiments. ${ }^{*} \mathrm{p}<0.05$ versus $\mathrm{LY} 2 \mathrm{EtOH}$ treated No TF.
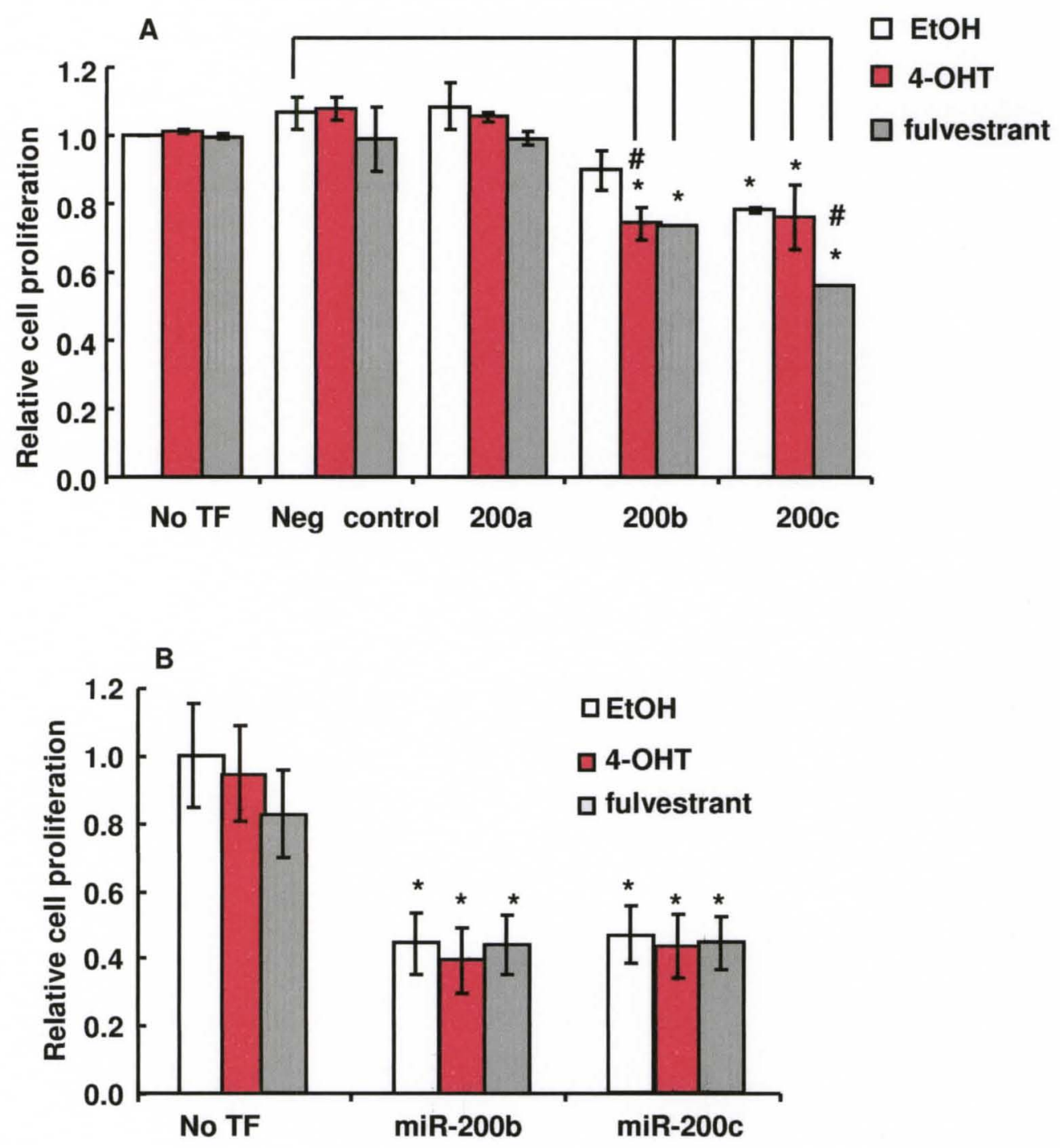
Converse experiments were performed using anti-miRNA to knockdown the expression of miR-200b or miR-200c in MCF-7 cells (Figure 17A and B). Surprisingly, knockdown of miR-200b and miR-200c reduced basal MCF-7 cell viability. However, there was no change in the sensitivity of cells to $100 \mathrm{nM} 4-\mathrm{OHT}$ or fulvestrant after knockdown of miR-200b or miR-200c (Figure 17C) in MCF-7 cells, indicating that other factors also contribute to the sensitivity of breast cancer cells to antiestrogens.

\section{Overexpression of miR-200b or miR-200c changes morphology of LY2 cells to a 'cobblestone' shaped appearance}

Overexpression of miR-200b and miR-200c (Appendix 8A) altered LY2 cell morphology (Figure 18). LY2 cells showed a change from an elongated to a more epithelial or 'cobble-stone' shaped appearance (Figure 18C and D). Overexpression of miR-200a had no effect on LY2 cell appearance, in agreement with the lack of effect of miR-200a on cell viability (Figure 18B). Overexpression of a control miRNA had no effect on cell appearance (Appendix 8B). Previous studies have reported the reversal of EMT in MDA-MB-231 breast cancer cells with miR-200c overexpression of [347]. These results are in agreement with my study and indicates that LY2 cells undergo change in morphology upon overexpression of miR-200b or miR-200c. 
Figure 17: Knockdown of miR-200b or miR-200c does not promote resistance of MCF-7 to 4-OHT or fulvestrant.

MCF-7 cells were either transfected with anti-miR -200b or anti-miR-200c. 1 day post-transfection, cells were treated with $100 \mathrm{nM} 4-\mathrm{OHT}$ or $100 \mathrm{nM}$ fulvestrant for 4 days and MTT assays were performed. Values are the mean \pm SEM of 3 experiments. $* \mathrm{P}<0.05$ versus EtOH treated (miR-200b). \# $\mathrm{p}<0.05$ versus EtOH treated (miR-200c)

A
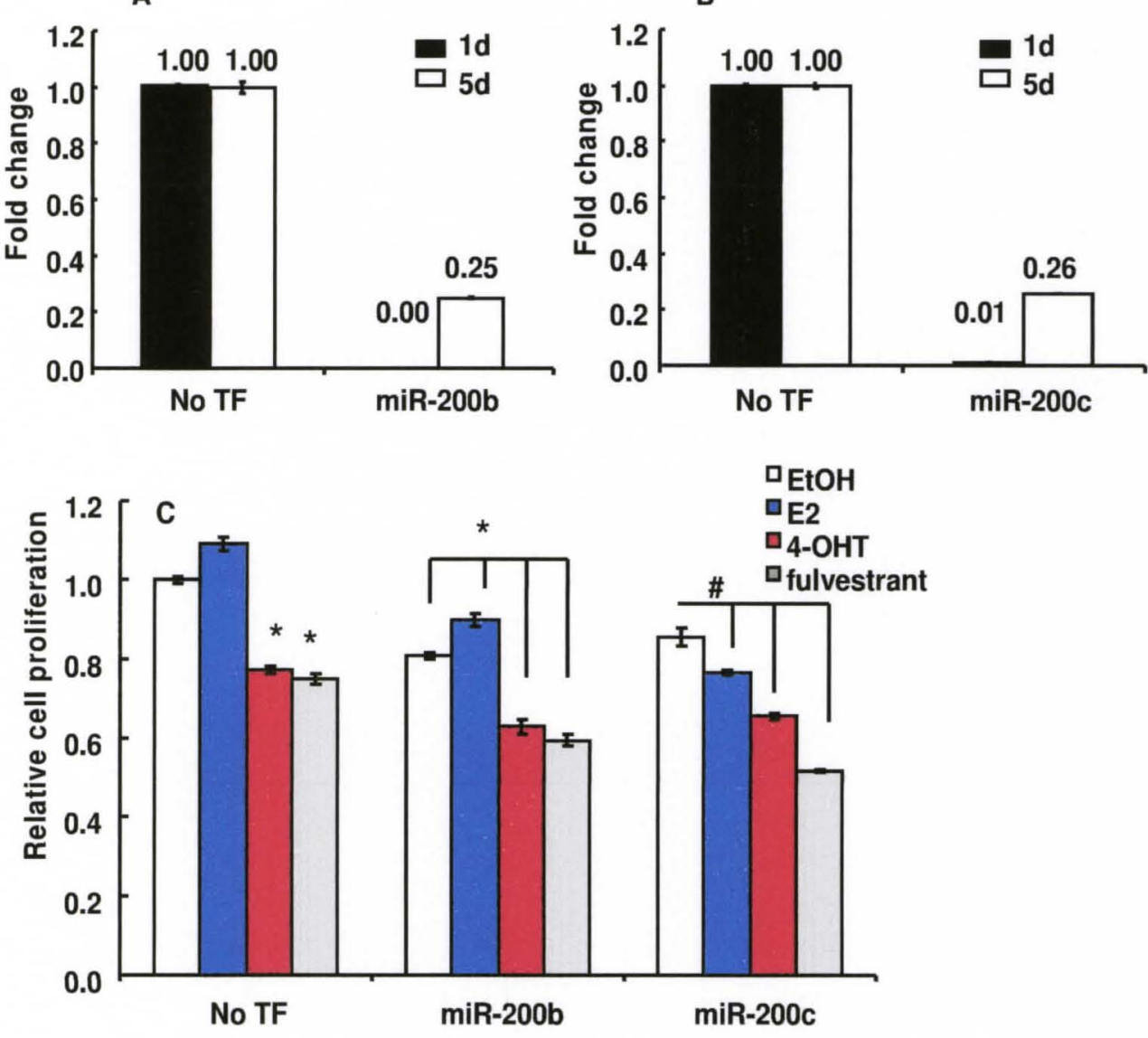
To confirm if the observed change in morphology of LY2 cells was due to reduced expression of mesenchymal markers, vimentin protein was examined in cells expressing transfected with miR-200b or miR-200c. Overexpression of miR-200b or miR-200c in LY2 cells did not induce MET (mesenchymal- to - epithelial transition) as indicated by unaltered vimentin or E-cadherin expression in cells transfected with miR-200b or miR-200c (Figure 18E). However, there was a decrease in ZEB1 mRNA in cells transiently overexpressiong miR-200a, miR-200b or miR-200c (Figure 18F). These results indicate that factors other than the reduction of miR-200b and miR-200c contribute to EMT in LY2 cells. 
Figure 18: Overexpression of miR-200 family changes morphology of LY2 cells. LY2 cells were transfected with pre-miR-200a, or pre-miR-200b or pre-miR-200c for 3 days. A-D. Images of LY2 cells captured using a digital microscope (20x magnification, bar-100 $\mu \mathrm{m}$ scale). E. Expression of vimentin protein in cells expressing miR-200a, miR-200b or miR-200c. Images and Western blots are representative of 3 separate experiments. F. Expression of ZEB1 mRNA in LY2 cells expressing miR-200a, miR-200b or miR-200c or negative control. Results are the mean \pm SEM of two separate experiments.

A. No transfection

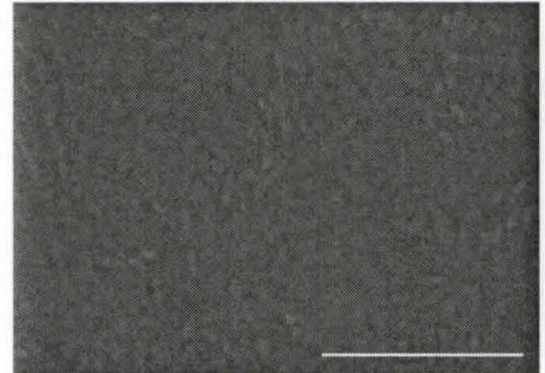

C. $\mathrm{miR}-200 \mathrm{~b}$

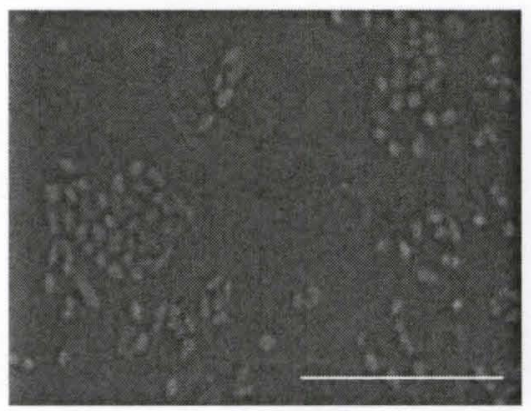

B. $\mathrm{miR}-200 \mathrm{a}$

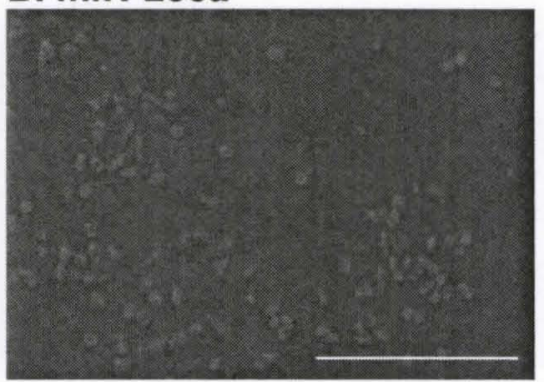

D. $\mathrm{miR}-200 \mathrm{c}$ 

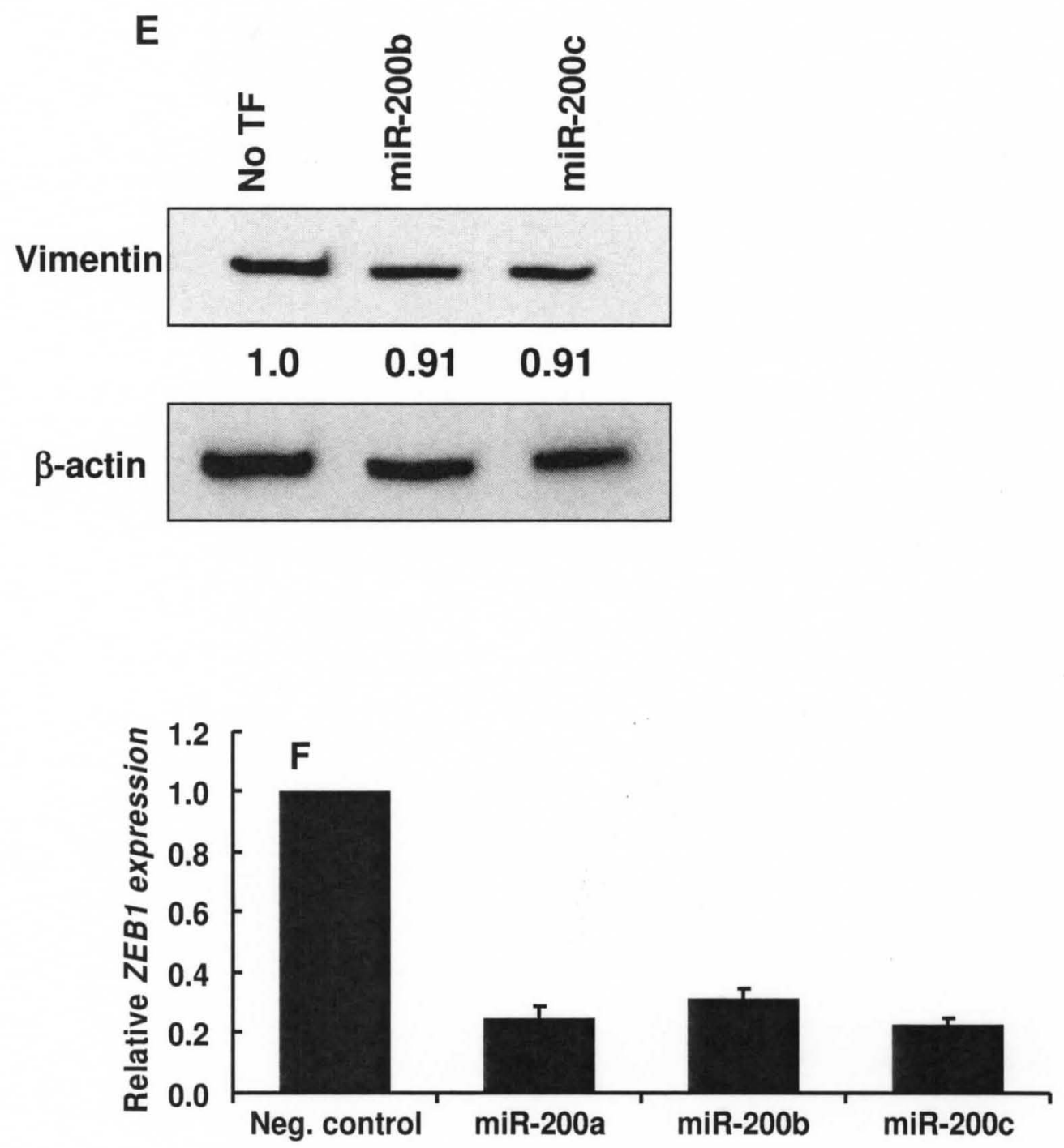
Inhibitors of deacetylation and methylation increase miR-200 family expression in $L Y 2$ cells

One possible mechanism responsible for reduced expression of miR-200 family members in LY2 cells could be DNA methylation or histone deacetylation. Previous studies have shown that the $\mathrm{CpG}$ island near the $\mathrm{miR}-200 \mathrm{c} / \mathrm{miR}-141$ transcription start site is methylated in fibroblasts and tumors cells that are miR-200c or miR-141-negative [350,351]. To determine if decreased expression of miR-200 family members in LY2 cells is due to epigenetic silencing, LY2 cells were treated with $2.5 \mu \mathrm{M} 5$-aza-dC alone in combination with $100 \mathrm{ng} / \mu \mathrm{l}$ trichostatin A (TSA), a histone deacetylase (HDAC) inhibitor for $72 \mathrm{~h}$. TSA was added in the last $16 \mathrm{~h}$ of the treatment period [352]. $2.5 \mu \mathrm{M} 5-\mathrm{aza}-\mathrm{dC}$ and TSA increased the expression of miR200b and miR-200c in LY2 cells (Figure 19A and B). Concomitant with the increased expression of $\mathrm{miR}-200 \mathrm{~b}$ and $\mathrm{miR}-200 \mathrm{c}$, there was a decrease in expression of its target, ZEB1 mRNA upon combined treatment with $2.5 \mu \mathrm{M}$ 5-aza-dC and TSA (Figure 19C). To determine if the observed decrease in ZEB1 mRNA level is due to a direct effect of the inhibitors, MCF-7 cells were treated with $2.5 \mu \mathrm{M}$ 5-aza-dC alone or in combination with $100 \mathrm{ng} / \mu \mathrm{l} \mathrm{TSA}$. Combined treatment with 5-aza-dC and TSA did not alter the expression of ZEB1 in MCF-7 cells (Figure 19F). However, it increased the expression of miR-200b and miR-200c in MCF-7 cells (Figure 19D and E). 
Figure 19: 5-aza-dC and TSA co-administration results in an increase in miR200b and miR-200c expression, and a concomitant decrease in ZEB1 mRNA in LY2 cells. A-C. LY2 cells were treated with $2.5 \mu \mathrm{M} 5$-aza-dCA in combination with $100 \mathrm{ng} / \mu \mathrm{l}$ TSA for $72 \mathrm{~h}$. TSA was added only during the last $16 \mathrm{~h}$ of treatment. QPCR was used to determine the fold change in the expression of miR-200b, or miR$200 \mathrm{c}$, or ZEB 1 mRNA. A an C are the mean \pm SEM of 2 separate experiments. $B$ is the mean of triplicate determinations in one experiment. D-F. MCF-7 cells were treated with $2.5 \mu \mathrm{M} 5$-aza-dCA alone or in combination with $100 \mathrm{ng} / \mu \mathrm{l}$ TSA for $72 \mathrm{~h}$. TSA was added only during the last $16 \mathrm{~h}$ of treatment. Q-PCR was used to determine the fold change in the expression of miR-200b, or miR-200c or ZEB1 mRNA. Values are the average of triplicate determinations in one experiment.
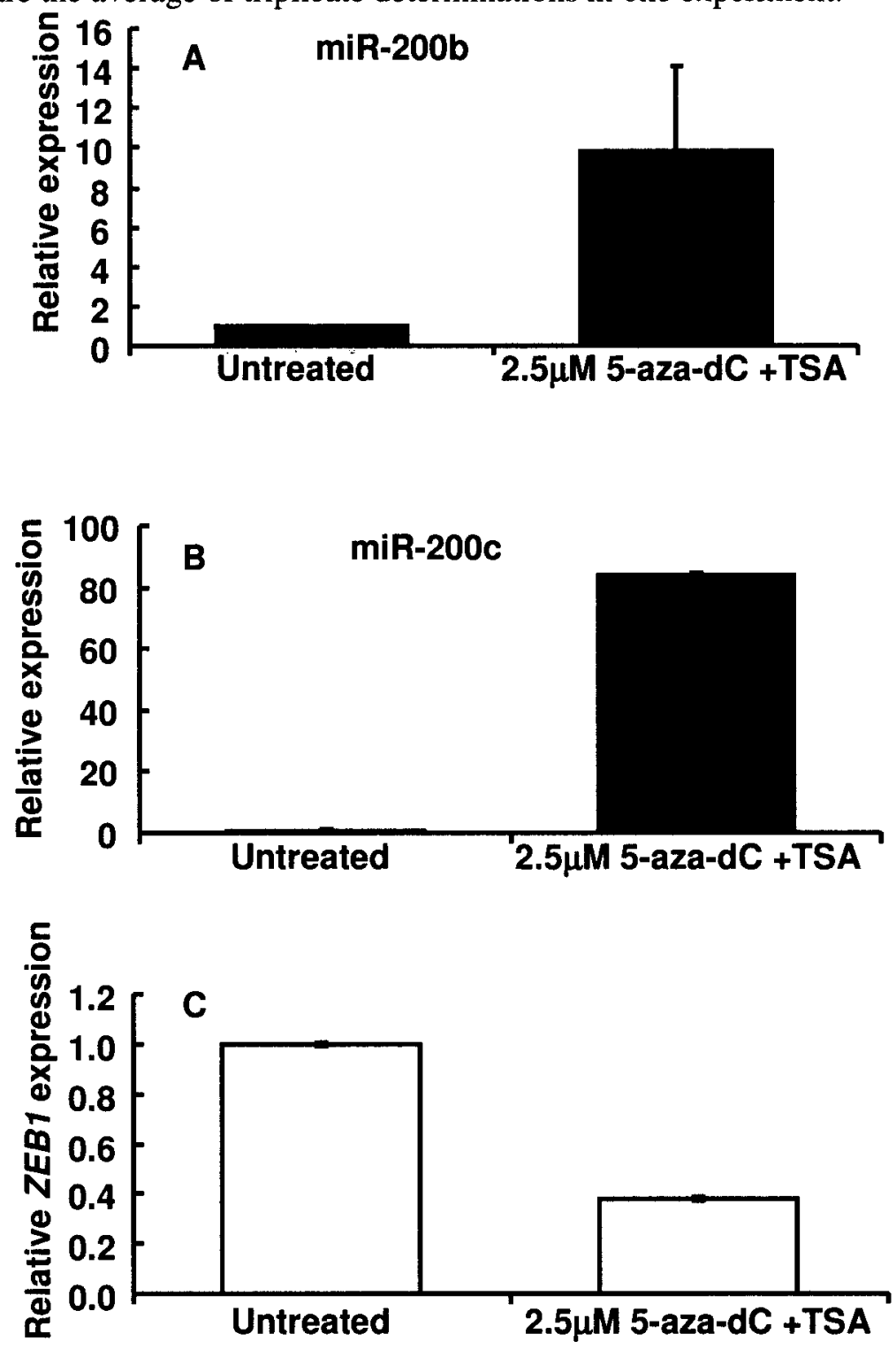
D
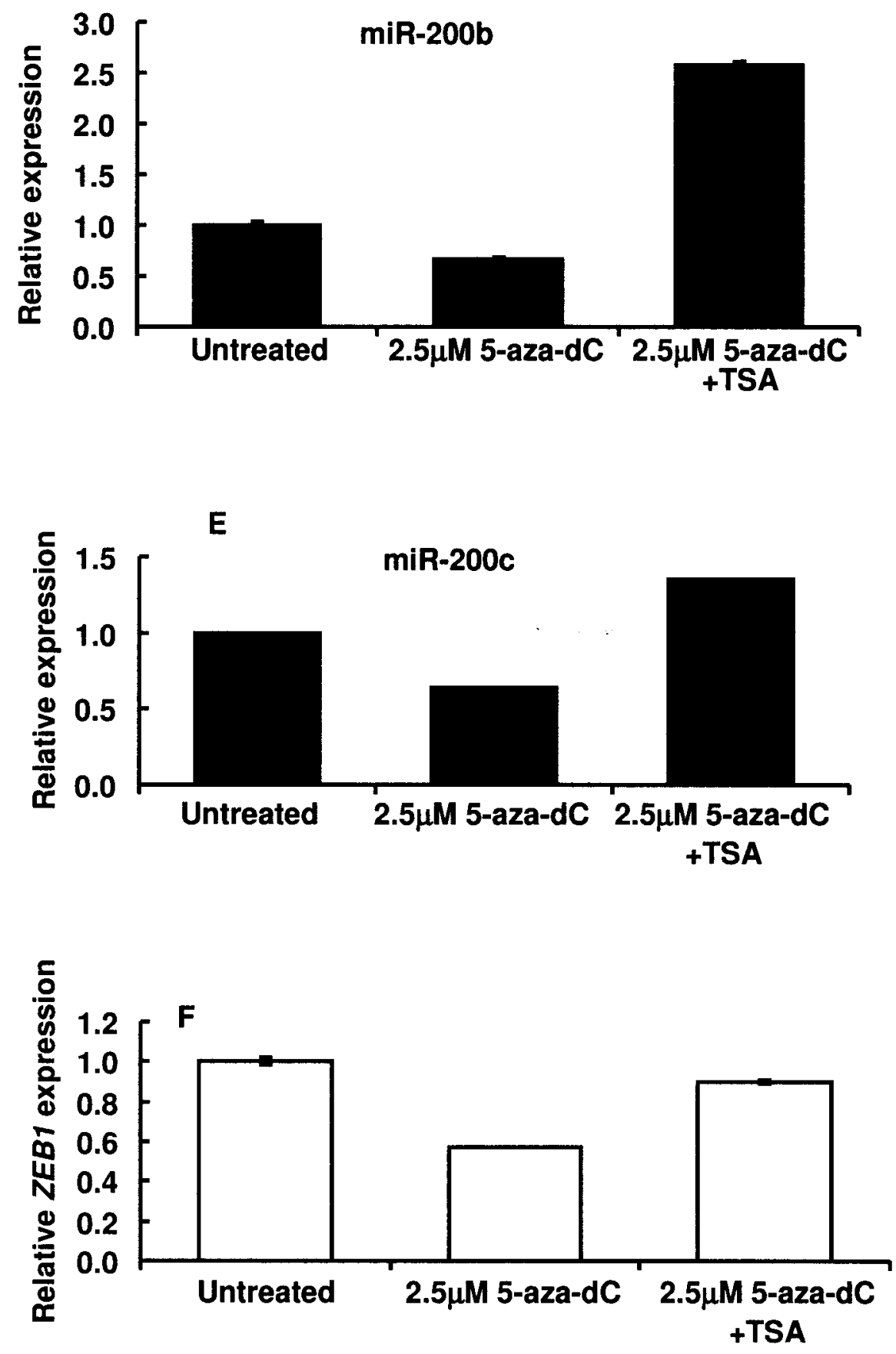


\section{DISCUSSION}

In this study I identified a novel role for miR-200b and $\mathrm{miR}-200 \mathrm{c}$ in modulating the sensitivity of endocrine-resistant LY2 cells to 4-OHT and fulvestrant in addition to the previously reported ability of these miRNAs to stimulate EMT. A progressive decrease in the expression of miR-200a, miR-200b, and miR-200c was detected in an MCF-7-derived cell line model of tamoxifen/endocrine resistance. The parental estrogen- dependent, endocrine-sensitive MCF-7 cells express all three miR200 family members. With the LCC2, LCC9, and LY2 cells derived for progressive tamoxifen and fulvestrant resistance, I observed a graded reduction in miR-200 family expression (Figure $12 \mathrm{~A}-\mathrm{C}$ ).

This is the first report demonstrating that overexpression of miR-200b and miR-200c enhanced the sensitivity of breast cancer cells to growth inhibition by antiestrogens 4-OHT and fulvestrant. Here I demonstrated that overexpression of miR-200b or miR-200c for 11 days increased sensitivity of LY2 cells to $100 \mathrm{nM} 4$ OHT and fulvestrant (Figure 16A). A shorter 5 day period of overexpression of miR200a and miR-200b reduced basal LY2 cell viability independent of antiestrogen treatment (Figure 16B). One possible explanation for these different results is lower levels of miR-200b and miR-200c in cells after longer periods of transfection. Hence the decrease in basal cell viability in the control treated cells may be due to higher miR-200b and miR-200c levels at earlier times after transfection. This result may explain why no additional inhibitory effect of 4-OHT on cell viability was detected.

A role for miR-200 family in drug resistance was reported in ovarian cancer [323]. Overexpression of miR-200c increased the sensitivity of ovarian cancer cells to a microtubule targeting drug Paclitaxel [323]. This was mediated by miR-200c targeting of a microtubule associated protein TUBB3. Overexpression of miR-200c 
reversed resistance of UMUC3 bladder cancer cells to anti-EGFR therapy [353]. Similarly gemcitabine-resistance in pancreatic cancer is associated with decreased miR-200 expression [354]. Resistance of pancreatic cancer cells to gemcitabine was reduced by treatment with natural compounds such curcumin, alone or in combination. This was accompanied by increased miR-200 expression $[353,355$ 357]. CDF, an analogue of curcumin was found to increase the sensitivity of pancreatic cancer cells to gemcitabine through inactivation of NFkB and COX-2 pathways which led to increased expression of miR-200b and miR-200c [356]. These studies show that miR-200 has a dual role in drug resistance.

Our results show that there is an inverse relationship between the expression of miR-200 family (miR-200a, miR-200b and miR-200c) and ZEB1 mRNA in LY2 cells. These data are in agreement with other reports showing an inverse correlation between miR-200 family and ZEB1 expression in basal-like, TNBC cells such as MDA-MB-231 and BT-549 cell lines [203,205,345,347].

LY2 cells overexpressing miR-200b or miR-200c showed a change in morphology from a 'cobblestone' or mesenchymal phenotype to a spindle shaped or epithelial phenotype (Figure 18C and D). However cells expressing miR-200a did not show a change in morphology or change in sensitivity to antiestrogens (Figure 16A and 18B). miR-200b and miR-200c share the same seed sequence [206]. The similarity in effects of these miRNAs can be attributed to this identical seed sequence of miR-200b and miR-200c. These results indicate a novel role for miR-200b and miR-200c in cellular morphology and response to 4-OHT and fulvestrant. Other studies have observed a reversal of EMT in aggressive breast cancer cell lines transfected with miR-200c or miR-141 [203,205,346,347]. For example, overexpression of miR-200b and miR-200c reverted EMT in mesenchymal breast 
cancer cell lines MDA-MB-231 and BT-549 by repressing the transcription and translation of transcription factors ZEB1 and ZEB2 [205,325]. Similar results were observed in miR-200b and miR-200b transfected MDCK- Paz (Madin-Darby canine kidney cells) [203]. Likewise, ectopic expression of miR-200c restored E-cadherin expression and reversed the mesenchymal phenotype in NMuMG (normal murine mammary epithelial cells) and 4TO7 breast carcinoma cell lines that had undergone EMT [346]. Our data showing a change in morphology of LY2 cells overexpressing miR-200b and miR-200c are in agreement with these observations, although we did not detect a reduction in vimentin or an increase in E-cadherin protein expression (data not shown).

One of the mechanisms for decreased miR-200 expression in LY2 cells could be due to epigenetic changes in the promoter, e.g., DNA methylation and histone deacetylation. $\mathrm{CpG}$ island methylation of $\mathrm{miR}-200 \mathrm{c} / \mathrm{miR}-141$ promoter has been previously reported in breast and prostate cancer cells $[350,351,358]$. Treatment of MDA-MB-231 and BT549 breast and PC3 prostate cancer cells with $3 \mu \mathrm{M}$ 5-aza-dC, an inhibitor of DNA methylation, increased miR-200c and miR-141 expression [350]. Analysis of histone modification by chromatin immunoprecipitation (ChIP) revealed dimethylation of Lysine 9 of histone H3 in miR-200c/miR-141-negative MDA-MB231 breast cancer cells, indicating repression of the miR-200c/miR-141 cluster. The data provided in this chapter agrees with these reports of epigenetic silencing of the miR-200 family. I demonstrated that treatment of LY2 cells with $2.5 \mu \mathrm{M} 5$-aza-dC in combination with TSA increased miR-200b and miR-200c expression when compared to untreated cells (Figure 19). There was a concomitant decrease in the expression of ZEBI mRNA. 
Previous studies have shown that endocrine resistance is accompanied by loss of cell-to-cell adhesion and EMT. Hiscox et al. showed that induction of EMT in MCF-7 breast cancer cells that are tamoxifen- resistant (TAM-R), is due to EGFR mediated phosphorylation and activation of the $\beta$-catenin pathway [340]. This promotes EMT and subsequently metastasis of cancer cells. Another study by the same group demonstrated that fulvestrant-resistant MCF-7 and T47D cells show enhanced migration and invasion due to overexpression of the c-Met receptor protein [359]. Further, elevated Src activity was also found to contribute to the invasive phenotype of TAM-R MCF-7 cells [360]. A recent study shows that prolonged mammosphere culture of MCF-7 cells makes them metastatic as well as resistant to tamoxifen [361]. Induction of Snail 1 transcription factor promotes EMT in MCF-7 TAM-R cells by downregulation of the epithelial marker E-cadherin [341]. This effect was seen upon overexpression of a peptidyl-prolyl isomerase Pin 1 which, in turn, activates GSK-3 $\beta$ or NFkB. These reports indicate a link between aberrant activation of signaling pathways such as NFKB to EMT and endocrine resistance. However, there is only one report of miRNA regulation of both EMT and endocrineresistance in breast cancer cells [343]. That study showed that overexpression of miR375 increased sensitivity of TAM-R MCF-7 cells to treatment with TAM by decreasing the expression of Metadherin (MTDH). My identification of reduced miR200 expression as a marker of endocrine resistance of breast cancer cells is a novel finding.

Although miR-200 is considered as a tumor suppressor miRNA, there are some reports of its role as an oncogene. There are many reports of miR-200 family expression as a marker of poor prognosis and chemoresistance in ovarian cancer [362364]. Contrary to the expected decrease in miR-200 expression in metastatic cells, 
Dykxhoorn et al. observed high levels of miR-200b and miR-200c in 4T1 metastatic mouse mammary tumor cells [365]. In concordance, 4T1 cells showed low ZEB1 and high E-cadherin expression. These results indicate that $\mathrm{mR}-200$ has a dual pattern of expression, i.e., it suppresses EMT while it promotes metastatic colonization after cells have invaded a distant site. Further, Korpal et al. reported pro-metastatic effects of miR-200 in a mouse model of breast cancer metastasis [366]. miR-200 was found to target $\operatorname{Sec} 23 \mathrm{a}$, a suppressor of metastasis that regulates the cell-secretome. These studies shed light on the dual role of miR-200 depending on the cell context.

In summary, the results presented in this chapter reveal a novel role for the loss of miR-200b and miR-200c in contributing to the loss of antiestrogen sensitivity in endocrine resistant breast cells. Of course, additional factors are also involved. Although most studies have identified a role for miR-200 as a suppressor of EMT, my studies provide new evidence (Fig.16A) to show miR-200 as a suppressor of endocrine resistance in breast cancer cells. Future experiments are needed to assess the dual role of $\mathrm{miR}-200 \mathrm{~b}$ and $\mathrm{miR}-200 \mathrm{c}$ in cancer progression so that appropriate targets can be used for targeted therapy. This would enable the use of this miRNA as a marker of endocrine-resistant breast cancer. 
Figure 20: Proposed model of miR-200 function in endocrine-resistant breast cancer. In endocrine-sensitive breast cancer, miR-200 suppresses ZEB 1 expression and promotes an epithelial phenotype. Decreased expression of miR-200 family in endocrine-resistant breast cancer is a result of DNA methylation, and results in increased ZEB1 expression and a change in morphology of cells from an epithelial to a mesenchymal appearance.
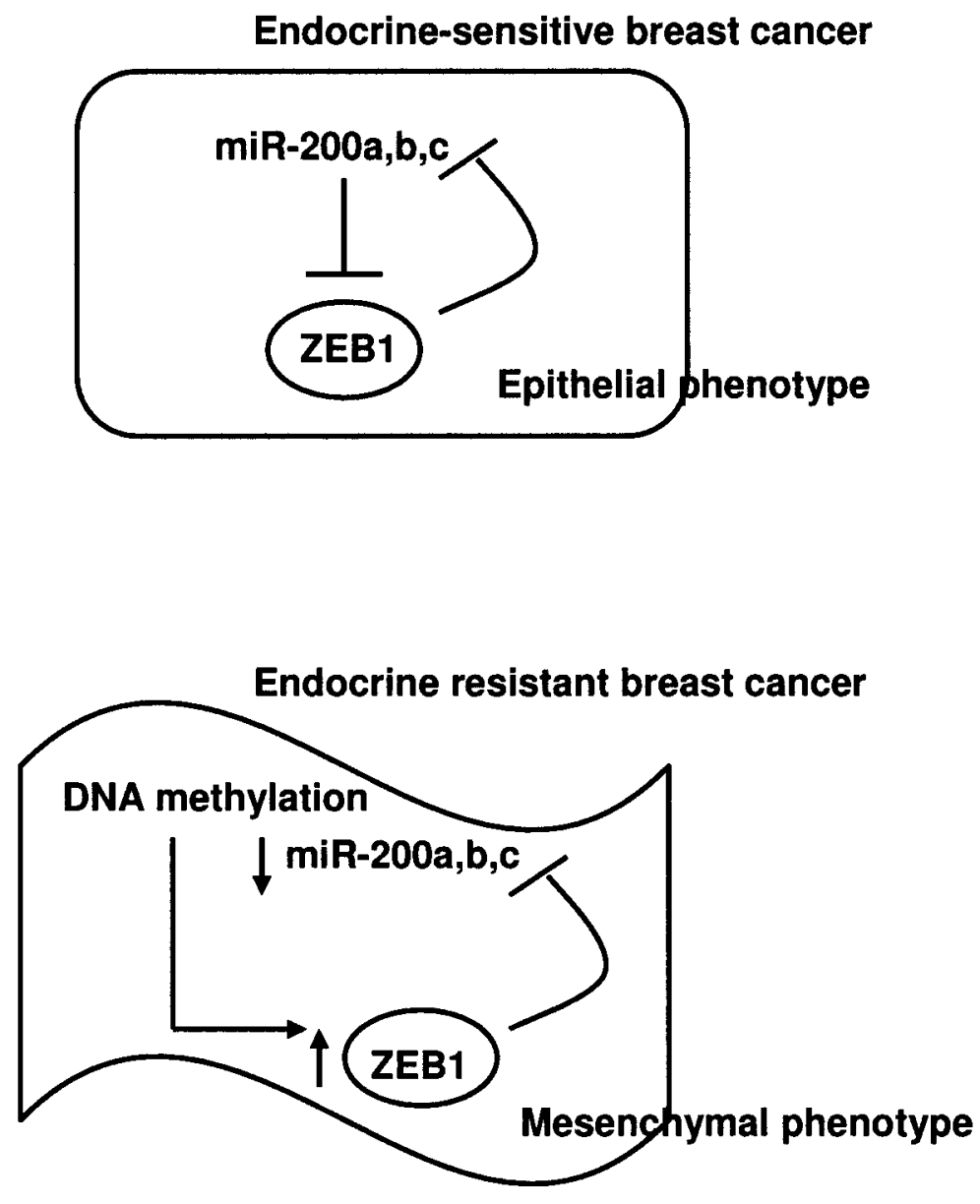


\section{CHAPTER V: RESEARCH IMPLICATIONS}

Adjuvant endocrine therapy is widely used in the treatment of premenopausal and postmenopausal women with ER-positive breast cancer. It involves the use of SERMs, e.g., TAM, Raloxifene, and pure antiestrogens, e.g., fulvestrant, that interfere with estrogen receptor function [248,367]. However, about $40 \%$ of women who receive adjuvant hormonal therapy acquire endocrine resistance [56]. Aberrant activation of growth factor signaling pathways, such as the EGFR, and the mutant EGFR (Her2), and altered expression of co-regulators are some of the mechanisms involved in endocrine resistance [368]. However, the complexity of endocrine resistance remains to be fully elucidated. My dissertation focused on identifying miRNAs that are aberrantly expressed in endocrine-resistant breast cancer. Deregulated expression of miRNAs has been reported in a number of cancers and these small RNAs are becoming increasingly important players affecting different signaling pathways [262]. By identifying miRNAs that are dysregulated in endocrineresistant breast cancer, it is possible to test their use as markers of resistance.

One major finding of my study is that there is an opposite pattern of expression of miRNAs in antiestrogen-sensitive MCF-7 vs. -resistant LY2 cells. In Chapter III, I identified $97 \mathrm{miRNAs}$ that are significantly differentially expressed in MCF-7 and LY2 cells. This is a significant finding as it shows that acquisition of endocrine resistance is associated with altered miRNA signature. Results from this chapter are important as this is one of the few studies that have profiled miRNAs in endocrine-resistant breast cancer cells. 
My study identified reliable endogenous control genes (ECGs) for normalization of miRNA Q-PCR data. Identification of an ideal ECG for normalization of gene expression data has remained a challenge for years. Ideally, a good ECG expression is one whose expression is independent of treatment condition and cell types. I demonstrated that the most commonly used ECGs, i.e., snoRNAs such as RNU6-1, vary in expression with 4-OHT treatment in MCF-7 and LY2 cells. SNORD38D, 5SrRNA and SNORD48 were identified as good ECGs as they showed the least variation with 4-OHT treatment. They also exhibited a consistent pattern of expression in MCF-7 and LY2 cells (Figure 4). My study shows the importance of the use of multiple ECGs to validate Q-PCR data. This is critical in miRNA gene analysis as the use of an inconsistent ECG leads to bias in results.

Regulation of miRNA expression by the ER has been studied by very few groups $[158,159,162,163]$. As indicated by results in Chapter III, ICI studies demonstrated that the expression of miR-10a, miR-21, miR-22, miR-200a, miR-221 and miR-222 are ER-mediated in MCF-7 cells (Figure 5B and C). ICI treatment alone relieved the basal expression of these miRNAs, indicating that ER normally suppresses their expression in MCF-7 cells. There are reports of ER $\alpha$ being a target of the miR-22 and miR-221/222 family $[231,234]$. Increased expression of miR221/222 has also been reported in TAM- and fulvestrant- resistant breast cancer [283,369]. Higher expression of miR-221/222 family and lower expression of ER $\alpha$ in LY2 cells compared to MCF-7 cells agree with these reports. More studies are required to determine if $E R \alpha$ or $E R \beta$ are involved in the expression of the miRNAs identified in Chapter III.

One important finding in my study is that there is a variable pattern of miRNA expression at different time points. 4-OHT increased the expression of miRNAs after 
$6 \mathrm{~h}$ of treatment (Figure 6). There was a corresponding increase in ER $\alpha$ protein levels after $6 \mathrm{~h}$ of 4-OHT treatment, further implying that the expression of miRNAs could be ER-mediated.

Bioinformatic analysis identified 36 putative mRNA targets of the 12 miRNAs that were analyzed in Aim 1 (Figure 8). Expression of PDCD4, BCL2, CYPIB1, $E S R I$ and $E R B B 3$ was validated at the mRNA and protein level. Although there was agreement in the direction of expression of specific miRNAs and their putative targets, discrepancy was seen in the expression of PDCD4 and BCL2 protein in LY2 cells. Contrary to the expected increase in PDCD4 and BCL2 protein with lower miR-21 in LY2 cells, there was undetectable PDCD4 and BCL2 protein in LY2 cells. It is likely that these genes are under regulation by other miRNAs or other mechanisms such as epigenetic modification. Additionally, there are reports of phosphorylation of PDCD4 by Akt and S6K1 leading to its proteasomal degradation in HEK293 cells [370,371].

In Chapter IV, I report lower expression of miR-200 family members as cells progress towards endocrine-resistance (Figure 12). The role of miR-200 in drug resistance in ovarian, bladder and pancreatic cancer has been studied $[323,353,355]$; however, there are no reports of its role in antiestrogen-resistant breast cancer. An interesting discovery in Chapter IV of my dissertation is that restoring miR-200 family members, miR-200b and miR-200c increased sensitivity of LY2 cells to inhibition by TAM and fulvestrant treatment (Figure 16A). These data imply that miR-200 contributes to endocrine-sensitivity of LY2 cells. However, the converse experiment (Figure 17) using antisense to miR-200b and miR-200c in MCF-7 cells did not make them resistant to TAM or fulvestrant. This implies that miR-200 is just 
one of the players in the complex network of genes and pathways associated with endocrine resistance.

Overexpression of miR-200 changed morphology of LY2 cells from an elongated, mesenchymal to an epithelial appearance. This agrees with previous reports of the ability of miR-200 to reverse EMT in TNBC cells such as MDA-MB231 and BT-549 [205,345,347]. It was intriguing to find that LY2 cells did not undergo MET when transfected with miR-200a, miR-200b or miR-200c as there was no decrease in expression of the mesenchymal marker, vimentin, nor an increase in epithelial marker, E-cadherin. Perhaps there are other factors in addition to miR-200 overexpression that are required to induce MET in LY2 cells. Previous studies have shown that ER $\alpha$ inhibits EMT by suppressing the expression of transcription factors such as SLUG and Snail 1 [372-375]. LY2 cells have lower ER $\alpha$ when compared to MCF-7 cells (Figure 4F). Future studies could determine if restoration of ER $\alpha$ induces MET and restore sensitivity of LY2 cells to treatment with 4-OHT and fulvestrant.

Although most studies have focused on the role of miR-200 as a tumor suppressor, there are a few reports of miR-200 as an oncogene promoting mestastasis in breast cancer. Pro-metastatic effects of miR-200 family have been reported in an animal model of lung metastasis [366]. This would be a major drawback in the use of miR-200 as therapy to restore endocrine-responsiveness in cells. The expression of miR-200 family in tumor samples of patients resistant to TAM or fulvestrant therapy remains to be tested. This would give a clear understanding of the pattern of expression of this miRNA and for its use in therapy.

Overall, this study contributes to better understanding of miRNAs that are dysregulated in endocrine-resistant breast cancer. By analyzing the miRNA signature 
of breast cancer patients, it would be possible to determine if they are susceptible to developing resistance to these antiestrogens such as TAM and fulvestrant. This would be beneficial in a timely and effective treatment of patients with endocrineresistant breast cancer. My study on miR-200 family provides a novel link between miRNA regulation of EMT and endocrine-resistant breast cancer. Finally, my study demonstrates that miR-200 is a significant contributor of sensitivity to antiestrogen therapy. By elucidating the exact mechanism involved in regulation of miR-200 expression, this could be an attractive target to restore TAM-responsiveness in cells. 


\section{REFERENCES}

1. Ademuyiwa FO, Edge SB, Erwin DO, Orom H, Ambrosone CB, et al. (2011) Breast Cancer Racial Disparities: Unanswered Questions. Cancer Research 71: 640644.

2. Jemal A, Bray F, Center MM, Ferlay J, Ward E, et al. (2011) Global cancer statistics. CA: A Cancer Journal for Clinicians 61: 69-90.

3. McDonnell DP, Norris JD (2002) Connections and regulation of the human estrogen receptor. Science 296: 1642-1644.

4. McDonnell DP (1999) The Molecular Pharmacology of SERMs. Trends Endocrinol Metab 10: 301-311.

5. Hall JM, Couse JF, Korach KS (2001) The Multifaceted Mechanisms of Estradiol and Estrogen Receptor Signaling. Journal of Biological Chemistry 276: 36869-36872.

6. Klinge CM (2001) Estrogen receptor interaction with estrogen response elements. Nucleic Acids Res 29: 2905-2919.

7. Mattingly KA, Ivanova MM, Riggs KA, Wickramasinghe NS, Barch MJ, et al. (2008) Estradiol stimulates transcription of nuclear respiratory factor-1 and increases mitochondrial biogenesis. Mol Endocrinol 22: 609-622.

8. Revankar CM, Cimino DF, Sklar LA, Arterburn JB, Prossnitz ER (2005) A transmembrane intracellular estrogen receptor mediates rapid cell signaling. Science 307: 1625-1630.

9. Zivadinovic D, Watson CS (2005) Membrane estrogen receptor-alpha levels predict estrogen-induced ERK1/2 activation in MCF-7 cells. Breast Cancer Res 7: R130-144.

10. Watson CS, Gametchu B (1999) Membrane-initiated steroid actions and the proteins that mediate them. Proc Soc Exp Biol Med 220: 9-19.

11. Filardo EJ, Thomas P (2005) GPR30: a seven-transmembrane-spanning estrogen receptor that triggers EGF release. Trends Endocrinol Metab 16: 362-367.

12. Thomas P, Pang Y, Filardo EJ, Dong J (2005) Identity of an estrogen membrane receptor coupled to a $G$ protein in human breast cancer cells. Endocrinology 146: 624632.

13. Filardo EJ, Quinn JA, Bland KI, Frackelton AR, Jr. (2000) Estrogen-induced activation of Erk-1 and Erk-2 requires the G protein-coupled receptor homolog, GPR30, and occurs via trans-activation of the epidermal growth factor receptor through release of HB-EGF. Mol Endocrinol 14: 1649-1660.

14. Ariazi EA, Ariazi JL, Cordera F, Jordan VC (2006) Estrogen receptors as therapeutic targets in breast cancer. Curr Top Med Chem 6: 181-202.

15. Wong CW, McNally C, Nickbarg E, Komm BS, Cheskis BJ (2002) Estrogen receptor-interacting protein that modulates its nongenomic activity-crosstalk with Src/Erk phosphorylation cascade. Proc Natl Acad Sci U S A 99: 14783-14788. 
16. Song RX, McPherson RA, Adam L, Bao Y, Shupnik M, et al. (2002) Linkage of rapid estrogen action to MAPK activation by ERalpha-Shc association and Shc pathway activation. Mol Endocrinol 16: 116-127.

17. Sun M, Paciga JE, Feldman RI, Yuan Z-q, Coppola D, et al. (2001) Phosphatidylinositol-3-OH Kinase (PI3K)/AKT2, Activated in Breast Cancer, Regulates and Is Induced by Estrogen Receptor $\alpha(\mathrm{ER} \alpha)$ via Interaction between ER $\alpha$ and PI3K. Cancer Research 61: 5985-5991.

18. Stoica GE, Franke TF, Moroni M, Mueller S, Morgan E, et al. (2003) Effect of estradiol on estrogen receptor-alpha gene expression and activity can be modulated by the ErbB2/PI 3-K/Akt pathway. Oncogene 22: 7998-8011.

19. Harper MJ, Walpole AL (1967) Mode of action of I.C.I. 46,474 in preventing implantation in rats. J Endocrinol 37: 83-92.

20. Harper MJ, Walpole AL (1966) Contrasting endocrine activities of cis and trans isomers in a series of substituted triphenylethylenes. Nature 212: 87.

21. Harper MJ, Walpole AL (1967) A new derivative of triphenylethylene: effect on implantation and mode of action in rats. J Reprod Fertil 13: 101-119.

22. Jordan VC (1976) Antiestrogenic and antitumor properties of tamoxifen in laboratory animals. Cancer Treat Rep 60: 1409-1419.

23. Jordan VC, Dowse LJ (1976) Tamoxifen as an anti-tumour agent: effect on oestrogen binding. J Endocrinol 68: 297-303.

24. Jordan VC, Dix CJ, Rowsby L, Prestwich G (1977) Studies on the mechanism of action of the nonsteroidal antioestrogen tamoxifen (I.C.I. 46,474) in the rat. Mol Cell Endocrinol 7: 177-192.

25. Jordan VC, Allen KE (1980) Evaluation of the antitumour activity of the nonsteroidal antioestrogen monohydroxytamoxifen in the DMBA-induced rat mammary carcinoma model. Eur J Cancer 16: 239-251.

26. Cole MP, Jones CT, Todd ID (1971) A new anti-oestrogenic agent in late breast cancer. An early clinical appraisal of ICI46474. Br J Cancer 25: 270-275.

27. Jordan VC, Koerner S (1975) Tamoxifen (ICI 46,474) and the human carcinoma $8 \mathrm{~S}$ oestrogen receptor. Eur J Cancer 11: 205-206.

28. Jordan VC (2001) Selective Estrogen Receptor Modulation: A Personal Perspective. Cancer Res 61: 5683-5687.

29. Brauch H, Jordan VC (2009) Targeting of tamoxifen to enhance antitumour action for the treatment and prevention of breast cancer: The 'personalised' approach? European Journal of Cancer 45: 2274-2283.

30. Jordan VC (1995) Tamoxifen: toxicities and drug resistance during the treatment and prevention of breast cancer. Annu Rev Pharmacol Toxicol 35: 195-211.

31. Ko SS, Jordan VC (2011) Treatment of osteoporosis and reduction in risk of invasive breast cancer in postmenopausal women with raloxifene. Expert Opin Pharmacother 12: 657-674. 
32. Barrett-Connor E, Mosca L, Collins P, Geiger MJ, Grady D, et al. (2006) Effects of raloxifene on cardiovascular events and breast cancer in postmenopausal women. $\mathrm{N}$ Engl J Med 355: 125-137.

33. Barrett-Connor E, Mosca L, Collins P, Geiger MJ, Grady D, et al. (2006) Effects of raloxifene on cardiovascular events and breast cancer in postmenopausal women. $\mathrm{N}$ Engl J Med 355: 125-137.

34. Vogel Vg Fau - Costantino JP, Costantino Jp Fau - Wickerham DL, Wickerham Dl Fau - Cronin WM, Cronin Wm Fau - Cecchini RS, Cecchini Rs Fau - Atkins JN, et al. Effects of tamoxifen vs raloxifene on the risk of developing invasive breast cancer and other disease outcomes: the NSABP Study of Tamoxifen and Raloxifene (STAR) P-2 trial.

35. Wijayaratne AL, McDonnell DP (2001) The human estrogen receptor-alpha is a ubiquitinated protein whose stability is affected differentially by agonists, antagonists, and selective estrogen receptor modulators. J Biol Chem 276: 35684-35692.

36. Johnston SR, Dowsett M (2003) Aromatase inhibitors for breast cancer: lessons from the laboratory. Nat Rev Cancer 3: 821-831.

37. E.R S (2003) Sources of estrogen and their importance. The Journal of Steroid Biochemistry and Molecular Biology 86: 225-230.

38. Chumsri S, Howes T, Bao T, Sabnis G, Brodie A (2011) Aromatase, aromatase inhibitors, and breast cancer. The Journal of Steroid Biochemistry and Molecular Biology 125: 13-22.

39. Santen RJ, Brodie H, Simpson ER, Siiteri PK, Brodie A (2009) History of aromatase: saga of an important biological mediator and therapeutic target. Endocr Rev 30: 343-375.

40. Harada N (1997) Aberrant expression of aromatase in breast cancer tissues. J Steroid Biochem Mol Biol 61: 175-184.

41. Winters L, Habin K, Gallagher J (2007) Aromatase inhibitors and musculoskeletal pain in patients with breast cancer. Clin J Oncol Nurs 11: 433-439.

42. Lin JH, Zhang SM, Manson JE (2011) Predicting adherence to tamoxifen for breast cancer adjuvant therapy and prevention. Cancer Prev Res (Phila) 4: 1360-1365.

43. Guarneri V, Conte PF (2004) The curability of breast cancer and the treatment of advanced disease. Eur J Nucl Med Mol Imaging 31 Suppl 1: S149-161.

44. Normanno N, Di Maio M, De Maio E, De Luca A, de Matteis A, et al. (2005) Mechanisms of endocrine resistance and novel therapeutic strategies in breast cancer. Endocr Relat Cancer 12: 721-747.

45. Roop RP, Ma CX (2012) Endocrine resistance in breast cancer: molecular pathways and rational development of targeted therapies. Future Oncol 8: 273-292.

46. Creighton CJ, Hilger AM, Murthy S, Rae JM, Chinnaiyan AM, et al. (2006) Activation of mitogen-activated protein kinase in estrogen receptor alpha-positive breast cancer cells in vitro induces an in vivo molecular phenotype of estrogen receptor alpha-negative human breast tumors. Cancer Res 66: 3903-3911.

47. Oh AS, Lorant LA, Holloway JN, Miller DL, Kern FG, et al. (2001) Hyperactivation of MAPK induces loss of ERalpha expression in breast cancer cells. Mol Endocrinol 15: 1344-1359. 
48. Yan L, Yang X, Davidson NE (2001) Role of DNA methylation and histone acetylation in steroid receptor expression in breast cancer. J Mammary Gland Biol Neoplasia 6: 183-192.

49. Stoner M, Saville B, Wormke M, Dean D, Burghardt R, et al. (2002) Hypoxia induces proteasome-dependent degradation of estrogen receptor alpha in ZR-75 breast cancer cells. Mol Endocrinol 16: 2231-2242.

50. Gutierrez MC, Detre S, Johnston S, Mohsin SK, Shou J, et al. (2005) Molecular Changes in Tamoxifen-Resistant Breast Cancer: Relationship Between Estrogen Receptor, HER-2, and p38 Mitogen-Activated Protein Kinase. Journal of Clinical Oncology 23: 2469-2476.

51. Shi L, Dong B, Li Z, Lu Y, Ouyang T, et al. (2009) Expression of ER- $\alpha 36$, a Novel Variant of Estrogen Receptor $\alpha$, and Resistance to Tamoxifen Treatment in Breast Cancer. Journal of Clinical Oncology 27: 3423-3429.

52. Klinge CM, Riggs KA, Wickramasinghe NS, Emberts CG, McConda DB, et al. (2010) Estrogen receptor alpha 46 is reduced in tamoxifen resistant breast cancer cells and re-expression inhibits cell proliferation and estrogen receptor alpha 66-regulated target gene transcription. Mol Cell Endocrinol 323: 268-276.

53. Clarke R, Liu MC, Bouker KB, Gu Z, Lee RY, et al. Antiestrogen resistance in breast cancer and the role of estrogen receptor signaling. Oncogene 22: 7316-7339.

54. Jordan VC, O'Malley BW (2007) Selective estrogen-receptor modulators and antihormonal resistance in breast cancer. J Clin Oncol 25: 5815-5824.

55. Ali S, Coombes RC (2002) Endocrine-responsive breast cancer and strategies for combating resistance. Nat Rev Cancer 2: 101-112.

56. Ring A, Dowsett M (2004) Mechanisms of tamoxifen resistance. Endocr Relat Cancer 11: 643-658.

57. Osborne CK, Bardou V, Hopp TA, Chamness GC, Hilsenbeck SG, et al. (2003) Role of the estrogen receptor coactivator AIB1 (SRC-3) and HER-2/neu in tamoxifen resistance in breast cancer. $\mathrm{J}$ Natl Cancer Inst 95: 353-361.

58. Lavinsky RM, Jepsen K, Heinzel T, Torchia J, Mullen TM, et al. (1998) Diverse signaling pathways modulate nuclear receptor recruitment of $\mathrm{N}-\mathrm{CoR}$ and SMRT complexes. Proc Natl Acad Sci U S A 95: 2920-2925.

59. Girault I, Lerebours F, Amarir S, Tozlu S, Tubiana-Hulin M, et al. (2003) Expression analysis of estrogen receptor alpha coregulators in breast carcinoma: evidence that NCOR 1 expression is predictive of the response to tamoxifen. Clin Cancer Res 9: 1259-1266.

60. Johnston SR, Lu B, Scott GK, Kushner PJ, Smith IE, et al. (1999) Increased activator protein-1 DNA binding and c-Jun NH2-terminal kinase activity in human breast tumors with acquired tamoxifen resistance. Clin Cancer Res 5: 251-256.

61. Schiff R, Reddy P, Ahotupa M, Coronado-Heinsohn E, Grim M, et al. (2000) Oxidative stress and AP-1 activity in tamoxifen-resistant breast tumors in vivo. J Natl Cancer Inst 92: 1926-1934.

62. Zhou Y, Yau C, Gray JW, Chew K, Dairkee SH, et al. (2007) Enhanced NF kappa $\mathrm{B}$ and AP-1 transcriptional activity associated with antiestrogen resistant breast cancer. BMC Cancer 7: 59. 
63. Paech K, Webb P, Kuiper GG, Nilsson S, Gustafsson J, et al. (1997) Differential ligand activation of estrogen receptors ERalpha and ERbeta at API sites. Science 277: 1508-1510.

64. Riggins RB, Schrecengost RS, Guerrero MS, Bouton AH (2007) Pathways to tamoxifen resistance. Cancer Lett 256: 1-24.

65. Gururaj AE, Rayala SK, Vadlamudi RK, Kumar R (2006) Novel mechanisms of resistance to endocrine therapy: genomic and nongenomic considerations. Clin Cancer Res 12: 1001s-1007s.

66. de Leeuw R, Neefjes J, Michalides R (2011) A role for estrogen receptor phosphorylation in the resistance to tamoxifen. Int J Breast Cancer 2011: 232435.

67. Chen D, Pace PE, Coombes RC, Ali S (1999) Phosphorylation of human estrogen receptor alpha by protein kinase A regulates dimerization. Mol Cell Biol 19: 10021015.

68. Kato S, Endoh H, Masuhiro Y, Kitamoto T, Uchiyama S, et al. (1995) Activation of the estrogen receptor through phosphorylation by mitogen-activated protein kinase. Science 270: 1491-1494.

69. Joel PB, Traish AM, Lannigan DA (1998) Estradiol-induced phosphorylation of serine 118 in the estrogen receptor is independent of $\mathrm{p} 42 / \mathrm{p} 44$ mitogen-activated protein kinase. J Biol Chem 273: 13317-13323.

70. Weitsman GE, Li L, Skliris GP, Davie JR, Ung K, et al. (2006) Estrogen receptoralpha phosphorylated at Ser118 is present at the promoters of estrogen-regulated genes and is not altered due to HER-2 overexpression. Cancer Res 66: 10162-10170.

71. Chen D, Riedl T, Washbrook E, Pace PE, Coombes RC, et al. (2000) Activation of estrogen receptor alpha by S118 phosphorylation involves a ligand-dependent interaction with TFIIH and participation of CDK7. Mol Cell 6: 127-137.

72. Likhite VS, Stossi F, Kim K, Katzenellenbogen BS, Katzenellenbogen JA (2006) Kinase-specific phosphorylation of the estrogen receptor changes receptor interactions with ligand, deoxyribonucleic acid, and coregulators associated with alterations in estrogen and tamoxifen activity. Mol Endocrinol 20: 3120-3132.

73. Cheng J, Zhang C, Shapiro DJ (2007) A functional serine 118 phosphorylation site in estrogen receptor-alpha is required for down-regulation of gene expression by 17beta-estradiol and 4-hydroxytamoxifen. Endocrinology 148: 4634-4641.

74. Michalides R, Griekspoor A, Balkenende A, Verwoerd D, Janssen L, et al. (2004) Tamoxifen resistance by a conformational arrest of the estrogen receptor alpha after PKA activation in breast cancer. Cancer Cell 5: 597-605.

75. Holm C, Kok M, Michalides R, Fles R, Koornstra RH, et al. (2009) Phosphorylation of the oestrogen receptor alpha at serine 305 and prediction of tamoxifen resistance in breast cancer. J Pathol 217: 372-379.

76. Bostner J, Skoog L, Fornander T, Nordenskjold B, Stal O (2010) Estrogen receptor-alpha phosphorylation at serine 305, nuclear p21-activated kinase 1 expression, and response to tamoxifen in postmenopausal breast cancer. Clin Cancer Res 16: 1624-1633. 
77. Wang RA, Mazumdar A, Vadlamudi RK, Kumar R (2002) P21-activated kinase-1 phosphorylates and transactivates estrogen receptor-alpha and promotes hyperplasia in mammary epithelium. EMBO J 21: 5437-5447.

78. Holm C, Rayala S, Jirstrom K, Stal O, Kumar R, et al. (2006) Association between Pakl expression and subcellular localization and tamoxifen resistance in breast cancer patients. J Natl Cancer Inst 98: 671-680.

79. Potapenko IO, Haakensen VD, Luders T, Helland A, Bukholm I, et al. (2010) Glycan gene expression signatures in normal and malignant breast tissue; possible role in diagnosis and progression. Mol Oncol 4: 98-118.

80. Jiang MS, Hart GW (1997) A subpopulation of estrogen receptors are modified by O-linked N-acetylglucosamine. J Biol Chem 272: 2421-2428.

81. Cheng X, Hart GW (2000) Glycosylation of the murine estrogen receptor-alpha. J Steroid Biochem Mol Biol 75: 147-158.

82. Fu M, Wang C, Zhang X, Pestell RG (2004) Acetylation of nuclear receptors in cellular growth and apoptosis. Biochem Pharmacol 68: 1199-1208.

83. Kim MY, Woo EM, Chong YT, Homenko DR, Kraus WL (2006) Acetylation of estrogen receptor alpha by p300 at lysines 266 and 268 enhances the deoxyribonucleic acid binding and transactivation activities of the receptor. Mol Endocrinol 20: 14791493.

84. Wang C, Fu M, Angeletti RH, Siconolfi-Baez L, Reutens AT, et al. (2001) Direct acetylation of the estrogen receptor alpha hinge region by $\mathrm{p} 300$ regulates transactivation and hormone sensitivity. J Biol Chem 276: 18375-18383.

85. Fuqua SA, Wiltschke C, Zhang QX, Borg A, Castles CG, et al. (2000) A hypersensitive estrogen receptor-alpha mutation in premalignant breast lesions. Cancer Res 60: 4026-4029.

86. Bettermann $\mathrm{K}$, Benesch $\mathrm{M}$, Weis S, Haybaeck J (2012) SUMOylation in carcinogenesis. Cancer Lett 316: 113-125.

87. Sentis S, Le Romancer M, Bianchin C, Rostan MC, Corbo L (2005) Sumoylation of the estrogen receptor alpha hinge region regulates its transcriptional activity. Mol Endocrinol 19: 2671-2684.

88. Dowsett M (2001) Overexpression of HER-2 as a resistance mechanism to hormonal therapy for breast cancer. Enđocr Relat Cancer 8: 191-195.

89. Pancholi S, Lykkesfeldt AE, Hilmi C, Banerjee S, Leary A, et al. (2008) ERBB2 influences the subcellular localization of the estrogen receptor in tamoxifen-resistant MCF-7 cells leading to the activation of AKT and RPS6KA2. Endocr Relat Cancer 15: 985-1002.

90. McClelland RA, Barrow D, Madden T-A, Dutkowski CM, Pamment J, et al. (2001) Enhanced Epidermal Growth Factor Receptor Signaling in MCF7 Breast Cancer Cells after Long-Term Culture in the Presence of the Pure Antiestrogen ICI 182,780 (Faslodex). Endocrinology 142: 2776-2788.

91. Knowlden JM, Hutcheson IR, Jones HE, Madden T, Gee JM, et al. (2003) Elevated levels of epidermal growth factor receptor/c-erbB2 heterodimers mediate an autocrine growth regulatory pathway in tamoxifen-resistant MCF-7 cells. Endocrinology 144: 1032-1044. 
92. Hutcheson IR, Knowlden JM, Madden TA, Barrow D, Gee JM, et al. (2003) Oestrogen receptor-mediated modulation of the EGFR/MAPK pathway in tamoxifenresistant MCF-7 cells. Breast Cancer Res Treat 81: 81-93.

93. Arpino G, Wiechmann L, Osborne CK, Schiff R (2008) Crosstalk between the estrogen receptor and the HER tyrosine kinase receptor family: molecular mechanism and clinical implications for endocrine therapy resistance. Endocr Rev 29: 217-233.

94. Kurokawa H, Lenferink AE, Simpson JF, Pisacane PI, Sliwkowski MX, et al. (2000) Inhibition of HER2/neu (erbB-2) and mitogen-activated protein kinases enhances tamoxifen action against HER2-overexpressing, tamoxifen-resistant breast cancer cells. Cancer Res 60: 5887-5894.

95. Pietras RJ, Arboleda J, Reese DM, Wongvipat N, Pegram MD, et al. (1995) HER2 tyrosine kinase pathway targets estrogen receptor and promotes hormoneindependent growth in human breast cancer cells. Oncogene 10: 2435-2446.

96. Kurokawa H, Arteaga CL (2003) ErbB (HER) receptors can abrogate antiestrogen action in human breast cancer by multiple signaling mechanisms. Clin Cancer Res 9: 511S-515S.

97. Caldon CE, Daly RJ, Sutherland RL, Musgrove EA (2006) Cell cycle control in breast cancer cells. J Cell Biochem 97: 261-274.

98. Cariou S, Donovan JC, Flanagan WM, Milic A, Bhattacharya N, et al. (2000) Down-regulation of $\mathrm{p} 21 \mathrm{WAF} 1 / \mathrm{CIP} 1$ or $\mathrm{p} 27 \mathrm{Kip} 1$ abrogates antiestrogen-mediated cell cycle arrest in human breast cancer cells. Proc Natl Acad Sci U S A 97: 9042-9046.

99. Prall OW, Rogan EM, Musgrove EA, Watts CK, Sutherland RL (1998) c-Myc or cyclin D1 mimics estrogen effects on cyclin E-Cdk2 activation and cell cycle reentry. Mol Cell Biol 18: 4499-4508.

100. Venditti M, Iwasiow B, Orr FW, Shiu RP (2002) C-myc gene expression alone is sufficient to confer resistance to antiestrogen in human breast cancer cells. Int $\mathbf{J}$ Cancer 99: 35-42.

101. Hui R, Finney GL, Carroll JS, Lee CS, Musgrove EA, et al. (2002) Constitutive overexpression of cyclin D1 but not cyclin E confers acute resistance to antiestrogens in T-47D breast cancer cells. Cancer Res 62: 6916-6923.

102. Bosco EE, Wang Y, Xu H, Zilfou JT, Knudsen KE, et al. (2007) The retinoblastoma tumor suppressor modifies the therapeutic response of breast cancer. $\mathrm{J}$ Clin Invest 117: 218-228.

103. Dubik D, Dembinski TC, Shiu RP (1987) Stimulation of c-myc oncogene expression associated with estrogen-induced proliferation of human breast cancer cells. Cancer Res 47: 6517-6521.

104. Butt AJ, Caldon CE, McNeil CM, Swarbrick A, Musgrove EA, et al. (2008) Cell cycle machinery: links with genesis and treatment of breast cancer. Adv Exp Med Biol 630: 189-205.

105. Hui R, Finney GL, Carroll JS, Lee CSL, Musgrove EA, et al. (2002) Constitutive Overexpression of Cyclin D1 but not Cyclin E Confers Acute Resistance to Antiestrogens in T-47D Breast Cancer Cells. Cancer Research 62: 6916-6923. 
106. Ishii Y, Waxman S, Germain D (2008) Tamoxifen stimulates the growth of cyclin D1-overexpressing breast cancer cells by promoting the activation of signal transducer and activator of transcription 3. Cancer Res 68: 852-860.

107. Butt AJ, McNeil CM, Musgrove EA, Sutherland RL (2005) Downstream targets of growth factor and oestrogen signalling and endocrine resistance: the potential roles of c-Myc, cyclin D1 and cyclin E. Endocr Relat Cancer 12 Suppl 1: S47-59.

108. Burkhart DL, Sage J (2008) Cellular mechanisms of tumour suppression by the retinoblastoma gene. Nat Rev Cancer 8: 671-682.

109. Varma H, Skildum AJ, Conrad SE (2007) Functional ablation of pRb activates $\mathrm{Cdk} 2$ and causes antiestrogen resistance in human breast cancer cells. PLoS One 2: e1256.

110. Templeton DJ, Park SH, Lanier L, Weinberg RA (1991) Nonfunctional mutants of the retinoblastoma protein are characterized by defects in phosphorylation, viral oncoprotein association, and nuclear tethering. Proc Natl Acad Sci U S A 88: 30333037.

111. Ertel A, Dean JL, Rui H, Liu C, Witkiewicz AK, et al. (2010) RB-pathway disruption in breast cancer: differential association with disease subtypes, diseasespecific prognosis and therapeutic response. Cell Cycle 9: 4153-4163.

112. Guarnieri DJ, DiLeone RJ (2008) MicroRNAs: a new class of gene regulators. Ann Med 40: 197-208.

113. Alvarez-Garcia I, Miska EA (2005) MicroRNA functions in animal development and human disease. Development 132: 4653-4662.

114. Lee RC, Feinbaum RL, Ambros V (1993) The C. elegans heterochronic gene lin4 encodes small RNAs with antisense complementarity to lin-14. Cell 75: 843-854.

115. Griffiths-Jones S, Grocock R, van Dongen S, Bateman A, Enright A (2006) miRBase: microRNA sequences, targets and gene nomenclature. Nucleic Acids Res 34: D140 - 144.

116. Okamura K, Phillips MD, Tyler DM, Duan H, Chou YT, et al. (2008) The regulatory activity of microRNA* species has substantial influence on microRNA and 3' UTR evolution. Nat Struct Mol Biol 15: 354-363.

117. Rodriguez A, Griffiths-Jones S, Ashurst JL, Bradley A (2004) Identification of Mammalian microRNA Host Genes and Transcription Units. Genome Research 14: 1902-1910.

118. Faller M, Guo F (2008) MicroRNA biogenesis: there's more than one way to skin a cat. Biochim Biophys Acta 1779: 663-667.

119. Borchert GM, Lanier W, Davidson BL (2006) RNA polymerase III transcribes human microRNAs. Nat Struct Mol Biol 13: 1097-1101.

120. Berezikov E, Chung W-J, Willis J, Cuppen E, Lai EC (2007) Mammalian Mirtron Genes. Molecular Cell 28: 328-336.

121. Filipowicz W, Bhattacharyya SN, Sonenberg N (2008) Mechanisms of posttranscriptional regulation by microRNAs: are the answers in sight? Nat Rev Genet 9: 102-114. 
122. Kiriakidou M, Tan GS, Lamprinaki S, De Planell-Saguer M, Nelson PT, et al. (2007) An mRNA m7G Cap Binding-like Motif within Human Ago2 Represses Translation. Cell 129: 1141-1151.

123. Chendrimada TP, Finn KJ, Ji X, Baillat D, Gregory RI, et al. (2007) MicroRNA silencing through RISC recruitment of eIF6. Nature 447: 823-828.

124. Petersen CP, Bordeleau M-E, Pelletier J, Sharp PA (2006) Short RNAs Repress Translation after Initiation in Mammalian Cells. Molecular Cell 21: 533-542.

125. Maroney PA, Yu Y, Fisher J, Nilsen TW (2006) Evidence that microRNAs are associated with translating messenger RNAs in human cells. Nat Struct Mol Biol 13: 1102-1107.

126. Wu L, Fan J, Belasco JG (2006) MicroRNAs direct rapid deadenylation of mRNA. Proceedings of the National Academy of Sciences of the United States of America 103: 4034-4039.

127. Giraldez AJ, Mishima Y, Rihel J, Grocock RJ, Van Dongen S, et al. (2006) Zebrafish MiR-430 Promotes Deadenylation and Clearance of Maternal mRNAs. Science 312: 75-79.

128. Sheth U, Parker R (2003) Decapping and decay of messenger RNA occur in cytoplasmic processing bodies. Science 300: 805-808.

129. Liu J, Valencia-Sanchez MA, Hannon GJ, Parker R (2005) MicroRNAdependent localization of targeted mRNAs to mammalian P-bodies. Nat Cell Biol 7: 719-723.

130. Parker R, Song H (2004) The enzymes and control of eukaryotic mRNA turnover. Nat Struct Mol Biol 11: 121-127.

131. Sayed D, Abdellatif M (2011) MicroRNAs in Development and Disease. Physiological Reviews 91: 827-887.

132. Lewis BP, Burge CB, Bartel DP (2005) Conserved seed pairing, often flanked by adenosines, indicates that thousands of human genes are microRNA targets. Cell 120: 15-20.

133. Inui M, Martello G, Piccolo S (2010) MicroRNA control of signal transduction. Nat Rev Mol Cell Biol 11: 252-263.

134. Gregory RI, Yan K-p, Amuthan G, Chendrimada T, Doratotaj B, et al. (2004) The Microprocessor complex mediates the genesis of microRNAs. Nature 432: 235240.

135. Han J, Pedersen JS, Kwon SC, Belair CD, Kim Y-K, et al. (2009) Posttranscriptional Crossregulation between Drosha and DGCR8. Cell 136: 75-84.

136. Davis BN, Hilyard AC, Lagna G, Hata A (2008) SMAD proteins control DROSHA-mediated microRNA maturation. Nature 454: 56-61.

137. Sakamoto S, Aoki K, Higuchi T, Todaka H, Morisawa K, et al. (2009) The NF90-NF45 Complex Functions as a Negative Regulator in the MicroRNA Processing Pathway. Molecular and Cellular Biology 29: 3754-3769.

138. Watanabe M, Yanagisawa J, Kitagawa H, Takeyama K-i, Ogawa S, et al. (2001) A subfamily of RNA-binding DEAD-box proteins acts as an estrogen receptor [alpha] 
coactivator through the $\mathrm{N}$-terminal activation domain (AF-1) with an RNA coactivator, SRA. EMBO J 20: 1341-1352.

139. Melo SA, Moutinho C, Ropero S, Calin GA, Rossi S, et al. (2010) A Genetic Defect in Exportin-5 Traps Precursor MicroRNAs in the Nucleus of Cancer Cells. Cancer Cell 18: 303-315.

140. Chiosea S, Jelezcova E, Chandran U, Acquafondata M, McHale T, et al. (2006) Up-Regulation of Dicer, a Component of the MicroRNA Machinery, in Prostate Adenocarcinoma. The American Journal of Pathology 169: 1812-1820.

141. Karube Y, Tanaka H, Osada H, Tomida S, Tatematsu Y, et al. (2005) Reduced expression of Dicer associated with poor prognosis in lung cancer patients. Cancer Science 96: 111-115.

142. Lee Y, Hur I, Park SY, Kim YK, Suh MR, et al. (2006) The role of PACT in the RNA silencing pathway. EMBO J 25: 522-532.

143. Chendrimada TP, Gregory RI, Kumaraswamy E, Norman J, Cooch N, et al. (2005) TRBP recruits the Dicer complex to Ago2 for microRNA processing and gene silencing. Nature 436: 740-744.

144. Paroo Z, Ye X, Chen S, Liu Q (2009) Phosphorylation of the human microRNAgenerating complex mediates MAPK/Erk signaling. Cell 139: 112-122.

145. Adams BD, Claffey KP, White BA (2009) Argonaute-2 expression is regulated by epidermal growth factor receptor and mitogen-activated protein kinase signaling and correlates with a transformed phenotype in breast cancer cells. Endocrinology 150: 14-23.

146. He L, He X, Lim LP, de Stanchina E, Xuan Z, et al. (2007) A microRNA component of the p53 tumour suppressor network. Nature 447: 1130-1134.

147. O'Donnell KA, Wentzel EA, Zeller KI, Dang CV, Mendell JT (2005) c-Mycregulated microRNAs modulate E2F1 expression. Nature 435: 839-843.

148. Conaco C, Otto S, Han JJ, Mandel G (2006) Reciprocal actions of REST and a microRNA promote neuronal identity. Proc Natl Acad Sci U S A 103: 2422-2427.

149. Davis BN, Hilyard AC, Nguyen PH, Lagna G, Hata A (2009) Induction of microRNA-221 by platelet-derived growth factor signaling is critical for modulation of vascular smooth muscle phenotype. J Biol Chem 284: 3728-3738.

150. Chan MC, Hilyard AC, Wu C, Davis BN, Hill NS, et al. (2010) Molecular basis for antagonism between PDGF and the TGFbeta family of signalling pathways by control of miR-24 expression. EMBO J 29: 559-573.

151. Waltering KK, Porkka KP, Jalava SE, Urbanucci A, Kohonen PJ, et al. (2011) Androgen regulation of micro-RNAs in prostate cancer. Prostate 71: 604-614.

152. Tessel MA, Krett NL, Rosen ST (2010) Steroid receptor and microRNA regulation in cancer. Curr Opin Oncol 22: 592-597.

153. Macias S, Michlewski G, Caceres JF (2009) Hormonal regulation of microRNA biogenesis. Mol Cell 36: 172-173.

154. Klinge CM (2009) Estrogen Regulation of MicroRNA Expression. Curr Genomics 10: 169-183. 
155. Fujiyama-Nakamura S, Yamagata K, Kato S (2010) Hormonal repression of miRNA biosynthesis through a nuclear steroid hormone receptor. Adv Exp Med Biol 700: 43-55.

156. Cohen A, Shmoish M, Levi L, Cheruti U, Levavi-Sivan B, et al. (2008) Alterations in micro-ribonucleic acid expression profiles reveal a novel pathway for estrogen regulation. Endocrinology 149: 1687-1696.

157. Kovalchuk O, Tryndyak VP, Montgomery B, Boyko A, Kutanzi K, et al. (2007) Estrogen-induced rat breast carcinogenesis is characterized by alterations in DNA methylation, histone modifications and aberrant microRNA expression. Cell Cycle 6: 2010-2018.

158. Castellano L, Giamas G, Jacob J, Coombes RC, Lucchesi W, et al. (2009) The estrogen receptor-alpha-induced microRNA signature regulates itself and its transcriptional response. Proc Natl Acad Sci U S A 106: 15732-15737.

159. Maillot G, Lacroix-Triki M, Pierredon S, Gratadou L, Schmidt S, et al. (2009) Widespread estrogen-dependent repression of micrornas involved in breast tumor cell growth. Cancer Res 69: 8332-8340.

160. Cicatiello L, Mutarelli M, Grober OM, Paris O, Ferraro L, et al. (2010) Estrogen receptor alpha controls a gene network in luminal-like breast cancer cells comprising multiple transcription factors and microRNAs. Am J Pathol 176: 2113-2130.

161. Manavalan TT, Teng Y, Appana SN, Datta S, Kalbfleisch TS, et al. (2011) Differential expression of microRNA expression in tamoxifen-sensitive MCF-7 versus tamoxifen-resistant LY2 human breast cancer cells. Cancer Letters 313: 26-43.

162. Wickramasinghe NS, Manavalan TT, Dougherty SM, Riggs KA, Li Y, et al. (2009) Estradiol downregulates miR-21 expression and increases miR-21 target gene expression in MCF-7 breast cancer cells. Nucl Acids Res: gkpl17.

163. Bhat-Nakshatri P, Wang G, Collins NR, Thomson MJ, Geistlinger TR, et al. (2009) Estradiol-regulated microRNAs control estradiol response in breast cancer cells. Nucleic Acids Res 37: 4850-4861.

164. Pan Q, Luo X, Chegini N (2008) Differential expression of microRNAs in myometrium and leiomyomas and regulation by ovarian steroids. J Cell Mol Med 12: 227-240.

165. Pan Q, Luo X, Toloubeydokhti T, Chegini N (2007) The expression profile of micro-RNA in endometrium and endometriosis and the influence of ovarian steroids on their expression. Mol Hum Reprod 13: 797-806.

166. Tilghman SL, Bratton MR, Segar HC, Martin EC, Rhodes LV, et al. (2012) Endocrine disruptor regulation of microRNA expression in breast carcinoma cells. PLoS One 7: e32754.

167. Klinge CM (2012) miRNAs and estrogen action. Trends Endocrinol Metab.

168. Saito Y, Liang G, Egger G, Friedman JM, Chuang JC, et al. (2006) Specific activation of microRNA-127 with downregulation of the proto-oncogene BCL6 by chromatin-modifying drugs in human cancer cells. Cancer Cell 9: 435-443.

169. Lujambio A, Esteller M (2009) How epigenetics can explain human metastasis: a new role for microRNAs. Cell Cycle 8: 377-382. 
170. Brueckner B, Stresemann C, Kuner R, Mund C, Musch T, et al. (2007) The human let-7a-3 locus contains an epigenetically regulated microRNA gene with oncogenic function. Cancer Res 67: 1419-1423.

171. Scott GK, Mattie MD, Berger CE, Benz SC, Benz CC (2006) Rapid alteration of microRNA levels by histone deacetylase inhibition. Cancer Res 66: 1277-1281.

172. Iorio MV, Croce CM (2009) MicroRNAs in cancer: small molecules with a huge impact. J Clin Oncol 27: 5848-5856.

173. Cimmino A, Calin GA, Fabbri M, Iorio MV, Ferracin M, et al. (2005) miR-15 and miR-16 induce apoptosis by targeting BCL2. Proc Natl Acad Sci U S A 102: 13944-13949.

174. Corney DC, Hwang CI, Matoso A, Vogt M, Flesken-Nikitin A, et al. (2010) Frequent downregulation of miR-34 family in human ovarian cancers. Clin Cancer Res 16: 1119-1128.

175. He C, Xiong J, Xu X, Lu W, Liu L, et al. (2009) Functional elucidation of MiR34 in osteosarcoma cells and primary tumor samples. Biochem Biophys Res Commun 388: $35-40$.

176. Ji Q, Hao X, Zhang M, Tang W, Yang M, et al. (2009) MicroRNA miR-34 inhibits human pancreatic cancer tumor-initiating cells. PLoS One 4: e6816.

177. Wei JS, Song YK, Durinck S, Chen QR, Cheuk AT, et al. (2008) The MYCN oncogene is a direct target of miR-34a. Oncogene 27: 5204-5213.

178. Yamakuchi M, Ferlito M, Lowenstein CJ (2008) miR-34a repression of SIRT1 regulates apoptosis. Proc Natl Acad Sci U S A 105: 13421-13426.

179. Eder M, Scherr M (2005) MicroRNA and lung cancer. N Engl J Med 352: 24462448.

180. Sampson VB, Rong NH, Han J, Yang Q, Aris V, et al. (2007) MicroRNA let-7a down-regulates MYC and reverts MYC-induced growth in Burkitt lymphoma cells. Cancer Res 67: 9762-9770.

181. Dong Q, Meng P, Wang T, Qin W, Wang F, et al. (2010) MicroRNA let-7a inhibits proliferation of human prostate cancer cells in vitro and in vivo by targeting E2F2 and CCND2. PLoS One 5: e10147.

182. Mayr C, Hemann MT, Bartel DP (2007) Disrupting the pairing between let-7 and Hmga2 enhances oncogenic transformation. Science 315: 1576-1579.

183. Johnson SM, Grosshans H, Shingara J, Byrom M, Jarvis R, et al. (2005) RAS is regulated by the let-7 microRNA family. Cell 120: 635-647.

184. Qi L, Bart J, Tan LP, Platteel I, Sluis T, et al. (2009) Expression of miR-21 and its targets (PTEN, PDCD4, TM1) in flat epithelial atypia of the breast in relation to ductal carcinoma in situ and invasive carcinoma. BMC Cancer 9: 163.

185. Lu Z, Liu M, Stribinskis V, Klinge CM, Ramos KS, et al. (2008) MicroRNA-21 promotes cell transformation by targeting the programmed cell death 4 gene. Oncogene 27: 4373-4379.

186. Frankel LB, Christoffersen NR, Jacobsen A, Lindow M, Krogh A, et al. (2008) Programmed cell death 4 (PDCD4) is an important functional target of the microRNA miR-21 in breast cancer cells. J Biol Chem 283: 1026-1033. 
187. Zhu S, Wu H, Wu F, Nie D, Sheng S, et al. (2008) MicroRNA-21 targets tumor suppressor genes in invasion and metastasis. Cell Res 18: 350-359.

188. Zhu S, Si ML, Wu H, Mo YY (2007) MicroRNA-21 targets the tumor suppressor gene tropomyosin 1 (TPM1). J Biol Chem 282: 14328-14336.

189. Hatley ME, Patrick DM, Garcia MR, Richardson JA, Bassel-Duby R, et al. (2010) Modulation of K-Ras-dependent lung tumorigenesis by MicroRNA-21. Cancer Cell 18: 282-293.

190. Bhatti I, Lee A, James V, Hall RI, Lund JN, et al. (2011) Knockdown of microRNA-21 inhibits proliferation and increases cell death by targeting programmed cell death 4 (PDCD4) in pancreatic ductal adenocarcinoma. J Gastrointest Surg 15: 199-208.

191. Folini M, Gandellini P, Longoni N, Profumo V, Callari M, et al. (2010) miR-21: an oncomir on strike in prostate cancer. Mol Cancer 9: 12.

192. Hayashita Y, Osada H, Tatematsu Y, Yamada H, Yanagisawa K, et al. (2005) A polycistronic microRNA cluster, miR-17-92, is overexpressed in human lung cancers and enhances cell proliferation. Cancer Res 65: 9628-9632.

193. Eis PS, Tam W, Sun L, Chadburn A, Li Z, et al. (2005) Accumulation of miR155 and BIC RNA in human B cell lymphomas. Proc Natl Acad Sci U S A 102: 3627 3632 .

194. John B, Enright AJ, Aravin A, Tuschl T, Sander C, et al. (2004) Human MicroRNA targets. PLoS Biol 2: e363.

195. ET Verghese AH, V Speirs, TA Hughes, (2008) Small is beautiful: microRNAs and breast cancer - where are we now? The Journal of Pathology 215: 214-221.

196. Castaneda CA, Agullo-Ortuno MT, Fresno Vara JA, Cortes-Funes H, Gomez HL, et al. (2011) Implication of miRNA in the diagnosis and treatment of breast cancer. Expert Rev Anticancer Ther 11: 1265-1275.

197. Varol N, Konac E, Gurocak OS, Sozen S (2011) The realm of microRNAs in cancers. Mol Biol Rep 38: 1079-1089.

198. Blenkiron C, Goldstein LD, Thorne NP, Spiteri I, Chin SF, et al. (2007) MicroRNA expression profiling of human breast cancer identifies new markers of tumor subtype. Genome Biol 8: R214.

199. Ferracin M, Querzoli P, Calin GA, Negrini M (2011) MicroRNAs: Toward the Clinic for Breast Cancer Patients. Seminars in Oncology 38: 764-775.

200. Park SM, Shell S, Radjabi AR, Schickel R, Feig C, et al. (2007) Let-7 prevents early cancer progression by suppressing expression of the embryonic gene HMGA2. Cell Cycle 6: 2585-2590.

201. Scott GK, Goga A, Bhaumik D, Berger CE, Sullivan CS, et al. (2007) Coordinate Suppression of ERBB2 and ERBB3 by Enforced Expression of MicroRNA miR-125a or miR-125b. J Biol Chem 282: 1479-1486.

202. Paterson EL, Kolesnikoff N, Gregory PA, Bert AG, Khew-Goodall Y, et al. (2008) The microRNA-200 family regulates epithelial to mesenchymal transition. ScientificWorldJournal 8: 901-904. 
203. Gregory PA, Bert AG, Paterson EL, Barry SC, Tsykin A, et al. (2008) The miR200 family and miR-205 regulate epithelial to mesenchymal transition by targeting ZEB1 and SIP1. Nat Cell Biol 10: 593-601.

204. Peter ME (2009) Let-7 and miR-200 microRNAs: guardians against pluripotency and cancer progression. Cell Cycle 8: 843-852.

205. Burk U, Schubert J, Wellner U, Schmalhofer O, Vincan E, et al. (2008) A reciprocal repression between $\mathrm{ZEB} 1$ and members of the miR-200 family promotes EMT and invasion in cancer cells. EMBO Rep 9: 582-589.

206. Uhlmann S, Zhang JD, Schwager A, Mannsperger H, Riazalhosseini Y, et al. (2010) miR-200bc/429 cluster targets PLCgammal and differentially regulates proliferation and EGF-driven invasion than miR-200a/141 in breast cancer. Oncogene 29: 4297-4306.

207. Gregory PA, Bracken CP, Smith E, Bert AG, Wright JA, et al. (2011) An autocrine TGF-beta/ZEB/miR-200 signaling network regulates establishment and maintenance of epithelial-mesenchymal transition. Mol Biol Cell 22: 1686-1698.

208. Negrini M, Calin GA (2008) Breast cancer metastasis: a microRNA story. Breast Cancer Res 10: 203.

209. Baffa R, Fassan M, Volinia S, O'Hara B, Liu CG, et al. (2009) MicroRNA expression profiling of human metastatic cancers identifies cancer gene targets. $J$ Pathol 219: 214-221.

210. Ma L, Reinhardt F, Pan E, Soutschek J, Bhat B, et al. (2010) Therapeutic silencing of miR-10b inhibits metastasis in a mouse mammary tumor model. Nat Biotechnol 28: 341-347.

211. Myers C, Charboneau A, Cheung I, Hanks D, Boudreau N (2002) Sustained expression of homeobox D10 inhibits angiogenesis. Am J Pathol 161: 2099-2109.

212. Zhu S, Si M-L, Wu H, Mo Y-Y (2007) MicroRNA-21 Targets the Tumor Suppressor Gene Tropomyosin 1 (TPM1). J Biol Chem 282: 14328-14336.

213. Hossain A, Kuo MT, Saunders GF (2006) Mir-17-5p regulates breast cancer cell proliferation by inhibiting translation of AIB1 mRNA. Mol Cell Biol 26: 8191-8201.

214. Torres-Arzayus MI, Font de Mora J, Yuan J, Vazquez F, Bronson R, et al. (2004) High tumor incidence and activation of the PI3K/AKT pathway in transgenic mice define AIB 1 as an oncogene. Cancer Cell 6: 263-274.

215. Torres-Arzayus MI, Zhao J, Bronson R, Brown M (2010) Estrogen-dependent and estrogen-independent mechanisms contribute to AIB1-mediated tumor formation. Cancer Res 70: 4102-4111.

216. Qin L, Liao L, Redmond A, Young L, Yuan Y, et al. (2008) The AIB1 oncogene promotes breast cancer metastasis by activation of PEA3-mediated matrix metalloproteinase 2 (MMP2) and MMP9 expression. Mol Cell Biol 28: 5937-5950.

217. Lahusen T, Henke RT, Kagan BL, Wellstein A, Riegel AT (2009) The role and regulation of the nuclear receptor co-activator AIB 1 in breast cancer. Breast Cancer Res Treat 116: 225-237.

218. Li H, Bian C, Liao L, Li J, Zhao RC (2011) miR-17-5p promotes human breast cancer cell migration and invasion through suppression of HBP1. Breast Cancer Res Treat 126: 565-575. 
219. Iorio M, Ferracin M, Liu C, Veronese A, Spizzo R, et al. (2005) MicroRNA gene expression deregulation in human breast cancer. Cancer Res 65: 7065 - 7070.

220. Lowery AJ, Miller N, Devaney A, McNeill RE, Davoren PA, et al. (2009) MicroRNA signatures predict oestrogen receptor, progesterone receptor and HER2/neu receptor status in breast cancer. Breast Cancer Res 11: R27.

221. Sempere LF, Christensen M, Silahtaroglu A, Bak M, Heath CV, et al. (2007) Altered MicroRNA Expression Confined to Specific Epithelial Cell Subpopulations in Breast Cancer. Cancer Res 67: 11612-11620.

222. Roth C, Rack B, Muller V, Janni W, Pantel K, et al. (2010) Circulating microRNAs as blood-based markers for patients with primary and metastatic breast cancer. Breast Cancer Res 12: R90.

223. Hu Z, Dong J, Wang LE, Ma H, Liu J, et al. (2012) Serum microRNA profiling and breast cancer risk: the use of miR-484/191 as endogenous controls. Carcinogenesis.

224. Zhao H, Shen J, Medico L, Wang D, Ambrosone CB, et al. (2010) A pilot study of circulating miRNAs as potential biomarkers of early stage breast cancer. PLoS One 5: e13735.

225. Asaga S, Kuo C, Nguyen T, Terpenning M, Giuliano AE, et al. (2011) Direct serum assay for microRNA-21 concentrations in early and advanced breast cancer. Clin Chem 57: 84-91.

226. Heneghan HM, Miller N, Kelly R, Newell J, Kerin MJ (2010) Systemic miRNA195 Differentiates Breast Cancer from Other Malignancies and Is a Potential Biomarker for Detecting Noninvasive and Early Stage Disease. Oncologist 15: 673682.

227. Heneghan HM, Miller N, Lowery AJ, Sweeney KJ, Newell J, et al. (2010) Circulating microRNAs as novel minimally invasive biomarkers for breast cancer. Ann Surg 251: 499-505.

228. Kondo N, Toyama T, Sugiura H, Fujii Y, Yamashita H (2008) miR-206 Expression Is Down-regulated in Estrogen Receptor \{alpha\}-Positive Human Breast Cancer. Cancer Res 68: 5004-5008.

229. Adams BD, Furneaux H, White BA (2007) The Micro-Ribonucleic Acid (miRNA) miR-206 Targets the Human Estrogen Receptor-\{alpha\} (ER \{alpha\}) and Represses ER \{alpha\} Messenger RNA and Protein Expression in Breast Cancer Cell Lines. Mol Endocrinol 21: 1132-1147.

230. Adams BD, Cowee DM, White BA (2009) The role of miR-206 in the epidermal growth factor (EGF) induced repression of estrogen receptor-alpha (ERalpha) signaling and a luminal phenotype in MCF-7 breast cancer cells. Mol Endocrinol 23: 1215-1230.

231. Pandey DP, Picard D (2009) miR-22 Inhibits Estrogen Signaling by Directly Targeting the Estrogen Receptor \{alpha\} mRNA. Mol Cell Biol 29: 3783-3790.

232. Xiong J, Yu D, Wei N, Fu H, Cai T, et al. (2010) An estrogen receptor alpha suppressor, microRNA-22, is downregulated in estrogen receptor alpha-positive human breast cancer cell lines and clinical samples. FEBS J. 
233. Zhao JJ, Lin J, Yang H, Kong W, He L, et al. (2008) MicroRNA-221/222 negatively regulates estrogen receptor alpha and is associated with tamoxifen resistance in breast cancer. J Biol Chem 283: 31079-31086.

234. Di Leva G, Gasparini P, Piovan C, Ngankeu A, Garofalo M, et al. (2010) MicroRNA Cluster 221-222 and Estrogen Receptor \{alpha\} Interactions in Breast Cancer. J Natl Cancer Inst 102: 706-721.

235. Rao X, Di Leva G, Li M, Fang F, Devlin C, et al. (2011) MicroRNA-221/222 confers breast cancer fulvestrant resistance by regulating multiple signaling pathways. Oncogene 30: 1082-1097.

236. Zhao Y, Deng C, Wang J, Xiao J, Gatalica Z, et al. (2011) Let-7 family miRNAs regulate estrogen receptor alpha signaling in estrogen receptor positive breast cancer. Breast Cancer Res Treat 127: 69-80.

237. Zhao Y, Deng C, Lu W, Xiao J, Ma D, et al. (2011) Let-7 microRNAs Induce Tamoxifen Sensitivity by Down-Regulation of Estrogen Receptor Alpha Signaling in Breast Cancer. Mol Med.

238. Leivonen SK, Makela R, Ostling P, Kohonen P, Haapa-Paananen S, et al. (2009) Protein lysate microarray analysis to identify microRNAs regulating estrogen receptor signaling in breast cancer cell lines. Oncogene 28: 3926-3936.

239. Xin F, Li M, Balch C, Thomson M, Fan M, et al. (2009) Computational analysis of microRNA profiles and their target genes suggests significant involvement in breast cancer antiestrogen resistance. Bioinformatics 25: 430-434.

240. Miller TE, Ghoshal K, Ramaswamy B, Roy S, Datta J, et al. (2008) MicroRNA221/222 confers tamoxifen resistance in breast cancer by targeting p27(Kip1). J Biol Chem: M804612200.

241. Miller TE, Ghoshal K, Ramaswamy B, Roy S, Datta J, et al. (2008) MicroRNA221/222 confers tamoxifen resistance in breast cancer by targeting p27Kip1. J Biol Chem 283: 29897-29903.

242. Shimono Y, Zabala M, Cho RW, Lobo N, Dalerba P, et al. (2009) Downregulation of miRNA-200c links breast cancer stem cells with normal stem cells. Cell 138: 592-603.

243. Lu Y, Roy S, Nuovo G, Ramaswamy B, Miller T, et al. (2011) Anti-miR-222 and $-181 \mathrm{~B}$ suppresses growth of tamoxifen resistant xenografts in mouse by targeting TIMP3 and modulating mitogenic signal. Journal of Biological Chemistry.

244. Cittelly DM, Das PM, Salvo VA, Fonseca JP, Burow ME, et al. (2010) Oncogenic HER2\{Delta\} 16 Suppresses miR-15a/16 and Deregulates BCL-2 to Promote Endocrine Resistance of Breast Tumors. Carcinogenesis.

245. Bergamaschi A, Katzenellenbogen BS (2011) Tamoxifen downregulation of miR-451 increases 14-3-3zeta and promotes breast cancer cell survival and endocrine resistance. Oncogene.

246. Lyng MB, Laenkholm AV, Sokilde R, Gravgaard KH, Litman T, et al. (2012) Global microRNA expression profiling of high-risk ER+ breast cancers from patients receiving adjuvant tamoxifen mono-therapy: a DBCG study. PLoS One 7: e36170. 
247. Manavalan TT, Teng Y, Appana SN, Datta S, Kalbfleisch TS, et al. (2011) Differential expression of microRNA expression in tamoxifen-sensitive MCF-7 versus tamoxifen-resistant LY2 human breast cancer cells. Cancer Lett 313: 26-43.

248. Jordan VC (2003) Is Tamoxifen the Rosetta Stone for Breast Cancer? J Natl Cancer Inst 95: 338-340.

249. Schafer JM, Bentrem DJ, Takei H, Gajdos C, Badve S, et al. (2002) A mechanism of drug resistance to tamoxifen in breast cancer. The Journal of Steroid Biochemistry and Molecular Biology 83: 75-83.

250. Peng J, Sengupta S, Jordan VC (2009) Potential of selective estrogen receptor modulators as treatments and preventives of breast cancer. Anticancer Agents Med Chem 9: 481-499.

251. Ring A, Dowsett M (2004) Mechanisms of tamoxifen resistance. Endocr Relat Cancer 11: 643-658.

252. Arpino G, Wiechmann L, Osborne CK, Schiff R (2008) Crosstalk between the Estrogen Receptor and the HER Tyrosine Kinase Receptor Family: Molecular Mechanism and Clinical Implications for Endocrine Therapy Resistance. Endocr Rev 29: 217-233.

253. Clarke R, Liu MC, Bouker KB, Gu Z, Lee RY, et al. (2003) Antiestrogen resistance in breast cancer and the role of estrogen receptor signaling. Oncogene 22: 7316-7339.

254. Friedman RC, Farh KK, Burge CB, Bartel DP (2009) Most mammalian mRNAs are conserved targets of microRNAs. Genome Res 19: 92-105.

255. Djuranovic S, Nahvi A, Green R (2011) A parsimonious model for gene regulation by miRNAs. Science 331: 550-553.

256. Nelson KM, Weiss GJ (2008) MicroRNAs and cancer: past, present, and potential future. Mol Cancer Ther 7: 3655-3660.

257. Iorio MV, Ferracin M, Liu C-G, Veronese A, Spizzo R, et al. (2005) MicroRNA Gene Expression Deregulation in Human Breast Cancer. Cancer Res 65: 7065-7070.

258. Volinia S, Calin GA, Liu C-G, Ambs S, Cimmino A, et al. (2006) A microRNA expression signature of human solid tumors defines cancer gene targets. Proceedings of the National Academy of Sciences 103: 2257-2261.

259. Yang N, Kaur S, Volinia S, Greshock J, Lassus H, et al. (2008) MicroRNA Microarray Identifies Let-7i as a Novel Biomarker and Therapeutic Target in Human Epithelial Ovarian Cancer. Cancer Res 68: 10307-10314.

260. Bhat-Nakshatri P, Wang G, Collins NR, Thomson MJ, Geistlinger TR, et al. (2009) Estradiol-regulated microRNAs control estradiol response in breast cancer cells. Nucl Acids Res 37: 4850-4861.

261. Maillot G, Lacroix-Triki M, Pierredon S, Gratadou L, Schmidt S, et al. (2009) Widespread Estrogen-Dependent Repression of microRNAs Involved in Breast Tumor Cell Growth. Cancer Res 69: 8332-8340.

262. O'Day E, Lal A (2010) MicroRNAs and their target gene networks in breast cancer. Breast Cancer Res 12: 201. 
263. Calin GA, Ferracin M, Cimmino A, Di Leva G, Shimizu M, et al. (2005) A MicroRNA Signature Associated with Prognosis and Progression in Chronic Lymphocytic Leukemia. N Engl J Med 353: 1793-1801.

264. Drakaki A, Iliopoulos D (2009) MicroRNA Gene Networks in Oncogenesis. Curr Genomics 10: 35-41.

265. Mocellin S, Pasquali S, Pilati P (2009) Oncomirs: From Tumor Biology to Molecularly Targeted Anticancer Strategies. Mini Reviews in Medicinal Chemistry 9: 70-80.

266. Verghese ET, Hanby AM, Speirs V, Hughes TA (2008) Small is beautiful: microRNAs and breast cancer-where are we now? J Pathol 215: 214-221.

267. Klinge CM (2009) Estrogen Regulation of MicroRNA Expression. Current Genomics 10: 169-183.

268. Wickramasinghe N, Manavalan T, Dougherty S, Riggs K, Li Y, et al. (2009) Estradiol downregulates miR-21 expression and increases miR-21 target gene expression in MCF-7 breast cancer cells. Nucleic Acids Res 37: 2584-2595

269. Castellano L, Giamas G, Jacob J, Coombes RC, Lucchesi W, et al. (2009) The estrogen receptor-alpha induced microRNA signature regulates itself and its transcriptional response. Proceedings of the National Academy of Sciences 106: 15732-15737.

270. Miller TE, Ghoshal K, Ramaswamy B, Roy S, Datta J, et al. (2008) MicroRNA221/222 confers tamoxifen resistance in breast cancer by targeting p27(Kip1). J Biol Chem 283: 29897-29903.

271. Rao X, Di Leva G, Li M, Fang F, Devlin C, et al. (2011) MicroRNA-221/222 confers breast cancer fulvestrant resistance by regulating multiple signaling pathways. Oncogene in press.

272. Xin F, Li M, Balch C, Thomson M, Fan M, et al. (2009) Computational analysis of microRNA profiles and their target genes suggests significant involvement in breast cancer antiestrogen resistance. Bioinformatics 25: 430-434.

273. Bronzert DA, Greene GL, Lippman ME (1985) Selection and characterization of a breast cancer cell line resistant to the antiestrogen LY 117018. Endocrinology 117: 1409-1417.

274. Mullick A, Chambon P (1990) Characterization of the estrogen receptor in two antiestrogen-resistant cell lines, LY2 and T47D. Cancer Res 50: 333-338.

275. Crawford AC, Riggins RB, Shajahan AN, Zwart A, Clarke R (2010) CoInhibition of BCL-W and BCL2 Restores Antiestrogen Sensitivity through BECN1 and Promotes an Autophagy-Associated Necrosis. PLoS ONE 5: e8604.

276. Frasor J, Chang EC, Komm B, Lin C-Y, Vega VB, et al. (2006) Gene Expression Preferentially Regulated by Tamoxifen in Breast Cancer Cells and Correlations with Clinical Outcome. Cancer Res 66: 7334-7340.

277. Riggs KA, Wickramasinghe NS, Cochrum RK, Watts MB, Klinge CM (2006) Decreased Chicken Ovalbumin Upstream Promoter Transcription Factor II Expression in Tamoxifen-Resistant Breast Cancer Cells. Cancer Res 66: 1018810198. 
278. Brunner N, Boysen B, Jirus S, Skaar TC, Holst-Hansen C, et al. (1997) MCF7/LCC9: an antiestrogen-resistant MCF-7 variant in which acquired resistance to the steroidal antiestrogen ICI 182,780 confers an early cross-resistance to the nonsteroidal antiestrogen tamoxifen. Cancer Res 57: 3486-3493.

279. Smyth GK, Speed TP (2003) Normalization of cDNA microarray data. Methods 31: 265-273.

280. Smyth GK (2004) Linear models and empirical bayes methods for assessing differential expression in microarray experiments. Stat Appl Genet Mol Biol 3: Article3.

281. Shang Y, Hu X, DiRenzo J, Lazar MA, Brown M (2000) Cofactor dynamics and sufficiency in estrogen receptor-regulated transcription. Cell 103: 843-852.

282. Kisanga ER, Gjerde J, Guerrieri-Gonzaga A, Pigatto F, Pesci-Feltri A, et al. (2004) Tamoxifen and Metabolite Concentrations in Serum and Breast Cancer Tissue during Three Dose Regimens in a Randomized Preoperative Trial. Clin Cancer Res 10: 2336-2343.

283. Rao X, Di Leva G, Li M, Fang F, Devlin C, et al. (2010) MicroRNA-221/222 confers breast cancer fulvestrant resistance by regulating multiple signaling pathways. Oncogene.

284. Jiang J, Lee EJ, Gusev Y, Schmittgen TD (2005) Real-time expression profiling of microRNA precursors in human cancer cell lines. Nucl Acids Res 33: 5394-5403.

285. Davoren PA, McNeill RE, Lowery AJ, Kerin MJ, Miller N (2008) Identification of suitable endogenous control genes for microRNA gene expression analysis in human breast cancer. BMC Mol Biol 9: 76.

286. Peltier HJ, Latham GJ (2008) Normalization of microRNA expression levels in quantitative RT-PCR assays: identification of suitable reference RNA targets in normal and cancerous human solid tissues. RNA 14: 844-852.

287. Roush S, Slack FJ (2008) The let-7 family of microRNAs. Trends in Cell Biology 18: 505-516.

288. Boyerinas B, Park S-M, Hau A, Murmann AE, Peter ME (2010) The role of let-7 in cell differentiation and cancer. Endocr Relat Cancer 17: F19-36.

289. Bader AG, Brown D, Winkler M (2010) The Promise of MicroRNA Replacement Therapy. Cancer Research 70: 7027-7030.

290. Sampson VB, Rong NH, Han J, Yang Q, Aris V, et al. (2007) MicroRNA Let-7a Down-regulates MYC and Reverts MYC-Induced Growth in Burkitt Lymphoma Cells. Cancer Res 67: 9762-9770.

291. Lan FF, Wang H, Chen YC, Chan CY, Ng SS, et al. (2010) Hsa-let-7g inhibits proliferation of hepatocellular carcinoma cells by downregulation of c-Myc and upregulation of p16INK4A. International Journal of Cancer 128: 319-331.

292. Dubik D, Dembinski TC, Shiu RPC (1987) Stimulation of c-myc oncogene expression associated with estrogen-induced proliferation of human breast cancer cells. Cancer Res 47: 6517-6521.

293. Zhao Y, Deng C, Wang J, Xiao J, Gatalica Z, et al. (2011) Let-7 family miRNAs regulate estrogen receptor alpha signaling in estrogen receptor positive breast cancer. Breast Cancer Res Treat in press. 
294. Chen J-Q, Russo J (2009) ER[alpha]-negative and triple negative breast cancer: Molecular features and potential therapeutic approaches. Biochimica et Biophysica Acta (BBA) - Reviews on Cancer 1796: 162-175.

295. Zhao J-J, Lin J, Yang H, Kong W, He L, et al. (2008) MicroRNA-221/222 negatively regulates ERalpha and associates with tamoxifen resistance in breast cancer. J Biol Chem 283: 31079-31086.

296. Wu H, Zhu S, Mo YY (2009) Suppression of cell growth and invasion by miR205 in breast cancer. Cell Res 19: 439-448.

297. Farazi TA, Horlings HM, ten Hoeve JJ, Mihailovic A, Halfwerk H, et al. (2011) MicroRNA Sequence and Expression Analysis in Breast Tumors by Deep Sequencing. Cancer Research 71: 4443-4453.

298. Wijayaratne AL, Nagel SC, Paige LA, Christensen DJ, Norris JD, et al. (1999) Comparative analyses of mechanistic differences among antiestrogens. Endocrinology 140: 5828-5840.

299. Prossnitz ER, Maggiolini M (2009) Mechanisms of estrogen signaling and gene expression via GPR30. Molecular and Cellular Endocrinology 308: 32-38.

300. Paroo Z, Ye X, Chen S, Liu Q (2009) Phosphorylation of the Human MicroRNA-Generating Complex Mediates MAPK/Erk Signaling. Cell 139: 112-122.

301. Huang H, Xie C, Sun X, Ritchie RP, Zhang J, et al. (2010) miR-10a Contributes to Retinoid Acid-induced Smooth Muscle Cell Differentiation. Journal of Biological Chemistry 285: 9383-9389.

302. Ørom UA, Nielsen FC, Lund AH (2008) MicroRNA-10a Binds the 5'UTR of Ribosomal Protein mRNAs and Enhances Their Translation. Molecular Cell 30: 460471 .

303. Davidson NE, Bronzert DA, Chambon P, Gelmann EP, Lippman ME (1986) Use of two $\mathrm{MCF}-7$ cell variants to evaluate the growth regulatory potential of estrogeninduced products. Cancer Res 46: 1904-1908.

304. Mattie MD, Benz CC, Bowers J, Sensinger K, Wong L, et al. (2006) Optimized high-throughput microRNA expression profiling provides novel biomarker assessment of clinical prostate and breast cancer biopsies. Mol Cancer 5: 24.

305. Kang L, Zhang X, Xie Y, Tu Y, Wang D, et al. (2010) Involvement of Estrogen Receptor Variant ER-\{alpha\}36, Not GPR30, in Nongenomic Estrogen Signaling. Mol Endocrinol 24: 709-721.

306. Wang Z, Zhang X, Shen P, Loggie BW, Chang Y, et al. (2005) Identification, cloning, and expression of human estrogen receptor-[alpha]36, a novel variant of human estrogen receptor-[alpha]66. Biochemical and Biophysical Research Communications 336: 1023-1027.

307. Wang Z, Zhang X, Shen P, Loggie BW, Chang Y, et al. (2006) A variant of estrogen receptor-\{alpha\}, hER-\{alpha\}36: Transduction of estrogen- and antiestrogen-dependent membrane-initiated mitogenic signaling. PNAS 103: 90639068.

308. Lee LMJ, Cao J, Deng H, Chen P, Gatalica Z, et al. (2008) ERalpha36, a Novel Variant of ERalpha, is Expressed in ER-positive and -negative Human Breast Carcinomas. Anticancer Research 28: 479-483. 
309. Wijayaratne AL, McDonnell DP (2001) The human estrogen receptor-alpha is a ubiquitinated protein whose stability is affected differentially by agonists, antagonists, and selective estrogen receptor modulators. J Biol Chem 276: 35684-35692.

310. Frasor J, Stossi F, Danes JM, Komm B, Lyttle CR, et al. (2004) Selective estrogen receptor modulators: discrimination of agonistic versus antagonistic activities by gene expression profiling in breast cancer cells. Cancer Res 64: 15221533.

311. Uhlmann S, Zhang JD, Schwager A, Mannsperger H, Riazalhosseini Y, et al. (2010) miR-200bc/429 cluster targets PLC[gamma]1 and differentially regulates proliferation and EGF-driven invasion than miR-200a/141 in breast cancer. Oncogene 29: 4297-4306.

312. Lim KB, Ng CY, Ong CK, Ong CS, Tran E, et al. (2001) Induction of apoptosis in mammary gland by a pure anti-estrogen ICI 182780. Breast Cancer Res Treat 68: 127-138.

313. El Etreby MF, Liang Y, Wrenn RW, Schoenlein PV (1998) Additive effect of mifepristone and tamoxifen on apoptotic pathways in MCF-7 human breast cancer cells. Breast Cancer Research and Treatment 51: 149-168.

314. Economopoulos K, Sergentanis T (2010) Three polymorphisms in cytochrome P450 1B1 (CYP1B1) gene and breast cancer risk: a meta-analysis. Breast Cancer Research and Treatment 122: 545-551.

315. Brockdorff BL, Skouv J, Reiter BE, Lykkesfeldt AE (2000) Increased expression of cytochrome p450 $1 \mathrm{~A} 1$ and $1 \mathrm{Bl}$ genes in anti-estrogen-resistant human breast cancer cell lines. Int J Cancer 88: 902-906.

316. Sindhu RK, Koo JR, Sindhu KK, Ehdaie A, Farmand F, et al. (2006) Differential regulation of hepatic cytochrome $\mathrm{P} 450$ monooxygenases in streptozotocin-induced diabetic rats. Free Radic Res 40: 921-928.

317. Spink DC, Spink BC, Cao JQ, DePasquale JA, Pentecost BT, et al. (1998) Differential expression of CYP1A1 and CYP1B1 in human breast epithelial cells and breast tumor cells. Carcinogenesis 19: 291-298.

318. Tsuchiya Y, Nakajima M, Kyo S, Kanaya T, Inoue M, et al. (2004) Human CYP1B1 Is Regulated by Estradiol via Estrogen Receptor. Cancer Res 64: 3119-3125.

319. Hamburger AW (2008) The role of ErbB3 and its binding partners in breast cancer progression and resistance to hormone and tyrosine kinase directed therapies. J Mammary Gland Biol Neoplasia 13: 225-233.

320. Liu B, Ordonez-Ercan D, Fan Z, Edgerton SM, Yang X, et al. (2007) Downregulation of erbB3 abrogates erbB2-mediated tamoxifen resistance in breast cancer cells. International Journal of Cancer 120: 1874-1882.

321. Revillion F, Pawlowski V, Lhotellier V, Louchez MM, Peyrat JP (2003) mRNA expression of the type I growth factor receptors in the human breast cancer cells MCF-7: regulation by estradiol and tamoxifen. Anticancer Res 23: 1455-1460.

322. Cochrane DR, Howe EN, Spoelstra NS, Richer JK (2010) Loss of miR-200c: A Marker of Aggressiveness and Chemoresistance in Female Reproductive Cancers. J Oncol 2010: 821717. 
323. Cochrane DR, Spoelstra NS, Howe EN, Nordeen SK, Richer JK (2009) MicroRNA-200c mitigates invasiveness and restores sensitivity to microtubuletargeting chemotherapeutic agents. Molecular Cancer Therapeutics 8: 1055-1066.

324. Hurteau GJ, Carlson JA, Spivack SD, Brock GJ (2007) Overexpression of the MicroRNA hsa-miR-200c Leads to Reduced Expression of Transcription Factor 8 and Increased Expression of E-Cadherin. Cancer Res 67: 7972-7976.

325. Bracken CP, Gregory PA, Kolesnikoff N, Bert AG, Wang J, et al. (2008) A Double-Negative Feedback Loop between ZEB1-SIP1 and the microRNA-200 Family Regulates Epithelial-Mesenchymal Transition. Cancer Res 68: 7846-7854.

326. Korpal M, Lee ES, Hu G, Kang Y (2008) The miR-200 Family Inhibits Epithelial-Mesenchymal Transition and Cancer Cell Migration by Direct Targeting of E-cadherin Transcriptional Repressors ZEB1 and ZEB2. J Biol Chem 283: 1491014914.

327. Kirschmann DA, Seftor EA, Nieva DR, Mariano EA, Hendrix MJ (1999) Differentially expressed genes associated with the metastatic phenotype in breast cancer. Breast Cancer Res Treat 55: 127-136.

328. Cannell IG, Kong YW, Bushell M (2008) How do microRNAs regulate gene expression? Biochem Soc Trans 36: 1224-1231.

329. Thiery JP, Acloque H, Huang RY, Nieto MA (2009) Epithelial-mesenchymal transitions in development and disease. Cell 139: 871-890.

330. Moustakas A, Heldin $\mathrm{CH}$ (2007) Signaling networks guiding epithelialmesenchymal transitions during embryogenesis and cancer progression. Cancer Sci 98: $1512-1520$.

331. Peinado H, Olmeda D, Cano A (2007) Snail, Zeb and bHLH factors in tumour progression: an alliance against the epithelial phenotype? Nat Rev Cancer 7: 415-428.

332. Lombaerts M, van Wezel T, Philippo K, Dierssen JW, Zimmerman RM, et al. (2006) E-cadherin transcriptional downregulation by promoter methylation but not mutation is related to epithelial-to-mesenchymal transition in breast cancer cell lines. Br J Cancer 94: 661-671.

333. Vandewalle C, Comijn J, De Craene B, Vermassen P, Bruyneel E, et al. (2005) SIP1/ZEB2 induces EMT by repressing genes of different epithelial cell-cell junctions. Nucleic Acids Res 33: 6566-6578.

334. Kang Y, Massague J (2004) Epithelial-mesenchymal transitions: twist in development and metastasis. Cell 118: 277-279.

335. Cano A, Perez-Moreno MA, Rodrigo I, Locascio A, Blanco MJ, et al. (2000) The transcription factor snail controls epithelial-mesenchymal transitions by repressing E-cadherin expression. Nat Cell Biol 2: 76-83.

336. Thiery JP, Sleeman JP (2006) Complex networks orchestrate epithelialmesenchymal transitions. Nat Rev Mol Cell Biol 7: 131-142.

337. Sreekumar R, Sayan BS, Mirnezami AH, Sayan AE (2011) MicroRNA Control of Invasion and Metastasis Pathways. Front Genet 2: 58.

338. Howe EN, Cochrane DR, Richer JK (2012) The miR-200 and miR-221/222 microRNA Families: Opposing Effects on Epithelial Identity. J Mammary Gland Biol Neoplasia. 
339. Wright JA, Richer JK, Goodall GJ (2010) microRNAs and EMT in mammary cells and breast cancer. J Mammary Gland Biol Neoplasia 15: 213-223.

340. Hiscox S, Jiang WG, Obermeier K, Taylor K, Morgan L, et al. (2006) Tamoxifen resistance in MCF7 cells promotes EMT-like behaviour and involves modulation of beta-catenin phosphorylation. Int J Cancer 118: 290-301.

341. Kim MR, Choi HK, Cho KB, Kim HS, Kang KW (2009) Involvement of Pin1 induction in epithelial-mesenchymal transition of tamoxifen-resistant breast cancer cells. Cancer Sci 100: 1834-1841.

342. Vesuna F, Lisok A, Kimble B, Domek J, Kato Y, et al. (2011) Twist contributes to hormone resistance in breast cancer by downregulating estrogen receptor-alpha. Oncogene.

343. Ward A, Balwierz A, Zhang JD, Kublbeck M, Pawitan Y, et al. (2012) Reexpression of microRNA-375 reverses both tamoxifen resistance and accompanying EMT-like properties in breast cancer. Oncogene.

344. Guttilla IK, Adams BD, White BA (2012) ER $\alpha$, microRNAs, and the epithelialmesenchymal transition in breast cancer. Trends in Endocrinology \&amp; Metabolism 23: 73-82.

345. Park SM, Gaur AB, Lengyel E, Peter ME (2008) The miR-200 family determines the epithelial phenotype of cancer cells by targeting the E-cadherin repressors ZEB1 and ZEB2. Genes Dev 22: 894-907.

346. Korpal M, Lee ES, Hu G, Kang Y (2008) The miR-200 family inhibits epithelialmesenchymal transition and cancer cell migration by direct targeting of E-cadherin transcriptional repressors ZEB1 and ZEB2. J Biol Chem 283: 14910-14914.

347. Hurteau GJ, Carlson JA, Spivack SD, Brock GJ (2007) Overexpression of the microRNA hsa-miR-200c leads to reduced expression of transcription factor 8 and increased expression of E-cadherin. Cancer Res 67: 7972-7976.

348. Brunner N, Boulay V, Fojo A, Freter CE, Lippman ME, et al. (1993) Acquisition of hormone-independent growth in MCF-7 cells is accompanied by increased expression of estrogen-regulated genes but without detectable DNA amplifications. Cancer Res 53: 283-290.

349. BRONZERT DA, GREENE GL, LIPPMAN ME (1985) Selection and Characterization of a Breast Cancer Cell Line Resistant to the Antiestrogen LY 117018. Endocrinology 117: 1409-1417.

350. Vrba L, Jensen TJ, Garbe JC, Heimark RL, Cress AE, et al. (2010) Role for DNA methylation in the regulation of miR-200c and miR-141 expression in normal and cancer cells. PLoS One 5: e8697.

351. Davalos V, Moutinho C, Villanueva A, Boque R, Silva P, et al. (2012) Dynamic epigenetic regulation of the microRNA-200 family mediates epithelial and mesenchymal transitions in human tumorigenesis. Oncogene 31: 2062-2074.

352. Pryzbylkowski P, Obajimi O, Keen JC (2008) Trichostatin A and 5 Aza-2' deoxycytidine decrease estrogen receptor mRNA stability in ER positive MCF7 cells through modulation of HuR. Breast Cancer Res Treat 111: 15-25.

353. Adam L, Zhong M, Choi W, Qi W, Nicoloso M, et al. (2009) miR-200 expression regulates epithelial-to-mesenchymal transition in bladder cancer cells and 
reverses resistance to epidermal growth factor receptor therapy. Clin Cancer Res 15: 5060-5072.

354. Li Y, VandenBoom TG, 2nd, Kong D, Wang Z, Ali S, et al. (2009) Upregulation of miR-200 and let-7 by natural agents leads to the reversal of epithelial-tomesenchymal transition in gemcitabine-resistant pancreatic cancer cells. Cancer Res 69: 6704-6712.

355. Li Y, VandenBoom TG, II, Kong D, Wang Z, Ali S, et al. (2009) Up-regulation of miR-200 and let-7 by Natural Agents Leads to the Reversal of Epithelial-toMesenchymal Transition in Gemcitabine-Resistant Pancreatic Cancer Cells. Cancer Res: 0008-5472.CAN-0009-1298.

356. Ali S, Ahmad A, Banerjee S, Padhye S, Dominiak K, et al. (2010) Gemcitabine sensitivity can be induced in pancreatic cancer cells through modulation of miR-200 and miR-21 expression by curcumin or its analogue CDF. Cancer Res 70: 3606-3617.

357. Bao B, Ali S, Kong D, Sarkar SH, Wang Z, et al. (2011) Anti-tumor activity of a novel compound-CDF is mediated by regulating miR-21, miR-200, and PTEN in pancreatic cancer. PLoS One 6: e17850.

358. Neves R, Scheel C, Weinhold S, Honisch E, Iwaniuk KM, et al. (2010) Role of DNA methylation in miR-200c/141 cluster silencing in invasive breast cancer cells. BMC Res Notes 3: 219.

359. Hiscox S, Jordan NJ, Jiang W, Harper M, McClelland R, et al. (2006) Chronic exposure to fulvestrant promotes overexpression of the c-Met receptor in breast cancer cells: implications for tumour-stroma interactions. Endocr Relat Cancer 13: 1085-1099.

360. Hiscox S, Morgan L, Green TP, Barrow D, Gee J, et al. (2006) Elevated Src activity promotes cellular invasion and motility in tamoxifen resistant breast cancer cells. Breast Cancer Res Treat 97: 263-274.

361. Guttilla IK, Phoenix KN, Hong X, Tirnauer JS, Claffey KP, et al. (2012) Prolonged mammosphere culture of MCF-7 cells induces an EMT and repression of the estrogen receptor by microRNAs. Breast Cancer Res Treat 132: 75-85.

362. Iorio MV, Visone R, Di Leva G, Donati V, Petrocca F, et al. (2007) MicroRNA signatures in human ovarian cancer. Cancer Res 67: 8699-8707.

363. Nam EJ, Yoon H, Kim SW, Kim H, Kim YT, et al. (2008) MicroRNA expression profiles in serous ovarian carcinoma. Clin Cancer Res 14: 2690-2695.

364. Hu X, Macdonald DM, Huettner PC, Feng Z, El Naqa IM, et al. (2009) A miR200 microRNA cluster as prognostic marker in advanced ovarian cancer. Gynecol Oncol 114: 457-464.

365. Dykxhoorn DM, Wu Y, Xie H, Yu F, Lal A, et al. (2009) miR-200 enhances mouse breast cancer cell colonization to form distant metastases. PLoS One 4: e7181.

366. Korpal M, Ell BJ, Buffa FM, Ibrahim T, Blanco MA, et al. (2011) Direct targeting of Sec23a by miR-200s influences cancer cell secretome and promotes metastatic colonization. Nat Med 17: 1101-1108.

367. Johnston SJ, Cheung KL (2010) Fulvestrant - a novel endocrine therapy for breast cancer. Curr Med Chem 17: 902-914. 
368. Foley J, Nickerson NK, Nam S, Allen KT, Gilmore JL, et al. (2010) EGFR signaling in breast cancer: bad to the bone. Semin Cell Dev Biol 21: 951-960.

369. Lu Y, Roy S, Nuovo G, Ramaswamy B, Miller T, et al. (2011) Anti-microRNA222 (anti-miR-222) and -181B suppress growth of tamoxifen-resistant xenografts in mouse by targeting TIMP3 protein and modulating mitogenic signal. J Biol Chem 286: 42292-42302.

370. Dorrello NV, Peschiaroli A, Guardavaccaro D, Colburn NH, Sherman NE, et al. (2006) S6K1- and betaTRCP-mediated degradation of PDCD4 promotes protein translation and cell growth. Science 314: 467-471.

371. Schmid T, Jansen AP, Baker AR, Hegamyer G, Hagan JP, et al. (2008) Translation inhibitor Pdcd4 is targeted for degradation during tumor promotion. Cancer Res 68: 1254-1260.

372. Park SH, Cheung LW, Wong AS, Leung PC (2008) Estrogen regulates Snail and Slug in the down-regulation of E-cadherin and induces metastatic potential of ovarian cancer cells through estrogen receptor alpha. Mol Endocrinol 22: 2085-2098.

373. Ye Y, Xiao Y, Wang W, Yearsley K, Gao JX, et al. (2008) ERalpha suppresses slug expression directly by transcriptional repression. Biochem J 416: 179-187.

374. Ye Y, Xiao Y, Wang W, Yearsley K, Gao JX, et al. (2010) ERalpha signaling through slug regulates E-cadherin and EMT. Oncogene 29: 1451-1462.

375. Dhasarathy A, Kajita M, Wade PA (2007) The transcription factor snail mediates epithelial to mesenchymal transitions by repression of estrogen receptor-alpha. Mol Endocrinol 21: 2907-2918.

376. Tan Y, Zhang B, Wu T, Skogerbo G, Zhu X, et al. (2009) Transcriptional inhibiton of Hoxd4 expression by miRNA-10a in human breast cancer cells. BMC Molecular Biology 10: 12.

377. Volanis D, Kadiyska T, Galanis A, Delakas D, Logotheti S, et al. (2010) Environmental factors and genetic susceptibility promote urinary bladder cancer. Toxicology Letters 193: 131-137.

378. Persson H, Kvist A, Rego N, Staaf J, Vallon-Christersson J, et al. (2011) Identification of New MicroRNAs in Paired Normal and Tumor Breast Tissue Suggests a Dual Role for the ERBB2/Her2 Gene. Cancer Research 71: 78-86.

379. Kulshreshtha R, Ferracin M, Wojcik SE, Garzon R, Alder H, et al. (2007) A MicroRNA Signature of Hypoxia. Mol Cell Biol 27: 1859-1867.

380. Pan Q, Luo X, Toloubeydokhti T, Chegini N (2007) The expression profile of micro-RNA in endometrium and endometriosis and the influence of ovarian steroids on their expression. Mol Hum Reprod 13: 797-806.

381. Pan Q, Luo X, Chegini N (2008) Differential expression of microRNAs in myometrium and leiomyomas and regulation by ovarian steroids. Journal of Cellular and Molecular Medicine 12: 227-240.

382. Hu S-J, Ren G, Liu J-L, Zhao Z-A, Yu Y-S, et al. (2008) MicroRNA Expression and Regulation in Mouse Uterus during Embryo Implantation. J Biol Chem 283: 23473-23484. 
383. Romero DG,' Plonczynski MW, Carvajal CA, Gomez-Sanchez EP, GomezSanchez CE (2008) MicroRNA-21 Increases Aldosterone Secretion and Proliferation in H295R Human Adrenocortical Cells. Endocrinology: en.2007-1686.

384. Fix LN, Shah M, Efferth T, Farwell MA, Zhang B (2010) MicroRNA Expression Profile of MCF-7 Human Breast Cancer Cells and the Effect of Green Tea Polyphenon-60. Cancer Genomics - Proteomics 7: 261-277.

385. Terao M, Fratelli M, Kurosaki M, Zanetti A, Guarnaccia V, et al. (2011) Induction of miR-21 by Retinoic Acid in Estrogen Receptor-positive Breast Carcinoma Cells. Journal of Biological Chemistry 286: 4027-4042.

386. Foekens JA, Sieuwerts AM, Smid M, Look MP, de Weerd V, et al. (2008) Four miRNAs associated with aggressiveness of lymph node-negative, estrogen receptorpositive human breast cancer. Proceedings of the National Academy of Sciences 105: 13021-13026.

387. Xiong J, Du Q, Liang Z (2010) Tumor-suppressive microRNA-22 inhibits the transcription of E-box-containing c-Myc target genes by silencing $\mathrm{c}-\mathrm{Myc}$ binding protein. Oncogene 29: 4980-4988.

388. Zhao J-J, Lin J, Lwin T, Yang H, Guo J, et al. (2010) microRNA expression profile and identification of miR-29 as a prognostic marker and pathogenetic factor by targeting CDK6 in mantle cell lymphoma. Blood 115: 2630-2639.

389. Muniyappa MK, Dowling P, Henry M, Meleady P, Doolan P, et al. (2009) MiRNA-29a regulates the expression of numerous proteins and reduces the invasiveness and proliferation of human carcinoma cell lines. European Journal of Cancer 45: 3104-3118.

390. Szczyrba J, Löprich E, Wach S, Jung V, Unteregger G, et al. (2010) The MicroRNA Profile of Prostate Carcinoma Obtained by Deep Sequencing. Molecular Cancer Research: -.

391. Xu H, Cheung IY, Guo H-F, Cheung N-KV (2009) MicroRNA miR-29 Modulates Expression of Immunoinhibitory Molecule B7-H3: Potential Implications for Immune Based Therapy of Human Solid Tumors. Cancer Res 69: 6275-6281.

392. Kapinas K, Kessler C, Ricks T, Gronowicz G, Delany AM (2010) miR-29 Modulates Wnt Signaling in Human Osteoblasts through a Positive Feedback Loop. Journal of Biological Chemistry 285: 25221-25231.

393. Tanzer A, Stadler PF (2004) Molecular Evolution of a MicroRNA Cluster. Journal of Molecular Biology 339: 327-335.

394. Donker RB, Mouillet JF, Nelson DM, Sadovsky Y (2007) The expression of Argonaute2 and related microRNA biogenesis proteins in normal and hypoxic trophoblasts. Mol Hum Reprod 13: 273-279.

395. Yeung ML, Yasunaga J-i, Bennasser Y, Dusetti N, Harris D, et al. (2008) Roles for MicroRNAs, miR-93 and miR-130b, and Tumor Protein 53-Induced Nuclear Protein 1 Tumor Suppressor in Cell Growth Dysregulation by Human T-Cell Lymphotrophic Virus 1. Cancer Res 68: 8976-8985.

396. Kim Y-K, Yu J, Han TS, Park S-Y, Namkoong B, et al. (2009) Functional links between clustered microRNAs: suppression of cell-cycle inhibitors by microRNA clusters in gastric cancer. Nucl Acids Res 37: 1672-1681. 
397. Raponi M, Dossey L, Jatkoe T, Wu X, Chen G, et al. (2009) MicroRNA Classifiers for Predicting Prognosis of Squamous Cell Lung Cancer. Cancer Res 69: 5776-5783.

398. Su H, Yang J-R, Xu T, Huang J, Xu L, et al. (2009) MicroRNA-101, Downregulated in Hepatocellular Carcinoma, Promotes Apoptosis and Suppresses Tumorigenicity. Cancer Res 69: 1135-1142.

399. Zhou M, Liu Z, Zhao Y, Ding Y, Liu H, et al. (2010) MicroRNA-125b Confers the Resistance of Breast Cancer Cells to Paclitaxel through Suppression of Proapoptotic Bcl-2 Antagonist Killer 1 (Bak1) Expression. Journal of Biological Chemistry 285: 21496-21507.

400. Iorio MV, Visone R, Di Leva G, Donati V, Petrocca F, et al. (2007) MicroRNA Signatures in Human Ovarian Cancer. Cancer Res 67: 8699-8707.

401. Wong T-S, Liu X-B, Wong BY-H, Ng RW-M, Yuen AP-W, et al. (2008) Mature miR-184 as Potential Oncogenic microRNA of Squamous Cell Carcinoma of Tongue. Clin Cancer Res 14: 2588-2592.

402. Dai R, Phillips RA, Zhang Y, Khan D, Crasta O, et al. (2008) Suppression of LPS-induced IFN \{gamma\} and nitric oxide in splenic lymphocytes by select estrogen-regulated miRNA: A novel mechanism of immune modulation. Blood 112: 4591-4597.

403. Ferretti E, De Smaele E, Miele E, Laneve P, Po A, et al. (2008) Concerted microRNA control of Hedgehog signalling in cerebellar neuronal progenitor and tumour cells. EMBO J.

404. Li W, Xie L, He X, Li J, Tu K, et al. (2008) Diagnostic and prognostic implications of microRNAs in human hepatocellular carcinoma. Int J Cancer 123: 1616-1622.

405. Lowery AJ, Miller N, McNeill RE, Kerin MJ (2008) MicroRNAs as prognostic indicators and therapeutic targets: potential effect on breast cancer management. Clin Cancer Res 14: 360-365.

406. Ohlsson Teague EMC, Van der Hoek KH, Van der Hoek MB, Perry N, Wagaarachchi P, et al. (2009) Differentially expressed microRNAs and their mRNA targets constitute molecular pathways associated with endometriosis. Mol Endocrinol 23: 265-275.

407. Murphy AJ, Guyre PM, Pioli PA (2010) Estradiol Suppresses NF-\{kappa\}B Activation through Coordinated Regulation of let-7a and miR-125b in Primary Human Macrophages. J Immunol 184: 5029-5037.

408. Rajabi H, Jin C, Ahmad R, McClary C, Joshi MD, et al. (2010) MUCIN 1 ONCOPROTEIN EXPRESSION IS SUPPRESSED BY THE MIR-125b ONCOMIR. Genes Cancer 1: 62-68.

409. Shi L, Cheng Z, Zhang J, Li R, Zhao P, et al. (2008) hsa-mir-181a and hsa-mir$181 \mathrm{~b}$ function as tumor suppressors in human glioma cells. Brain Research 1236: 185193.

410. Pekarsky Y, Santanam U, Cimmino A, Palamarchuk A, Efanov A, et al. (2006) Tcll Expression in Chronic Lymphocytic Leukemia Is Regulated by miR-29 and miR-181. Cancer Res 66: 11590-11593. 
411. Xi Y, Formentini A, Chien M, Weir DB, Russo JJ, et al. (2006) Prognostic Values of microRNAs in Colorectal Cancer. Biomark Insights 2: 113-121.

412. Schetter AJ, Leung SY, Sohn JJ, Zanetti KA, Bowman ED, et al. (2008) MicroRNA expression profiles associated with prognosis and therapeutic outcome in colon adenocarcinoma. JAMA 299: 425-436.

413. Garzon R, Pichiorri F, Palumbo T, Visentini M, Aqeilan R, et al. (2007) MicroRNA gene expression during retinoic acid-induced differentiation of human acute promyelocytic leukemia. Oncogene 26: 4148-4157.

414. Ambs S, Prueitt RL, Yi M, Hudson RS, Howe TM, et al. (2008) Genomic Profiling of MicroRNA and Messenger RNA Reveals Deregulated MicroRNA Expression in Prostate Cancer. Cancer Res 68: 6162-6170.

415. Yan L-X, Huang X-F, Shao Q, Huang M-Y, Deng L, et al. (2008) MicroRNA miR-21 overexpression in human breast cancer is associated with advanced clinical stage, lymph node metastasis and patient poor prognosis. RNA 14: 2348-2360.

416. Cuesta R, Martinez-Sanchez A, Gebauer F (2009) miR-181a Regulates CapDependent Translation of p27kip1 mRNA in Myeloid Cells. Mol Cell Biol 29: 28412851.

417. Fei J, Lan F, Guo M, Li Y, Liu Y (2008) Inhibitory effects of anti-miRNA oligonucleotides (AMOs) on A549 cell growth. J Drug Target 16: 688-693.

418. Galluzzi L, Morselli E, Vitale I, Kepp O, Senovilla L, et al. (2010) miR-181a and miR-630 Regulate Cisplatin-Induced Cancer Cell Death. Cancer Res 70: 1793-1803.

419. Gao W, Yu Y, Cao H, Shen H, Li X, et al. (2010) Deregulated expression of miR-21, miR-143 and miR-181a in non small cell lung cancer is related to clinicopathologic characteristics or patient prognosis. Biomedicine \& Pharmacotherapy In Press, Corrected Proof.

420. Huang S, Wu S, Ding J, Lin J, Wei L, et al. (2010) MicroRNA-181 a modulates gene expression of zinc finger family members by directly targeting their coding regions. Nucl Acids Res: gkq564.

421. Bandres E, Cubedo E, Agirre X, Malumbres R, Zarate R, et al. (2006) Identification by Real-time PCR of 13 mature microRNAs differentially expressed in colorectal cancer and non-tumoral tissues. Mol Cancer 5: 29.

422. Uhlmann S, Zhang JD, Schwager A, Mannsperger H, Riazalhosseini Y, et al. (2010) miR-200bc/429 cluster targets PLC[gamma]1 and differentially regulates proliferation and EGF-driven invasion than miR-200a/141 in breast cancer. Oncogene.

423. Yang H, Kong W, He L, Zhao J-J, O'Donnell JD, et al. (2008) MicroRNA Expression Profiling in Human Ovarian Cancer: miR-214 Induces Cell Survival and Cisplatin Resistance by Targeting PTEN. Cancer Res 68: 425-433.

424. Xia H, Cheung WKC, Sze J, Lu G, Jiang S, et al. (2010) miR-200a Regulates Epithelial-Mesenchymal to Stem-like Transition via ZEB2 and $\beta$-Catenin Signaling. Journal of Biological Chemistry 285: 36995-37004.

425. Hurteau GJ, Spivack SD, Brock GJ (2006) Potential mRNA degradation targets of hsa-miR-200c, identified using informatics and qRT-PCR. Cell Cycle 5: 19511956. 
426. Iorio MV, Casalini P, Piovan C, Di Leva G, Merlo A, et al. (2009) microRNA205 Regulates HER3 in Human Breast Cancer. Cancer Res 69: 2195-2200.

427. le Sage C, Nagel R, Egan DA, Schrier M, Mesman E, et al. (2007) Regulation of the $\mathrm{p} 27$ (Kip1) tumor suppressor by miR-221 and miR-222 promotes cancer cell proliferation. Embo J 26: 3699-3708.

428. Medina R, Zaidi SK, Liu C-G, Stein JL, vanWijnen AJ, et al. (2008) MicroRNAs 221 and 222 Bypass Quiescence and Compromise Cell Survival. Cancer Res 68: 2773-2780.

429. Chen Y, Zaman MS, Deng G, Majid S, Saini S, et al. (2011) MicroRNAs 221/222 and Genistein-Mediated Regulation of ARHI Tumor Suppressor Gene in Prostate Cancer. Cancer Prevention Research 4: 76-86.

430. Zhang C, Zhang J, Zhang A, Wang Y, Han L, et al. (2010) PUMA is a novel target of miR-221/222 in human epithelial cancers. Int J Oncol 37: 1621-1626.

431. Wong QW-L, Ching AK-K, Chan AW-H, Choy K-W, To K-F, et al. (2010) MiR-222 Overexpression Confers Cell Migratory Advantages in Hepatocellular Carcinoma through Enhancing AKT Signaling. Clinical Cancer Research 16: 867875. 


\title{
APPENDICES
}

\begin{abstract}
APPENDIX 1: Differentially expressed miRNAs in MCF-7 estrogen/TAMsensitive versus LY2 TAM/ endocrine resistant cells and their roles in breast and other cancers.
\end{abstract}




\begin{tabular}{|c|c|}
\hline & omments \\
\hline & $\begin{array}{l}\text { iR-10a inhibits hoxd } 4 \text { gene expression in breast cancer cells [376]. } \\
\text { iR-10a interacts with the } 5^{\prime} \text { untranslated region of mRNAs encoding } \\
\text { bosomal proteins to enhance their translation and increases global protein } \\
\text { pression [302]. } \\
\text { embryonic stem cells, RA induces binding of p65 to the miR-10a } \\
\text { omoter, leading to an increased in miR-10a and enhanced miR-10a } \\
\text { pression suppresses HDAC4 expression [301]. } \\
\text { iR-10a is upregulated in bladder cancer and targets FGFR3 [377]. miR-10a } \\
\text { pression is increased by retinoic acid-induced NFKB activation during } \\
\text { nooth muscle cell (SMC) differentiation from mouse embryonic stem cells } \\
\text { SCs) [301]. }\end{array}$ \\
\hline & $\begin{array}{l}\text { miR-21 is an oncomiR that is significantly up-regulated in all types of breast } \\
\text { tumors [378] and in breast cancer cell lines [257]. miR-21 is overexpressed in } \\
\text { all solid tumors (lung, breast, stomach, prostate, colon, and pancreatic) [258]. } \\
\text { The role of miR-21 in breast cancer was recently reviewed [262]. miR-21 was } \\
\text { significantly higher in ER } \alpha+v s \text {. ER } \alpha \text {-, ErbB2 }-v s \text {. ErbB2 }+ \text {, and in PR+vs. } \\
\text { PR- breast tumors [304]. Hypoxia increasedmiR-21 expression in MCF-7 } \\
\text { [379]. miR-21 in mammary gland was increased after } 18 \text { wks of } E_{2} \text { treatment } \\
\text { of female ACI rats [157]. Both } \mathrm{E}_{2} \text { and ICI decreased miR-21 in human } \\
\text { endometrial stromal and glandular epithelial cells, but when combined, miR-21 } \\
\text { expression returned to basal [380]. } \mathrm{E}_{2} \text { suppressed and ICI increased miR-21 in } \\
\text { human myometrial smooth muscle cells [381]. } \mathrm{E}_{2} \text { inhibited the ICI-induced } \\
\text { increase in miR-21 in these cells [381]. } \mathrm{E}_{2} \text { and Progesterone reduced miR-21 } \\
\text { expression on the uterus of ovex mice [382]. Angiotensin II increased miR-21 } \\
\text { expression, aldosterone secretion and proliferation in H295R human } \\
\text { adrenocortical cells [383]. miR-21 expression was significantly reduced in } \\
\text { tamoxifen-resistant MCF-7 cells [270]. Another group reported that } \mathrm{E}_{2}(4 \mathrm{~h} \text { ) } \\
\text { increased miR-21 in MCF-7 cells [260]. Knockdown of miR-21 in ER- } \\
\text { negative/basal- like MDA-MB-231 breast cancer cells decreased cell migration } \\
\text { in vitro and the formation of tumors in the lungs of female nude mice after tail } \\
\text { vein injection of the si-miR-21 transfected MDA-MB-231 cells [187]. miR-21 } \\
\text { was downregulated in MCF-7 cells with } 48 \text { h of treatment with } 10 \mu \mathrm{g} / \mathrm{ml} \\
\text { Polyphenon-60 (green tea extract) [384]. miR-21 expression is induced by all- } \\
\text { trans retinoic acid in ER } \alpha+\text { breast cancer cells [385]. }\end{array}$ \\
\hline & $\begin{array}{l}\text { MiR-22 was increased in rat mammary gland by } 6 \text { and } 12 \text { wks. of } E_{2} \text { treatment } \\
\text { of female August Copenhagen Irish (ACI) rats [157]. MiR-22 was } \\
\text { differentially expressed between patients with a short time to distant metastasis } \\
\text { (TDM) (i.e., tumor aggressiveness) versus those with a long TDM [386]. } \\
\text { miR-22 represses ER } \alpha \text { expression by directly targeting the ER } \alpha \text { mRNA 3' } \\
\text { UTR [231]. } \\
\text { miR-22 is a tumor suppressor that represses the c-Myc-binding protein } \\
\text { MYCBP, a positive regulator of c-Myc [387]. } \\
\text { miR-22 repressed the c-Myc-binding protein MYCBP, a positive regulator of } \\
\text { c-Myc, which resulted in inhibition of growth of MCF-7 breast cancer cells } \\
\text { [387]. } \\
\text { miR-22 is a tumor suppressor [387]. }\end{array}$ \\
\hline & $\begin{array}{l}\text { miR-29 family is a tumor suppressor miRNA [388]. } \\
\text {-29a expression was down-regulated in invasive lung and pancreatic cell } \\
\text { and re-expression of miR-29a reduced the in vitro invasive ability of lung } \\
\text { pancreatic cancer cell lines [389]. }\end{array}$ \\
\hline
\end{tabular}




\begin{tabular}{|c|c|}
\hline & $\begin{array}{l}\text { miR-29a was downregulated in prostate tumors [390]. } \\
\text { miR-29 regulates CDK6 as well as oncogenes Tcl-141 and Mcl-1; cell growth } \\
\text { and survival genes, YY1, p85, CDC42 and DNMT3; as well as natural killer } \\
\text { and T-cell inhibitor B7-H3 [388]. } \\
\text { miR-29a targets the 3'UTR of B7-H3, a surface immunomodulatory } \\
\text { lycoprotein that inhibits natural killer cells and T cells, thus offering a } \\
\text { nechanism by which loss of miR-29a plays a role in immune escape by solid } \\
\text { umors [391]. } \\
\text { miR-29 is induced by Wnt signaling and in turn, the negative regulators of } \\
\text { Wnt signaling, Dikkopf-1 (Dkk1), Kremen2, and secreted frizzled related } \\
\text { protein } 2 \text { (sFRP2), are direct targets of miR-29a in osteoblasts [392]. } \\
\text { miR-29a was downregulated in human prostate cancer tumors } \sim 42 \% \text { [390]. }\end{array}$ \\
\hline miR-93 & $\begin{array}{l}\text { miR-93 is in the tri-cistronic miR-106b cluster that expresses miR-106b, miR- } \\
93 \text { and miR-25. } \\
\text { microRNAs mir-17, mir-106a, mir-106b, mir-93, mir-20, and mir-18 are } \\
\text { ancient paralogs [393]. } \\
\text { expression of miR-93 was up-regulated in hypoxic trophoblasts [394]. } \\
\text { miR-93 was among the miRNAs determined to be the most stable miRNA } \\
\text { normalizers in normal human tissues [286]. } \\
\text { miR-93 was upregulated in HTLV-1-transformed human T-cell lines and } \\
\text { primary peripheral blood mononuclear cells from adult T-cell leukemia } \\
\text { patients [395]. } \\
\text { miR-93 inhibits p21 expression, thus reducing a 'brake' on cell cycle } \\
\text { progression [396]. . } \\
\text { miR-93 is upregulated in squamous cell carcinoma (SCC), a type of nonsmall } \\
\text { cell lung carcinoma (NSCLC) [397]. } \\
\text { miR-93 is upregulated in human hepatocellular carcinoma (HCC) compared to } \\
\text { normal hepatic tissues [398]. }\end{array}$ \\
\hline $\begin{array}{l}\text { miR- } \\
125 \mathrm{~b}\end{array}$ & $\begin{array}{l}\text { miR-125b is a tumor suppressor miRNA in breast cancer [262]. } \\
\text { miR-125b is consistently down-regulated in human breast cancer cell lines } \\
{[257] \text {. }} \\
\text { miR-125b was upregulated in Taxol-resistant breast cancer cell lines, 435TRa } \\
\text { NA } 435 \mathrm{TRP} \text { compared to their parental MDA-MB-435 cell line [399]. } \\
\text { Significantly higher in ErbB2- vs. ErbB2+ tumors [304]. } \\
\text { Significantly higher in ER } \alpha+\text { than ER } \alpha \text { - tumors [304]. } \\
\text { Significantly higher in PR+ than PR-tumors [304]. } \\
\text { miR-125b inhibits ERBB2 and ERBB3 translation [201] } \\
\text { miR-125b expression was increased by hypoxia in MCF-7 cells [379]. } \\
\text { miR-125b was downregulated in epithelial ovarian cancer [400] and in } \\
\text { squamous cell carcinoma (SCC) of the tongue [401]. } \\
\mathrm{E}_{2} \text { down-regulated miR-125b in mouse splenic lymphocytes [402]. } \\
\text { miR-125b was identified as a suppressor of the pathway activator Smoothened } \\
\text { in cerebellar neuronal progenitor and tumor cells [403]. } \\
\text { miR-125b is reduced in human hepatocellular carcinoma (HCC) [398] and } \\
\text { high miR-125b was correlated with good survival of HCC patients [404]. } \\
\text { miR-125b was downregulated in prostate tumors [390]. } \\
\text { miR-125b is located at chromosome } 11 \text { a } 23-24 \text {, one of the regions most } \\
\text { frequently deleted in breast, ovarian, and lung tumors [405]. } \\
\text { miR-125b repressed C-Raf protein expression in MDA-MB-453 breast cancer } \\
\text { cells. } \\
\text { miR-125b is upregulated in endometriosis [406]. } \\
\mathrm{E}_{2} \text { did not affect miR-125b expression in macrophages [407]. }\end{array}$ \\
\hline
\end{tabular}




\begin{tabular}{|c|c|}
\hline & $\begin{array}{l}\text { miR-125b inhibits MUC1 protein expression in MCF- } 7 \text { breast cancer cells } \\
\text { [408]. } \\
\text { miR-125b confers paclitaxel resistance in breast cancer cells by suppressing } \\
\text { Baklexpression [399]. }\end{array}$ \\
\hline & $\begin{array}{l}\text { miR-181a expression was reduced by } \mathrm{E}_{2} \text { in } \mathrm{MCF}-7 \text { cells [261]. } \\
\text { miR-181a and miR-181b are down-regulated in human gliomas and act as } \\
\text { tumor suppressors which triggered growth inhibition, induced apoptosis and } \\
\text { inhibited invasion in glioma cells [409]. } \\
\text { Regulates oncogene TCL1 in Chronic Lymphocytic Leukemia (CLL) [410] } \\
\text { miR-181b was over-expressed in tumors compared to normal colorectal } \\
\text { samples [ } 411,412] \text {. } \\
\text { miR-181b was downregulated in during retinoic acid-induced differentiation of } \\
\text { human acute promyelocytic leukemia [413]. } \\
\text { miR181b-1, miR-181c were down-regulated in prostate cancer [414]. } \\
\text { miR-181a was upregulated in 4-OHT-resistant MCF-7 cells [270]. } \\
\text { Predicted targets [381]: hsa-miR181a 9q33.3 ESR2, ABI1, ABI3BP, } \\
\text { ADAM11, BMP3, BMPER, BMPR2, EGR1,EGR3, FGFR3, MMP14, } \\
\text { MPP5, NCOA2, NEGR1, PAK4, PAK7, RUNX1, S100PBP, SMAD7, } \\
\text { SOX5, SOX6, STC1, TGFBI, TGFBR1, TMP3,TSC22D2 [381]. } \\
\text { miR-181d was up-regulated greater than twofold in breast cancer compared } \\
\text { with normal adjacent tissue [415]. } \\
\text { miR-181 inhibits the translation of p27kip1 (p27), a cell cycle inhibitor and } \\
\text { tumor suppressor, in myeloid cell differentiation [416]. } \\
\text { Antisense-microRNA oligonucleotides (AMOs) against miR-181a inhibited } \\
\text { the growth of A549 human lung adenocarcinoma cells [417]. } \\
\text { Overexpression of miR-181a in A549 lung cancer cells sensitized the cells to } \\
\text { the lethal action of cisplatin by stimulating Bax oligomerization and the } \\
\text { activation of proapoptotic caspase [418]. } \\
\text { miR-181a was reduced in human NSCLC tissues [419]. } \\
\text { miR-181a inhibits the expression of a large number of zinc finger genes } \\
\text { (ZNFs) by interacting with seed elements within the coding regions [420]. }\end{array}$ \\
\hline $\begin{array}{l}\text { miR-200 } \\
\text { family } \\
\text { member } \\
\text { s miR- } \\
200 a \\
\text { miR- } \\
200 \mathrm{~b}\end{array}$ & $\begin{array}{l}\text { miR-200a correlated with ER } \alpha \text { status in human breast tumors [304]. miR-200a } \\
\text { expression significantly up-regulated in all types of breast tumors compared to } \\
\text { adjacent normal tissue [378]. } \\
\text { Significantly > in ER } \alpha+\text { than ER } \alpha \text { - human breast tumors (1) and PR+ than } \\
\text { PR- breast tumors(1), miR-200a is expressed in MCF-7 and other epithelial } \\
\text { breast cancer cell lines [203]. } \\
\text { miR-200a was increased in colorectal cancer cell lines [421] and in epithelial } \\
\text { ovarian cancer [400]. } \\
\text { miR-200 expression was reduced in tamoxifen-resistant MCF-7 cells [270]. } \\
\text { All five members of the microRNA-200 family (miR-200a, miR-200b, miR- } \\
200 c \text { c miR-141 and miR-429) and miR-205 were markedly downregulated in } \\
\text { cells that had undergone EMT in response to transforming growth factor } \\
\text { (TGF)-beta [203] } \\
\text { The miR-200 family inhibits expression of the related transcriptional } \\
\text { repressors ZEB } 1 / \text { deltaEF1 and SIP1/ZEB2 in epithelial cells and play a major } \\
\text { role in preventing these factors from triggering epithelial to mesenchymal } \\
\text { transition (EMT) [203]. } \\
\text { However, miR-200 family members differentially regulate EGF-driven } \\
\text { invasion, viability, apoptosis and cell cycle progression of breast cancer cells, } \\
\text { with the miR-200bc/429 cluster showing stronger effects than the miR- } \\
200 \text { a/ } 141 \text { cluster [422]. }\end{array}$ \\
\hline
\end{tabular}




\begin{tabular}{|c|c|}
\hline & $\begin{array}{l}\text { miR-200a expression is increased in ovarian tumors compared to normal ovary } \\
\text { [423]. } \\
\text { miR-200a expression was reduced in endometriosis [406]. } \\
\text { miR-200a is upregulated in squamous cell carcinoma (SCC), a type of } \\
\text { nonsmall cell lung carcinoma (NSCLC) [397]. } \\
\mathrm{E}_{2}(4 \mathrm{~h}) \text { increased miR-200a } 2 \text {-fold in MCF-7 cells [260]. } \\
\mathrm{E}_{2}(48 \mathrm{~h}) \text { reduced miR-200c expression in MCF-7 cells [261]. } \\
\text { miR-200a regulated ZEB1 expression, thus regulating epithelial to } \\
\text { mesenchymal transition (EMT) [424]. } \\
\text { Likewise, there is a double negative feedback loop of miR-200ab and ZEB1, } \\
\text { which regulates E-cadherin expression, in EMT [325]. } \\
\text { miR-200c was highly expressed in MCF-7 cells with lower and more variable } \\
\text { expression in MDA-MB-231 cells [425]. } \\
\text { TCF8, also termed ZEB1, which is a key regulator of epithelial to } \\
\text { mesenchymal transition (EMT) by repressing E-cadherin expression, was } \\
\text { identified as the target of miR-200c in A549 lung cancer cells [324]. } \\
\text { Recent studies have implicated a negative feedback loop of miR-200c and } \\
\text { ZEB } 1 \text { in cancer cells including breast [205,322,323,325]. } \\
\text { miR-200b and miR-200c are reduced in lymph node metastases of primary } \\
\text { breast tumors [209]. }\end{array}$ \\
\hline miR-205 & $\begin{array}{l}\text { Early studies reported that miR-205 expression was higher in ER } \alpha / \text { PR-positive } \\
\text { breast tumors and reduced in ErbB2-positive breast tumors [304]. } \\
\text { Expression of miR-205 was restricted to the myoepithelial/basal cell } \\
\text { compartment of normal mammary ducts and lobules and miR-205 expression } \\
\text { was reduced or completely eliminated in matching tumor specimens [221]. } \\
\text { miR-205 expression is reduced in breast cancer cells that had undergone EMT } \\
\text { in response to transforming growth factor (TGF)-beta or to ectopic expression } \\
\text { of the protein tyrosine phosphatase Pez [203]. } \\
\text { miR-205 was downregulated in breast tumors and miR-205 directly targets } \\
\text { HER3 and inhibits the activation of the downstream mediator Akt [426]. The } \\
\text { reintroduction of miR-205 into SKBr3 breast cancer cells inhibited colony } \\
\text { formation and increased inhibition by tyrosine-kinase inhibitors Gefitinib and } \\
\text { Lapatinib, abrogating the HER3-mediated resistance and restoring a potent } \\
\text { proapoptotic activity [426] } \\
\text { MCF-7 and MDA-MB-231 express lower miR-205 than non-malignant MCF- } \\
10 A \text { cells [296]. Ectopic expression of miR-205 in MCF-7 cells significantly } \\
\text { inhibited cell proliferation and overexpression of miR-205 inhibited MDA- } \\
\text { MB-231 cell invasion and metastasis to lung when injected into nude mice } \\
\text { [296]. ErbB3 and vascular endothelial growth factor A (VEGF-A) are direct } \\
\text { targets for miR-205 [296]. }\end{array}$ \\
\hline miR-221 & $\begin{array}{l}\text { Upregulated in 4-OHT-resistant [270] and Fulvestrant-resistant [272] MCF-7 } \\
\text { cells. } \\
\text { Variably expressed in human breast tumors: highly expressed in some and } \\
\text { completely absent in other specimens [221]. } \\
\text { miR-221 is part of a gene cluster also expressing miR-222, a close homologue } \\
\text { of miR-221 [427]. Both miRNAs share an identical seed sequence [427]. } \\
\text { Reduction of the p27Kip 1 tumor suppressor by miR-221 and miR-222 } \\
\text { promotes cancer cell proliferation [427]. } \\
\text { MiR-221 and miR-222 both directly target the } 3 \text { ' untranslated regions of p27 } \\
\text { and p57 mRNAs [428]. } \\
\text { MiR-221 and miR-222 are elevated in ER } \alpha \text {-negative breast cancer cells and }\end{array}$ \\
\hline
\end{tabular}




\begin{tabular}{|l|l|}
\hline both directly target the 3' untranslated region of ESR1 (ER $\alpha$ ) and reduced ER $\alpha$ \\
expression [295]. \\
ER $\alpha$ inhibits miR-221 expression [234]. \\
miR-221 was upregulated in Taxol-resistant breast cancer cell lines, 435TRa \\
NA 435TRP compared to their parental MDA-MB-435 cell line [399]. \\
miR-221 is down-regulated in prostate cancer [414] and regulates tumor \\
suppressor ARHI expression [429]. \\
miR-221 inhibits expression of p53 upregulated modulator of apoptosis \\
(PUMA) in breast and lung cancer cells [430]. \\
$\begin{array}{l}\text { Upregulated in 4-OHT-resistant [270] and Fulvestrant-resistant [272] MCF-7 } \\
\text { cells. } \\
\text { Variably expressed in human breast tumors: highly expressed in some and } \\
\text { completely absent in other specimens [221]. } \\
\text { miR-222 was upregulated in Taxol-resistant breast cancer cell lines, 435TRa } \\
\text { NA 435TRP compared to their parental MDA-MB-435 cell line [399]. } \\
\text { Overexpression of miR-222 in hepatocellular cancer activates AKT signaling } \\
\text { [431]. } \\
\text { Overexpression of miR-221 and } 222 \text { increased proliferation in ER } \alpha+\text { MCF-7 } \\
\text { breast cancer cells and reduced ER } \alpha \text { protein levels [234]. ER } \alpha \text { inhibits miR- } \\
\text { 222 expression [234]. } \\
\text { miR-222 inhibits expression of p53 upregulated modulator of apoptosis } \\
\text { (PUMA) in breast and lung cancer cells [430]. } \\
\text { Overexpression of miR-222 activates AKT signaling in hepatocellular } \\
\text { carcinoma by suppressing the protein phosphatase 2A subunit B (PPP2R2A) } \\
{[431] \text {. }}\end{array}$ \\
\hline miR-222
\end{tabular}


APPENDIX 2:

mRNA gene targets of the indicated miRNAs differentially expressed in MCF-7

versus LY2 cells that were identified in Frasor et al. Cancer Research 2004 


\begin{tabular}{|c|c|c|c|c|c|c|}
\hline & & & & & Frasor et & Cancer Res. \\
\hline & & microarray & microarray & in MCF-7 & $\begin{array}{l}8 \mathrm{~h} \quad 4- \\
\mathrm{OHT}^{*}\end{array}$ & $\begin{array}{l}48 \\
4 \mathrm{OHT}^{*}\end{array}$ \\
\hline $\begin{array}{l}\text { mRNA } \\
\text { target }\end{array}$ & miRNA & $\begin{array}{l}\text { MCF-7 + 4- } \\
\text { OHT }\end{array}$ & $\begin{array}{l}\text { LY2 + 4- } \\
\text { OHT }\end{array}$ & $\begin{array}{l}\text { expect } \\
\text { mRNA }\end{array}$ & $\begin{array}{c}4 \mathrm{~h} \mathrm{4-} \\
\mathrm{OHT}\end{array}$ & $\begin{array}{c}24 \mathrm{~h} \mathrm{4-} \\
\mathrm{OHT}\end{array}$ \\
\hline SMPD1 & $\begin{array}{l}\text { hsa-miR- } \\
10 a\end{array}$ & -2 & 3 & $\begin{array}{l}\text { higher than } \\
\text { LY2 }\end{array}$ & $0.62^{\star}$ & $0.49^{*}$ \\
\hline EFNB2 & $\begin{array}{l}\text { hsa-miR- } \\
10 a\end{array}$ & & & & 1.2 & 2.7 \\
\hline GPR56 & $\begin{array}{l}\text { hsa-miR- } \\
10 a\end{array}$ & & & & 1.4 & 2.3 \\
\hline$S D C 1$ & $\begin{array}{l}\text { hsa-miR- } \\
10 a\end{array}$ & & & & & \\
\hline LTBP1 & $\begin{array}{l}\text { hsa-miR- } \\
\text { 10a }\end{array}$ & & & & 0.7 & 2.8 \\
\hline B3GNT1 & $\begin{array}{l}\text { hsa-miR- } \\
\text { 125b }\end{array}$ & -2 & 1 & $\begin{array}{l}\text { higher than } \\
\text { LY2 }\end{array}$ & 1.4 & 2 \\
\hline ERBB3 & $\begin{array}{l}\text { hsa-miR- } \\
125 \mathrm{~b}\end{array}$ & & & & $0.61^{*}$ & $0.53^{*}$ \\
\hline C140rf43 & $\begin{array}{l}\text { hsa-miR- } \\
125 \mathrm{~b}\end{array}$ & & & & & \\
\hline GGA2 & $\begin{array}{l}\text { hsa-miR- } \\
125 b\end{array}$ & & & & 0.9 & 2.5 \\
\hline NATS & $\begin{array}{l}\text { hsa-miR- } \\
125 \mathrm{~b}\end{array}$ & & & & 0.9 & 0.5 \\
\hline$S D C 1$ & $\begin{array}{l}\text { hsa-miR- } \\
125 b\end{array}$ & & & & 1.2 & 2 \\
\hline$B A K 1$ & $\begin{array}{l}\text { hsa-miR- } \\
\text { 125b }\end{array}$ & & & & $0.49^{\star}$ & $0.27^{\star}$ \\
\hline IL 13RA1 & $\begin{array}{l}\text { hsa-miR- } \\
\text { 125b }\end{array}$ & & & & 1.1 & 2.6 \\
\hline ZNF185 & $\begin{array}{l}\text { hsa-miR- } \\
125 \mathrm{~b}\end{array}$ & & & & 1 & 2.3 \\
\hline PDCD4 & $\begin{array}{l}\text { hsa-miR- } \\
200 a\end{array}$ & 0.3 & -3 & $\begin{array}{l}\text { lower in } \\
\text { MCF-7 }\end{array}$ & 0.7 & 0.5 \\
\hline ETNK1 & $\begin{array}{l}\text { hsa-miR- } \\
200 a\end{array}$ & & & than in LY2 & 0.9 & 2 \\
\hline$R B L 2$ & $\begin{array}{l}\text { hsa-miR- } \\
200 a\end{array}$ & & & & $0.54^{*}$ & $0.91^{*}$ \\
\hline BHLHB2 & $\begin{array}{l}\text { hsa-miR- } \\
200 a\end{array}$ & & & & 1.6 & 3 \\
\hline PTPRG & $\begin{array}{l}\text { hsa-miR- } \\
200 a\end{array}$ & & & & 1 & 4.3 \\
\hline$C D C 2 L 6$ & $\begin{array}{l}\text { hsa-miR- } \\
200 a\end{array}$ & & & & 0.7 & 2.5 \\
\hline IL13RA1 & $\begin{array}{l}\text { hsa-miR- } \\
200 a\end{array}$ & & & & 1.1 & 2.6 \\
\hline ZNF185 & $\begin{array}{l}\text { hsa-miR- } \\
200 a\end{array}$ & & & & 1 & 2.3 \\
\hline$P D C D 4$ & $\begin{array}{l}\text { hsa-miR- } \\
200 \mathrm{~b}\end{array}$ & -0.1 & -3 & $\begin{array}{l}\text { lower in } \\
\text { MCF-7 }\end{array}$ & 0.7 & 0.5 \\
\hline B3GNT1 & $\begin{array}{l}\text { hsa-miR- } \\
\text { 200b }\end{array}$ & & & than in LY2 & 1.4 & 2 \\
\hline$R D X$ & $\begin{array}{l}\text { hsa-miR- } \\
200 \mathrm{~b}\end{array}$ & & & & 1 & 3 \\
\hline EFNB2 & $\begin{array}{l}\text { hsa-miR- } \\
200 \mathrm{~b}\end{array}$ & & & & 1.2 & 2.7 \\
\hline
\end{tabular}




\begin{tabular}{|c|c|c|c|c|c|c|}
\hline C140rt43 & $\begin{array}{l}\text { hsa-miR- } \\
200 \mathrm{~b}\end{array}$ & & & & 2 & 1.5 \\
\hline$A B A T$ & $\begin{array}{l}\text { hsa-miR- } \\
200 b\end{array}$ & & & & 0.6 & 0.3 \\
\hline CYP1B1 & $\begin{array}{l}\text { hsa-miR- } \\
200 \mathrm{~b}\end{array}$ & & & & $24.01^{*}$ & $4.24^{\star}$ \\
\hline GBE1 & $\begin{array}{l}\text { hsa-miR- } \\
200 \mathrm{~b}\end{array}$ & & & & 0.8 & 2.5 \\
\hline PKIA & $\begin{array}{l}\text { hsa-miR- } \\
200 \mathrm{~b}\end{array}$ & & & & 0.9 & 3.7 \\
\hline$P D C D 4$ & $\begin{array}{l}\text { hsa-miR- } \\
200 \mathrm{c}\end{array}$ & 0.3 & -3 & $\begin{array}{l}\text { lower in } \\
\text { MCF-7 }\end{array}$ & 0.7 & 0.5 \\
\hline B3GNT1 & $\begin{array}{l}\text { hsa-miR- } \\
\text { 200c }\end{array}$ & & & than in $L Y 2$ & 1.4 & 2 \\
\hline$R D X$ & $\begin{array}{l}\text { hsa-miR- } \\
200 \mathrm{c}\end{array}$ & & & & 1 & 3 \\
\hline ETNK1 & $\begin{array}{l}\text { hsa-miR- } \\
200 \mathrm{c}\end{array}$ & & & & 0.9 & 2 \\
\hline EFNB2 & $\begin{array}{l}\text { hsa-miR- } \\
200 \mathrm{c}\end{array}$ & & & & 1.2 & 2.7 \\
\hline$A B A T$ & $\begin{array}{l}\text { hsa-miR- } \\
200 \mathrm{c}\end{array}$ & & & & 0.6 & 0.3 \\
\hline CYP1B1 & $\begin{array}{l}\text { hsa-miR- } \\
200 \mathrm{c}\end{array}$ & & & & $24.01^{\star}$ & $4.24^{*}$ \\
\hline GBE1 & $\begin{array}{l}\text { hsa-miR- } \\
200 \mathrm{c}\end{array}$ & & & & & \\
\hline$P D C D 4$ & $\begin{array}{l}\text { hsa-miR- } \\
21\end{array}$ & -0.5 & -0.9 & $\begin{array}{l}\text { lower in } \\
\text { MCF-7 }\end{array}$ & 0.7 & 0.5 \\
\hline B3GNT1 & $\begin{array}{l}\text { hsa-miR- } \\
21\end{array}$ & & & than in LY2 & 1.4 & 2 \\
\hline$R D X$ & $\begin{array}{l}\text { hsa-miR- } \\
21\end{array}$ & & & & 1 & 3 \\
\hline ETNK1 & $\begin{array}{l}\text { hsa-miR- } \\
21\end{array}$ & & & & 0.9 & 2 \\
\hline ABAT & $\begin{array}{l}\text { hsa-miR- } \\
21\end{array}$ & & & & 0.6 & 0.3 \\
\hline$\angle T B P 1$ & $\begin{array}{l}\text { hsa-miR- } \\
21\end{array}$ & & & & 0.7 & 2.8 \\
\hline PTPRG & $\begin{array}{l}\text { hsa-miR- } \\
21\end{array}$ & & & & 1 & 4.3 \\
\hline SMPD1 & $\begin{array}{l}\text { hsa-miR- } \\
22\end{array}$ & -0.4 & 1 & $\begin{array}{l}\text { higher in } \\
\text { MCF-7 }\end{array}$ & $0.62^{*}$ & $0.49^{*}$ \\
\hline GALNT6 & $\begin{array}{l}\text { hsa-miR- } \\
22\end{array}$ & & & than in $L Y 2$ & 0.7 & 0.4 \\
\hline ERBB3 & $\begin{array}{l}\text { hsa-miR- } \\
22\end{array}$ & & & & $0.61^{*}$ & $0.53^{\star}$ \\
\hline TTC9 & $\begin{array}{l}\text { hsa-miR- } \\
22\end{array}$ & & & & $0.47^{\star}$ & $0.31^{*}$ \\
\hline RBL2 & $\begin{array}{l}\text { hsa-miR- } \\
22\end{array}$ & & & & $0.54^{*}$ & $0.91^{*}$ \\
\hline YWHAZ & $\begin{array}{l}\text { hsa-miR- } \\
22\end{array}$ & & & & 1.5 & 2 \\
\hline IL13RA1 & $\begin{array}{l}\text { hsa-miR- } \\
22\end{array}$ & & & & 1.1 & 2.6 \\
\hline ERBB3 & $\begin{array}{l}\text { hsa-miR- } \\
222\end{array}$ & -1.5 & 1.4 & $\begin{array}{l}\text { higher in } \\
\text { MCF-7 }\end{array}$ & $0.61^{*}$ & $0.53^{*}$ \\
\hline EFNB2 & $\begin{array}{l}\text { hsa-miR- } \\
222\end{array}$ & & & than in LY2 & 1.2 & 2.7 \\
\hline
\end{tabular}




\begin{tabular}{|c|c|c|c|c|c|c|}
\hline CYP1B1 & $\begin{array}{l}\text { hsa-miR- } \\
222\end{array}$ & & & & $24.01^{*}$ & $4.24^{\star}$ \\
\hline MYLIP & $\begin{array}{l}\text { hsa-miR- } \\
222\end{array}$ & & & & 0.7 & 0.4 \\
\hline$C D C 2 L 6$ & $\begin{array}{l}\text { hsa-miR- } \\
222\end{array}$ & & & & 0.7 & 2.5 \\
\hline PRPS1 & $\begin{array}{l}\text { hsa-miR- } \\
222\end{array}$ & & & & 2.2 & 3 \\
\hline SMPD1 & $\begin{array}{l}\text { hsa-miR- } \\
29 a\end{array}$ & -0.8 & 0.7 & $\begin{array}{l}\text { higher in } \\
\text { MCF-7 }\end{array}$ & $0.62^{*}$ & $0.49^{\star}$ \\
\hline RAB30 & $\begin{array}{l}\text { hsa-miR- } \\
29 a\end{array}$ & & & than in LY2 & 1.3 & 2.2 \\
\hline C14ort43 & $\begin{array}{l}\text { hsa-miR- } \\
29 a\end{array}$ & & & & 2 & 1.5 \\
\hline$C D 44$ & $\begin{array}{l}\text { hsa-miR- } \\
93\end{array}$ & 0.6 & -0.7 & $\begin{array}{l}\text { lower in } \\
\text { MCF-7 }\end{array}$ & 1 & 2 \\
\hline SHANK2 & $\begin{array}{l}\text { hsa-miR- } \\
93\end{array}$ & & & than in LY2 & 0.8 & 2.5 \\
\hline RAB30 & $\begin{array}{l}\text { hsa-miR- } \\
93\end{array}$ & & & & 1.3 & 2.2 \\
\hline$R D X$ & $\begin{array}{l}\text { hsa-miR- } \\
93\end{array}$ & & & & 1 & 3 \\
\hline ERBB3 & $\begin{array}{l}\text { hsa-miR- } \\
93\end{array}$ & & & & $0.61^{*}$ & $0.53^{*}$ \\
\hline EFNB2 & $\begin{array}{l}\text { hsa-miR- } \\
93\end{array}$ & & & & 1.2 & 2.7 \\
\hline TTC9 & $\begin{array}{l}\text { hsa-miR- } \\
93\end{array}$ & & & & $0.47^{\star}$ & $0.31^{*}$ \\
\hline C14ort43 & $\begin{array}{l}\text { hsa-miR- } \\
93\end{array}$ & & & & 2 & 1.5 \\
\hline$R B L 2$ & $\begin{array}{l}\text { hsa-miR- } \\
93\end{array}$ & & & & $0.54^{*}$ & $0.91^{*}$ \\
\hline$\angle A S P 1$ & $\begin{array}{l}\text { hsa-miR- } \\
93\end{array}$ & & & & 1 & 2.5 \\
\hline $\mathrm{MSH} 2$ & $\begin{array}{l}\text { hsa-miR- } \\
93\end{array}$ & & & & 0.8 & 2.1 \\
\hline IER3 & $\begin{array}{l}\text { hsa-miR- } \\
93\end{array}$ & & & & 5 & 4.3 \\
\hline$C D C 2 L 6$ & $\begin{array}{l}\text { hsa-miR- } \\
93\end{array}$ & & & & 0.7 & 2.5 \\
\hline$P K I A$ & $\begin{array}{l}\text { hsa-miR- } \\
93\end{array}$ & & & & 0.9 & 3.7 \\
\hline$Y W H A Z$ & $\begin{array}{l}\text { hsa-miR- } \\
93\end{array}$ & & & & 1.5 & 2 \\
\hline DNAJC12 & $\begin{array}{l}\text { has-miR- } \\
181 \mathrm{a}\end{array}$ & 1.6 & 0.01 & $\begin{array}{l}\text { lower in } \\
\text { MCF-7 }\end{array}$ & 0.5 & 0.3 \\
\hline & & & & than in LY2 & & \\
\hline
\end{tabular}


APPENDIX 3: Identity and location of genes shown in networks 1 and 2 (Appendix 7)

\begin{tabular}{|c|c|c|}
\hline Symbol & Entrez Gene Name & Location \\
\hline \multicolumn{3}{|l|}{ Network1 } \\
\hline APC & adenomatous polyposis coli & Nucleus \\
\hline ATP2A2 & $\begin{array}{l}\text { ATPase, Ca++ transporting, cardiac muscle, } \\
\text { slow twitch } 2\end{array}$ & Cytoplasm \\
\hline $\mathrm{BLZF1}$ & basic leucine zipper nuclear factor 1 & Cytoplasm \\
\hline $\mathrm{BPHL}$ & biphenyl hydrolase-like (serine hydrolase) & Cytoplasm \\
\hline CASP3 & caspase 3 , apoptosis-related cysteine peptidase & Cytoplasm \\
\hline CCDC88B & coiled-coil domain containing $88 \mathrm{~B}$ & Nucleus \\
\hline CSF1 & colony stimulating factor 1 (macrophage) & $\begin{array}{l}\text { Extracellular } \\
\text { Space } \\
\end{array}$ \\
\hline CYR61 & cysteine-rich, angiogenic inducer, 61 & $\begin{array}{l}\text { Extracellular } \\
\text { Space }\end{array}$ \\
\hline DGAT1 & diacylglycerol O-acyltransferase 1 & Cytoplasm \\
\hline DNAJB5 & DnaJ (Hsp40) homolog, subfamily B, member 5 & unknown \\
\hline FBLN5 & fibulin 5 & $\begin{array}{l}\text { Extracellular } \\
\text { Space }\end{array}$ \\
\hline FMNL3 & formin-like 3 & unknown \\
\hline HOXA1 & homeobox $A 1$ & Nucleus \\
\hline LMNA & $\operatorname{lamin} \mathrm{A} / \mathrm{C}$ & Nucleus \\
\hline MAP4 & microtubule-associated protein 4 & Cytoplasm \\
\hline $\begin{array}{ll}\text { MIR10A } & \text { (includes } \\
\text { EG:406902) } & \\
\end{array}$ & -- & unknown \\
\hline MIR125B (human) & -- & unknown \\
\hline $\begin{array}{ll}\text { MIR200A } & \text { (includes } \\
\text { EG:406983) } & \end{array}$ & -.- & unknown \\
\hline $\begin{array}{ll}\text { MIR200B } \quad \text { (includes } \\
\text { EG:406984) }\end{array}$ & -- & unknown \\
\hline $\begin{array}{ll}\text { MIR205 } & \text { (includes } \\
\text { EG:406988) } & \\
\end{array}$ & -- & unknown \\
\hline $\begin{array}{ll}\text { MIR22 } & \text { (includes } \\
\text { EG:407004) } & \\
\end{array}$ & -- & unknown \\
\hline $\begin{array}{ll}\text { MIR222 } & \text { (includes } \\
\text { EG:407007) } & \end{array}$ & .. & unknown \\
\hline $\begin{array}{l}\text { MIR29A } \quad \text { (includes } \\
\text { EG:407021) }\end{array}$ & -. & unknown \\
\hline $\begin{array}{ll}\text { MIR93 } & \text { (includes } \\
\text { EG:407050) } & \\
\end{array}$ & - & unknown \\
\hline MYC & $\begin{array}{l}\text { v-myc myelocytomatosis viral oncogene } \\
\text { homolog (avian) }\end{array}$ & Nucleus \\
\hline MYT1L & myelin transcription factor 1 -like & Nucleus \\
\hline NPTX1 & neuronal pentraxin I & $\begin{array}{l}\text { Extracellular } \\
\text { Space } \\
\end{array}$ \\
\hline PARP6 & poly (ADP-ribose) polymerase family, member 6 & unknown \\
\hline PLK2 & polo-like kinase 2 & Nucleus \\
\hline RAB10 & RAB10, member RAS oncogene family & Cytoplasm \\
\hline retinoic acid & - & unknown \\
\hline RSF1 & remodeling and spacing factor 1 & Nucleus \\
\hline TDG & -- & \begin{tabular}{|l|} 
Nucleus \\
\end{tabular} \\
\hline UNCX & UNC homeobox & unknown \\
\hline VIM & vimentin & Cytoplasm \\
\hline
\end{tabular}




\begin{tabular}{|l|l|l|} 
Network 2 & & \\
\hline beta-estradiol & & unknown \\
\hline Estrogen Receptor & & unknown \\
\hline IL6 & interleukin 6 (interferon, beta 2) & $\begin{array}{l}\text { Extracellular } \\
\text { Space }\end{array}$ \\
\hline MAP2 & microtubule-associated protein 2 & Cytoplasm \\
\hline Mapk & & unknown \\
\hline MIR181A (human) (includes & & unknown \\
\hline $\begin{array}{l}\text { MIR200C (includes } \\
\text { EG:406985) }\end{array}$ & & unknown \\
\hline $\begin{array}{l}\text { MIR21 } \\
\text { EG:406991) }\end{array}$ & unknown \\
\hline PGR & & Nucleus \\
\hline
\end{tabular}


APPENDIX 4: ER $\alpha 36$ is not expressed in MCF-7 or LY2 cell lines. Whole cell extracts $(30 \mu \mathrm{g})$ indicated breast cancer cell lines (tamoxifen (TAM)- sensitive (S) or TAM-resistant (TAM-R) were immunoblotted for ER $\alpha$ with G-20 (SantaCruz Biotechnology). The membrane was stripped and reprobed for $\beta$-actin. ER $\alpha 36$ lacks the $\mathrm{A} / \mathrm{B}$ and $\mathrm{F}$ domains of ER $\alpha 66$, but contains the DNA binding domain (DBD, C region), hinge region ( $\mathrm{D}$ region), and most of the ligand binding domain (LBD, $\mathrm{E}$ region). It also has an extra, unique 27aa domain instead of the last 138 aa encoded by exons 7 and 8 of the hER $\alpha 66$ gene (Wang et al. PNAS 103: 9063-8, 2006). The G-20 antibody recognizes ER $\alpha$ aa 281-360 in the DBD and hinge region and thus, it should recognize ER $\alpha 36$, but we do not see any evidence of ER $\alpha 36$.

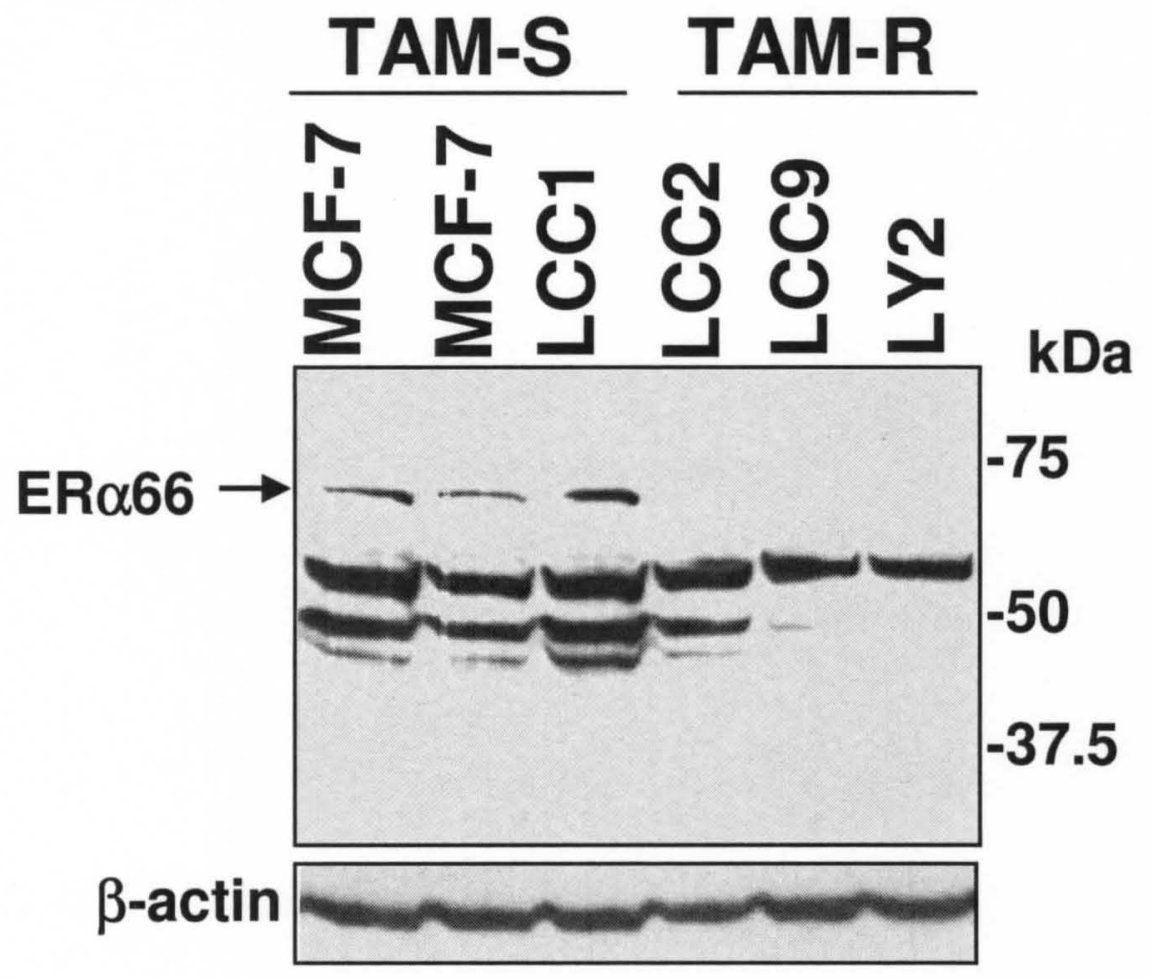


APPENDIX 5: GAPDH levels in MCF-7 and LY2 are comparable. MCF-7 and LY2 cells were treated with $10 \mathrm{nM}$ estradiol $\left(E_{2}\right)$ or $100 \mathrm{nM}$ 4-hydroxytamoxifen (4OHT) for $6 \mathrm{~h}$. Quantitative real time PCR was employed to evaluate glyceraldehyde 3-phosphate dehydrogenase (GAPDH) expression because GAPDH is often used as a control gene for normalization of "test" mRNAs. Values are CT (cycle threshold) values and are the mean $+/$ - SEM of triplicate determinations.

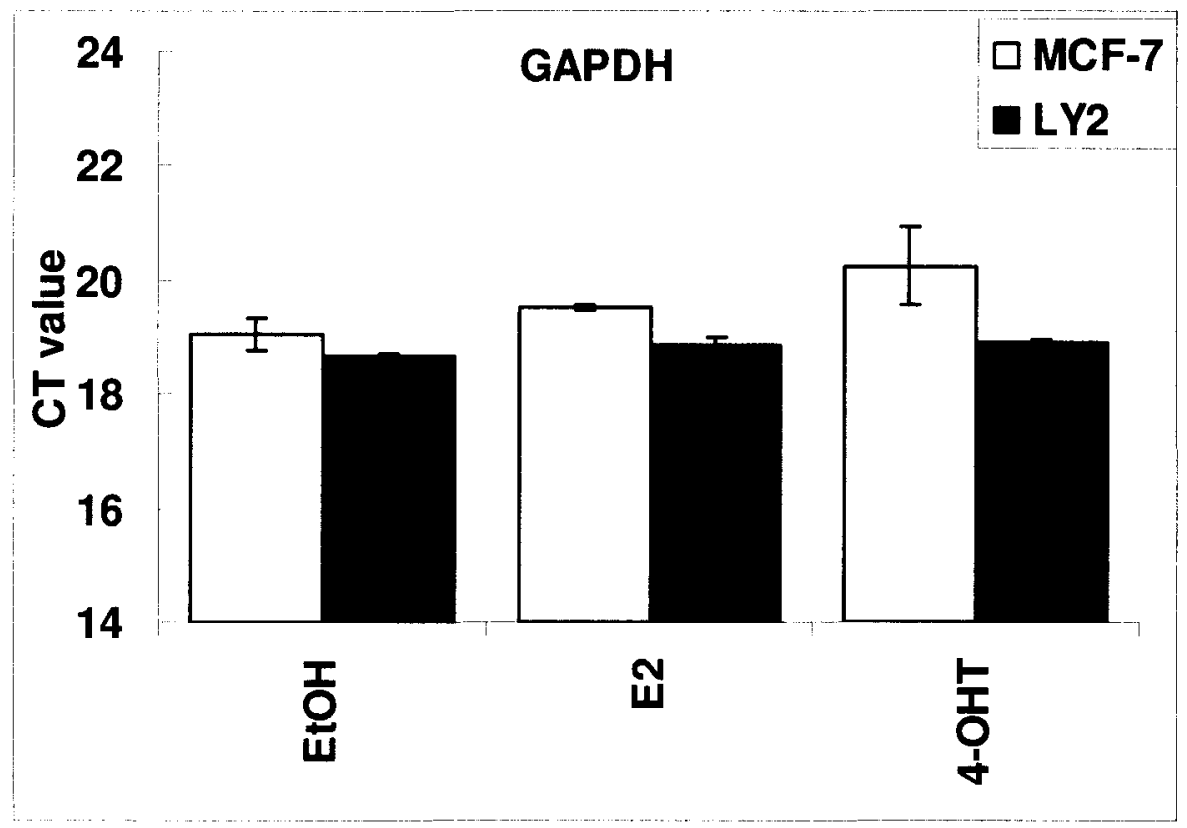


APPENDIX 6: Results of Ingenuity Pathway Analysis. The top biological function and disease categories enriched with miRNAs in our dataset (Figure 3) are displayed along the $\mathrm{x}$-axis. The $\mathrm{y}$-axis displays the -(log) significance. Taller bars are more significant than shorter bars. Functions are listed from most significant to least and the red vertical line denotes the cutoff for significance ( $p$-value of 0.05 ).

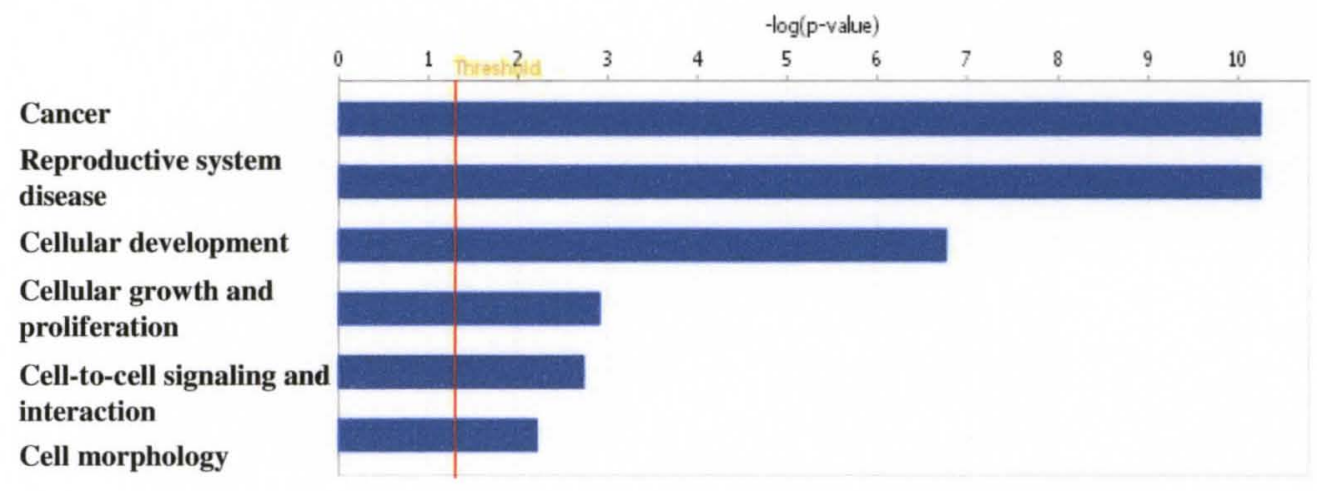


APPENDIX 7: Ingenuity Pathway Analysis (IPA) identified 2 networks of molecules that interact with the 12 miRNAs that are differentially expressed in MCF-7 versus LY2 breast cancer cells. Core analysis identified 2 separate networks that are associated with our miRNA dataset (Figure 3). Analysis identified a total of 44 molecules, 35 in Network 1 (A) and 9 in Network 2 (B).
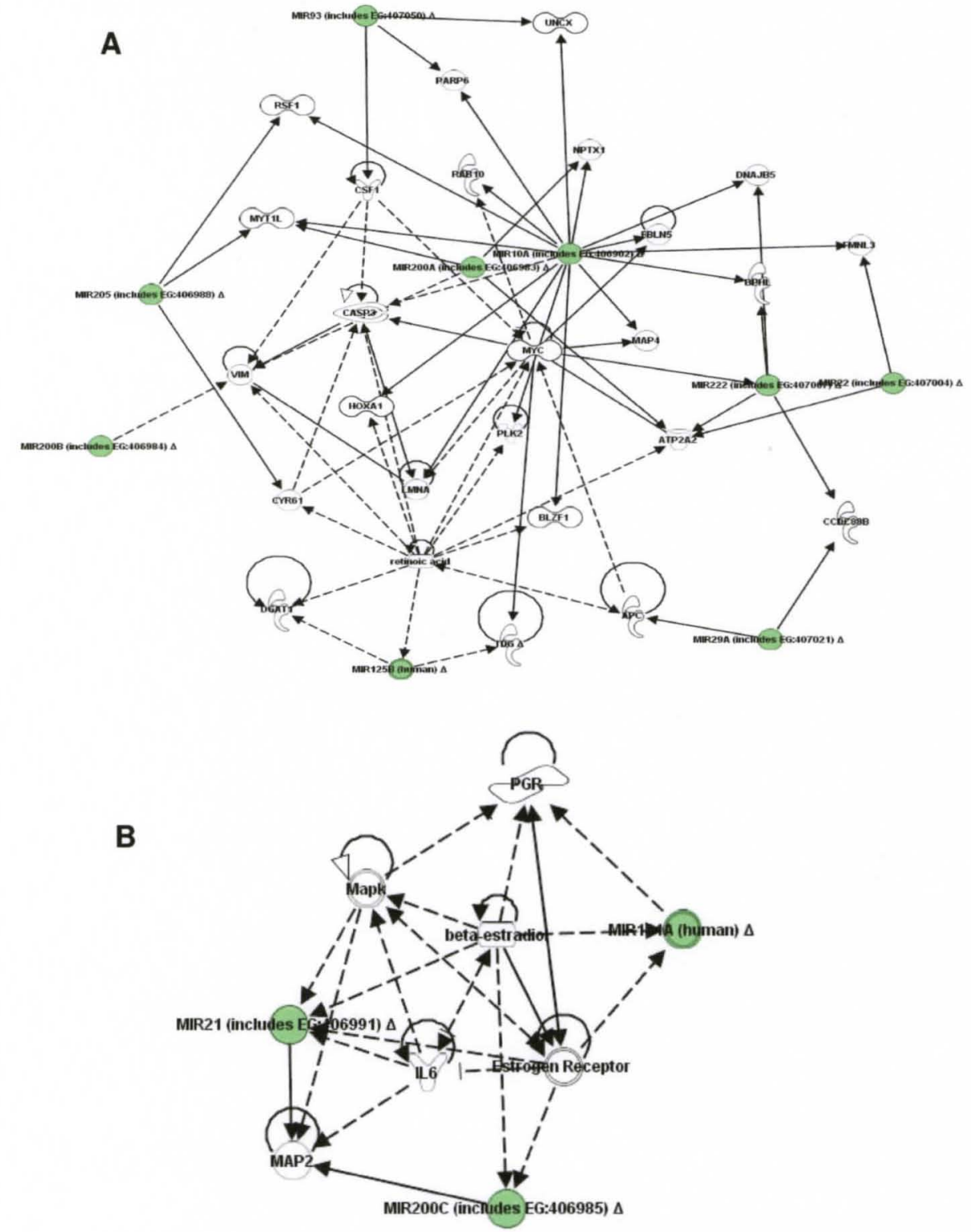
Appendix 8: Overexpression of miR-200b or miR-200c in LY2 cells transfected with pre-miR-200b or pre-miR-200c or negative control. LY2 cells were transfected either with negative control or pre-miR-200a, pre-miR-200b or pre-miR200c. A. RNA was harvested after 3 days and Q-PCR performed to confirm overexpression of miR-200a, miR-200b or miR-200c. Values are the mean \pm SEM of triplicate determinations. B. Image of LY2 cells transfected with negative control, captured using a light microscope (20x magnification, $100 \mu \mathrm{m}$ scale).

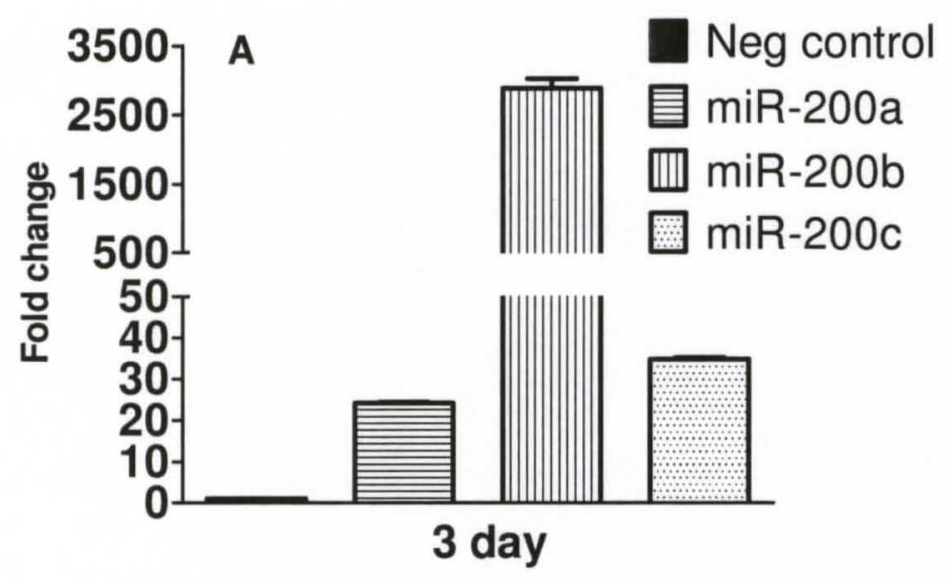

B.Negative control 


\section{Appendix 9}

\section{ELSEVIER LICENSE}

TERMS AND CONDITIONS

Aug 27, 2012

This is a License Agreement between Tissa T Manavalan ("You") and Elsevier ("Elsevier") provided by Copyright Clearance Center ("CCC"). The license consists of your order details, the terms and conditions provided by Elsevier, and the payment terms and conditions.

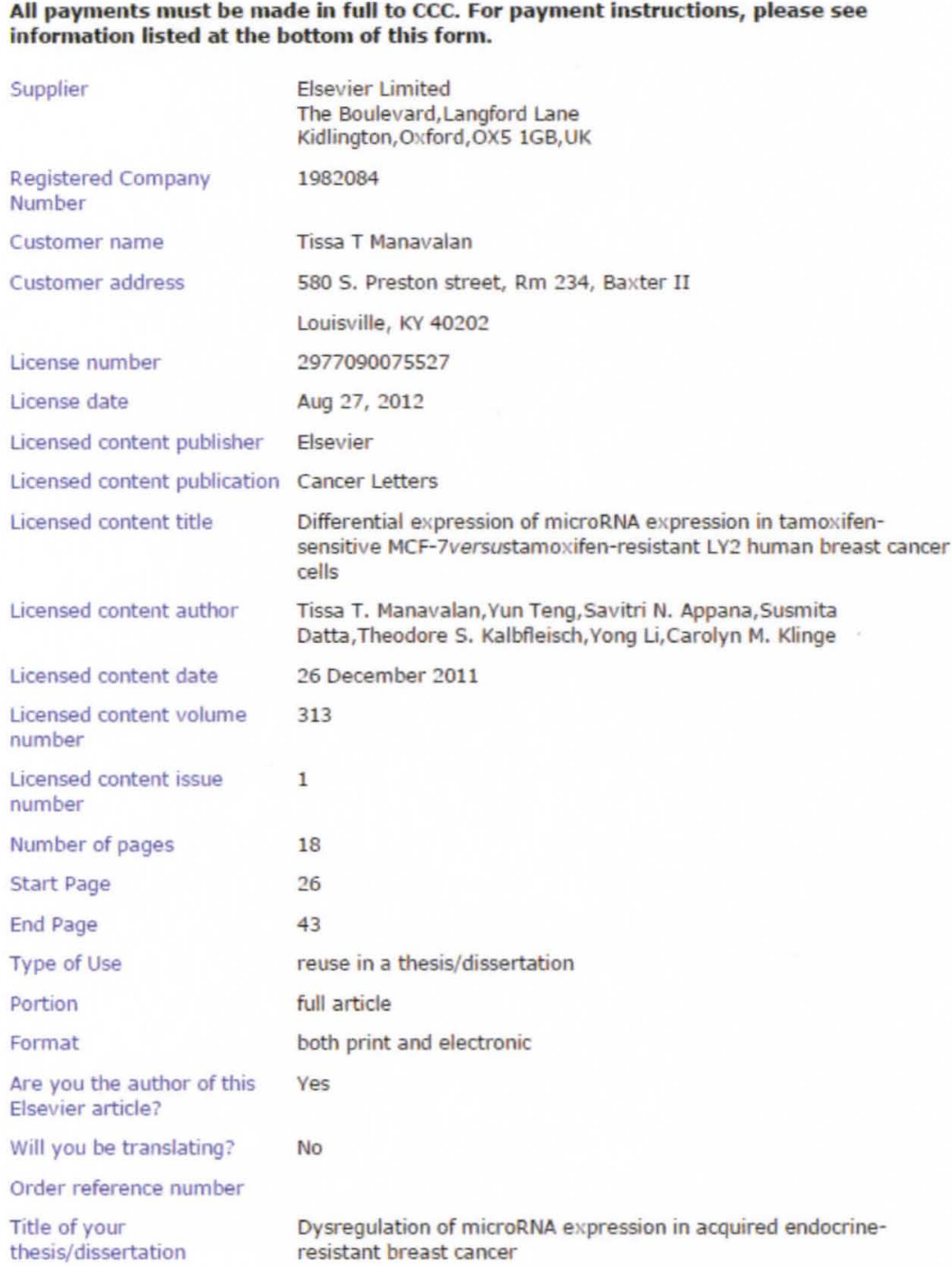


Expected completion date

Estimated size (number of

pages)

Elsevier VAT number

Permissions price

VAT/Local Sales Tax

Total
Oct 2012

200

GB 494627212

0.00 USD

0.0 USD / $0.0 \mathrm{GBP}$

0.00 USD 


\section{CURRICULUM VITAE}

Tissa T. Manavalan

Department of Biochemistry and Molecular Biology

University of Louisville School of Medicine

Louisville, KY 40292

ttmana01@louisville.edu or tissatm@gmail.com

\section{$\underline{\text { EDUCATION }}$}

2012 Ph.D. in Biochemistry and Molecular Biology (dissertation defended 20.September 2012 with degree to be conferred at December 2012 graduation) University of Louisville School of Medicine, Louisville, KY

2011 M.S. in Biochemistry and Molecular Biology, University of Louisville School of Medicine, Louisville, KY

2007 M.Sc. in Biochemistry, Bangalore University, Karnataka, India

2005 B.Sc. in Microbiology Chemistry, Botany, Bangalore University, Karnataka, India

\section{PUBLICATIONS}

1. Teng, Y*., Manavalan, T.T.*, Hu, C., Medjakovic, S., Jungbauer, A., and Klinge, C.M.. Endocrine Disruptors Fludioxonil and Fenhexamid Stimulate miR-21 Expression in Breast Cancer Cells. * equal contribution as first authors. Toxicological Sciences, in press, 2012, \# TOXSCI-12-0551-R1.

2. Manavalan, T.T., Teng, Y., Appana, S.N., Datta, S., Kalbfleisch, T.S., Li, Y., and Klinge, C.M. Differential expression of microRNA expression in tamoxifen-sensitive MCF-7 versus tamoxifen-resistant LY2 human breast cancer cells. Cancer Letters 313: 26-43, 2011. PMID:21955614

3. Wickramasinghe, N.S., Manavalan, T.T., Dougherty, S.M., Riggs, K.A., Li, Y., and Klinge, C.M. Estradiol downregulates miR-21 expression and increases miR-21 target gene expression in MCF-7 breast cancer cells. Nucleic Acids Res. 37: 2584-2595, 2009. PMID:19264808

\section{BOOK CHAPTERS}

1. Manavalan, T.T and Klinge, C.M, Estrogen regulation of microRNA expression. Book chapter. Advances of Genomic science. in press. (Editor Christian Neri) 


\section{HONORS AND AWARDS}

2011 Second place in the Graduate Student poster competition ( $2^{\text {nd }}$ of 127 posters) at the $10^{\text {th }}$ Annual Brown Cancer Retreat, October 28, 2011. (Manavalan, T.T., Teng, Y., Datta, S., Kalbfleisch, T.S., Li, Y. and Klinge, C.M. Differential expression of miRNAs in antiestrogensensitive MCF-7 versus antiestrogen-resistant LY2 human breast cancer cells. Abstract \#84)

2011

Third place in the poster competition at the $13^{\text {th }}$ annual Institute for Molecular Diversity and Drug Design ( $\mathrm{IMD}^{3}$ ) Symposium March 8, 2011. (Manavalan, T.T., Teng, Y., Datta, S., Kalbfleisch, T.S., Li, Y. and Klinge, C.M. Differential expression of miRNAs in antiestrogensensitive MCF-7 versus antiestrogen-resistant LY2 breast cancer cells. Abstract \#16)

2010

Second place in the poster competition at the $12^{\text {th }}$ annual Institute for Molecular Diversity and Drug Design (IMD ${ }^{3}$ ) Symposium March 9, 2010 ( $2^{\text {nd }}$ of 32 posters). (Manavalan, T.T., Wickramasinghe, N.S., Datta, S., Kalbfleisch, T., Li, Y.and Klinge, C.M. Differential expression of microRNAs in tamoxifen-sensitive versus - resistant human breast cancer cell lines. Abstract \#18)

2009

Third place in the Graduate Student poster competition ( $3^{\text {rd }}$ of 82 posters) $7^{\text {th }}$ annual Brown Cancer Center Retreat, October 29, 2008. (Manavalan, T.T., Wickramasinghe, N.S., Li, Y., and Klinge, C.M. Regulation of miRNA expression by 4-hydroxytamoxifen in MCF-7 breast cancer cells. Abstract \#49)

2007- 2009 Integrated Program in Biomedical Sciences (IPIBS) Fellowship, University of Louisville School of Medicine, Louisville KY 40202

\section{RESEARCH EXPERIENCE}

Dissertation research: University of Louisville School of Medicine, 2007-present (Advisor: Dr. Carolyn M. Klinge)

- Identified miRNAs that are differentially expressed in antiestrogen-sensitive MCF-7 and anti-estrogen-resistant LY2 human breast cancer cells. Using bioinformatics, putative targets of the dysregulated miRNAs were identified.

- Correlated changes in miRNA expression with mRNA and protein changes of key tumor suppressors and oncogenes associated with breast cancer.

- Investigated the role of microRNA-200 family members in modulating resistance to antiestrogens, Tamoxifen and Fulvestrant.

\section{TECHNICAL SKILLS}

Molecular biology techniques: mammalian cell culture, miRNA analyses, QRT-PCR for mRNA and miRNA, Western blotting, transient transfection, immunocytochemistry

\section{EDUCATIONAL ACTIVITIES}


- Attended Trainee day at the $93^{\text {rd }}$ annual meeting of the Endocrine Society, June 4, 2011

- Teaching assistant for Advanced Biochemistry II (BIOCHEM 647), Spring 2009

- Trained 2 undergraduate students (summer of 2009 and 2011)

\section{POSTERS}

Abstracts presented at National meetings:

1. Manavalan, T.T and Klinge, C.M. Loss of miR-200 family of microRNAs confers resistance to tamoxifen in human breast cancer cells. (Abstract \#1096), Abstracts of the $103^{\text {rd }}$ annual meeting presented at the American Association for Cancer Research (AACR),Chicago, IL March 31-April 4, 2012

2. Manavalan, T.T, Klinge, C.M., Datta, S., and Kalbfleisch, T.S. Differential Expression of MiRNAs In Antiestrogen-Sensitive MCF-7 versus Antiestrogen-Resistant LY2 Breast Cancer Cells. (Abstract P3-68) Abstracts of the $93^{\text {rd }}$ annual meeting of the Endocrine Society, Boston, MA, June 4-7, 2011 .

Abstracts presented at local meetings:

1. Barry, P., Riggs, K.A., Manavalan, T.T., Patel, N.S., and Klinge, C.M. Role of estrogen receptor alpha isoform $\mathrm{hER} \alpha 46$ in tamoxifen resistant breast cancer. (Abstract SMED 2) Research Louisville! University of Louisville School of Medicine, Louisville, KY, October 21, 2008.

2. Manavalan, T.T., Wickramasinghe, N.S., Li, Y., and Klinge, C.M. Regulation of miRNA expression by 4-hydroxytamoxifen in MCF-7 breast cancer cells. (Abstract GRD-30) Research Louisville! University of Louisville School of Medicine, Louisville, KY, October 21, 2008.

3. Wickramasinghe, N.S., Manavalan, T.T., Riggs, K.A., Li, Y., and Klinge, C.M. Estradiol regulates miR-21 and its targets via ERalpha in MCF-7 breast cancer cells. (Abstract RA-53) Research Louisville! University of Louisville School of Medicine, Louisville, KY, October 22, 2008. *This poster was awarded third place in the Postdoctoral Fellow/Research Associate poster competition ( $3{ }^{\text {rd }}$ of 70 posters).

4. Manavalan, T.T., Wickramasinghe, N.S., Li, Y., and Klinge, C.M. Regulation of miRNA expression by 4-hydroxytamoxifen in MCF-7 breast cancer cells. (Abstract\# 49) $7^{\text {th }}$ annual Brown Cancer Center Retreat, October $29,2008$.

5. Wickramasinghe, N.S., Manavalan, T.T., Riggs, K.A., Li, Y., and Klinge, C.M. Estradiol downregulates miR-21 expression and miR-21 gene targets in MCF-7 breast cancer cells. Abstract 3051 presented at the $31^{\text {st }}$ annual San Antonio Breast Cancer Symposium, Dec. 10-14, 2008.

6. Wickramasinghe, N.S., Manavalan T.T., Dougherty, S. M., Yong Li, and 
Klinge, C.M. Estradiol regulates miR-21 and its targets via ER-alpha in MCF7 breast cancer cells. (Abstract \# 10) 11 th annual Institute for Molecular Diversity and Drug Design (IMD3) Symposium, March 10, 2009. *This poster was awarded the first place in the poster competition.

7. Kapur, A., Manavalan, T.T., Wickramasinghe, N.S., Klinge, C.M. Regulation of protein targets of microRNAs by 4-hydroxytamoxifen in breast cancer cells. SROP poster presentations, University of Louisville School of Medicine, Louisville, KY, August, 2009.

8. Manavalan T.T., Wickramasinghe, N.S., Datta, S., Kalbfleisch, T., and Klinge, C.M. Differential expression of microRNAs in tamoxifen-resistant versus-sensitive human breast cancer cells. Abstract \#13 presented as a poster at the 2009 Colloquium in Biochemistry and Molecular Biology (BMB), University of Louisville School of Medicine, August 21, 2009. (Honorable Mention (2nd of 17 posters selected for presentation by the BMB Research Committee).

9. Manavalan, T.T., Wickramasinghe, N.S., Datta, S., Kalbfleisch, T., Li, Y. and Klinge, C.M. Differential expression of microRNAs in tamoxifensensitive versus - resistant human breast cancer cell lines. (Abstract GRD-54 ) Research Louisville! University of Louisville School of Medicine, Louisville, KY, October 15, 2009.

10. Manavalan, T.T., Wickramasinghe, N.S., Datta, S., Kalbfleisch, T., Li, Y. and Klinge, C.M. Differential expression of microRNAs in tamoxifensensitive versus - resistant human breast cancer cell lines. (Abstract \#54) $8^{\text {th }}$ Annual Retreat, James Graham Brown Cancer Center, Louisville, KY, November 6, 2009.

11. Manavalan, T.T., Wickramasinghe, N.S., Datta, S., Kalbfleisch, T., Li, Y. and Klinge, C.M. Differential expression of microRNAs in tamoxifensensitive versus - resistant human breast cancer cell lines. (Abstract \#18) 12th annual Institute for Molecular Diversity and Drug Design (IMD3) Symposium, IMD3 Symposium, March 9, 2010.

12. Manavalan, T.T., Teng, Y., Datta, S., Kalbfleisch, T.S., Li, Y. and Klinge, C.M. Differential expression of miRNAs in antiestrogen-sensitive MCF-7 versus antiestrogen-resistant LY2 breast cancer cells. (Abstract GRD-42) Research Louisville! University of Louisville School of Medicine, Louisville, KY, October 13, 2010.

13. Manavalan, T.T., Teng, Y., Datta, S., Kalbfleisch, T.S., Li, Y. and Klinge, C.M. Differential expression of miRNAs in antiestrogen-sensitive MCF-7 versus antiestrogen-resistant LY2 breast cancer cells. (Abstract \# 67) $9^{\text {th }}$ annual Brown Cancer Center Retreat, Louisville, KY. November 5, 2010.

14. Manavalan, T.T., Teng, Y., Datta, S., Kalbfleisch, T.S., Li, Y. and Klinge, C.M. Differential expression of miRNAs in antiestrogen-sensitive MCF-7 versus antiestrogen-resistant LY2 breast cancer cells. (Abstract \#16) 13th 
annual Institute for Molecular Diversity and Drug Design (IMD3) Symposium, March 8, 2011.

15. Bell, J.D., Teng, Y., Manavalan, T.T., Kareparembil, S.A, Klinge, C.M. DHEA stimulates miR-21 expression in breast cancer cells. SROP poster presentation, University of Louisville School of Medicine, Louisville, KY, August 1, 2011.

16. Manavalan, T.T., Teng, Y., Datta, S., Kalbfleisch, T.S., Li, Y. and Klinge, C.M. Differential expression of miRNAs in antiestrogen-sensitive MCF-7 versus antiestrogen-resistant LY2 breast cancer cells. Abstract \#3 presented as a poster at the 2011 Colloquium in Biochemistry and Molecular Biology (BMB), University of Louisville, School of Medicine, August 26, 2011.

17. Manavalan, T.T., Teng, Y., Datta, S., Kalbfleisch, T.S., Li, Y. and Klinge, C.M. Differential expression of miRNAs in antiestrogen-sensitive MCF-7 versus antiestrogen-resistant LY2 human breast cancer cells. (Abstract GRD53) Research Louisville! University of Louisville School of Medicine, Louisville, KY, October 11, 2011.

18. Manavalan, T.T., Teng, Y., Datta, S., Kalbfleisch, T.S., Li, Y. and Klinge, C.M. Differential expression of miRNAs in antiestrogen-sensitive MCF-7 versus antiestrogen-resistant LY2 human breast cancer cells. (Abstract \#84) $10^{\text {th }}$ annual Brown Cancer Center Retreat, Louisville, KY. October 28, 2011.

19. Manavalan, T.T and Klinge, C.M. Loss of miR-200 family of microRNAs confers resistance to tamoxifen in human breast cancer cells. (Abstract \#17), $14^{\text {th }}$ Annual $\mathrm{IMD}^{3}$ (Institute for Molecular Diversity and Drug Design) Symposium, March 13th, 2012. 